ALEXANDRE FACINI DOS SANTOS

GERENCIAMENTO DA CONFIABILIDADE EM PROJETOS DE MATERIAL RODANTE FERROVIÁRIO

Dissertação apresentada à Escola Politécnica da Universidade de São Paulo para obtenção de Título de Mestre em Engenharia.

São Paulo 
ALEXANDRE FACINI DOS SANTOS

\section{GERENCIAMENTO DA CONFIABILIDADE EM PROJETOS DE MATERIAL RODANTE FERROVIÁRIO}

Dissertação apresentada à Escola Politécnica da Universidade de São Paulo para obtenção de Título de Mestre em Engenharia.

Área de Concentração:

Engenharia de Projeto e Fabricação

Orientador:

Prof. Dr. Gilberto Francisco Martha de Souza

São Paulo 
Este exemplar foi revisado e alterado em relação à versão original, sob responsabilidade única do autor e com a anuência de seu orientador.

São Paulo, de Outubro de 2007.

Assinatura do autor

Assinatura do orientador

FICHA CATALOGRÁFICA

Santos, Alexandre Facini dos

Gerenciamento da confiabilidade em projetos de material rodante ferrroviário / A.F. dos Santos. -- ed. rev. -- São Paulo, 2007.

$256 \mathrm{p}$.

Dissertação (Mestrado) - Escola Politécnica da Universidade de São Paulo. Departamento de Engenharia Mecânica.

1.Ferrovias (Gerenciamento; Eficiência) 2.Trens 3.Material rodante (Confiabilidade) I.Universidade de São Paulo. Escola Politécnica. Departamento de Engenharia Mecânica II.t. 


\section{DEDICATÓRIA}

Aos meus pais Lúcio e Gracia, e à minha irmã Amanda, pelo amor, carinho e apoio em todos os momentos, de alegria ou de tristeza, que sempre me deram forças para prosseguir e possibilitaram minhas conquistas e superações.

À minha esposa Gisele, por todo amor, amizade e companheirismo habituais e que fazem dela a mulher da minha vida.

Ao meu filho Giovanni, razão maior da minha vontade de viver, e aos meus sobrinhos Paloma e Breno. Três crianças que enchem minha vida de alegrias e esperança em um futuro cada vez melhor.

Amo todos vocês!

Dedico também este trabalho ao meu avô paterno Benedito (in memorian), pelos ensinamentos de vida, ao meu avô materno Felipe (in memorian), e a minha irmã Andreza (in memorian). 


\section{AGRADECIMENTOS}

Agradeço a Deus em primeiro lugar, por tudo que me proporcionou nesta vida maravilhosa.

À minha esposa pela paciência, compreensão e incentivo neste período de "ausência virtual".

À empresa ALSTOM pelas oportunidades profissionais ao longo dos últimos 9 anos. Em especial aos engenheiros Ronaldo Silva e Cid Nakao, pela flexibilização do meu horário quando necessário para cumprir as tarefas do mestrado.

Ao também colega de empresa, o franco-americano Jacques Durand por me apresentar o mundo da engenharia da confiabilidade, por viabilizar minha participação em simpósios nos Estados Unidos e pelos contatos com cientistas e profissionais mundialmente renomados da área de confiabilidade e segurança.

Ao professor e amigo Dr. Gilberto Francisco Martha de Souza pela orientação e apoio, além de toda confiança depositada em meu trabalho desde o princípio.

À Escola Politécnica da Universidade de São Paulo, através de seus professores e funcionários, que me proporcionou o conhecimento e a infra-estrutura necessária para realização deste mestrado.

E a todos os amigos, parentes e colegas que, de alguma forma, contribuíram para idealização e realização deste trabalho. 
Se você conhece o inimigo e conhece a si mesmo, não precisa temer o resultado de cem batalhas. Se você se conhece mas não conhece o inimigo, para cada vitória ganha sofrerá também uma derrota. Se você não conhece nem o inimigo nem a si mesmo, perderá todas as batalhas.

(Sun Tzu, A arte da guerra)

O futuro tem muitos nomes. Para os fracos, é o inatingível. Para os temerosos, o desconhecido. Para os valentes, é a oportunidade.

(Victor Hugo)

Vencer é o que importa. O resto é conseqüência.

(Ayrton Senna da Silva) 


\section{RESUMO}

É cada vez maior a demanda pela eficiência dos sistemas ferroviários. A confiabilidade do material rodante é um dos fatores de desempenho mais importantes para a eficiência global dos trens de passageiros. Para que índices satisfatórios de confiabilidade, disponibilidade, mantenabilidade e segurança (CDMS) sejam alcançados, deve-se considerar esses fatores desde a elaboração da especificação técnica do material rodante até a operação da frota, incluindo projeto, fabricação, testes, comissionamento e garantia. No presente trabalho foram pesquisados os principais requisitos, normas e boas práticas empregadas na indústria ferroviária mundial para o gerenciamento da confiabilidade em projetos de material rodante, levando-se em conta os aspectos práticos e científicos. Para isso, foram inicialmente apresentadas algumas especificidades do setor ferroviário assim como alguns dos principais tipos de veículos ferroviários e seus sistemas, para que se tenha uma visão geral do contexto em que o trabalho está inserido. Em relação ao gerenciamento de CDMS propriamente dito, são mencionadas as principais tarefas a serem realizadas, de acordo com as referências consultadas. Foi dada uma atenção especial às especificações técnicas de CDMS, levando-se em conta a classificação das falhas e a determinação de parâmetros contratuais. Também foram abordados os aspectos teóricos e práticos das principais ferramentas e métodos de análise de CDMS empregados, tais como alocação de metas, predição de confiabilidade, diagrama de blocos, FMECA, FTA, monitoramento da confiabilidade em campo, etc.

Palavras-chave: Confiabilidade. Material Rodante. Trem de Passageiros. Projeto. Gerenciamento. Ferrovia. Predição. 


\begin{abstract}
Demand for efficiency in railway systems is increasing through the years. Rolling stock reliability is one of the most important performance factors for the global efficiency of passenger trains. To attain satisfactory reliability, availability, maintainability and safety (RAMS) figures, these factors must be considered from the elaboration of rolling stock technical specifications up to the operation of the fleet, including design, manufacturing, tests, commissioning and warranty. In the present work a research on main requirements, standards and good practices applied in worldwide railway industry for managing reliability in rolling stock designs was carried out, taking into account practical and scientific aspects. Some specificities of railway industry as well as some of the main railway vehicles types and related systems were presented, so that one can have an overview of the context where this work is inserted. Related to RAMS management, the main tasks to be done are presented, according to the references. Special attention was paid to RAMS technical specifications, considering failure classifications and determination of contractual parameters. The theoretical and practical aspects of the main tools and analysis methods of RAMS applied to the rolling stock design, such as apportionment of targets, reliability predictions, reliability block diagrams, FMECA, FTA, monitoring of field reliability, etc., were also covered.
\end{abstract}

Keywords: Reliability. Rolling Stock. Passengers Train. Design. Management. Railway. Reliability Prediction. 


\section{LISTA DE ILUSTRAÇÕES}

Figura 1: Exemplo de acoplamento em trens de grande velocidade (8) …..............34

Figura 2: Inclinação do Trem Pendular no contorno de uma curva (7)....................37

Figura 3: Carros 1 e 4 com falha no sistema pendular (7) ...................................... 38

Figura 4: Diagrama funcional de um trem de passageiros ....................................40

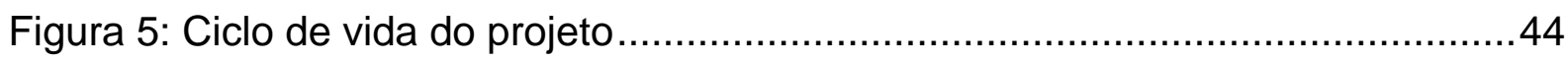

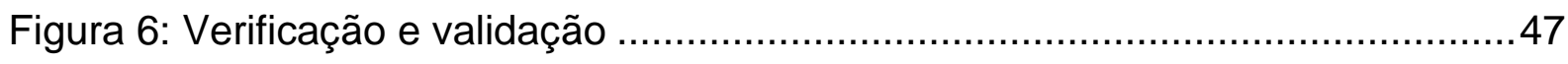

Figura 7: Inter-relacionamento dos elementos de CDMS .....................................48

Figura 8: Efeitos das falhas em um sistema ferroviário ...........................................49

Figura 9: Exemplo de meta de confiabilidade variável no tempo …..........................71

Figura 10: Outro exemplo de meta variável no tempo........................................... 72

Figura 11: Fluxograma de alocação de metas de confiabilidade..............................80

Figura 12: Taxa de falhas aparente de um sistema reparável, (22) .........................94

Figura 13: Exemplo de apresentação de dados da NPRD95 ………........................96

Figura 14: Representação da probabilidade de falha .............................................97

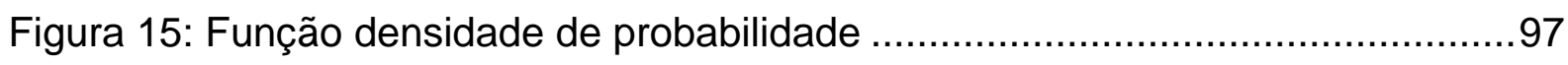

Figura 16: Plano quando solicitação = resistência ...............................................98

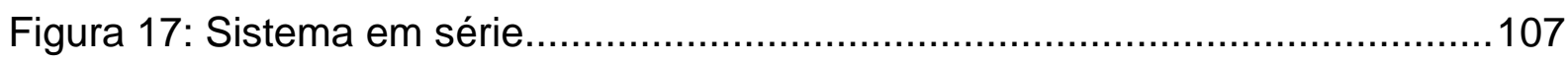

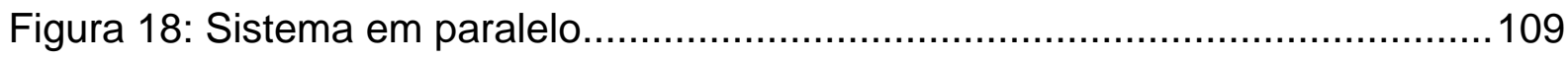

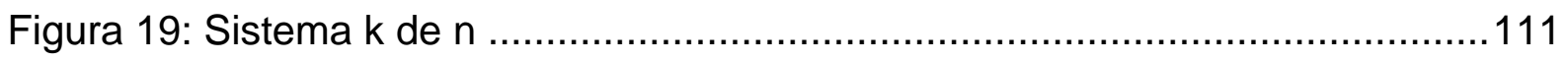

Figura 20: Redundância passiva com chaveamento perfeito …………………......114

Figura 21: Redundância passiva com chaveamento imperfeito ............................. 115

Figura 22: Exemplo de sistema complexo....................................................117

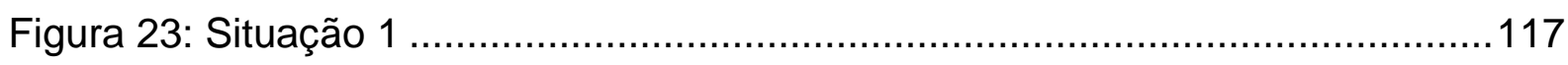

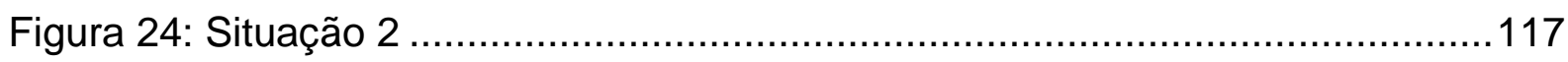

Figura 25: Atividades típicas de FMECA em um projeto ...................................... 121

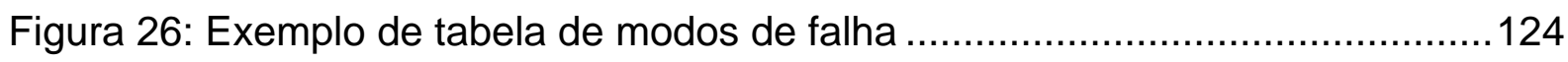

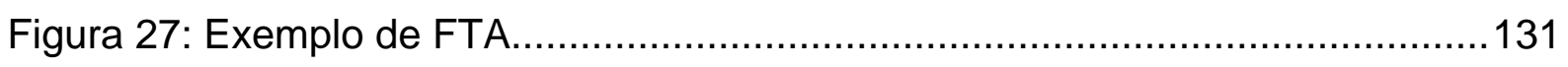

Figura 28: Exemplo de gráfico de Pareto ....................................................... 136

Figura 29: Crescimento da confiabilidade ..................................................... 142

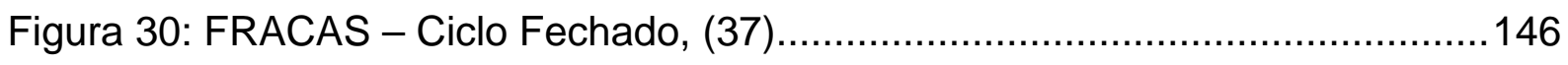


Figura 31: Contribuição por sistema - Falhas tipo A ..........................................159

Figura 32: Contribuição por sistema - Falhas tipo B ............................................159

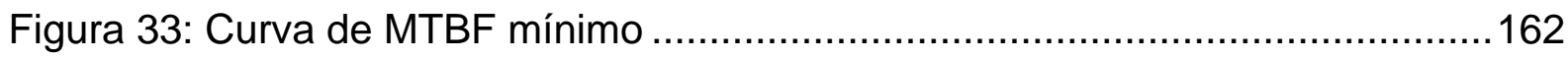

Figura 34: Planilha de predição de confiabilidade …….........................................176

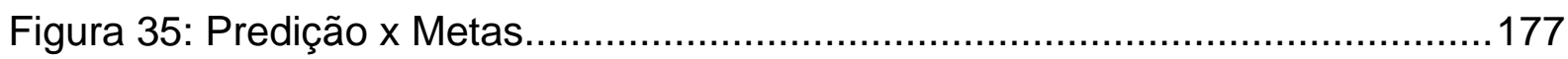

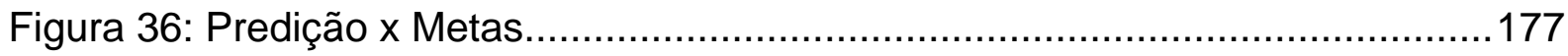

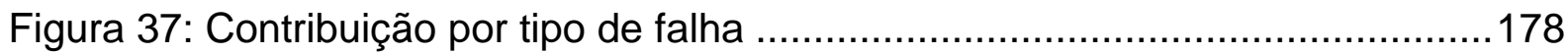

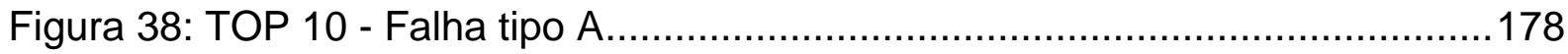

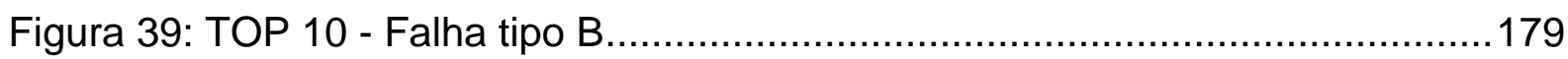

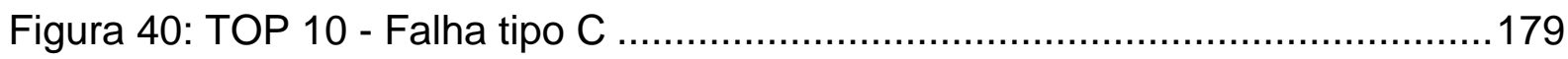

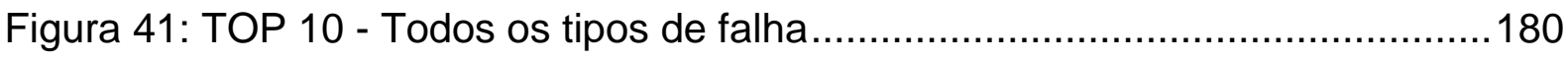

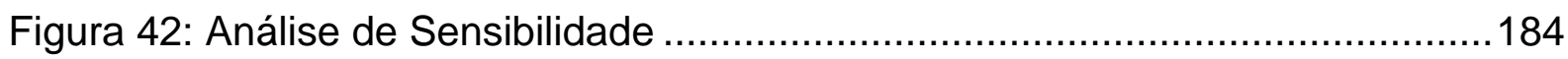

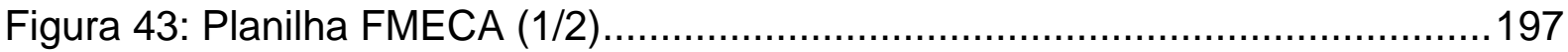

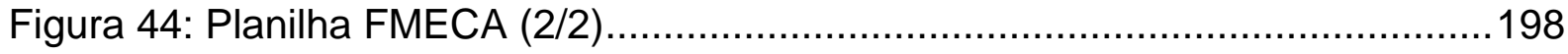

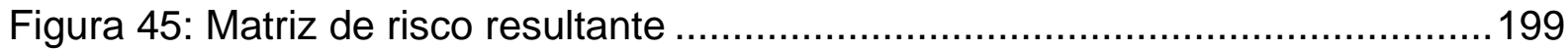

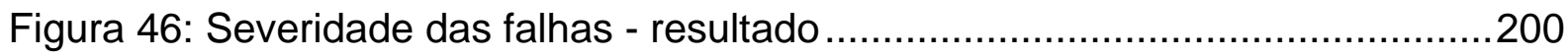

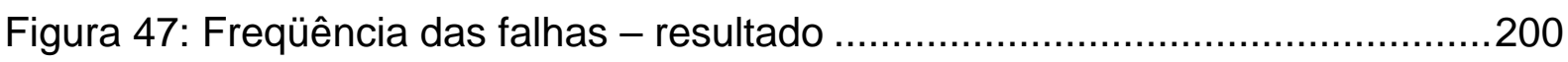

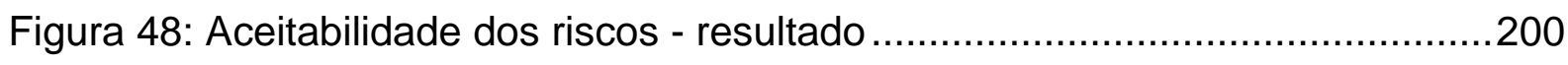

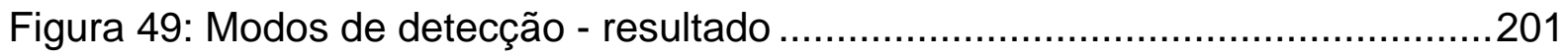

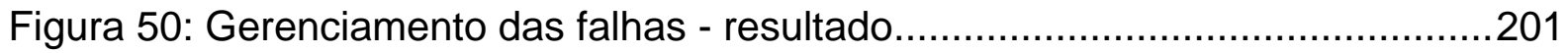

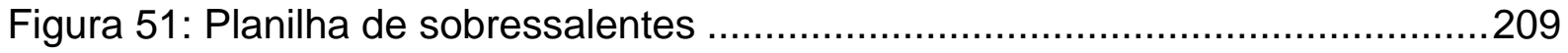

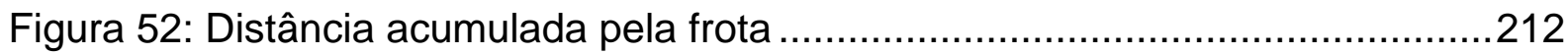

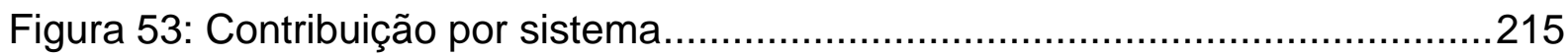

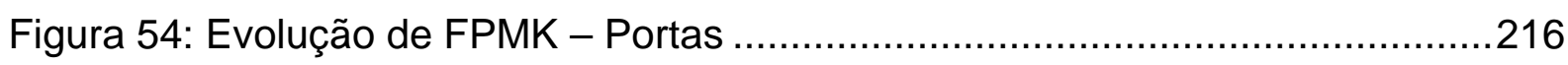

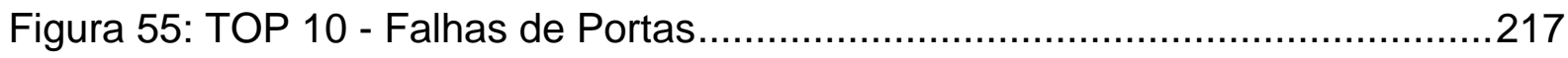

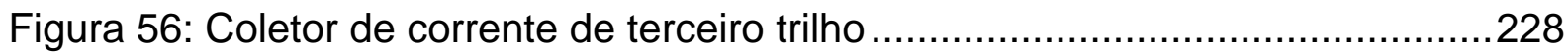

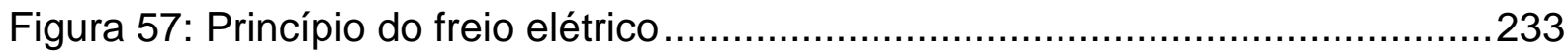

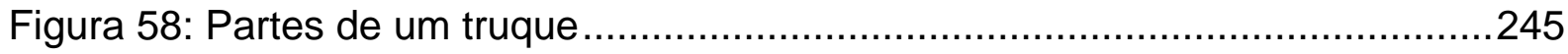

Figura 59: Diagrama simplificado de um engate universal .................................246

Figura 60: Etapas de acoplamento de um engate universal ...............................247

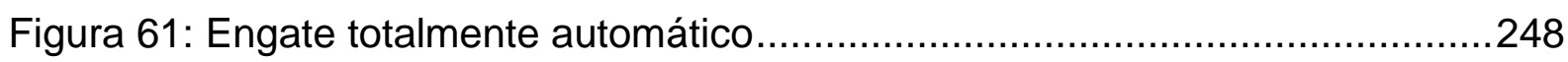

Figura 62: Partes de um engate totalmente automático ......................................248 


\section{LISTA DE TABELAS}

Tabela 1: Tarefas relacionadas ao projeto (continua) .......................................45

Tabela 2: Tarefas relacionadas com CDM (continua) .......................................50

Tabela 3: Tarefas relacionadas à segurança (continua) ...................................51

Tabela 4: Implementação de CDM (continua) .............................................53

Tabela 5: Tarefas de CDMS - Fase de Proposta (continua) ...............................55

Tabela 6: Tarefas de CDMS - Fase de Projeto (continua) ................................56

Tabela 7: Tarefas de CDMS - Fase de Fabricação ........................................58

Tabela 8: Tarefas de CDMS - Fase de Comissionamento .................................59

Tabela 9: Tarefas de CDMS - Fase de Operação ..........................................60

Tabela 10: Exemplo de classificação de falhas............................................. 64

Tabela 11: Classificação conforme desempenho ......................................... 65

Tabela 12: Exemplo de incentivos e penalizações......................................... 73

Tabela 13: Tempo em que o valor assintótico é atingido, (22) ............................94

Tabela 14: Razão $\alpha /$ MTTF em função de $\beta$, (22) .................................................95

Tabela 15: MTBF no arranjo em paralelo ............................................... 110

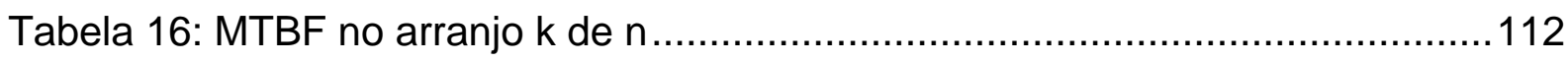

Tabela 17: Símbolos empregados em FTA (continua) ................................127

Tabela 18: Exemplo de uso da tabela verdade ............................................ 134

Tabela 19: Tabela de avaliação da taxa de crescimento necessária ..................... 142

Tabela 20: Atividades mais importantes de confiabilidade, (41)......................... 144

Tabela 21: Exemplo de registro com "Tempo Calendário" ................................ 151

Tabela 22: Exemplo de registro com "Tempo Equivalente" .............................. 152

Tabela 23: Exemplo de registro com "Tempo Transcorrido" .............................. 153

Tabela 24: Alocação pelo método EQUAL ................................................... 158

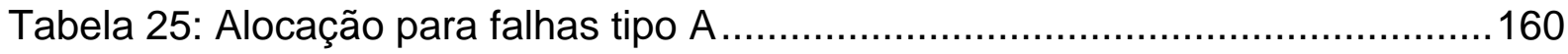

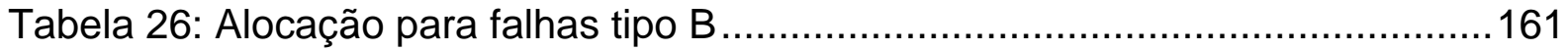

Tabela 27: Classificação de falhas - Suprimento elétrico .................................164

Tabela 28: Estrutura analítica - Suprimento Elétrico ...................................... 165

Tabela 29: Valores de MTBF e fonte de informação ...................................167

Tabela 30: Contribuição por tipo de falha...............................................171 
Tabela 31: Taxas de falha distribuídas por tipo de falha 173

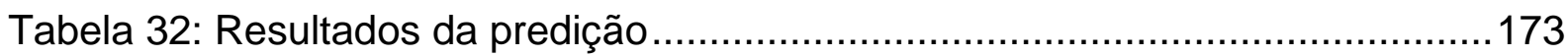

Tabela 33: Classificação de falhas - CAIXA - Miscelâneas ....................................186

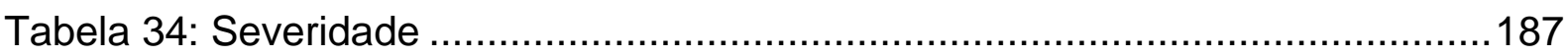

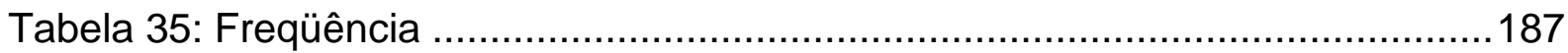

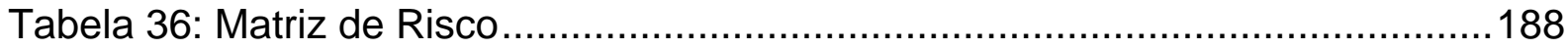

Tabela 37: Ações a serem tomadas para cada categoria de risco ..........................188

Tabela 38: Estrutura analítica - Sistema Caixa - Miscelâneas................................190

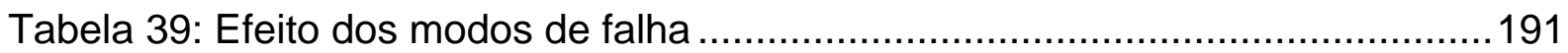

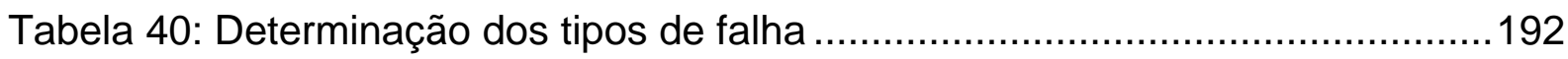

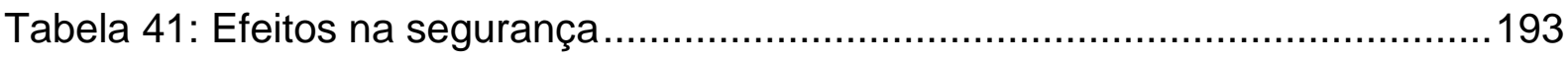

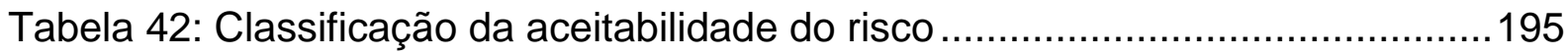

Tabela 43: Modos de deteç̧ão e gerenciamento da falha .....................................196

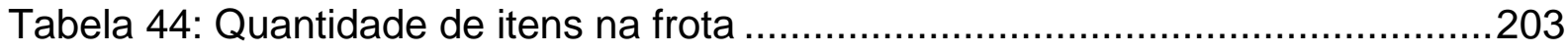

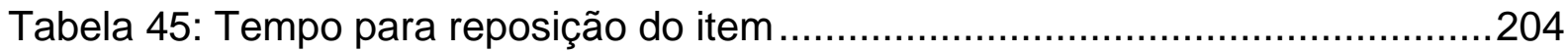

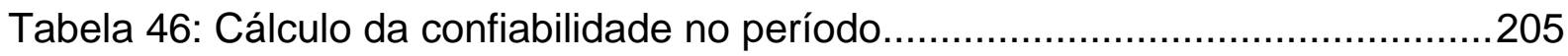

Tabela 47: Cálculo detalhado de sobressalentes..............................................206

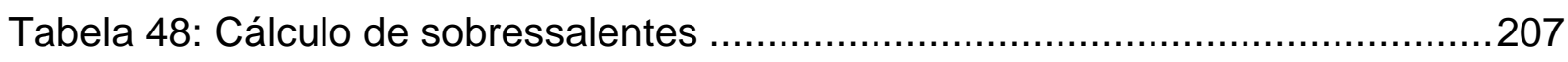

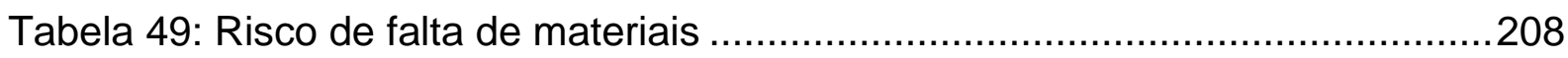

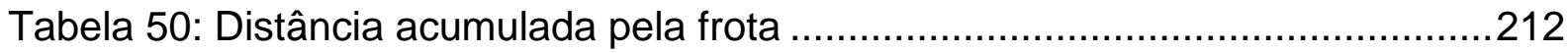

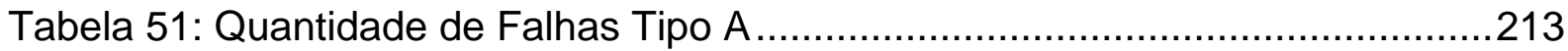

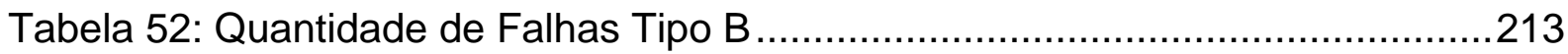

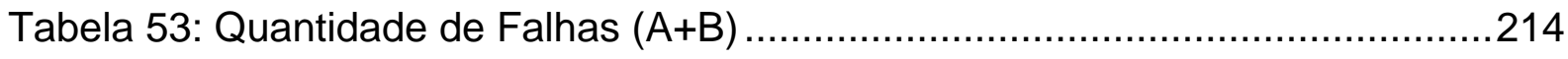

Tabela 54: Evolução de MKBF - Falhas Tipo A ………...................................214

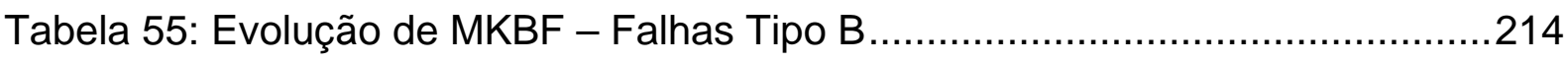

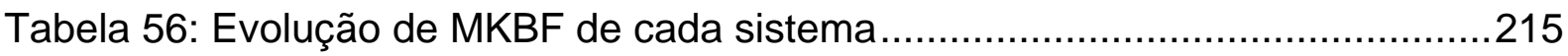

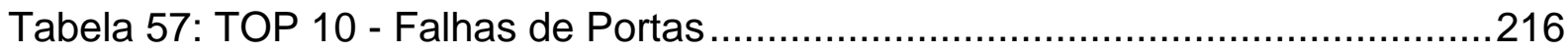




\section{LISTA DE ABREVIATURAS E SIGLAS}

ANTT Agência Nacional de Transportes Terrestres

AT Alta Tensão

BT Baixa Tensão

CA Corrente Alternada

CC Corrente Contínua

CDM Confiabilidade, Disponibilidade e Mantenabilidade

CDMS Confiabilidade, Disponibilidade, Mantenabilidade e Segurança

ET Especificação Técnica

f.d.p. $\quad$ Função densidade de probabilidade

FMEA Análise dos Modos de Falha e seus Efeitos, do inglês Failure Modes Effects Analysis

FMECA Análise dos Modos de Falha e seus Efeitos Críticos, do inglês Failure Modes Effects and Criticality Analysis

FPMH Falhas por Milhão de Horas, do inglês Failure Per Million Hours

FPMK Falhas por Milhão de Quilômetro, do inglês Failure Per Million Kilometers

FRACAS Sistema de Registro de Falhas, Análise e Ações Corretivas, do inglês Failure Reporting Analysis and Corrective Action System

FTA Análise de Árvore de Falhas, do inglês Fault Tree Analysis

LIC Lista de Itens Críticos 
LRU Item Substituível em Linha, do inglês Line Replaceable Unit

MCBF Número Médio de Ciclos entre Falhas, do Inglês Mean Cycles Between Failures

MKBF Quilometragem Média entre Falhas, do Inglês Mean Kilometers Between Failures

MR Material Rodante

MTBF Tempo Médio entre Falhas, do Inglês Mean Time Between Failures

NC Nível de Confiança

PPC Plano do Programa de Confiabilidade

RAC Centro de Análises de Confiabilidade, do Inglês Reliability Analysis Center

RBD Diagrama de Blocos de Confiabilidade, do inglês Reliability Block Diagram

SRU Item Substituível em Bancada, do inglês Shop Replaceable Unit

TU Trem-Unidade

TUE Trem-Unidade Elétrico

VLT Veículo Leve Sobre Trilho 


\section{LISTA DE SÍMBOLOS}

$\hat{\theta} \quad$ Estimativa de MTBF, MKBF ou MCBF

$\mathrm{R}(\mathrm{t}) \quad$ Função Confiabilidade

$\chi^{2} \quad$ Distribuição de probabilidade "Qui-quadrado"

$\lambda \quad$ Taxa de Falhas (por unidade de tempo, distância ou número de ciclos)

$\theta \quad$ MTBF, MKBF ou MCBF 


\section{SUMÁRIO}

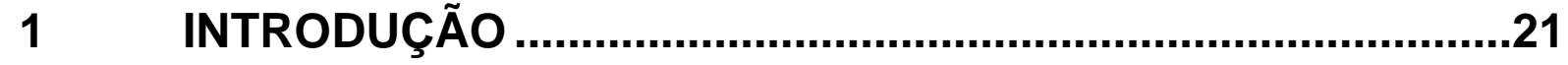

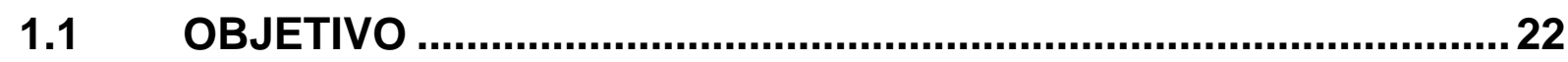

2 ESPECIFICIDADES DO SETOR FERROVIÁRIO .....................23

2.1 ORGANIZAÇÃO DA INDÚSTRIA FERROVIÁRIA ...........................23

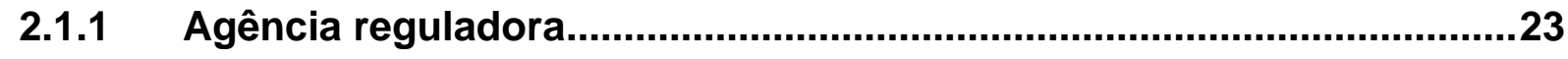

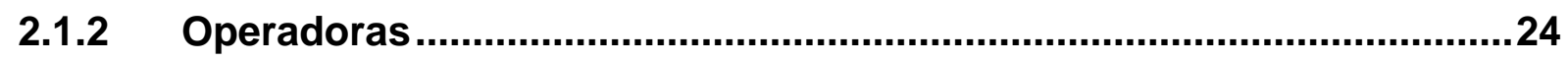

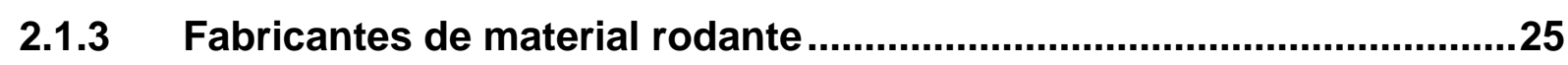

2.1.4 Fabricantes de subsistemas ..........................................................25

2.2 TIPOS DE VEÍCULOS FERROVIÁRIOS.................................................

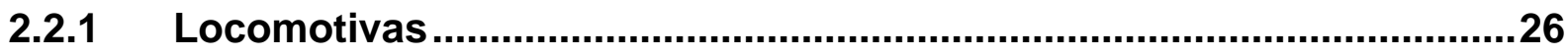

2.2.2 Veículos leves sobre trilhos.............................................................27

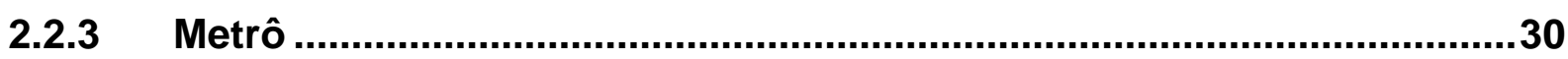

2.2.3.1 Tipos de construção ..................................................................31

2.2.4 Trens regionais e de subúrbio ...........................................................32

2.2.5 Trens de alta velocidade ...............................................................33

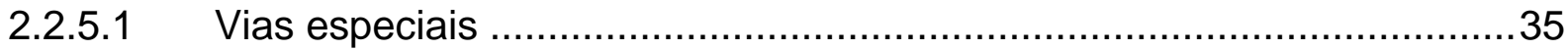

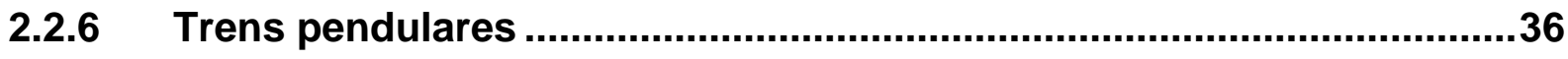

2.2.7 Outros tipos de veículos ................................................................38

2.3 PRINCIPAIS SISTEMAS DOS TRENS DE PASSAGEIROS.............38

3 GERENCIAMENTO DE CDMS .............................................

3.1 POLÍTICA CORPORATIVA E PROGRAMAS INTEGRADOS............41

3.2 CICLO DE VIDA DO PROJETO ..................................................... 43

3.3 CDMS NO DOMÍNIO FERROVIÁRIO............................................. 47

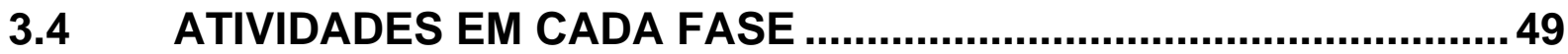

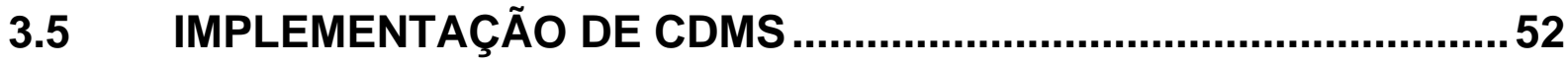

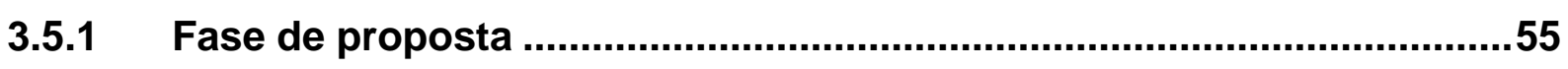

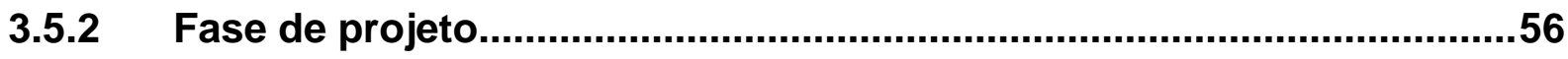

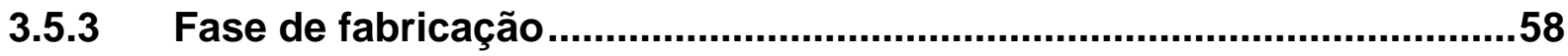

3.5.4 Fase de comissionamento ............................................................58 


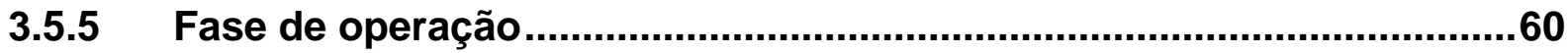

3.6 ESPECIFICAÇÃO DE CDMS DO MATERIAL RODANTE ..............61

3.6.1 Classificação das falhas do material rodante ......................................61

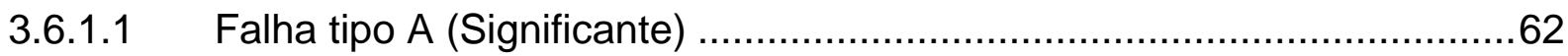

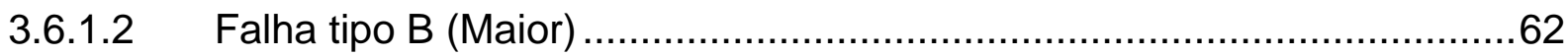

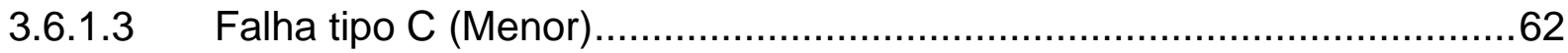

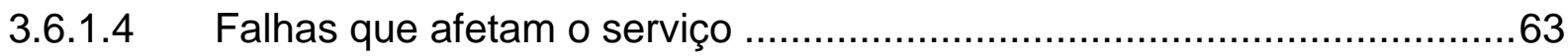

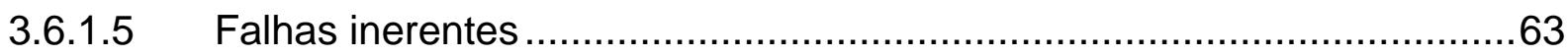

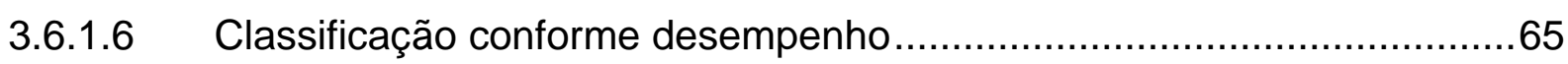

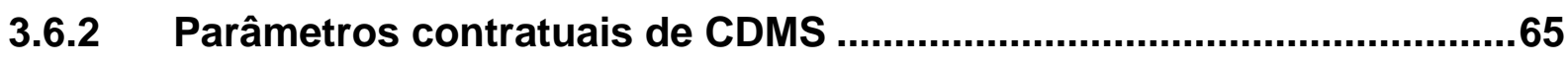

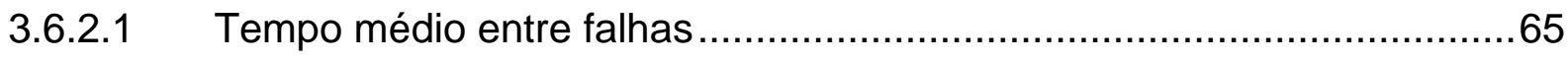

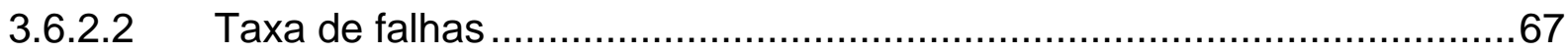

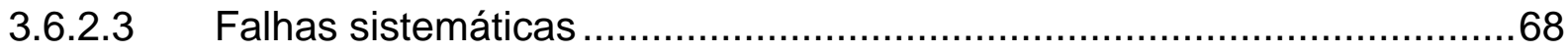

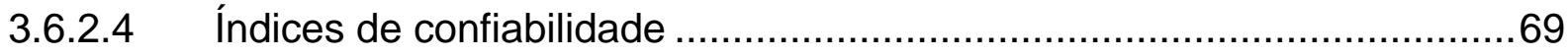

3.6.2.5 Parâmetros de CDMS definidos por intervalo de confiança ....................69

3.6.2.6 Períodos de medição.....................................................................

3.6.3 Incentivos e penalizações ...................................................................

3.7 PLANO DO PROGRAMA DE CDMS …......................................74

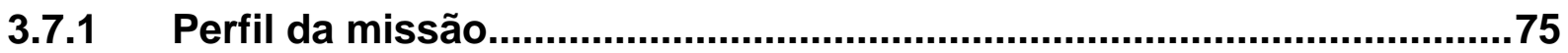

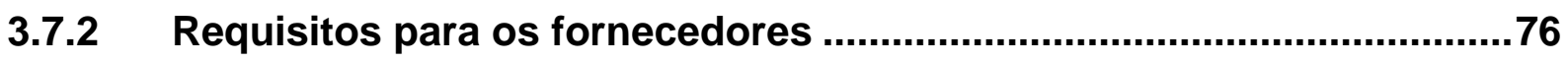

3.8 RELATÓRIOS DE ANÁLISE DE CDMS …......................................76

CUSTOS DE CDMS ...........................................................................

4 ANÁLISES E FERRAMENTAS DE CDMS ..............................79

4.1 ALOCAÇÃO DE METAS DE CONFIABILIDADE ............................79

4.1.1 Métodos de alocação da confiabilidade................................................79

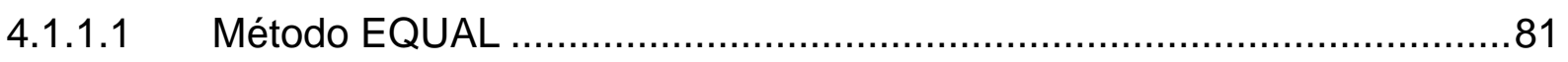

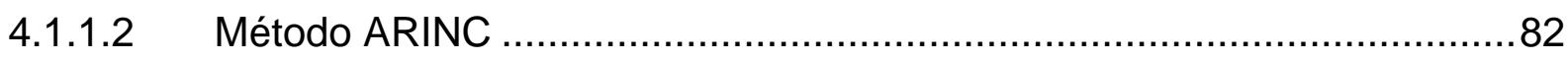

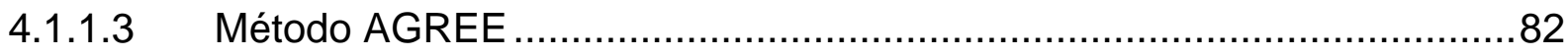

4.1.1.4 Método da avaliação da viabilidade dos objetivos...................................84

4.1.2 MTBF mínimo dos equipamentos.............................................................

4.2 PREDIÇÃO DA CONFIABILIDADE DE COMPONENTES ................86

4.2.1 Limitações fundamentais da predição da confiabilidade ......................87

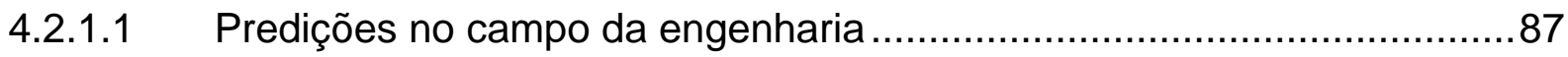


4.2.1.2 Predições no campo da confiabilidade ........................................ 87

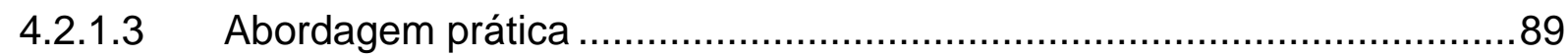

4.2.2 Predições conforme normas e bancos de dados.................................90

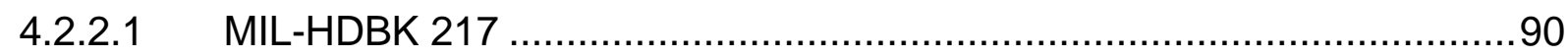

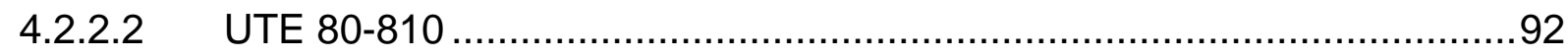

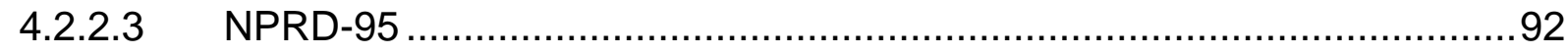

4.2.3 Análise da solicitação e resistência ......................................................96

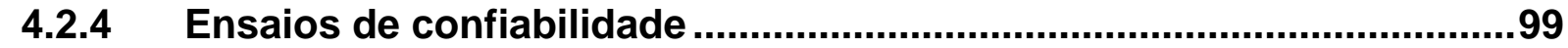

4.2.4.1 Planejamento dos testes ......................................................... 99

4.2.4.2 Realização dos testes e coleta de dados .......................................100

4.2.4.3 Uso de retorno de experiências ..................................................100

4.2.4.4 Estimação pontual .................................................................. 101

4.2.4.5 Estimação por intervalo de confiança.......................................... 104

4.2.5 Predição da confiabilidade de sistemas redundantes.........................106

4.3 DIAGRAMA DE BLOCOS ......................................................... 106

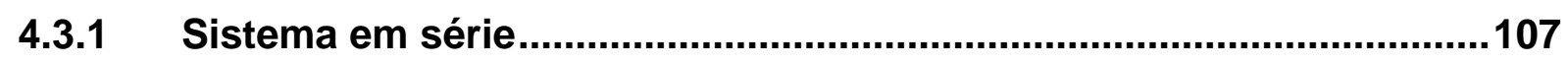

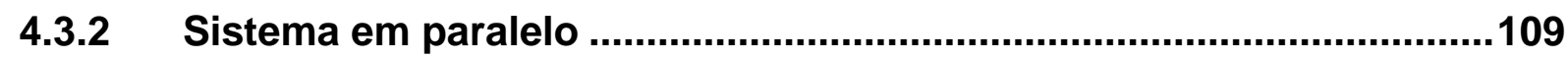

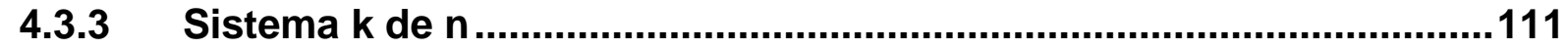

4.3.4 Sistema em paralelo com cobertura de falhas ...................................113

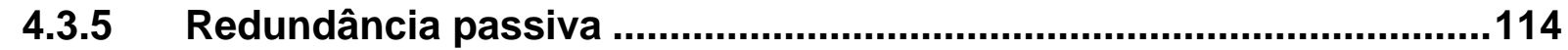

4.3.6 Sistemas complexos......................................................................116

4.3.7 Sistemas com carga distribuída ....................................................118

4.3.8 Falhas de modo comum .............................................................118

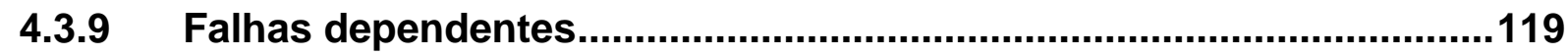

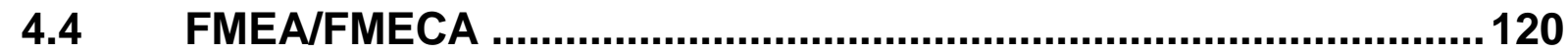

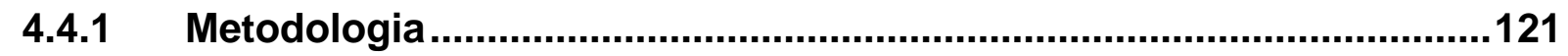

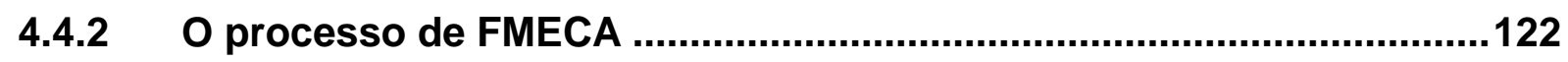

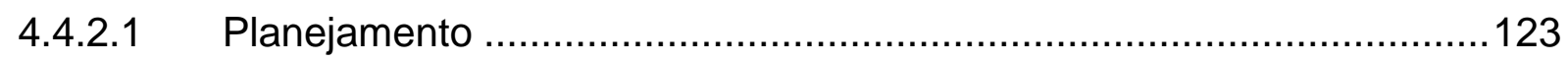

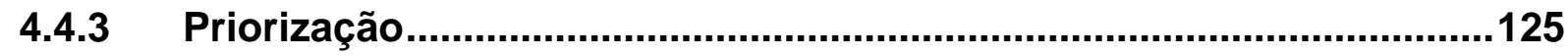

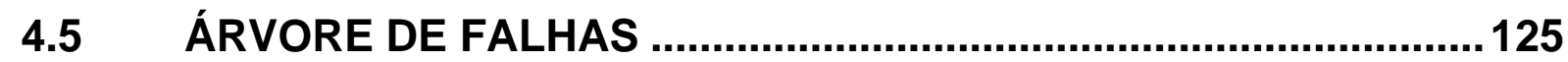

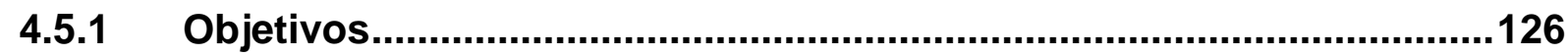

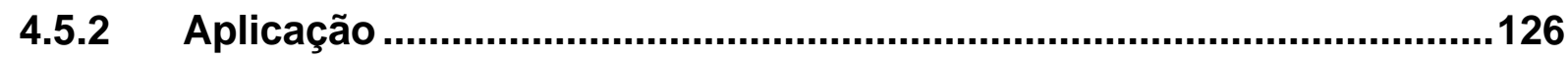

4.5.3 Construção da árvore de falhas...................................................127 


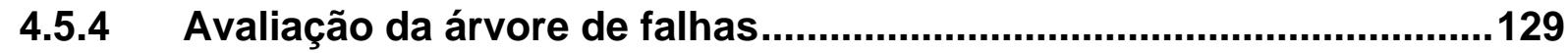

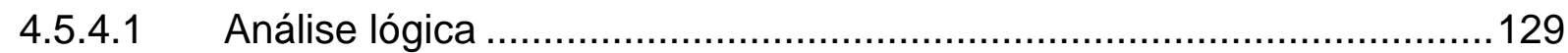

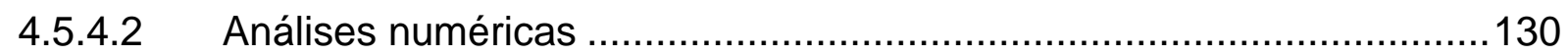

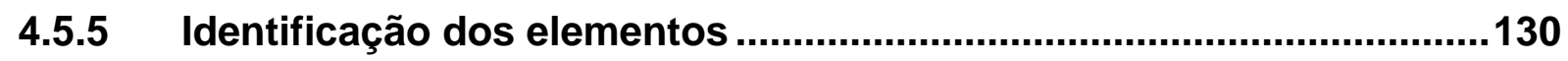

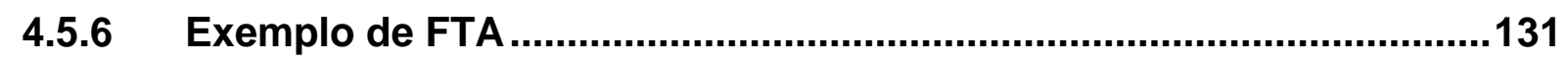

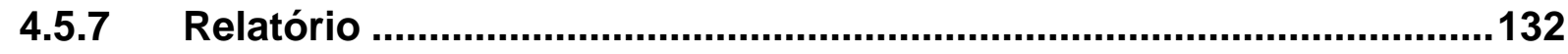

4.6 MÉTODO DA TABELA VERDADE ............................................ 132

4.6.1 Exemplo de aplicação da tabela verdade ............................................133

$4.7 \quad$ LISTA DE ITENS CRÍTICOS ......................................................... 134

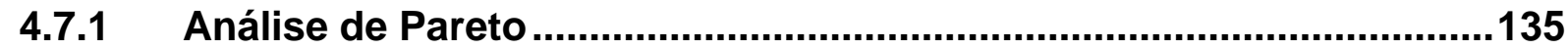

4.8 CÁLCULO DE SOBRESSALENTES ........................................... 136

4.9 MONITORAMENTO DA CONFIABILIDADE EM CAMPO...............137

4.9.1 Procedimento de seguimento operacional da confiabilidade.............137

4.9.2 Registro e consolidação de falhas .....................................................138

4.9.3 Relatórios periódicos e comparação com as metas..............................139

4.9.4 Crescimento da confiabilidade ........................................................139

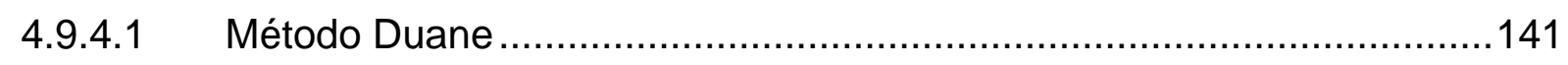

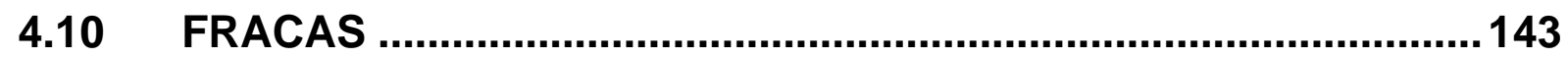

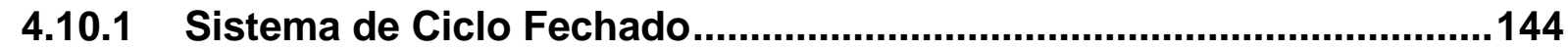

4.10.2 Sistemática no registro de falhas ........................................................147

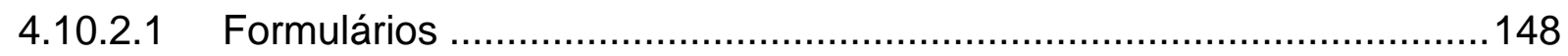

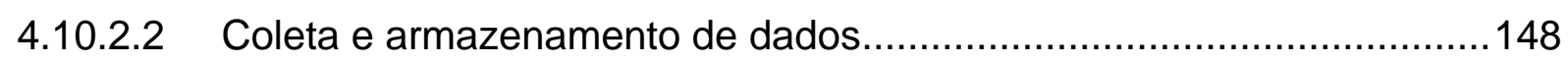

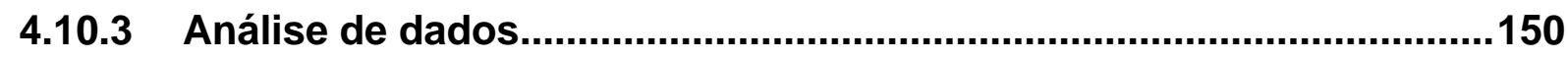

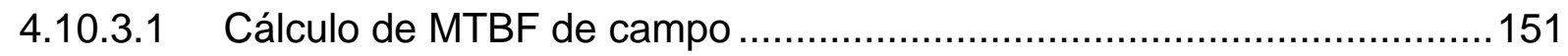

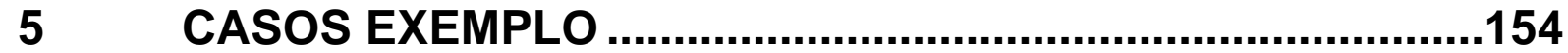

5.1 EXEMPLO 1: ALOCAÇÃO DE METAS DE CONFIABILIDADE .... 155

5.1.1 Descrição .....................................................................................155

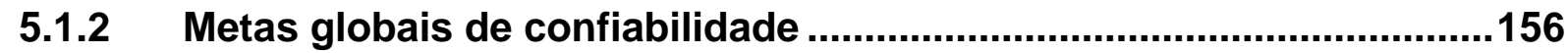

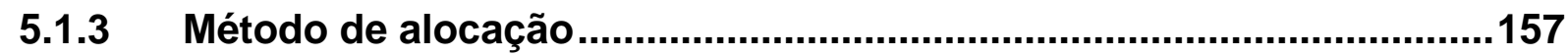

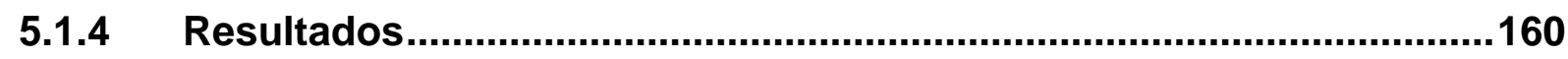

5.1.5 MTBF mínimo dos equipamentos................................................161

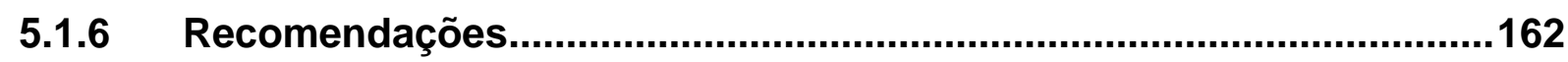

5.2 EXEMPLO 2: PREDIÇÃO DA CONFIABILIDADE ........................163 


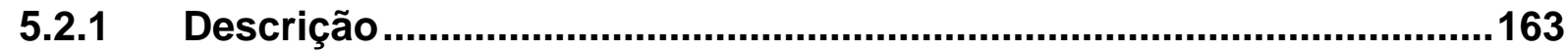

5.2.2 Metas de confiabilidade do sistema ...................................................163

5.2.3 Estrutura analítica do sistema ........................................................164

5.2.4 Determinação da confiabilidade dos componentes...........................166

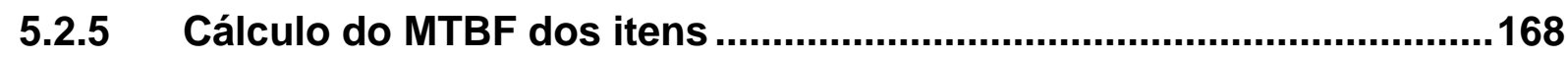

5.2.6 Contribuição para cada tipo de falha ……..........................................170

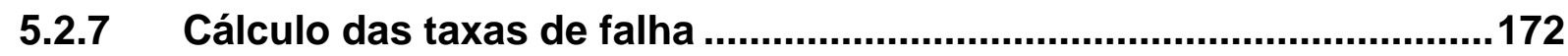

5.2.8 Apresentação e interpretação dos resultados ....................................174

5.2.9 Recomendações..........................................................................180

5.3 EXEMPLO 3: ANÁLISE DE SOLICITAÇÃO E RESISTÊNCIA .......181

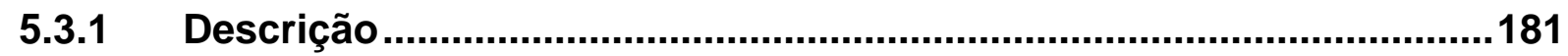

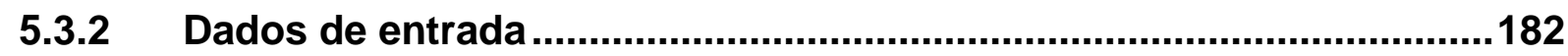

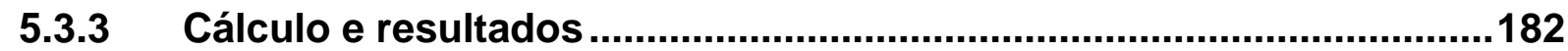

5.3.4 Recomendações e considerações.......................................................183

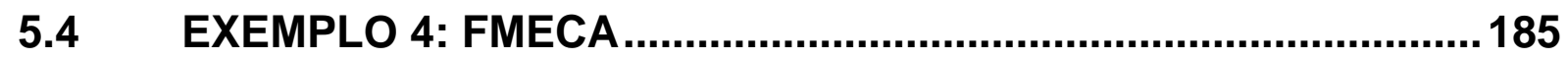

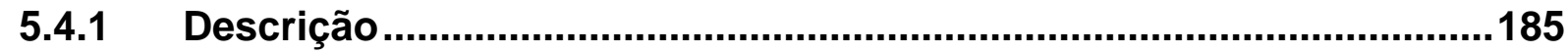

5.4.2 Premissas do Plano de Confiabilidade e Segurança ...........................185

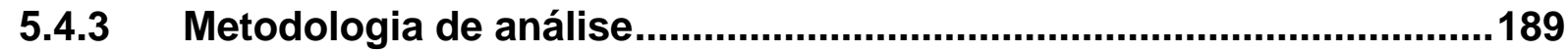

5.4.4 Apresentação e interpretação dos resultados .....................................196

5.5 EXEMPLO 5: CÁLCULO DE SOBRESSALENTES ......................201

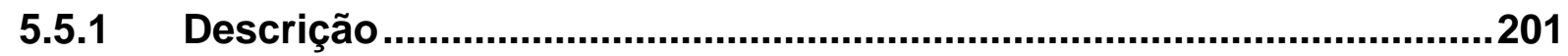

5.5.2 Requisitos da especificação técnica....................................................202

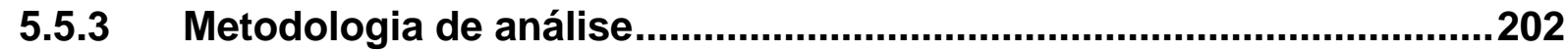

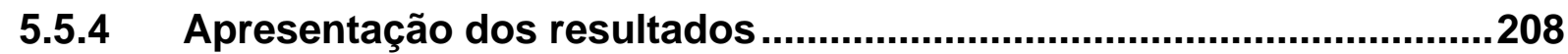

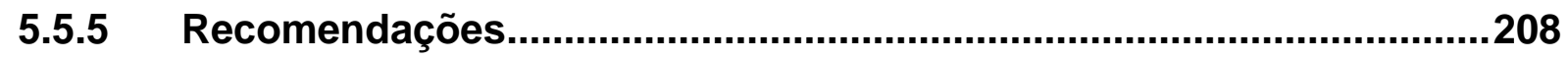

5.6 EXEMPLO 6: MONITORAMENTO DA CONFIABILIDADE............210

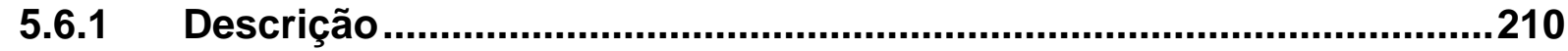

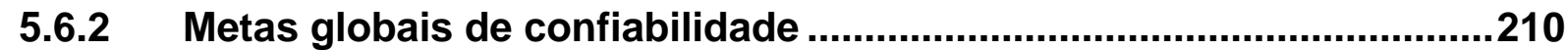

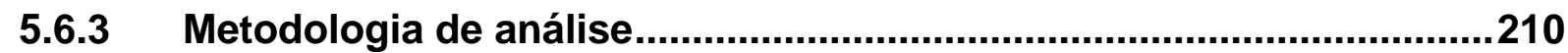

5.6.4 Apresentação e interpretação dos resultados ...................................212

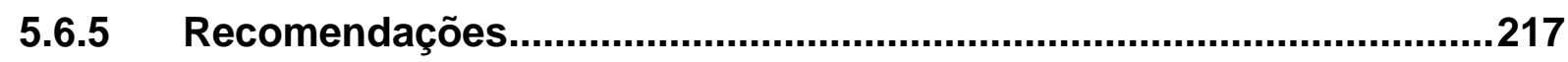

6 CONCLUSÕES ................................................................219

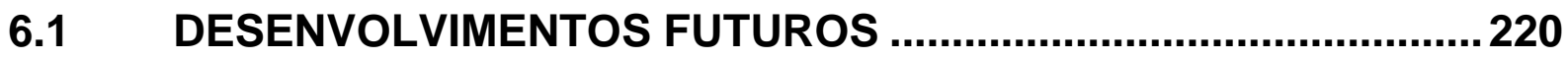


REFERÊNCIAS

.222

APÊNDICE A - CARACTERÍSTICAS BÁSICAS DOS PRINCIPAIS

SISTEMAS:

227

APÊNDICE B - ARTIGO...........................................................251

ANEXO A - TABELA QUI-QUADRADO ......................................253 


\section{INTRODUÇÃO}

O crescimento desordenado das cidades brasileiras nas últimas décadas e a falta de investimentos significativos em transportes públicos de massa levaram o país a um enorme déficit nessa área, se comparado com outros países mais desenvolvidos ou mesmo com nossos vizinhos da América Latina.

As políticas públicas de transporte nesse período priorizaram apenas 0 transporte rodoviário, tanto o coletivo como o individual, tais como corredores de ônibus, viadutos, túneis, etc. As conseqüências não podiam ser outras senão o aumento descontrolado do trânsito, da poluição, do número de acidentes e dos custos operacionais do transporte público. Esse modal oferece um limite relativamente baixo de capacidade de transporte, sendo ideal para pequenas cidades ou para integrar e complementar outros modais de alta capacidade nos grandes centros urbanos, como metrôs e trens de subúrbio.

Grandes cidades como São Paulo, Rio de Janeiro ou mesmo outras capitais requerem um sistema complexo de transporte, de alta capacidade e eficiente ao mesmo tempo. A única maneira de se atender à demanda necessária nessas cidades é através de metrôs e trens de subúrbio formando a espinha dorsal do sistema, e integrada com ônibus ou Veículos Leves sobre Trilhos (VLTs) para efetuar as ramificações necessárias em torno das estações. É assim que ocorre em grandes centros urbanos do mundo como Paris, Londres e Nova lorque, por exemplo.

Portanto, o país carece urgentemente de investimentos no transporte de massa sobre trilhos. Felizmente, os governantes têm acenado para que a priorização de investimentos na ferrovia volte a ser uma realidade brasileira.

Sem dúvida, os altos custos de implantação, operação e manutenção dos sistemas ainda inibem de certa forma um crescimento mais acelerado das malhas metroferroviárias, uma vez que os recursos são escassos. Há então que se fazer bom uso dos recursos existentes para que possam ser mais bem aproveitados.

Uma das várias formas de se economizar os recursos públicos é através do aumento da eficiência do sistema, reduzindo assim os custos de operação e manutenção. 
É justamente nesse ponto que a confiabilidade e a segurança dos trens têm papel fundamental. Porém, a confiabilidade e a segurança dos trens nasce no projeto dos mesmos. Dificilmente um trem que não fora originalmente projetado considerando a confiabilidade e a segurança como fatores prioritários poderá ser melhorado no futuro sem que sejam necessários investimentos adicionais.

A idéia central deste trabalho é abordar o projeto de trens de passageiros, enfatizando o gerenciamento da confiabilidade e segurança durante esse processo.

\subsection{OBJETIVO}

O objetivo deste trabalho é pesquisar os requisitos, normas e boas práticas empregadas na indústria ferroviária para gerenciamento da confiabilidade de projetos de material rodante.

Este trabalho leva em conta a realidade do mercado ferroviário mundial e brasileiro, suas limitações e desafios, procurando abordar os aspectos práticos e científicos da confiabilidade de trens de passageiros, e como tais aspectos devem ser analisados, monitorados e controlados durante um projeto ferroviário de material rodante.

O foco do trabalho está concentrado nos trens de subúrbio e metrô, por serem mais utilizados no Brasil para transporte de passageiros que os trens de grande velocidade e os veículos leves sobre trilhos, por exemplo. Todavia, com algumas adaptações e respeitando as devidas proporções, o mesmo processo de gerenciamento pode ser empregado no projeto desses tipos de trens. 


\section{ESPECIFICIDADES DO SETOR FERROVIÁRIO}

\subsection{ORGANIZAÇÃO DA INDÚSTRIA FERROVIÁRIA}

A indústria ferroviária pode ser dividida em transporte de cargas e transporte de passageiros. Existem muitas coisas em comum mas também algumas diferenças entre ambos.

No caso do transporte de passageiros, podemos mencionar algumas entidades principais que compõem esse segmento do transporte ferroviário. São elas:

- Agencia Reguladora;

- Operadoras de transporte público;

- Fabricantes de material rodante, também chamados de montadoras;

- Fabricantes de subsistemas para o material rodante.

Algumas características dessas entidades são apresentadas nos itens subseqüentes.

Além dessas, obviamente existem outras entidades que complementam a indústria ferroviária, como por exemplo os institutos de pesquisas tecnológicas, as universidades e consultorias técnicas, as empresas fornecedoras de componentes em geral, as empresas de obras civis e de infra-estrutura, e também o próprio governo do país com suas políticas de investimento.

\subsubsection{Agência reguladora}

As agências reguladoras são órgãos independentes que tomam decisões estratégicas sobre os assuntos de interesse do país em determinado segmento. Possuem poderes, direitos e privilégios para exercerem suas autoridades. 
$\mathrm{Na}$ área ferroviária, além de desempenhar o papel de regulador econômico e autoridade ferroviária, as agências trabalham para facilitar a expansão do transporte de cargas e de passageiros.

Servem ainda como tribunal de julgamento quanto a tarifas e reclamações relacionadas aos serviços prestados e em disputas entre companhias sobre assuntos específicos, atuando como mediadoras.

Emitem certificados de autorização para construção e operação de novas linhas e fornecem pareceres técnicos e orientações gerais. Também emitem relatórios com estatísticas do setor.

No Brasil, a Agência Nacional de Transportes Terrestres (ANTT), ligada ao Ministério dos Transportes, regulamenta a área de transporte rodoviário e ferroviário, principalmente o transporte de cargas. Já para o transporte de passageiros, a ANTT concentra o foco no segmento rodoviário. Existem algumas associações, porém não existe ainda uma agência reguladora nacional específica para o transporte ferroviário de passageiros no país, ao contrário do que ocorre em outros países. Quem acaba fazendo de certa forma esse papel são as próprias operadoras através de especificações e de acordos bilaterais com seus fornecedores.

\subsubsection{Operadoras}

As operadoras de transporte público ferroviário são empresas estatais ou mesmo empresas privadas que atuam com concessão de operação por parte do governo. São as operadoras as responsáveis por manter todo sistema em funcionamento, incluindo os trens, as vias, plataformas, áreas de circulação de público, etc.

A arrecadação é feita principalmente através da bilhetagem, da concessão de espaço para publicidade nos trens e nas áreas de circulação de público, e de subsídio por parte do governo.

São as operadoras, também, as responsáveis pela elaboração das especificações técnicas dos sistemas que compreendem o transporte ferroviário, 
como o material rodante, por exemplo. Muitas vezes são assessoradas por consultorias externas contratadas exclusivamente para essa finalidade.

\subsubsection{Fabricantes de material rodante}

Os fabricantes de material rodante, também chamados de montadoras, são empresas de grande porte, geralmente multinacionais, que desenvolvem, projetam e constroem os veículos ferroviários e integram os subsistemas correspondentes, tais como freio, tração, etc.

Fornecem diretamente às operadoras através de processos de licitação e, em função disso, é comum a existência de consórcios entre empresas para participar desses processos. Até porque, muitas vezes o fornecimento do material rodante está atrelado aos investimentos em infra-estrutura, como a construção de vias, por exemplo.

\subsubsection{Fabricantes de subsistemas}

Os fabricantes de subsistemas são os parceiros das montadoras que fornecem sistemas completos ou em partes para serem integrados no trem. Normalmente são empresas de médio e grande porte que possuem estrutura apropriada e expertise específico para o produto que fornecem. Por essa razão, participam intensamente do projeto do trem desde a fase de especificação e propostas juntamente com as montadoras.

Eventualmente, algumas montadoras desenvolvem subsistemas específicos por conta própria, por razões técnicas, estratégicas ou mesmo comercias. 


\subsection{TIPOS DE VEÍCULOS FERROVIÁRIOS}

No transporte ferroviário, o chamado Material Rodante (MR) consiste em um ou vários veículos, ligados entre si e capazes de se movimentarem sobre uma linha ou trilho, para transportar pessoas ou carga de um lado para outro, segundo uma rota previamente planejada. O comboio pode ser puxado por uma locomotiva ou pode ser formado por uma unidade auto-alimentada também chamado de tremunidade (TU).

Existem diversos tipos de veículos que são utilizados nas ferrovias ao redor do mundo. Nos itens subseqüentes estão relacionados alguns deles.

\subsubsection{Locomotivas}

Uma locomotiva é um veículo ferroviário que fornece a energia necessária para a colocação de um trem em movimento. As locomotivas não têm capacidade de transporte própria, quer de passageiros, quer de carga. Existem várias razões para que ao longo dos tempos se tenha isolado a unidade fornecedora de energia do resto do trem:

- Facilidade de manutenção - é mais fácil a manutenção de um único veículo;

- Segurança - Existe mais facilidade de afastar a fonte de energia dos passageiros, em caso de perigo;

- Fácil substituição da fonte de energia - em caso de avaria, só existe a necessidade de substituir a locomotiva e não todo o comboio;

- Eficiência - Os comboios fora de circulação, gastam menos energia quando há necessidade da sua movimentação;

- Obsolescência - Quando a unidade de energia ou as unidades de carga se tornam obsoletas não é necessária a substituição de todos os elementos. 
É comum classificarem-se as locomotivas conforme os seus meios de propulsão. Os mais comuns incluem:

- Vapor

- Diesel-mecânico

- Diesel-elétrico

- Diesel-hidráulica

- Turbina de gás

- Elétricas

Dentre essas, as mais empregadas atualmente são as que possuem propulsão diesel-elétrica e as que possuem propulsão puramente elétrica.

Segundo Connor (1), "[...] as modernas locomotivas diesel produzem apenas $35 \%$ da potência de uma locomotiva elétrica de igual peso. Contudo, os altos custos de implantação e manutenção de um sistema ferroviário eletrificado inibem, na maioria das vezes, a adoção de locomotivas elétricas como material de tração".

Existem ainda as locomotivas adaptadas, também chamadas slug, que possuem motores de tração elétrica, mas não possuem geradores a diesel. São feitas para trabalhar em conjunto com outras locomotivas convencionais que fornecem a energia necessária para seu funcionamento (2).

\subsubsection{Veículos leves sobre trilhos}

Os Veículos Leves sobre Trilhos (VLT) são mais leves que os trens convencionais, projetados para o transporte de passageiros e muito raramente para o transporte de cargas. Normalmente operam entre bairros, em pequenas cidades ou mesmo em grandes centros urbanos, interligados com outros modais de transporte público.

Os VLTs trafegam nas ruas, em corredores exclusivamente dedicados a eles ou ainda compartilhando espaço com carros e ônibus. A grande maioria dos sistemas que utilizam VLT dispensa o uso de plataformas para embarque e desembarque. O passageiro simplesmente entra da calçada para o trem. Essa é 
uma das características que possibilitam a integração com outras formas de transporte público e o uso simultâneo das ruas.

Em grandes cidades o VLT faz um percurso tipicamente mas não obrigatoriamente turístico. Os VLTs são uma evolução do bonde e encontram-se em expansão em várias cidades de todo o mundo, já que possuem grandes vantagens com relação aos ônibus, entre as quais destaca-se a menor poluição (tanto sonora quanto atmosférica) e a prioridade no trânsito.

Vantagens:

- A maior vantagem dos VLTs modernos é mais social do que técnica. Em muitos países os VLTs não sofrem com o problema de imagem que afeta os ônibus. Ao contrário - a maioria das pessoas associam VLTs com uma imagem positiva. Diferentemente dos ônibus, os VLTs tendem a ser populares para uma gama maior de usuários, incluindo aqueles com maior poder aquisitivo e que normalmente evitam ônibus. Esse alto nível de aceitação pública significa maior utilização e maior pressão para investimentos em infraestrutura e expansão das malhas de VLTs.

- O investimento inicial, embora alto, é menor que o investimento necessário para construção de linhas subterrâneas de metrô. Um quilômetro de linha de VLT geralmente custa um terço do investimento para um quilômetro de metrô subterrâneo, já que nenhuma perfuração é necessária. Apenas as vias públicas devem ser adaptadas para receber os trilhos e os cabos de alimentação.

- As linhas de VLT podem ser subterrâneas como as linhas de metrô. Mesmo as linhas de metrô de superfície são mais caras, especialmente aquelas que utilizam terceiro trilho para alimentação.

- Os sistemas de VLT necessitam menos energia que os sistemas de metrô. Iluminação, ventilação, escadas rolantes, etc, consomem energia e em alguns casos, podem até superar o próprio consumo dos trens.

- Os VLTs podem se adaptar ao número de passageiros acrescentando carros nos horários de pico, assim como removendo carros nos 
horários de vale. Para tal, não são necessários operadores adicionais como ocorre com motoristas de ônibus, por exemplo.

- Em geral, a capacidade de transporte dos VLTs é maior que a dos ônibus.

- Sistemas elevados requerem urbanismos especiais com avenidas largas e construções que permitam integrar as estações.

- Ao contrário dos ônibus com motor a combustão, os VLTs não emitem gases poluentes na atmosfera e a poluição sonora é geralmente menor.

- Os espaços necessários para passagem dos VLTs são geralmente menores que para ônibus. Isso economiza espaço valioso nas cidades com alta densidade populacional e/ou vias estreitas.

- Como operam sobre trilhos, os VLTs impõem mais respeito no trânsito em relação aos demais veículos. Em condições de trânsito pesado ou em cruzamentos, a probabilidade dos motoristas bloquearem a passagem dos VLTs é bem menor. Isso leva a menores atrasos. Como regra, especialmente em cidades européias, os VLTs sempre têm a preferência no trânsito.

- O conforto dos passageiros é normalmente superior aos ônibus devido à operação controlada de aceleração, frenagem e inserção em curvas.

Desvantagens:

- O custo inicial é maior que para ônibus, daí a razão para a preferência deste último em pequenas cidades.

- A velocidade média é menor que a dos metrôs, o que de certa forma é compensada por uma freqüência maior de paradas.

- As velocidades são comparáveis desde que sejam utilizadas grandes extensões de linha reservadas apenas para o tráfego de VLT, fora das ruas.

- Capacidade de transporte menor que a dos metrôs.

- As vias de VLT podem ser perigosas para ciclistas e para carros estacionados. Estes problemas podem ser evitados com a construção das vias e das plataformas no meio das ruas. 
- A infra-estrutura necessária ocupa espaço urbano na superfície e gera a necessidade de modificações no fluxo do tráfego.

- Rodas de aço provocam mais ruídos que pneus, especialmente nas curvas.

Os VLTs podem ser classificados de diversas maneiras. De acordo com Gölitz (3), "As diversas vertentes provenientes dos primeiros bondes variam mais na aplicação que em sua capacidade de transporte".

\subsubsection{Metrô}

Metrô é definido como um modo ferroviário para o transporte de passageiros em áreas urbanas o qual é projetado e construído com a finalidade de transportar grandes volumes de pessoas de forma rápida e segura, em trensunidade formados por vários carros. Opera normalmente com rodas de aço sobre trilhos, embora alguns sistemas empreguem pneus. As vias são absolutamente exclusivas, impedindo qualquer tipo de acesso, exceto é claro para manutenção. Plataformas altas e portas largas são utilizadas para se obter segurança e rápido embarque e desembarque. Os carros possuem propulsão própria com motores elétricos para obter rápidas acelerações e desacelerações, evitando ainda emissão de gases tóxicos em túneis. Se qualquer uma dessas características for eliminada ou modificada para um dado sistema, haverá sempre a dúvida de que se trata ou não de um sistema de metrô. Uma vez que cada sistema de metrô é, de alguma forma, diferente uns dos outros visando atender as necessidades e condições locais, muitas vezes é preciso uma avaliação cuidadosa para classificá-los.

Metrô é um tipo de trem urbano, sendo que uma de suas principais diferenças é o fato de ser tipicamente, mas não exclusivamente, subterrâneo e dedicado ao transporte de passageiros em redes relativamente densas e com grande integração com os demais meios de transportes, apesar de serem construídos independentemente.

O termo metrô se tornou genérico no uso popular, porém essa denominação vem do nome original do Metropolitan Line of London, de 1863. É o modo capaz de executar a maior quantidade de serviço, carregando pessoas em 
massa de forma rápida e eficiente para a escala das grandes cidades. Nada impedindo porém sua expansão a municípios e províncias próximas. É um meio de transporte ferroviário simples mas efetivo desde quando foi instituído há pouco mais de 100 anos atrás. Por muito tempo, as melhorias técnicas foram graduais e muitas vezes marginais. Apenas nas últimas duas décadas que melhorias significativas têm sido feitas, mas essas mudanças não afetam o caráter básico do serviço observado pelos usuários exceto, talvez, a inclusão de ar condicionado nos trens. Os avanços técnicos recentes têm focado principalmente questões de eficiência e segurança (alimentação, freio, tração, sistemas de controle, etc), para uma operação automática e para melhorar ainda mais essa característica de trens de grande capacidade com paradas freqüentes e que se movem rapidamente entre estações. Infelizmente, esses benefícios são conseguidos a um custo considerável.

Como o volume de passageiros que um trem de metrô pode carregar é geralmente alto, um sistema de metrô é freqüentemente visto como a espinha dorsal do transporte público nas grandes cidades. Em várias cidades do mundo os passageiros iniciam suas jornadas em VLTs, ônibus ou trens de subúrbio com destino aos grandes centros urbanos, passando pelo metrô e suas estações para evitar o congestionamento das ruas da cidade (4).

Segundo Grieco (5), "Apesar dos trens de metrô serem parecidos com os de subúrbio, eles se diferenciam pelas altas densidades de passageiros no sistema, acelerações e desacelerações, curtas distâncias entre estações e carregamento não pendular".

\subsubsection{Tipos de construção}

Os sistemas de metrô podem ser subterrâneos, de superfície ou em vias elevadas não sendo raro, inclusive, a existência de sistemas com mais de um tipo de construção em diferentes trechos.

- Subterrâneo

- Sistema NATM - New Austrian Tunnelling Method ou túneis austríacos ou ainda túneis de mineração. 
- Trincheiras ou VCA - Valas a Céu Aberto, também denominado sistema destrutivo, exige remoção de interferências externas, tais como: água, luz e outras.

- Mecanizado, ou por máquinas tuneladoras - TBM - Tunnel Boring Machines.

- Superfície

São mais indicadas para regiões de baixa ocupação, vazios urbanos, faixas previamente garantidas através de legislação, ou canteiros centrais de avenidas com larguras adequadas. Dessa forma fica mais barata a obra evitando-se grande volume de desapropriações, principalmente junto às estações, o que eleva consideravelmente o custo final. Nesse caso há necessidade de terraplanar o terreno e remover as interferências superficiais.

Pode-se aproveitar leitos ferroviários antigos para a implantação desse tipo de serviço, mas como sua conversão é cara, evita-se esse tipo de aproveitamento.

- Elevado

- Estrutura metálica

- Concreto

- Pré-moldado

\subsubsection{Trens regionais e de subúrbio}

O modo ferroviário tradicional ainda é a forma mais eficiente de se transportar grandes volumes de pessoas por distâncias relativamente longas com uma velocidade razoável. São os chamados trens regionais. Quando esses sistemas operam também em escalas metropolitanas, eles são chamados de trens de subúrbio.

De fato, sua operação apenas ocorre entre lugares com concentração populacional que sejam suficientemente próximos e de certa forma alinhados, uma 
vez que as estações devem ser relativamente afastadas entre si e atrair um número de usuários que justifique a parada do trem.

Esses trens costumam ser os mais pesados entre os veículos ferroviários e são também aqueles que necessitam da maior infra-estrutura. Costumam ser o principal meio de ligar as cidades menores às maiores em vários países, mesmo hoje em dia.

São normalmente menos ágeis, mais lentos e com um volume de operações menor que os metrôs. Isso é verdade principalmente pelo fato das vias que operam não terem sido originalmente projetadas apenas para o transporte de passageiros mas também de carga. Além disso, a utilização dessas vias para transporte de passageiros visa oferecer conforto e confiabilidade para um público que viaja não só a trabalho, mas também a passeio e portanto não está necessariamente apressado (4).

\subsubsection{Trens de alta velocidade}

Alta velocidade é um termo relativo. Não há uma velocidade específica que defina um trem como de alta velocidade, porém usualmente são assim considerados aqueles cuja velocidade supere os $200 \mathrm{~km} / \mathrm{h}$, (6) e (7).

São normalmente alimentados por locomotivas, porém o que os torna especiais não é apenas a sua aerodinâmica, mas também sua forma de acoplamento e articulação. Os carros não são simplesmente acoplados. Ao invés disso, são unidos de forma semipermanente nas extremidades de dois carros adjacentes através de um truque comum a ambos os carros (8). Ver Figura 1, na seqüência. 


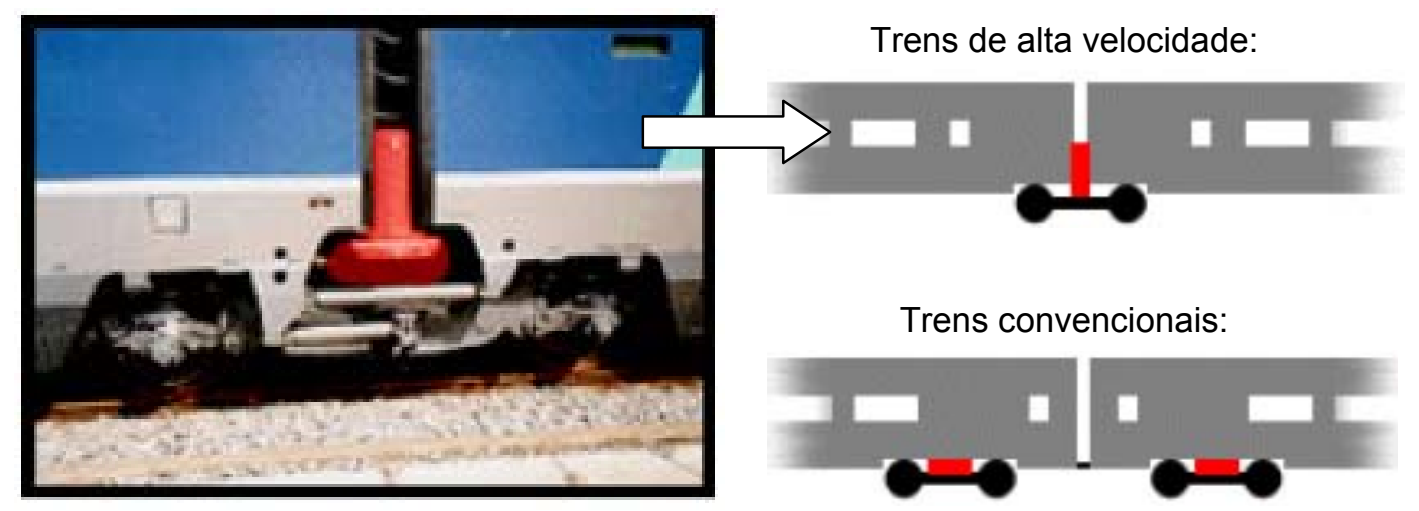

Suspensão secundária em vermelho

Figura 1: Exemplo de acoplamento em trens de grande velocidade (8)

Como esse tipo de trem é projetado para ser muito leve, a redução no número de truques se torna possível. Essa colocação do truque entre carros também reduz os níveis de ruído interno, proporciona maior espaço para instalação de equipamentos sob estrado, um plano mais alto para a suspensão e melhora a aerodinâmica, devido ao pequeno espaço entre carros e à altura menor em relação ao chão (8).

A articulação do trem também permite que carros adjacentes sejam dinamicamente acoplados por amortecedores e possibilitem uma passagem confortável e silenciosa de passageiros de um carro para outro. A articulação nos trens de alta velocidade é uma importante característica de segurança evitando que, em uma colisão, o trem se dobre feito um canivete, o que é mais comum nos trens convencionais (8).

Um problema nos trens de alta velocidade é o custo elevado que sempre é colocado em questão quando comparado com o investimento necessário em outros meios de transporte. Por outro lado, existem vários benefícios que podem justificar sua implementação (9):

- São mais rápidos que as viagens de avião para as mesmas distâncias devido à conexão direta entre as áreas centrais, eliminando a necessidade de translados e tempos perdidos em check in;

- Não são necessárias reservas com antecedência;

- Tempos de viagens precisos. Não há atrasos por condições climáticas;

- Segurança. Menor índice de acidentes e fatalidades comparado com carros ou mesmo com aviões; 
- Redução da poluição atmosférica e sonora nas imediações;

- Apesar de serem trens de alta velocidade o consumo de energia não é excessivamente maior;

\subsubsection{Vias especiais}

Em um sistema de alta velocidade as vias são fundamentais para o desempenho adequado do sistema. Assim como em rodovias, existem restrições de velocidade as quais geralmente são bem inferiores às velocidades máximas dos trens.

As vias devem permitir que os trens trafeguem suavemente e com segurança com velocidades da ordem de 250 a $320 \mathrm{~km} / \mathrm{h}$. Devem ainda ser longas o suficiente para permitir a aceleração e desaceleração dos trens.

O maior problema da utilização das vias existentes para tráfego de trens de alta velocidade é a ação das forças centrífugas em função da existência de curvas acentuadas (7).

Outro problema da utilização das vias existentes é que deve haver uma coordenação entre os trens de alta velocidade e os trens convencionais, pois muito facilmente os trens mais rápidos podem ficar travados pelos mais lentos, resultando em atrasos e, conseqüentemente, na perda dos benefícios dos trens de alta velocidade.

A segurança também é fundamental. Apesar dos trilhos serem substituídos quando necessário, as fundações são as mesmas, o que significa que após chuvas pesadas, por exemplo, as vias podem ceder levemente causando problemas perceptíveis apenas em altas velocidades. Os cruzamentos em nível também são problemas para a segurança.

Por essas razões os trens de grande velocidade necessitam de vias especiais. As principais características das vias especialmente destinadas a trens de alta velocidade são:

- Vias fechadas e exclusivas;

- Inexistência de cruzamentos em nível; 
- Fundações em concreto;

- Grande distância entre linhas paralelas;

- Curvas com raio menor que $5 \mathrm{~km}$ são evitadas;

- Inclinações maiores que em vias convencionais;

- Estações passantes são construídas com 4 vias;

- Túneis são evitados;

\subsubsection{Trens pendulares}

Os trens pendulares possuem um mecanismo que os inclina lateralmente nas curvas permitindo que se alcance velocidades maiores nas vias convencionais (6).

Os trens podem ser construídos de tal forma que as próprias forças inerciais provoquem sua inclinação, comumente referenciados como trens pendulares passivos. Podem também ser inclinados por mecanismos controlados eletronicamente, sendo nesse caso chamados de trens pendulares ativos (7).

Apesar de não serem tão rápidos quanto os trens de alta velocidade, os trens pendulares são muito mais rápidos que os trens convencionais. Têm ainda a vantagem de serem capazes de operar em vias existentes, reduzindo os tempos de viagem e criando assim uma opção viável aos trens de alta velocidade que demandam um nível de investimento muito alto (10). A Figura 2 mostra a inclinação de um trem pendular no contorno de uma curva. 


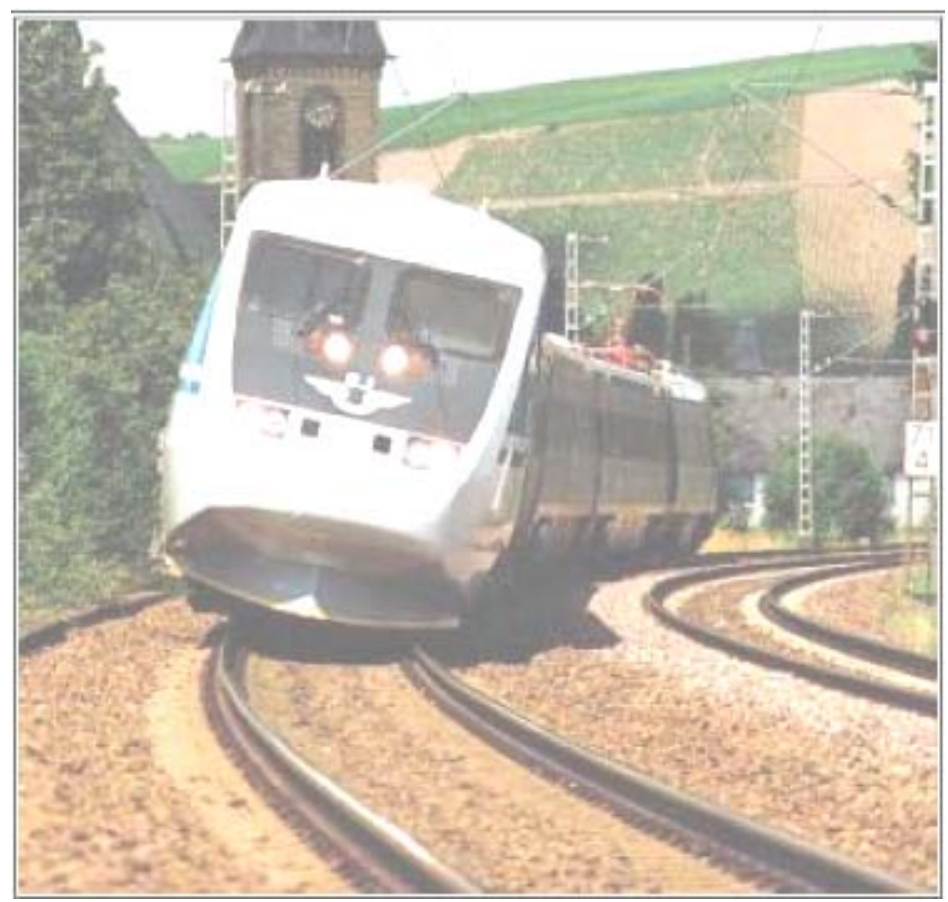

Figura 2: Inclinação do Trem Pendular no contorno de uma curva (7)

A primeira impressão é de que não seja seguro contornar curvas em alta velocidade e que esse é o motivo principal para existência dos trens pendulares. Todavia, a velocidade na qual o trem se torna inseguro nas curvas, ou seja, a velocidade capaz de produzir força suficiente para empurrar o trem para fora da via é alta de forma que seria suficiente para que os passageiros ficassem presos em um dos lados do trem sem se poder mover (7).

O problema é justamente o desconforto causado pela ação da força centrífuga sobre o passageiro. Com o movimento pendular dos trens, o passageiro não é empurrado lateralmente mas sim contra o próprio acento, tendo a mesma sensação provocada pela força da gravidade.

A Figura 3 mostra um exemplo de trem com falha no sistema pendular em alguns carros. 


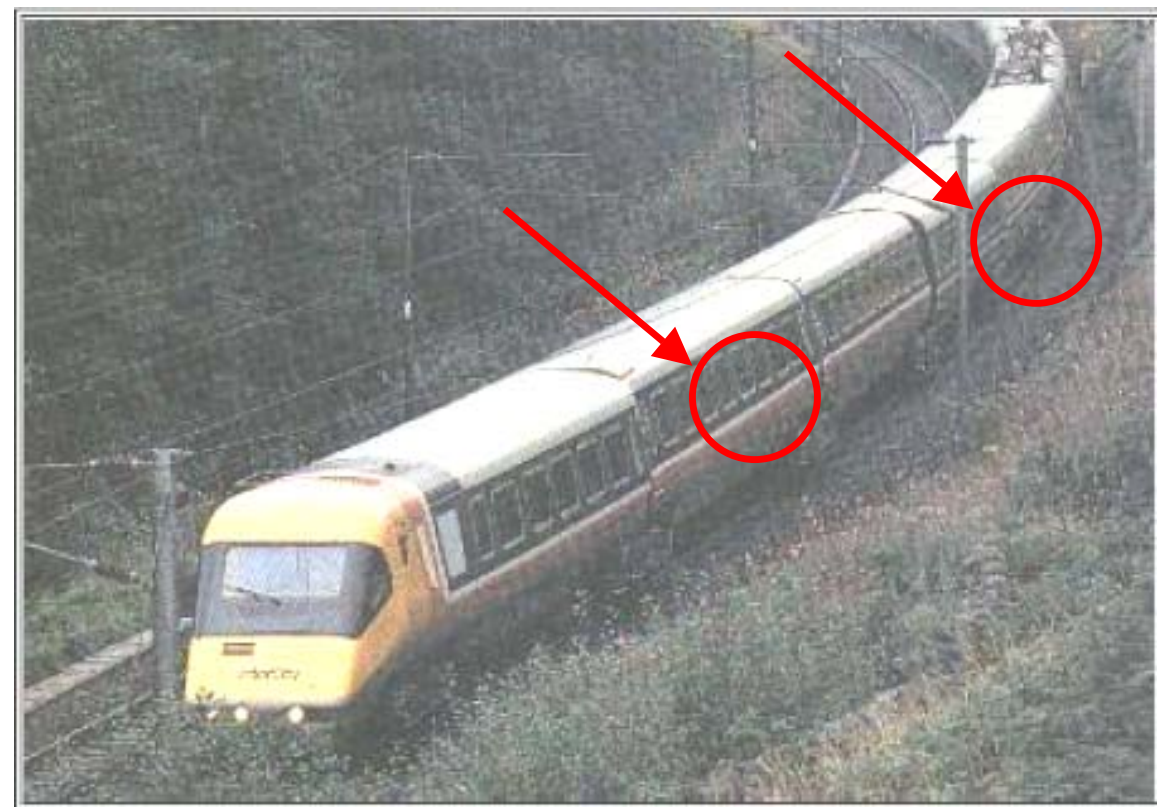

Figura 3: Carros 1 e 4 com falha no sistema pendular (7)

\subsubsection{Outros tipos de veículos}

Existem ainda outros tipos de veículos ferroviários, que não serão abordados neste trabalho. São eles:

- Vagões de carga

- Monotrilho

- Trens que operam por levitação magnética

\subsection{PRINCIPAIS SISTEMAS DOS TRENS DE PASSAGEIROS}

Os trens de passageiros são compostos por sistemas com funções específicas, como propulsão e frenagem que são fundamentais para o funcionamento dos trens. Possuem sistemas voltados para a acessibilidade e o conforto dos passageiros como portas e climatização, além dos sistemas voltados para controle do trem, sinalização de falhas e comunicação, entre outros. 
Os trens modernos possuem diversos sistemas auxiliares tanto para o conforto dos passageiros como para o controle do trem. Esses sistemas são geralmente alimentados eletricamente, porém alguns requerem ar comprimido e, em casos particulares, até mesmo água, como por exemplo em trens equipados com toalete. Como o trem é uma unidade móvel independente, todos os sistemas internos devem ser supridos por fontes locais, instaladas no próprio trem (11).

No APÊNDICE A são apresentadas algumas das características básicas dos principais sistemas empregados nos materiais rodantes atuais, em especial nos trens de subúrbio e metrôs. Apesar disso, os demais tipos de veículo possuem sistemas equivalentes, exceto, é claro, pelas particularidades requeridas para cada aplicação. Na Figura 4 é apresentado um diagrama funcional com os principais sistemas de um trem de passageiros e suas respectivas funções primárias. 


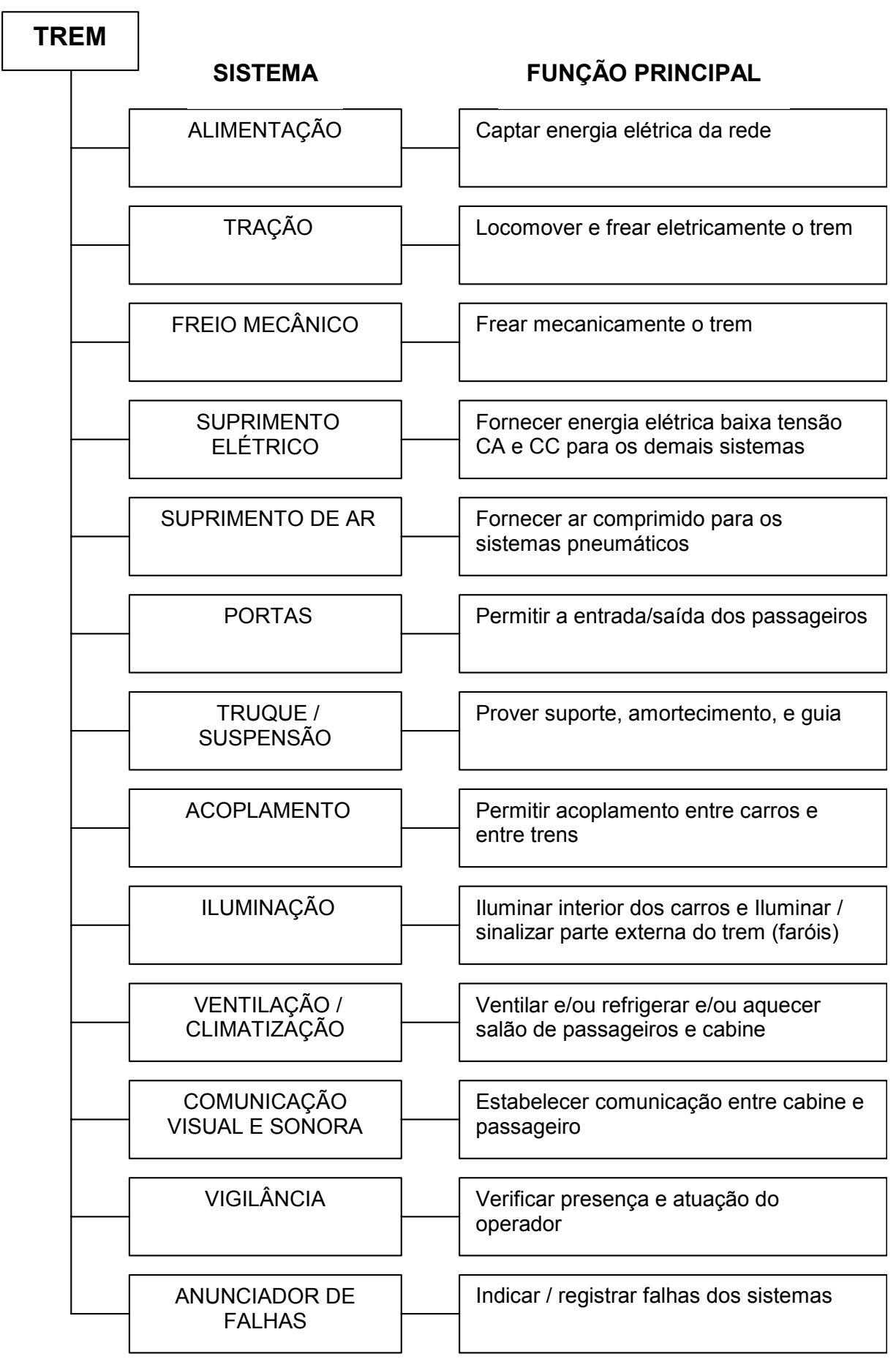

Figura 4: Diagrama funcional de um trem de passageiros 


\section{GERENCIAMENTO DE CDMS}

O projeto de trens de passageiros é uma atividade complexa que envolve uma grande coordenação das ações técnicas e administrativas de uma empresa e consome uma grande quantidade de recursos em um processo de engenharia simultânea integrando o desenvolvimento, a fabricação e a assistência técnica. Essa abordagem faz com que sejam considerados, desde as etapas iniciais do projeto, todos os elementos do seu ciclo de vida (12).

Um dos aspectos que fazem parte desse processo de engenharia simultânea é a engenharia de Confiabilidade, Disponibilidade, Mantenabilidade e Segurança (CDMS), que é intrinsecamente ligada com as demais áreas de desenvolvimento (12).

\subsection{POLÍTICA CORPORATIVA E PROGRAMAS INTEGRADOS}

Segundo O’Connor (13), “...Um programa realmente efetivo de confiabilidade pode existir apenas em uma organização onde o alcance de altos índices de confiabilidade é reconhecido como parte da estratégia corporativa e recebe o apoio da alta direção...". Isso explica o porquê de alguns segmentos darem mais importância aos assuntos de CDMS do que outros.

O'Connor (13) diz ainda que “...as diretrizes e os cuidados com qualidade e confiabilidade devem começar no topo da hierarquia e se disseminar por todos os níveis onde a confiabilidade possa ser afetada...". Portanto, mesmo nas empresas onde CDMS é efetivamente reconhecido como fundamental, se não houver o devido comprometimento das pessoas que compõem a chamada alta administração, pouco se poderá fazer.

Os esforços de CDMS devem sempre ser tratados como parte integral do desenvolvimento do produto e não apenas como uma atividade paralela e desconexa do restante do desenvolvimento. 
Em empresas com estrutura de gerenciamento matricial, o gerente de projeto é responsável pela alocação dos recursos necessários entre as diversas áreas de desenvolvimento. Também é responsabilidade do gerente de projeto o controle dos riscos reportados pelas diversas áreas do desenvolvimento e a tomada de decisões apoiado pelas respectivas equipes técnicas. Em função disso, é fundamental que o mesmo tenha conhecimento das etapas principais do programa de CDMS, de que forma elas estão relacionadas com o restante do desenvolvimento e quais os possíveis efeitos que tal programa pode causar ao projeto, sejam eles positivos ou negativos.

Um programa integrado de CDMS deve, acima de tudo, ser organizado e disciplinado. Enquanto o trabalho de desenvolvimento é geralmente mais efetivo quando não existem muitas restrições de regras e burocracia que limitam a criatividade, os esforços de CDMS devem ser direcionados de forma a estimular a utilização de soluções padronizadas e consagradas, cuja confiabilidade já tenha sido comprovada em uso. Esse controle pode ser obtido através da implementação de banco de dados, manuais, procedimentos e verificações de projeto, por exemplo.

Deve-se garantir através de procedimentos obrigatórios que as análises de projeto, verificações, testes funcionais, análise e correção de falhas sejam corretamente conduzidas, uma vez que qualquer descuido pode resultar em redução da confiabilidade final do produto.

Deve-se ainda evitar a tendência natural de se reduzir a rigorosidade das análises, como por exemplo não atribuindo a devida relevância a uma falha, em função de pressões por prazo ou dificuldades técnicas que geralmente aparecem no decorrer do projeto. Esse tipo de comportamento apenas adia a manifestação do problema. É preciso que fique claro para todos os envolvidos que uma das principais atribuições da engenharia de CDMS é justamente identificar eventuais problemas em potencial no desenvolvimento do projeto.

A maneira mais efetiva para se assegurar a não ocorrência de desvios que possam comprometer a CDMS de um projeto é através da excelência de um plano de confiabilidade e da implantação de procedimentos padrão, com definições claras de responsabilidades. A efetividade desse processo deve ser checada através de auditorias periódicas. 


\subsection{CICLO DE VIDA DO PROJETO}

O ciclo de vida do projeto é uma sucessão de fases, cada uma contendo tarefas específicas e cobrindo a vida total do desenvolvimento do sistema desde sua concepção inicial até a retirada de operação e disposição final no seu descarte. $O$ ciclo de vida provê uma estrutura para planejar, administrar, controlar e monitorar todos os aspectos de um sistema, inclusive CDMS, à medida que o projeto progride pelas fases, de forma a entregar o produto certo dentro dos parâmetros de qualidade, custo e tempo de entrega acordados. O conceito de ciclo de vida é fundamental na implementação de um projeto ferroviário. De acordo com a norma IEC 62278 (14), a representação apropriada para o ciclo de vida do projeto está representada na Figura 5, e as principais tarefas a serem cumpridas para cada fase do ciclo de vida estão na Tabela 1.

Nessa representação em "V" do ciclo de vida, o lado esquerdo é geralmente chamado de desenvolvimento e é um processo de refinamento culminando com a fabricação dos componentes do sistema. O lado direito é relacionado com a montagem, instalação, recepção e operação do sistema como um todo. A representação de " $\mathrm{V}$ " assume que as atividades de aceitação são intrinsecamente ligadas ao desenvolvimento das atividades na medida em que o que é de fato projetado deva ser finalmente verificado em relação aos requisitos.

A Figura 6 mostra tarefas de verificação e validação dentro do ciclo de vida. O objetivo da verificação é demonstrar que, para entradas específicas, as saídas de cada fase satisfazem, sob todos os aspectos, as exigências daquela fase. O objetivo da validação é demonstrar que o sistema sob consideração, em qualquer passo de seu desenvolvimento e depois de sua instalação, satisfaz as exigências especificadas. 
1
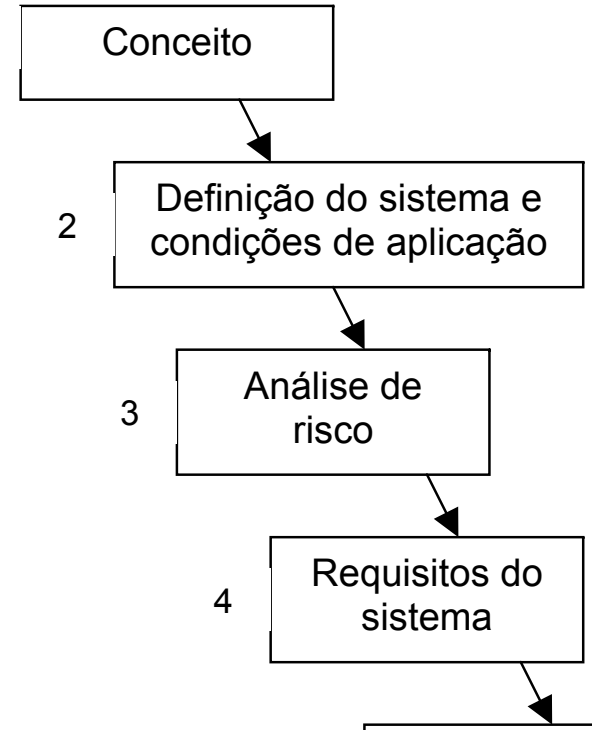

Divisão dos requisitos dos sistemas

6

\section{Projeto e} Implementação

7
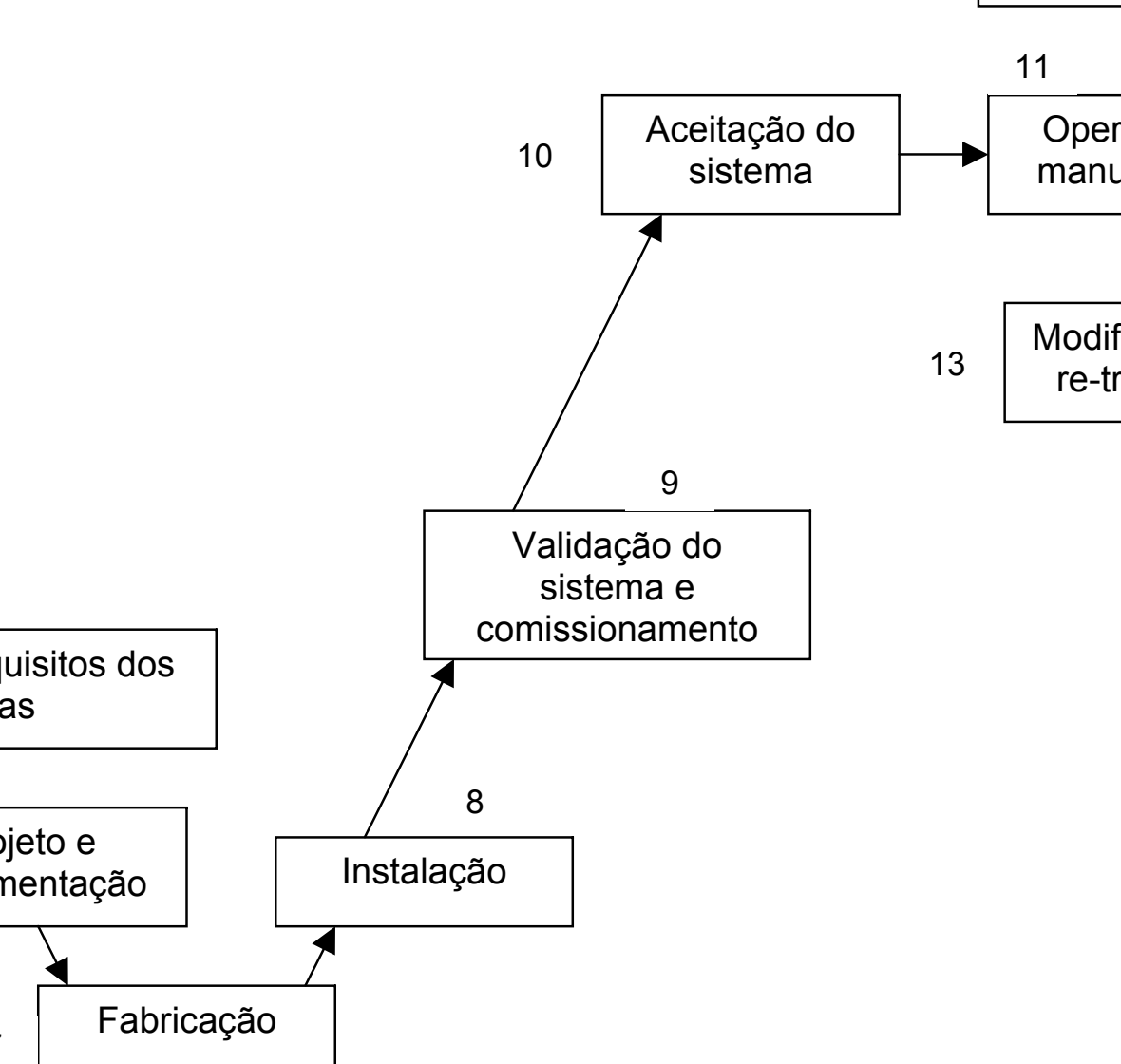
sistema manutenção

Modificações e re-trabalhos

Figura 5: Ciclo de vida do projeto 
Tabela 1: Tarefas relacionadas ao projeto (continua)

\begin{tabular}{|c|c|c|}
\hline \multicolumn{2}{|r|}{$\begin{array}{l}\text { FASE DO CICLO } \\
\text { DE VIDA }\end{array}$} & TAREFAS RELACIONADAS AO PROJETO \\
\hline 1 & Conceito & $\begin{array}{l}\text { - Estabelecer escopo e propósito do projeto ferroviário; } \\
\text { - Definir conceito do projeto ferroviário; } \\
\text { - Elaboração de análises financeiras e estudos de viabilidade; } \\
\text { - Estabelecer responsabilidades; }\end{array}$ \\
\hline 2 & $\begin{array}{l}\text { Definição do } \\
\text { sistema e condições } \\
\text { de aplicação }\end{array}$ & $\begin{array}{l}\text { - Estabelecer o perfil da missão do sistema; } \\
\text { - Preparar a descrição do sistema; } \\
\text { - Identificar tarefas de operação e manutenção; } \\
\text { - Identificar condições operacionais; } \\
\text { - Identificar condições de manutenção; } \\
\text { - Identificar influência das restrições de infra-estrutura existentes; }\end{array}$ \\
\hline 3 & Análise de risco & $\begin{array}{l}\text { - Elaborar análise dos riscos técnicos e financeiros relacionada ao } \\
\text { projeto }\end{array}$ \\
\hline 4 & $\begin{array}{l}\text { Requisitos do } \\
\text { sistema }\end{array}$ & $\begin{array}{l}\text { - Elaborar análise dos requisitos; } \\
\text { - Especificar o sistema (requisitos gerais); } \\
\text { - Especificar o ambiente; } \\
\text { - Definir a demonstração do sistema e os critérios de aceitação } \\
\text { (requisitos gerais); } \\
\text { - Estabelecer o plano de validação; } \\
\text { - Estabelecer os requisitos de qualidade, de gerenciamento e de } \\
\text { organização; } \\
\text { - Implementar procedimento de controle de modificações; }\end{array}$ \\
\hline 5 & $\begin{array}{l}\text { Divisão dos } \\
\text { requisitos dos } \\
\text { sistemas }\end{array}$ & $\begin{array}{l}\text { - Especificar requisitos dos subsistemas e componentes; } \\
\text { - Definir critério de aceitação de subsistemas e componentes; }\end{array}$ \\
\hline 6 & $\begin{array}{l}\text { Projeto e } \\
\text { Implementação }\end{array}$ & $\begin{array}{l}\text { - Elaborar planejamento; } \\
\text { - Elaborar projeto e desenvolvimento; } \\
\text { - Efetuar análises do projeto e testes; } \\
\text { - Efetuar verificação do projeto; } \\
\text { - Efetuar implementação e validação; } \\
\text { - Planejar suporte logístico; }\end{array}$ \\
\hline 7 & Fabricação & $\begin{array}{l}\text { - Elaborar planejamento da produção; } \\
\text { - Produção; } \\
\text { - Produção e teste de sub-montagens; } \\
\text { - Preparar documentação; } \\
\text { - Realizar treinamentos; }\end{array}$ \\
\hline 8 & Instalação & $\begin{array}{l}\text { - Montar sistema; } \\
\text { - Instalar sistema; }\end{array}$ \\
\hline
\end{tabular}


Tabela 1: Tarefas relacionadas ao projeto (conclusão)

\begin{tabular}{|c|c|c|}
\hline 9 & $\begin{array}{l}\text { Validação do } \\
\text { sistema e } \\
\text { comissionamento }\end{array}$ & $\begin{array}{l}\text { - Comissionamento; } \\
\text { - Executar operação comprobatória; } \\
\text { - Efetuar treinamentos; }\end{array}$ \\
\hline 10 & $\begin{array}{l}\text { Aceitação do } \\
\text { sistema }\end{array}$ & $\begin{array}{l}\text { - Elaborar procedimentos baseados nos critérios de aceitação; } \\
\text { - Coletar evidências para aceitação; } \\
\text { - Entrada em serviço do sistema; } \\
\text { - Continuação da operação comprobatória (quando apropriado); }\end{array}$ \\
\hline 11 & $\begin{array}{l}\text { Operação e } \\
\text { manutenção }\end{array}$ & $\begin{array}{l}\text { - Operação de longo prazo do sistema; } \\
\text { - Manutenção; } \\
\text { - Treinamentos; }\end{array}$ \\
\hline 12 & $\begin{array}{l}\text { Monitoramento do } \\
\text { desempenho }\end{array}$ & $\begin{array}{l}\text { - Coletar dados estatísticos do desempenho operacional; } \\
\text { - Analisar e avaliar dados; }\end{array}$ \\
\hline 13 & $\begin{array}{l}\text { Modificações e re- } \\
\text { trabalhos }\end{array}$ & $\begin{array}{l}\text { - Implementar procedimentos de solicitação de modificação; } \\
\text { - Implementar procedimentos de modificações e re-trabalhos; }\end{array}$ \\
\hline 14 & Descarte & - Planejar e efetuar retirada de operação e descarte; \\
\hline
\end{tabular}



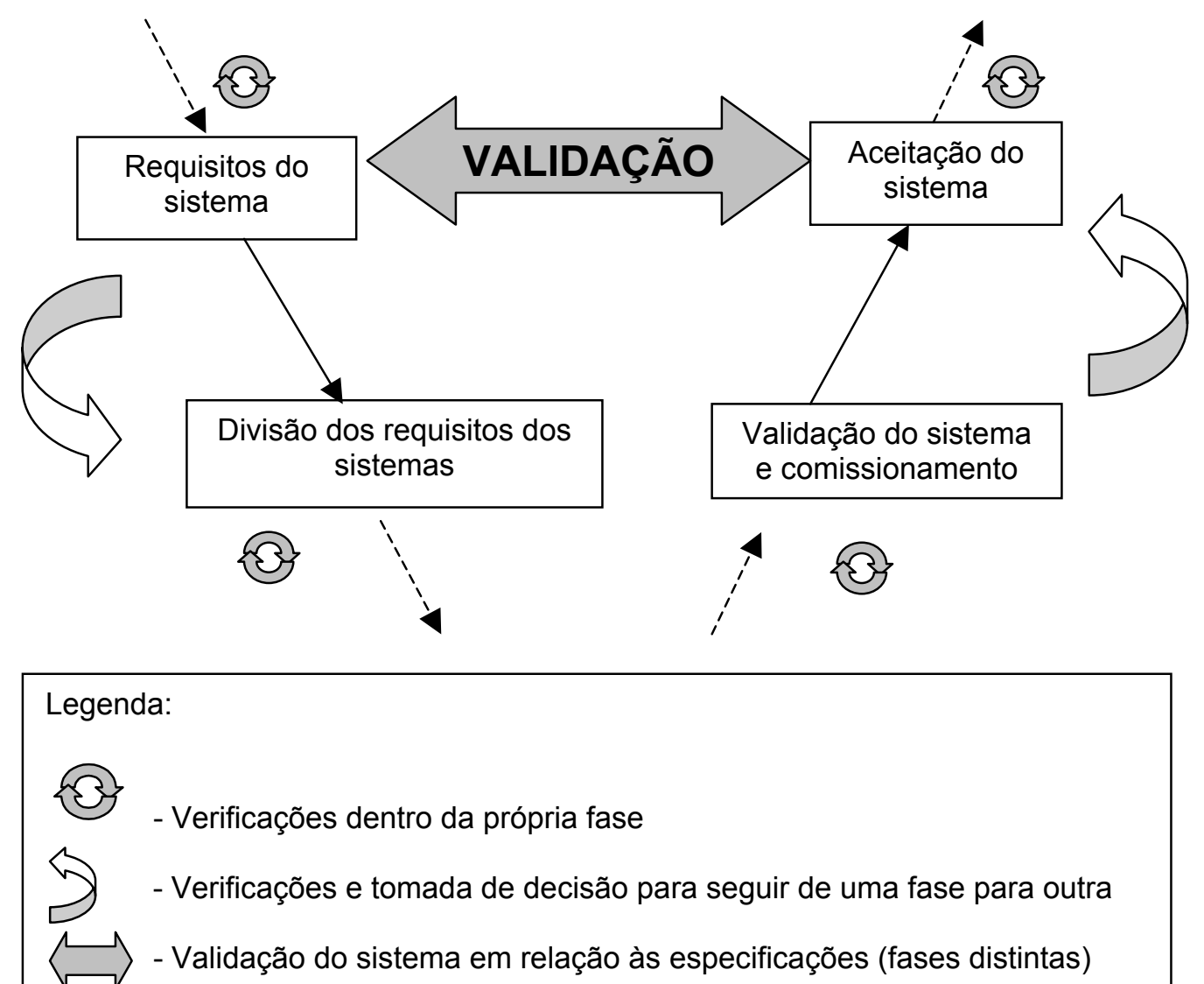

Figura 6: Verificação e validação

\subsection{CDMS NO DOMÍNIO FERROVIÁRIO}

A norma IEC 62278 (14), é baseada na norma EN 50126 (15) e pode ser considerada a principal norma internacional de CDMS para projetos ferroviários. Essa norma apresenta as definições dos elementos de CDMS e suas relações, define um método de gerenciamento de CDMS dentro de um projeto, baseado no ciclo de vida dos sistemas ferroviários e nas atividades em cada etapa do ciclo de vida, além de definir um processo sistemático para especificação dos requisitos de CDMS e demonstração de que tais requisitos são alcançáveis.

Porém essa norma não define metas de CDMS, requisitos e/ou soluções para problemas específicos na ferrovia. Também não define regras e/ou ferramentas para assegurar o cumprimento com os parâmetros de CDMS. 
CDMS são características de operação do sistema por um longo período e são obtidas pela aplicação de conceitos consagrados de engenharia, métodos, ferramentas e técnicas durante o ciclo de vida do sistema.

CDMS de um sistema podem ser caracterizadas como a capacidade, avaliada em termos qualitativos e quantitativos, de funcionar conforme as especificações e estar disponível para operação de forma segura.

O objetivo de um sistema ferroviário é alcançar um determinado nível de tráfego sobre os trilhos em um dado tempo, de forma segura. CDMS no domínio ferroviário descreve a confiança de que o sistema possa garantir o atendimento a essa meta. Por isso, tem uma forte e clara influência na qualidade do serviço prestado ao usuário.

De acordo com a norma IEC 62278 (14), a qualidade do serviço prestado também é influenciada por outros fatores relacionados com a funcionalidade e desempenho, como por exemplo a freqüência e regularidade do serviço, além do preço.

O inter-relacionamento dos elementos de CDMS para aplicação ferroviária é representado na Figura 7.

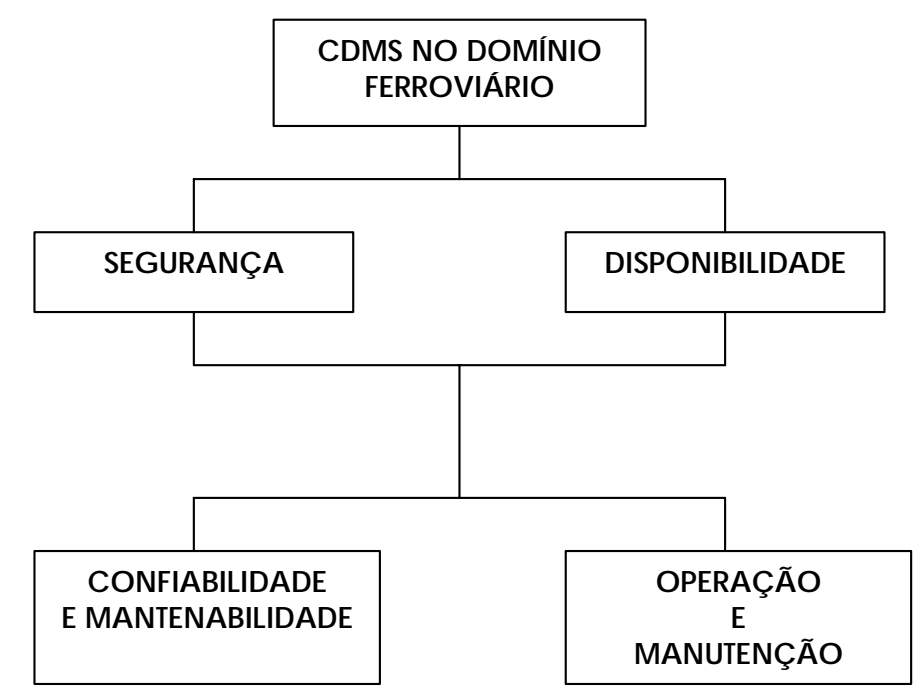

Figura 7: Inter-relacionamento dos elementos de CDMS 
Todas as falhas ocorridas em um sistema afetam negativamente a confiabilidade do mesmo, porém apenas algumas falhas muito específicas afetam negativamente tanto a confiabilidade quanto a segurança do sistema, conforme mostrado na Figura 8.

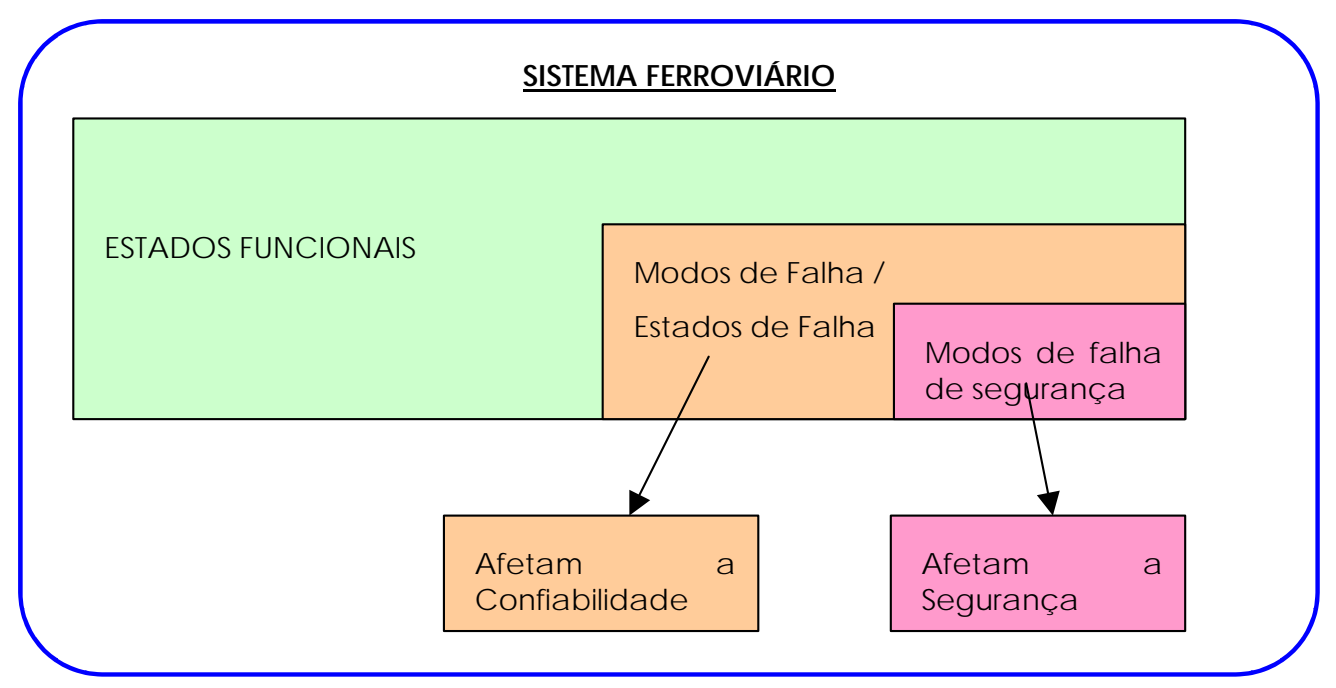

Figura 8: Efeitos das falhas em um sistema ferroviário

CDMS em um sistema ferroviário são afetadas por 3 fatores: internos ao sistema em qualquer fase do seu ciclo de vida (Condições do Sistema); externos impostos ao sistema durante a operação (Condições Operacionais); e fatores externos impostos ao sistema durante as atividades de manutenção (Condições de Manutenção), havendo interação entre os mesmos.

\subsection{ATIVIDADES EM CADA FASE}

A norma IEC 62278 (14), define os objetivos, os requisitos, as entradas e as saídas relacionadas com CDMS em cada etapa do ciclo de vida do projeto. $\mathrm{Na}$ Tabela 2 constam as principais tarefas relacionadas com CDM e na Tabela 3 constam as principais tarefas relacionadas com a segurança. 
Tabela 2: Tarefas relacionadas com CDM (continua)

\begin{tabular}{|c|c|c|}
\hline \multicolumn{2}{|c|}{ FASE DO CICLO DE VIDA } & \multirow{2}{*}{\begin{tabular}{|l|} 
TAREFAS RELACIONADAS COM CDM \\
- Rever o desempenho de CDM previamente alcançado; \\
- Considerar as implicações de CDM no projeto;
\end{tabular}} \\
\hline 1 & Conceito & \\
\hline 2 & $\begin{array}{l}\text { Definição do } \\
\text { sistema e condições } \\
\text { de aplicação }\end{array}$ & $\begin{array}{l}\text { - Avaliar dados de retorno de experiências passadas com CDM; } \\
\text { - Efetuar análise preliminar de CDM; } \\
\text { - Estabelecer a política de CDM; } \\
\text { - Identificar as condições de operação e manutenção; } \\
\text { - Identificar a influência das restrições de infra-estrutura existentes em } \\
\text { CDM; }\end{array}$ \\
\hline 3 & Análise de risco & $\begin{array}{l}\text { - Elaborar análise de risco relacionada com o cumprimento dos } \\
\text { requisitos de CDM; }\end{array}$ \\
\hline 4 & $\begin{array}{l}\text { Requisitos do } \\
\text { sistema }\end{array}$ & $\begin{array}{l}\text { - Especificar requisitos de CDM do sistema; } \\
\text { - Definir critério de aceitação de CDM; } \\
\text { - Definir estrutura funcional do sistema; } \\
\text { - Estabelecer programa de CDM; } \\
\text { - Estabelecer a forma de gerenciamento de CDM; } \\
\text { - }\end{array}$ \\
\hline 5 & $\begin{array}{l}\text { Divisão dos } \\
\text { requisitos dos } \\
\text { sistemas }\end{array}$ & $\begin{array}{l}\text { - Alocação dos requisitos de CDM do sistema nos sub-sistemas, } \\
\text { definindo requisitos e critérios de aceitação; }\end{array}$ \\
\hline 6 & $\begin{array}{l}\text { Projeto e } \\
\text { Implementação }\end{array}$ & $\begin{array}{l}\text { - Implementar programa de CDM através de revisões de projeto, } \\
\text { análises, testes e avaliação de resultados; } \\
\text { - Controlar a evolução do programa de CDM, incluindo as interfaces } \\
\text { com fornecedores; }\end{array}$ \\
\hline 7 & Fabricação & $\begin{array}{l}\text { - Executar ensaios ambientais; } \\
\text { - Executar ensaios de melhoria de CDM; } \\
\text { - Iniciar um de Sistema de Registro de Falhas, Análise e Ações } \\
\text { Corretivas (FRACAS); }\end{array}$ \\
\hline 8 & Instalação & $\begin{array}{l}\text { - Iniciar treinamentos dos responsáveis pela manutenção; } \\
\text { - Efetuar previsões de sobressalentes e ferramentas especiais; }\end{array}$ \\
\hline 9 & $\begin{array}{l}\text { Validação do } \\
\text { sistema e } \\
\text { comissionamento }\end{array}$ & - Efetuar a demonstração de CDM \\
\hline 10 & $\begin{array}{l}\text { Aceitação do } \\
\text { sistema }\end{array}$ & - Avaliar a demonstração de CDM \\
\hline 11 & $\begin{array}{l}\text { Operação e } \\
\text { manutenção }\end{array}$ & $\begin{array}{l}\text { - Gerenciar estoques de sobressalentes e ferramentas especiais; } \\
\text { - Realizar manutenção Centrada em Confiabilidade; }\end{array}$ \\
\hline
\end{tabular}


Tabela 2: Tarefas relacionadas com CDM (conclusão)

\begin{tabular}{|c|c|l|}
\hline 12 & $\begin{array}{c}\text { Monitoramento do } \\
\text { desempenho }\end{array}$ & - Coletar, analisar, avaliar e utilizar estatísticas de desempenho e CDM; \\
\hline 13 & $\begin{array}{c}\text { Modificações e re- } \\
\text { trabalhos }\end{array}$ & - Considerar as implicações de CDM em modificações e retrabalhos; \\
\hline 14 & Descarte & - Sem atividades de CDM; \\
\hline
\end{tabular}

Tabela 3: Tarefas relacionadas à segurança (continua)

\begin{tabular}{|c|c|c|}
\hline \multicolumn{2}{|c|}{ FASE DO CICLO DE VIDA } & TAREFAS RELACIONADAS COM SEGURANÇA \\
\hline 1 & Conceito & $\begin{array}{l}\text { - Rever o desempenho de Segurança previamente alcançado; } \\
\text { - Considerar as implicações de Segurança no projeto; } \\
\text { - Rever políticas e metas de Segurança; }\end{array}$ \\
\hline 2 & $\begin{array}{l}\text { Definição do } \\
\text { sistema e condições } \\
\text { de aplicação }\end{array}$ & $\begin{array}{l}\text { - Avaliar dados de retorno de experiências passadas com Segurança; } \\
\text { - Efetuar Análise Preliminar dos Perigos (PHA); } \\
\text { - Estabelecer plano de Segurança; } \\
\text { - Definir critério de tolerância ao risco; } \\
\text { - Identificar a influência das restrições de infra-estrutura existentes na } \\
\text { Segurança; }\end{array}$ \\
\hline 3 & Análise de risco & $\begin{array}{l}\text { - Efetuar análises de perigo e de riscos à segurança do sistema; } \\
\text { - Preparar um controle dos perigos; } \\
\text { - Efetuar avaliação de risco; }\end{array}$ \\
\hline 4 & $\begin{array}{l}\text { Requisitos do } \\
\text { sistema }\end{array}$ & $\begin{array}{l}\text { - Especificar requisitos de Segurança do sistema; } \\
\text { - Definir critério de aceitação de Segurança; } \\
\text { - Definir requisitos das funções relacionadas à segurança; } \\
\text { - Estabelecer a forma de gerenciamento da Segurança; }\end{array}$ \\
\hline 5 & $\begin{array}{l}\text { Divisão dos } \\
\text { requisitos dos } \\
\text { sistemas }\end{array}$ & $\begin{array}{l}\text { - Alocação dos requisitos de Segurança do sistema nos sub-sistemas, } \\
\text { definindo requisitos e critérios de aceitação; } \\
\text { - Atualizar plano de Segurança; }\end{array}$ \\
\hline 6 & $\begin{array}{c}\text { Projeto e } \\
\text { Implementação }\end{array}$ & $\begin{array}{l}\text { - Implementar programa de Segurança através de revisões de projeto, } \\
\text { análises, testes e avaliação de resultados, registros e análises dos } \\
\text { perigos; } \\
\text { - Controlar a evolução do programa de CDM, incluindo as interfaces } \\
\text { com fornecedores; } \\
\text { - Justificar decisões de projeto relacionadas com a segurança; } \\
\text { - Preparar arquivos com evidências de segurança; }\end{array}$ \\
\hline
\end{tabular}


Tabela 3: Tarefas relacionadas à segurança (conclusão)

\begin{tabular}{|c|c|c|}
\hline 7 & Fabricação & $\begin{array}{l}\text { - Implementar programa de Segurança através de revisões de } \\
\text { processo, análises, testes e avaliação de resultados, registros e } \\
\text { análises dos perigos; }\end{array}$ \\
\hline 8 & Instalação & $\begin{array}{l}\text { - Estabelecer um programa de instalação; } \\
\text { - Implementar programa de instalação; }\end{array}$ \\
\hline 9 & $\begin{array}{l}\text { Validação do } \\
\text { sistema e } \\
\text { comissionamento }\end{array}$ & $\begin{array}{l}\text { - Estabelecer um plano de comissionamento; } \\
\text { - Implementar plano de comissionamento; } \\
\text { - Preparar a aplicação das medidas de segurança; }\end{array}$ \\
\hline 10 & $\begin{array}{l}\text { Aceitação do } \\
\text { sistema }\end{array}$ & - Avaliar a aplicação das medidas de segurança; \\
\hline 11 & $\begin{array}{l}\text { Operação e } \\
\text { manutenção }\end{array}$ & $\begin{array}{l}\text { - Realizar manutenção Centrada em Confiabilidade; } \\
\text { - Realizar monitoramento do desempenho de segurança e atualização } \\
\text { dos arquivos de segurança; }\end{array}$ \\
\hline 12 & $\begin{array}{l}\text { Monitoramento do } \\
\text { desempenho }\end{array}$ & $\begin{array}{l}\text { - Coletar, analisar, avaliar e utilizar estatísticas de desempenho e } \\
\text { Segurança; }\end{array}$ \\
\hline 13 & $\begin{array}{l}\text { Modificações e re- } \\
\text { trabalhos }\end{array}$ & $\begin{array}{l}\text { - Considerar as implicações de Segurança em modificações e } \\
\text { retrabalhos; }\end{array}$ \\
\hline 14 & Descarte & $\begin{array}{l}\text { - Estabelecer plano de segurança; } \\
\text { - Realizar análise de perigo e avaliação de risco; } \\
\text { - Implementar plano de segurança; }\end{array}$ \\
\hline
\end{tabular}

\subsection{IMPLEMENTAÇÃO DE CDMS}

A implementação de CDMS em um projeto de material rodante ferroviário deve ser feita levando-se em conta, inicialmente, a existência ou não de requisitos de CDMS por parte do cliente e também a configuração do trem que está sendo projetado. Ou seja, se é um trem totalmente novo e, portando, com uma quantidade considerável de incertezas técnicas, ou um trem baseado em projetos anteriormente elaborados e, portanto, com um grau de comprovação bem maior.

Essa distinção é feita com o objetivo de se cumprir com o especificado e, ao mesmo tempo, obter o melhor aproveitamento possível de recursos, levando-se em conta os riscos tecnológicos associados. 
Só é possível deixar de se elaborar algumas das atividades caso as soluções de referência para o novo trem tenham sido analisadas anteriormente e, portanto, boa parte da documentação possa ser considerada tecnicamente válida. Caso contrário, o tratamento deve ser o mesmo dado no projeto de um trem novo, efetuando-se todas as atividades previstas.

$\mathrm{Na}$ Tabela 4 há uma sugestão das atividades de CDM a serem feitas nas principais etapas do projeto. Nela estão assinaladas que tarefas são aplicáveis dependendo do nível de inovação tecnológica, considerando o grau de aproveitamento de projetos anteriores e os requisitos de CDM estabelecidos pelos clientes.

Tabela 4: Implementação de CDM (continua)

\begin{tabular}{|c|c|c|c|c|}
\hline \multirow[b]{2}{*}{ TAREFAS POR FASE } & \multicolumn{2}{|c|}{$\begin{array}{l}\text { Projeto } \\
\text { Novo }\end{array}$} & \multicolumn{2}{|c|}{$\begin{array}{l}\text { Projeto } \\
\text { provado }\end{array}$} \\
\hline & 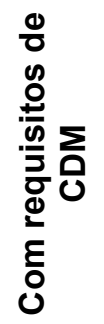 & 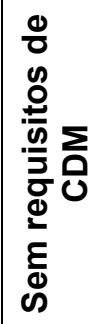 & 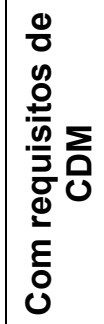 & 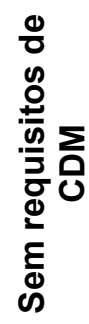 \\
\hline \multicolumn{5}{|l|}{ PROPOSTA } \\
\hline - Avaliar soluções em relação às exigências contratuais & $\mathrm{X}$ & $X$ & $X$ & $x$ \\
\hline $\begin{array}{l}\text { - Analisar risco financeiro devido a riscos tecnológicos e } \\
\text { percentuais de aproveitamento de soluções anteriormente } \\
\text { empregadas. }\end{array}$ & $\mathrm{X}$ & & & \\
\hline $\begin{array}{l}\text { - Analisar risco financeiro devido a penalidades previstas em } \\
\text { contrato. }\end{array}$ & $\mathrm{X}$ & & $X$ & \\
\hline - Fornecer suporte às negociações & $X$ & & $X$ & \\
\hline
\end{tabular}


Tabela 4: Implementação de CDM (conclusão)

\begin{tabular}{|c|c|c|c|c|}
\hline \multicolumn{5}{|l|}{ PROJETO } \\
\hline $\begin{array}{l}\text { - Assegurar ao cliente que os aspectos de CDMS serão } \\
\text { integrados no processo de desenvolvimento do projeto. }\end{array}$ & $x$ & & $x$ & \\
\hline $\begin{array}{l}\text { - Especificar aos parceiros suas contribuições na integração de } \\
\text { CDMS no processo de desenvolvimento. }\end{array}$ & $\mathrm{x}$ & $\mathrm{x}$ & $\mathrm{x}$ & $x$ \\
\hline - Validar e consolidar as predições de parceiros e fornecedores; & $\mathrm{X}$ & $\mathrm{X}$ & $\mathrm{X}$ & $x$ \\
\hline $\begin{array}{l}\text { - Destacar os itens críticos relacionados a CDM e gerenciar } \\
\text { plano de ações associado para solução dos problemas; }\end{array}$ & $x$ & $x$ & $\mathrm{x}$ & \\
\hline $\begin{array}{l}\text { - Avaliar capacidades industriais para alcançar as exigências de } \\
\text { projeto; }\end{array}$ & $\mathrm{X}$ & & & \\
\hline \multicolumn{5}{|l|}{ FABRICAÇÃOO } \\
\hline $\begin{array}{l}\text { - Identificar as áreas críticas de CDM nas quais devam ser } \\
\text { dispensadas atenção especial; }\end{array}$ & $\mathrm{X}$ & $\mathrm{X}$ & & \\
\hline $\begin{array}{l}\text { - Verificar aplicação do plano de ação dedicada às áreas críticas } \\
\text { previamente identificadas }\end{array}$ & $\mathrm{X}$ & $\mathrm{X}$ & & \\
\hline \multicolumn{5}{|l|}{ COMISSIONAMENTO } \\
\hline - Assegurar eficiência de testes de confiabilidade & $\mathrm{X}$ & & & \\
\hline $\begin{array}{l}\text { - Fornecer apoio administrativo para processo de crescimento } \\
\text { de confiabilidade }\end{array}$ & $x$ & $\mathrm{x}$ & $\mathrm{x}$ & $x$ \\
\hline $\begin{array}{l}\text { - Coletar informações para executar tarefas previamente } \\
\text { identificadas }\end{array}$ & $x$ & $x$ & $x$ & $\mathrm{x}$ \\
\hline $\begin{array}{l}\text { - Aproveitar dados de CDM para realimentar propostas e } \\
\text { projetar processo de integração de CDM com outros } \\
\text { processos. }\end{array}$ & $\mathrm{X}$ & $\mathrm{x}$ & $\mathrm{x}$ & $x$ \\
\hline \multicolumn{5}{|l|}{ OPERAÇÃO } \\
\hline $\begin{array}{l}\text { - Apoio de administrativo para processo de melhoria de } \\
\text { confiabilidade. }\end{array}$ & $\mathrm{X}$ & $\mathrm{x}$ & $\mathrm{x}$ & \\
\hline $\begin{array}{l}\text { - Coletar informações para executar tarefas previamente } \\
\text { identificadas }\end{array}$ & $\mathrm{X}$ & $\mathrm{x}$ & $\mathrm{X}$ & \\
\hline - Aproveitar dados de CDM para realimentar propostas & $x$ & $x$ & $\mathrm{x}$ & \\
\hline
\end{tabular}


Considerando um projeto de material rodante sob o ponto de vista do fabricante, essas atividades estão detalhadas na forma de tabela, nos itens subseqüentes.

\subsubsection{Fase de proposta}

As tarefas de CDMS que são relacionadas com a fase de proposta estão descritas na Tabela 5, assim como os principais dados de entrada, as ferramentas utilizadas e as principais informações de saída.

Tabela 5: Tarefas de CDMS - Fase de Proposta (continua)

\begin{tabular}{|c|c|c|c|}
\hline \multicolumn{4}{|c|}{ TAREFA PRINCIPAL } \\
\hline Descrição detalhada da tarefa & Dados de entrada & Ferramentas & Saídas \\
\hline \multicolumn{4}{|c|}{ Avaliar soluções em relação às exigências contratuais } \\
\hline $\begin{array}{l}\text { - Elaborar modelo permitindo cálculo } \\
\text { dos indicadores contratuais } \\
\text { - A partir da base de dados do } \\
\text { retorno de experiências, calcular os } \\
\text { desempenhos mais realistas que } \\
\text { podem ser oferecidos } \\
\text { - Propor alterações,de maneira a } \\
\text { alcançar as metas }\end{array}$ & $\begin{array}{l}\text { - Definição do produto } \\
\text { oferecido } \\
\text { - Perfil da missão e } \\
\text { regras operacionais } \\
\text { - Requisitos e outros } \\
\text { elementos fornecidos } \\
\text { pelo Responsável de } \\
\text { Segurança }\end{array}$ & $\begin{array}{l}\text { - FMECA } \\
\text { - RBD } \\
\text { - FTA }\end{array}$ & - Relatório \\
\hline \multicolumn{4}{|c|}{$\begin{array}{l}\text { Analisar risco financeiro devido a riscos tecnológicos e percentuais de aproveitamento de soluções } \\
\text { anteriormente empregadas }\end{array}$} \\
\hline $\begin{array}{l}\text { - Analisar o impacto de mudanças } \\
\text { técnicas sobre o desempenho em } \\
\text { CDM }\end{array}$ & \begin{tabular}{|l} 
- Definição do produto \\
oferecido \\
- Perfil da missão e \\
regras operacionais \\
\end{tabular} & $\begin{array}{l}- \text { - FMECA } \\
\text { - RBD } \\
\text { - FTA }\end{array}$ & $\begin{array}{l}\text { - Relatório de } \\
\text { Impacto }\end{array}$ \\
\hline \multicolumn{4}{|c|}{ Analisar risco financeiro devido a penalidades previstas em contrato } \\
\hline $\begin{array}{l}\text { - Partindo dos compromissos } \\
\text { assumidos e dos desempenhos } \\
\text { mais realistas, calcular a } \\
\text { probabilidade de se pagar por } \\
\text { penalidades previstas em contrato }\end{array}$ & $\begin{array}{l}\text { - Análises prévias } \\
\text { - Compromissos } \\
\text { validados pela área } \\
\text { Comercial }\end{array}$ & $\begin{array}{l}\text { - Planilhas de } \\
\text { Cálculo }\end{array}$ & - Relatório \\
\hline
\end{tabular}


Tabela 5: Tarefas de CDMS - Fase de Proposta (conclusão)

\begin{tabular}{|c|c|c|c|}
\hline \multicolumn{4}{|c|}{ Fornecer suporte às negociações } \\
\hline $\begin{array}{l}\text { - Responder às perguntas feitas } \\
\text { pelos negociadores } \\
\text { - Dar apoio às equipes de } \\
\text { negociação } \\
\text { - Participar das reuniões de } \\
\text { negociação de CDMS } \\
\text { - Redigir as seções da proposta } \\
\text { dedicadas a CDMS }\end{array}$ & $\begin{array}{l}\text { - Informações } \\
\text { fornecidas pela } \\
\text { equipe de } \\
\text { negociadores }\end{array}$ & $\begin{array}{l}\text { - Planilhas de } \\
\text { Cálculo } \\
\text { - Editores de } \\
\text { Texto }\end{array}$ & $\begin{array}{l}\text { - E-mail } \\
\text { - Telefonema } \\
\text { - Memorando }\end{array}$ \\
\hline
\end{tabular}

\subsubsection{Fase de projeto}

As tarefas de CDMS que são relacionadas com a fase de projeto estão descritas na Tabela 6, assim como os principais dados de entrada, as ferramentas utilizadas e as principais informações de saída.

Tabela 6: Tarefas de CDMS - Fase de Projeto (continua)

\begin{tabular}{|c|c|c|c|}
\hline \multicolumn{4}{|c|}{ TAREFA PRINCIPAL } \\
\hline Descrição detalhada da tarefa & Dados de entrada & Ferramentas & Saídas \\
\hline \multicolumn{4}{|c|}{$\begin{array}{l}\text { Assegurar ao cliente que os aspectos de CDMS serão integrados no processo de desenvolvimento } \\
\text { do projeto }\end{array}$} \\
\hline $\begin{array}{l}\text { - Redigir e propor o Plano do } \\
\text { programa de CDM para } \\
\text { validação pelo cliente } \\
\text { - Definir marcos em relação ao } \\
\text { processo gerencial do projeto } \\
\text { (pontos de revisão) } \\
\text { - Integrar Impacto de segurança } \\
\text { no processo de } \\
\text { desenvolvimento }\end{array}$ & $\begin{array}{l}\text { - Contrato } \\
\text { - Perfil da missão e } \\
\text { regras operacionais } \\
\text { - Regras internas da } \\
\text { empresa para } \\
\text { Proposta e Projeto } \\
\text { - Definição do produto } \\
\text { proposto }\end{array}$ & $\begin{array}{l}\text { - Planilhas de } \\
\text { Cálculo } \\
\text { - Editores de } \\
\text { texto }\end{array}$ & \begin{tabular}{|l}
- Plano do \\
programa de \\
CDM
\end{tabular} \\
\hline
\end{tabular}


Tabela 6: Tarefas de CDMS - Fase de Projeto (conclusão)

\begin{tabular}{|c|c|c|c|}
\hline \multicolumn{4}{|c|}{$\begin{array}{c}\text { Especificar aos parceiros suas contribuições na integração de CDMS no processo de } \\
\text { desenvolvimento }\end{array}$} \\
\hline $\begin{array}{l}\text { - Realizar Análises Críticas } \\
\text { Preliminares de CDM } \\
\text { - Preparar o processo de } \\
\text { alocação para estabelecer as } \\
\text { metas globais para os } \\
\text { fornecedores e parceiros. } \\
\text { - Propor cláusulas e requisitos } \\
\text { de CDM para serem integrados } \\
\text { aos sub-contratos de } \\
\text { fornecedores e parceiros. } \\
\text { - Redigir um Plano de Ações } \\
\text { Gerenciais de CDM }\end{array}$ & \begin{tabular}{|l} 
- Contrato \\
- Perfil da missão e \\
regras operacionais \\
- Definição do produto \\
proposto \\
- Análise Preliminar de \\
Perigos ou resumo de \\
providências e \\
recomendações \\
relacionadas à \\
Segurança
\end{tabular} & $\begin{array}{l}\text { - FMECA } \\
\text { - RBD } \\
\text { - FTA } \\
\text { - Planilhas de } \\
\quad \text { Cálculo } \\
\text { - Editores de } \\
\text { texto }\end{array}$ & \begin{tabular}{|l} 
- Lista dos cenários \\
críticos de CDM \\
- Lista dos itens \\
críticos de CDM \\
- Lista dos \\
processos críticos \\
de CDM e Plano de \\
Ação de Mitigação \\
- Relatório de \\
alocação \\
- Plano de Ações \\
Gerenciais de CDM
\end{tabular} \\
\hline \multicolumn{4}{|c|}{ Validar e consolidar as predições de parceiros e fornecedores } \\
\hline $\begin{array}{l}\text { - Acompanhar o progresso do } \\
\text { Plano de Ações Gerenciais } \\
\text { com os fornecedores e } \\
\text { parceiros } \\
\text { - Revisar e validar as análises } \\
\text { dos fornecedores e parceiros. } \\
\text { - Consolidar as análises dos } \\
\text { sistemas } \\
\end{array}$ & $\begin{array}{l}\text { - Plano do programa de } \\
\text { CDM } \\
\text { - Plano de Ações } \\
\text { Gerenciais de CDM } \\
\text { - Análises fornecidas } \\
\text { pelos fornecedores e } \\
\text { parceiros } \\
\text { - Registro dos perigos } \\
\end{array}$ & $\begin{array}{l}\text { - FMECA } \\
\text { - RBD } \\
\text { - FTA } \\
\text { - Planilhas de } \\
\text { Cálculo } \\
\text { - Editores de } \\
\quad \text { texto }\end{array}$ & $\begin{array}{l}\text { - Relatório Final de } \\
\text { CDM } \\
\text { - Acompanhamento } \\
\text { da Lista de Itens } \\
\text { Críticos de CDM }\end{array}$ \\
\hline \multicolumn{4}{|c|}{$\begin{array}{c}\text { Destacar os itens críticos relacionados a CDM e gerenciar plano de ações associado para solução } \\
\text { dos problemas }\end{array}$} \\
\hline $\begin{array}{l}\text { - Realizar análises de } \\
\text { sensibilidade para destacar os } \\
\text { itens críticos relacionados a } \\
\text { CDM } \\
\text { - Propor um plano de ação para } \\
\text { eliminar aspectos críticos de } \\
\text { CDM } \\
\text { - Acompanhar o progresso do } \\
\text { plano de ação }\end{array}$ & $\begin{array}{l}\text { - Análises fornecidas } \\
\text { pelos fornecedores e } \\
\text { parceiros }\end{array}$ & $\begin{array}{l}\text { - FMECA } \\
\text { - RBD } \\
\text { - FTA } \\
\text { - Planilhas de } \\
\text { Cálculo } \\
\text { - Editores de } \\
\quad \text { texto }\end{array}$ & $\begin{array}{l}\text { - Relatório Final de } \\
\text { CDM } \\
\text { - Acompanha-mento } \\
\text { da Lista de Itens } \\
\text { Críticos de CDM }\end{array}$ \\
\hline \multicolumn{4}{|c|}{ Avaliar capacidades industriais para alcançar as exigências de projeto } \\
\hline $\begin{array}{l}\text { - Identificar processos críticos } \\
\text { de manufatura ou montagem } \\
\text { - Realizar análises de } \\
\text { capacidade para processos } \\
\text { específicos }\end{array}$ & $\begin{array}{l}\text { - Lista de processos } \\
\text { críticos }\end{array}$ & $\begin{array}{c}\text { - FMECA de } \\
\text { processos } \\
\text { - Análises de } \\
\text { Capacidade }\end{array}$ & $\begin{array}{l}\text { - Relatório Final de } \\
\text { CDM } \\
\text { - Lista de Itens } \\
\text { Críticos Residuais } \\
\text { de CDM }\end{array}$ \\
\hline
\end{tabular}




\subsubsection{Fase de fabricação}

As tarefas de CDMS que são relacionadas com a fase de fabricação estão descritas na Tabela 7, assim como os principais dados de entrada, as ferramentas utilizadas e as principais informações de saída.

Tabela 7: Tarefas de CDMS - Fase de Fabricação

\begin{tabular}{|c|c|c|c|}
\hline \multicolumn{4}{|c|}{ TAREFA PRINCIPAL } \\
\hline Descrição detalhada da tarefa & Dados de entrada & $\begin{array}{c}\text { Ferramentas } \\
\text { padrão }\end{array}$ & Saídas \\
\hline \multicolumn{4}{|c|}{ Identificar as áreas críticas de CDM às quais devam ser dispensadas atenção especial } \\
\hline $\begin{array}{l}\text { - Elaborar e divulgar uma lista de } \\
\text { processos críticos que levam à falha } \\
\text { e que necessitam ser corrigidos como } \\
\text { falhas relacionadas a CDM }\end{array}$ & $\begin{array}{l}\text { - Retorno de } \\
\text { experiências em } \\
\text { equipamentos ou } \\
\text { sistemas similares } \\
\text { - Providências de } \\
\text { mitigação resultantes } \\
\text { de análises } \\
\text { preliminares e } \\
\text { detalhadas (FMECA) }\end{array}$ & $\begin{array}{l}\text { - FRACAS } \\
\text { - Planilhas de } \\
\text { Cálculo }\end{array}$ & $\begin{array}{l}\text { - Lista de } \\
\text { processos } \\
\text { críticos }\end{array}$ \\
\hline \multicolumn{4}{|c|}{ Verificar aplicação do plano de ação dedicada às áreas críticas previamente identificadas } \\
\hline $\begin{array}{l}\text { - Assegurar-se de que providências de } \\
\text { mitigação obrigatórias foram } \\
\text { corretamente implementadas antes } \\
\text { de consolidar previsões incluindo } \\
\text { seus impactos }\end{array}$ & $\begin{array}{l}\text { - } \text { Relatório de } \\
\text { progresso de } \\
\text { implementação de } \\
\text { mudanças na } \\
\text { manufatura } \\
\end{array}$ & $\begin{array}{l}\text { - Editores de } \\
\text { texto }\end{array}$ & $\begin{array}{l}\text { - Relatório } \\
\text { de acompa- } \\
\text { nhamento }\end{array}$ \\
\hline
\end{tabular}

\subsubsection{Fase de comissionamento}

As tarefas de CDMS que são relacionadas com a fase de comissionamento estão descritas na Tabela 8, assim como os principais dados de entrada, as ferramentas utilizadas e as principais informações de saída. 
Tabela 8: Tarefas de CDMS - Fase de Comissionamento

\begin{tabular}{|c|c|c|c|}
\hline \multicolumn{4}{|c|}{ TAREFA PRINCIPAL } \\
\hline Descrição detalhada da tarefa & Dados de entrada & $\begin{array}{l}\text { Ferramentas } \\
\text { padrão }\end{array}$ & Saídas \\
\hline \multicolumn{4}{|c|}{ Assegurar eficiência de testes de confiabilidade } \\
\hline $\begin{array}{l}\text { - Definir o teste de confiabilidade } \\
\text { mais eficiente, rascunhar o } \\
\text { procedimento para implementar o } \\
\text { teste da melhor forma e } \\
\text { acompanhar sua implementação de } \\
\text { maneira a coletar todas as } \\
\text { informações necessárias. }\end{array}$ & $\begin{array}{l}\text { - Análises preliminares } \\
\text { e detalhadas de CDM } \\
\text { - Relatório de } \\
\text { Acompanhamento de } \\
\text { providências de } \\
\text { mitigação }\end{array}$ & $\begin{array}{l}\text { - Editores de } \\
\text { texto }\end{array}$ & $\begin{array}{l}\text { - Relatório de } \\
\text { teste }\end{array}$ \\
\hline \multicolumn{4}{|c|}{ Fornecer apoio administrativo para processo de crescimento de confiabilidade } \\
\hline $\begin{array}{l}\text { - Redigir o plano de demonstração e } \\
\text { monitoramento do processo de } \\
\text { crescimento de CDM }\end{array}$ & $\begin{array}{l}\text { - Contrato } \\
\text { - Normas Internas }\end{array}$ & $\begin{array}{l}\text { - Editores de } \\
\text { texto }\end{array}$ & $\begin{array}{l}\text { - Plano de de- } \\
\text { monstração e } \\
\text { monitoramento } \\
\text { do processo de } \\
\text { crescimento de } \\
\text { CDM }\end{array}$ \\
\hline \multicolumn{4}{|c|}{ Coletar informações para executar tarefas previamente identificadas } \\
\hline $\begin{array}{l}\text { - Obter e validar informações para } \\
\text { destacar corretamente os } \\
\text { problemas que mais contribuem e } \\
\text { certificar-se de que as causas } \\
\text { corretas serão identificadas e a } \\
\text { ação corretiva implementada }\end{array}$ & $\begin{array}{l}\text { - FRACAS } \\
\text { - Informações técnicas } \\
\text { adicionais sobre a } \\
\text { falha e códigos de } \\
\text { defeito; } \\
\text { - Outras informações } \\
\text { técnicas do cliente } \\
\end{array}$ & $\begin{aligned} & \text { - } \text { FRACAS } \\
& \text { - Planilhas de } \\
& \\
& \quad \text { Cálculo }\end{aligned}$ & $\begin{array}{l}\text { - Relatório } \\
\text { mensal }\end{array}$ \\
\hline \multicolumn{4}{|c|}{$\begin{array}{c}\text { Aproveitar dados de CDM para realimentar propostas e projetar processo de integração de CDM com } \\
\text { outros processos }\end{array}$} \\
\hline $\begin{array}{l}\text { - Especificar e implementar o } \\
\text { processo de coleta de dados, } \\
\text { permitindo coletar e validar as } \\
\text { informações necessárias para } \\
\text { alimentar os engenheiros de CDM } \\
\text { com todos os dados necessários } \\
\text { para desenvolver a proposta e } \\
\text { desenvolver análises preditivas. }\end{array}$ & $\begin{aligned} \text { - } & \text { FRACAS } \\
\text { - } & \text { Relatórios de } \\
& \text { serviços } \\
\text { - Informações do } & \\
& \text { cliente ou relatórios }\end{aligned}$ & $\begin{array}{l}\text { - Editores de } \\
\text { texto }\end{array}$ & $\begin{array}{l}\text { - Procedimento } \\
\text { para coletar } \\
\text { informações de } \\
\text { CDM de campo }\end{array}$ \\
\hline
\end{tabular}




\subsubsection{Fase de operação}

As tarefas de CDMS que são relacionadas com a fase de operação estão descritas na Tabela 9, assim como os principais dados de entrada, as ferramentas utilizadas e as principais informações de saída.

Tabela 9: Tarefas de CDMS - Fase de Operação

\begin{tabular}{|c|c|c|c|}
\hline \multicolumn{4}{|c|}{ TAREFA PRINCIPAL } \\
\hline Descrição detalhada da tarefa & Dados de entrada & $\begin{array}{l}\text { Ferramentas } \\
\text { padrão }\end{array}$ & Saídas \\
\hline \multicolumn{4}{|c|}{ Fornecer apoio administrativo para processo de melhoria de confiabilidade. } \\
\hline $\begin{array}{l}\text { - Redigir o plano de demonstração } \\
\text { e monitoramento do processo de } \\
\text { crescimento de CDM }\end{array}$ & $\begin{array}{l}\text { - Contrato } \\
\text { - Normas Internas }\end{array}$ & $\begin{array}{l}- \text { Editores de } \\
\text { texto }\end{array}$ & \begin{tabular}{|l|} 
- Plano de de- \\
monstração e \\
monitoramento \\
do processo de \\
crescimento de \\
CDM \\
\end{tabular} \\
\hline \multicolumn{4}{|c|}{ Coletar informações para executar tarefas previamente identificadas } \\
\hline $\begin{array}{l}\text { - Obter e validar informações para } \\
\text { destacar corretamente os } \\
\text { problemas que mais contribuem e } \\
\text { certificar-se de que as causas } \\
\text { corretas serão identificadas e a } \\
\text { ação corretiva implementada }\end{array}$ & $\begin{array}{l}\text { - FRACAS } \\
\text { - Informações técnicas } \\
\text { adicionais sobre a } \\
\text { falha e códigos de } \\
\text { defeito; } \\
\text { - Outras informações } \\
\text { técnicas do cliente } \\
\end{array}$ & $\begin{array}{l}\text { - FRACAS } \\
\text { - Planilhas de } \\
\text { Cálculo } \\
\end{array}$ & 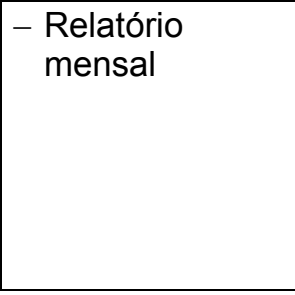 \\
\hline \multicolumn{4}{|c|}{ Aproveitar dados de CDM para realimentar propostas } \\
\hline $\begin{array}{l}\text { - Especificar e implementar o } \\
\text { processo de coleta de dados, } \\
\text { permitindo coletar e validar as } \\
\text { informações necessárias para } \\
\text { alimentar os engenheiros de CDM } \\
\text { com todos os dados necessários } \\
\text { para desenvolver a proposta e } \\
\text { desenvolver análises preditivas. }\end{array}$ & $\begin{array}{l}\text { - FRACAS } \\
\text { - Relatórios de } \\
\text { serviços } \\
\text { - Informações do } \\
\text { cliente ou relatórios }\end{array}$ & $\begin{array}{l}- \text { Editores de } \\
\text { texto }\end{array}$ & $\begin{array}{l}\text { - Procedimento } \\
\text { para coletar } \\
\text { informações de } \\
\text { CDM de campo }\end{array}$ \\
\hline
\end{tabular}




\subsection{ESPECIFICAÇÃO DE CDMS DO MATERIAL RODANTE}

As especificações de CDMS são de vital importância para o ciclo de CDMS dentro do projeto. Nelas são expressos os requisitos por parte do cliente e, conforme visto nos itens anteriores, tais requisitos determinam o grau de atuação das equipes de engenharia com aspectos de CDMS. Da mesma forma, o custo final do material rodante é diretamente relacionado com tais requisitos.

No final do ano de 2004, o autor deste trabalho escreveu um artigo técnico sobre esse assunto, mais especificamente para confiabilidade, o qual foi adaptado e publicado em fevereiro de 2005. O artigo tal como foi publicado, consta no APÊNDICE B.

Em relação às especificações de disponibilidade e mantenabilidade, as preocupações são análogas. Já no caso da segurança, deve haver uma preocupação adicional, uma vez que as falhas podem comprometer vidas humanas.

\subsubsection{Classificação das falhas do material rodante}

As falhas não afetam o material rodante sempre da mesma maneira. Existem falhas que impedem a circulação do trem, assim como existem falhas que não são sequer notadas pelos passageiros. Isso faz com que abordagens diferentes sejam dadas a cada tipo específico de falha.

A definição de falha pode variar de um sistema para outro do trem, dependendo das condições operacionais. Cada operadora define as categorias de falhas e as metas de confiabilidade para cada uma delas.

De acordo com a norma IEC 62278 (14), as categorias de falha adequadas para uso em aplicações ferroviárias são:

- "Significante",

- "Maior" e

- "Menor". 
3.6.1.1 Falha tipo A (Significante)

Falhas que afetam a circulação do trem, paralisando ou prejudicando completamente a operação. O trem não tem mais condições de trafegar e é evacuado e retirado de operação imediatamente.

A norma define esse tipo de falha como "Falha Total", cujo efeito na operação é "Operação Impossível”.

\subsubsection{Falha tipo B (Maior)}

Falhas que afetam parcialmente a circulação do trem, paralisando ou prejudicando parcialmente a operação, com atrasos superiores a um tempo especificado. $O$ trem possui condições de trafegar até o final da via por seus próprios meios para ser retirado de operação.

A norma define esse tipo de falha como "Falha Funcional Crítica", cujo efeito na operação é "Operação Emergencial 1".

\subsubsection{Falha tipo C (Menor)}

São as falhas que não afetam a circulação dos trens. $O$ trem tem condições de cumprir a programação do dia ou pode aguardar em operação por uma programação de parada, desde que não provoque atrasos na operação que a caracterizem como falha tipo B. Falhas encontradas na manutenção preventiva também são consideradas como do tipo $C$.

A norma define esse tipo de falha como "Falha Funcional Não Crítica", cujo efeito na operação é "Operação Emergencial 2".

Algumas operadoras costumam agrupar as falhas dos tipos A e B, destacando apenas as falhas que de alguma forma afetam o serviço das demais. Em 
função disso, para que as montadoras tenham um padrão para comparação de desempenho de seus produtos em diferentes operadoras, são estabelecidas metas internas considerando 2 categorias de falha: Falhas que afetam o serviço e falhas inerentes.

3.6.1.4 Falhas que afetam o serviço

Falhas que afetam o serviço são aquelas que podem causar:

- Atrasos na operação superiores a um determinado tempo;

- Evacuação de passageiros da composição com falha;

- Necessidade de reboque do trem com falha;

3.6.1.5 Falhas inerentes

São todas as falhas que se apresentam no trem, afetando ou não o serviço. Normalmente, na contagem de falhas excluem-se aquelas originadas por:

- Vandalismo;

- Operação incorreta;

- Manutenção deficiente ou incorreta;

- Substituição de peças de desgaste ou consumíveis;

- Falhas interdependentes ou decorrentes: um componente defeituoso poderá causar falhas seqüenciais em outros componentes. Para evitar contagens duplas, as falhas interdependentes ou decorrentes não são consideradas como falhas próprias, mas atribuídas à falha original.

$\mathrm{Na}$ Tabela 10 são apresentadas algumas definições de categorias de falhas que são adotadas por algumas operadoras ferroviárias no mundo. É importante destacar o grau de variação que existem entre elas. Em alguns casos, 
comparando-se com a norma, percebe-se até uma inversão na denominação das categorias.

Tabela 10: Exemplo de classificação de falhas

\begin{tabular}{|c|c|}
\hline Operadora & Definição de falha \\
\hline Metrô de Singapura & $\begin{array}{l}\text { - Falha Maior: Falha na prestação de serviço. Atrasos superiores a } 2 \text { horas; } \\
\text { - Falha Significante: Produz interrupção do serviço na área afetada com } \\
\text { atrasos superiores a } 15 \text { minutos e menores que } 2 \text { horas; } \\
\text { - Falha Menor: Produz uma redução ou perturbação no serviço, com atrasos } \\
\text { entre } 2 \text { e } 15 \text { minutos; } \\
\text { - Falha desprezível: Provoca atraso inferior a } 2 \text { minutos; }\end{array}$ \\
\hline $\begin{array}{l}\text { Metrô de } \\
\text { Bangkok }\end{array}$ & $\begin{array}{l}\text { - Falha de Serviço: Falha de um sistema principal ou parte dele resultando em } \\
\text { funcionamento incorreto e possivelmente em degradação da operação; } \\
\text { - Falha Relevante: Falha de um sistema do trem que cause atraso na } \\
\text { circulação superior a } 5 \text { minutos. }\end{array}$ \\
\hline Metrô de Bucareste & $\begin{array}{l}\text { - Falha Categoria A (Maior): Provoca evacuação de passageiros e reboque do } \\
\text { trem; } \\
\text { - Falha Categoria B (Significante): Permite que o trem continue em serviço, } \\
\text { com passageiros, até o fim da viagem; } \\
\text { - Falha Categoria C (Significante): Permite que o trem continue em serviço, } \\
\text { com passageiros, até o fim do período normal planejado; }\end{array}$ \\
\hline $\begin{array}{l}\text { VLT de } \\
\text { Montpellier }\end{array}$ & $\begin{array}{l}\text { - Falha Maior: Falha na prestação de serviço. Trem necessita de reboque; } \\
\text { - } \text { Falha Significante: Provoca evacuação dos passageiros e retirada do trem } \\
\text { de operação; } \\
\text { - Falha Menor: Produz atrasos superiores a } 3 \text { minutos; } \\
\text { - Falha desprezível: Provoca a substituição de um trem por outro; }\end{array}$ \\
\hline $\begin{array}{l}\text { Metrô de } \\
\text { Santiago }\end{array}$ & $\begin{array}{l}\text { - Falha Tipo A: Falha que provoca a evacuação do trem e/ou reboque, ou } \\
\text { retirada iminente de serviço por seus próprios meios; } \\
\text { - Falha Tipo B: Todas as falhas que ocorrem no trem (inclusive as Tipo A); }\end{array}$ \\
\hline $\begin{array}{c}\text { Metrô de } \\
\text { Buenos Aires }\end{array}$ & $\begin{array}{l}\text { - Falha: Qualquer anomalia que afete o serviço do trem, interrompendo seu } \\
\text { funcionamento normal e provoque a evacuação de passageiros ou ainda } \\
\text { que gere atraso superior a } 10 \text { minutos. }\end{array}$ \\
\hline $\begin{array}{l}\text { Metrô de } \\
\text { Atlanta }\end{array}$ & $\begin{array}{l}\text { - Falha que interrompe o serviço: Produz atrasos superiores a } 3 \text { minutos; } \\
\text { - Falha inerente: Toda falha que ocorrer no trem e que provoque atraso de até } \\
3 \text { minutos; }\end{array}$ \\
\hline
\end{tabular}


3.6.1.6 Classificação conforme desempenho

De acordo com a norma IEC 62278 (14), deve-se definir as condições técnicas e operacionais que caracterizem cada tipo de falha com base na degradação dos parâmetros de desempenho do trem, tais como velocidade, número de portas operacionais, percentual de esforço de tração disponível, etc. A Tabela 11, extraída dessa mesma norma, ilustra como isso pode ser feito.

Tabela 11: Classificação conforme desempenho

\begin{tabular}{|c|c|c|c|c|c|}
\hline \multirow{2}{*}{$\begin{array}{c}\text { Categoria de } \\
\text { Falha }\end{array}$} & \multirow{2}{*}{$\begin{array}{c}\text { Efeito na } \\
\text { Operação }\end{array}$} & \multicolumn{3}{|c|}{ Desempenho } & \multirow{2}{*}{ Comentários } \\
\cline { 3 - 6 } & & $\begin{array}{c}\text { Potência } \\
\text { (\%) }\end{array}$ & $\begin{array}{c}\text { Velocidade } \\
(\%)\end{array}$ & etc & \\
\hline Significante & $\begin{array}{c}\text { Operação } \\
\text { impossível }\end{array}$ & 0 & 0 & & \\
\hline Maior & $\begin{array}{c}\text { Operação } \\
\text { emergencial 1 }\end{array}$ & & & & \\
\hline Menor & $\begin{array}{c}\text { Operação } \\
\text { emergencial 2 }\end{array}$ & & & & \\
\hline Desprezível & $\begin{array}{c}\text { Operação } \\
\text { Normal }\end{array}$ & 100 & 100 & & \\
\hline
\end{tabular}

Essa classificação também pode ser feita considerando cada sistema individualmente e os efeitos provocados na operação em caso de falhas desses sistemas.

\subsubsection{Parâmetros contratuais de CDMS}

3.6.2.1 Tempo médio entre falhas

O tempo médio entre falhas de um determinado tipo, digamos tipo " $x$ ", em um determinado período pode ser expresso em tempo (horas, anos), em distância (quilômetros, milhas), ou mesmo em número de ciclos. 
A fórmula geral para calcular o Tempo Médio entre Falhas (MTBF) do tipo x é:

$$
M T B F_{x}=\frac{T}{n f_{x}}
$$

Onde:

- $M T B F_{\chi}$ : Tempo médio entre falhas do tipo x;

- $\quad T$ : Tempo total de operação;

- $n f_{x}$ : Número total de falhas do tipo $\mathrm{x}$;

A fórmula geral para calcular a Quilometragem Média entre Falhas (MKBF) do tipo $x$ é:

$$
M K B F_{x}=\frac{D}{n f_{x}}
$$

Onde:

- $M K B F_{x}$ : Quilometragem média entre falhas do tipo x;

- D: Distância total percorrida em operação;

- $n f_{x}$ : Número total de falhas do tipo $\mathrm{x}$;

Da mesma forma, a fórmula geral para calcular o Número Médio de Ciclos entre Falhas (MCBF) do tipo x é:

$$
M C B F_{x}=\frac{C}{n f_{x}}
$$

Onde:

- $M C B F_{x}$ : Número médio de ciclos entre falhas do tipo x;

- C: Número total de ciclos em operação;

- $n f_{x}$ : Número total de falhas do tipo $\mathrm{x}$;

É possível estabelecer as seguintes relações entre MTBF, MKBF e MCBF: 


$$
\begin{aligned}
& M T B F=\frac{M K B F}{V C} \\
& M K B F=\frac{M C B F}{C p d}
\end{aligned}
$$

onde:

- $\quad V c$ : Velocidade comercial;

- Cpt: Ciclos por unidade de tempo;

- Cpd: Ciclos por unidade de distância;

\subsubsection{Taxa de falhas}

De forma análoga, a taxa de falhas do tipo x em um determinado período pode ser expressa em falhas por unidade de tempo, de distância, ou de ciclos.

$$
\begin{aligned}
& \lambda_{\text {tempo }}=\frac{n f}{T}=\frac{1}{M T B F} \\
& \lambda_{\text {distância }}=\frac{n f}{D}=\frac{1}{M K B F} \\
& \lambda_{\text {ciclos }}=\frac{n f}{C}=\frac{1}{M C B F}
\end{aligned}
$$

É possível também estabelecer a taxa de falhas para os períodos de pico e de vale operacionais:

$$
\begin{aligned}
& \lambda_{\text {pico }}=\frac{\text { horas_de_pico_por_dia }}{\text { horas_operacionais_por_dia }} \cdot \lambda_{\text {tempo }} \\
& \lambda_{\text {vale }}=\frac{\text { horas_de_vale_por_dia }}{\text { horas_operaciona is_por_dia }} \cdot \lambda_{\text {tempo }}
\end{aligned}
$$


As proporções de horas de pico e de horas de vale são, geralmente, informações de retorno de experiências, e devem ser indicadas na especificação técnica.

\subsubsection{Falhas sistemáticas}

Algumas operadoras, como a espanhola RENFE por exemplo, definem um valor de MTBF relacionado a falhas sistemáticas. Essas falhas são, geralmente, definidas da seguinte forma: se um componente falhar em mais de $10 \%$ dos trens durante o período de garantia, de forma que mais de $10 \%$ do total de itens de um mesmo tipo falhem, essas falhas são consideradas falhas sistemáticas.

Supondo uma distribuição de vida exponencial, existe uma relação entre o percentual de falhas de $10 \%$ (ou outro valor) e o MTBF mínimo do equipamento considerado.

$$
M_{\text {min_eq }}=\frac{-t}{\ln [R(T)]}=\frac{-t}{\ln [0,9]}=\frac{t}{0,105}
$$

onde:

- $t$ : Tempo de trabalho de um equipamento durante o período de garantia;

- MTBF $_{\text {min_eq }}$ : MTBF mínimo intrínseco do equipamento;

- $\quad R(T)$ : Confiabilidade do equipamento. Proporção de itens sobreviventes após um período $\mathrm{t}$ (por exemplo, $90 \%$ em caso de falha sistemática de $10 \%)$;

No período considerado, os equipamentos não possuem o mesmo tempo operacional. Alguns são usados quando o trem está em movimento e outros são usados mesmo quando o trem está energizado, porém parado. 
3.6.2.4 Índices de confiabilidade

Os números-índices são bastante utilizados nas ciências econômicas, administrativas, financeiras e também no controle de qualidade das empresas, pois permitem a associação de valores numéricos ao desempenho de determinados processos, (16).

Normalmente são adimensionais e refletem um conjunto de fatores associados entre si. Por essa razão, são um importante instrumento para sintetizar variações complexas ao longo do tempo.

Eventualmente, algumas operadoras estabelecem índices internos para avaliar, monitorar e comparar a CDMS de seus trens. Esses índices visam, entre outras coisas, estabelecer indicadores para acompanhamento da qualidade do serviço prestado.

Um exemplo simples de número-índice voltado para confiabilidade poderia ser:

$$
I C_{1}=\frac{K C}{S_{1}+2 \cdot S_{2}}
$$

onde:

- $I C_{1}$ : Índice de confiabilidade " 1 ";

- Kc: Número de quilômetros percorridos por toda a frota no período considerado;

- $S_{1}$ : Número de atrasos entre 10 e 60 minutos no período considerado;

- $S_{2}$ : Número de atrasos de mais de 60 minutos no período considerado;

3.6.2.5 Parâmetros de CDMS definidos por intervalo de confiança

Os intervalos de confiança representam uma faixa onde existe uma determinada probabilidade, ou nível de confiança, de se encontrar o valor real da grandeza estimada. 
Considerando uma distribuição exponencial, o intervalo de confiança bilateral para o tempo médio entre falhas é determinado da seguinte maneira:

$$
\begin{aligned}
& \theta_{\text {inf }}=\frac{2 \cdot T}{\chi_{1-\alpha / 2}^{2}(2 r+2)} \\
& \theta_{\text {sup }}=\frac{2 \cdot T}{\chi_{\alpha / 2}^{2}(2 r)}
\end{aligned}
$$

Onde:

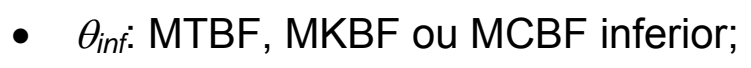

- $\theta_{\text {sup: }}$ MTBF, MKBF ou MCBF superior;

- $\quad T$ : Tempo, distância ou número de ciclos acumulados;

- $\quad r$ : Quantidade de falhas no período;

- $\chi^{2}$ : Distribuição de probabilidade "Qui-quadrado";

- $\quad \alpha$ : 1- NC (Nível de confiança);

Para o cálculo do intervalo de confiança da taxa de falhas:

$$
\begin{aligned}
& \lambda_{\text {inf }}=\frac{1}{\theta_{\text {sup }}} \\
& \lambda_{\text {sup }}=\frac{1}{\theta_{\text {inf }}}
\end{aligned}
$$

A título de exemplo, é apresentado no ANEXO A uma tabela com os valores de qui-quadrado para um nível de confiança de $60 \%$, ou seja para (1 $\alpha / 2)=80 \%$ e $\alpha / 2=20 \%$. Este valor de $60 \%$ é usualmente empregado para um equilíbrio entre o risco do fornecedor e do cliente, porém outros valores podem ser adotados desde que sejam avaliados os impactos para se evitar custos desnecessários e/ou metas impossíveis de serem alcançadas.

Essas equações só devem ser usadas para cálculo do intervalo de confiança bilateral e, portanto, quando existir ao menos uma falha. No caso de inexistência de falhas $(r=0)$ só é possível calcular o intervalo de confiança unilateral e com isso estabelecer um valor mínimo de $\theta$ ou um valor máximo de $\lambda$. 


$$
\theta_{\mathrm{inf}}=\frac{2 \cdot T}{\chi_{1-\alpha}^{2}(2 r+2)}
$$

Para um nível de confiança de $60 \%$, a equação (3.17) ficaria assim:

$$
\theta_{\mathrm{inf}}=\frac{2 \cdot T}{\chi_{1-\alpha}^{2}(2 r+2)}=\frac{2 \cdot T}{\chi_{1-\alpha}^{2}(2)}=\frac{2 \cdot T}{1,832}=\frac{T}{0,916}=1,092 \cdot T
$$

\subsubsection{Períodos de medição}

Metas diferentes podem ser definidas período a período, estabelecendo uma curva de crescimento da confiabilidade. O gráfico da Figura 9, mostra um exemplo de meta de confiabilidade variável no tempo. Neste exemplo, a meta está estabelecida para a taxa de falha global dos trens em falhas por milhão de quilômetros (FPMK). A curva máxima permitida possui uma inclinação entre os meses 0 e 6 da garantia, outra inclinação entre os meses 7 e 24 e fica constante a partir do mês 25 .

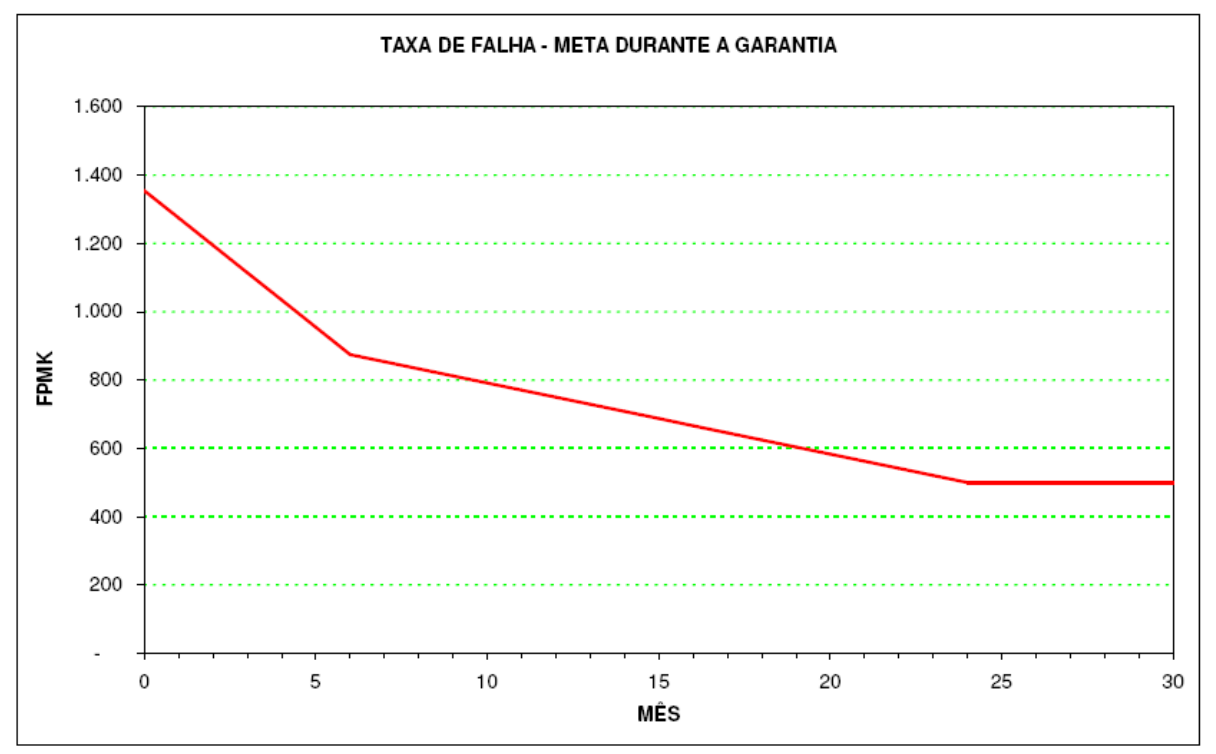

Figura 9: Exemplo de meta de confiabilidade variável no tempo 
O gráfico da Figura 10 apresenta outro exemplo de meta variável no tempo. Neste caso, não existem metas entre os meses 0 e 12, apenas a partir do mês 13. Do mês 25 em diante, a meta é reduzida pela metade.

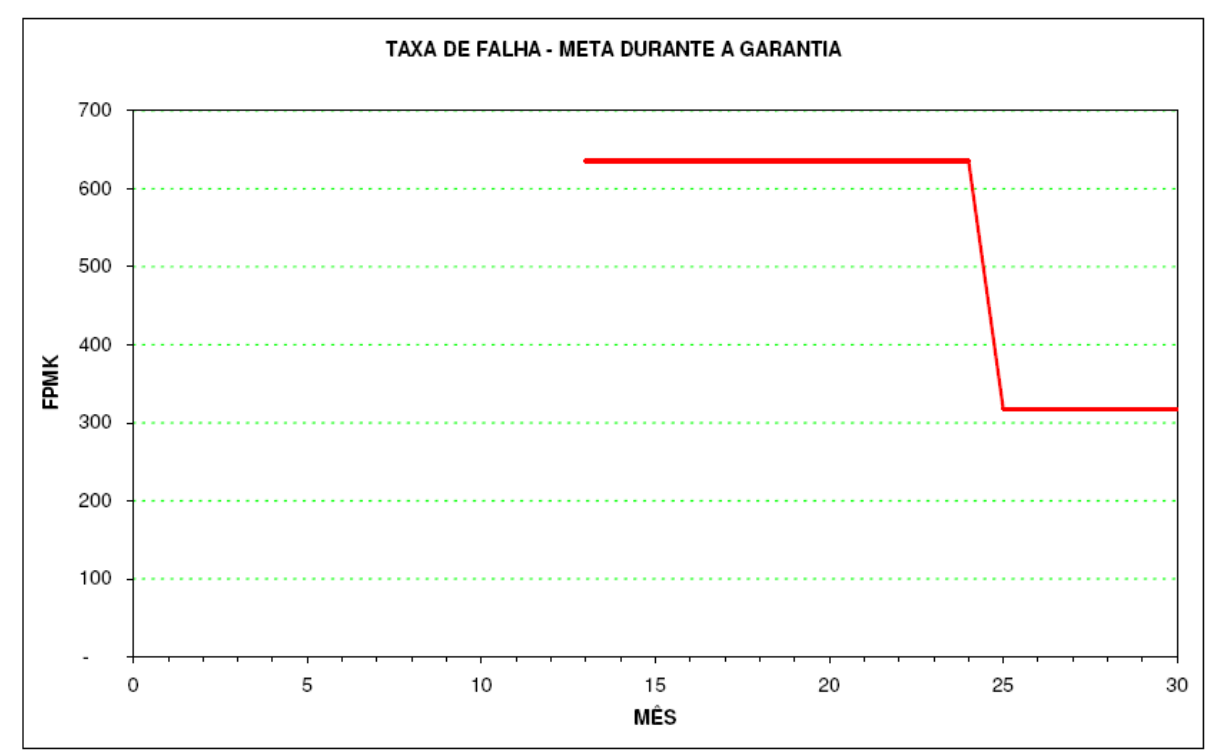

Figura 10: Outro exemplo de meta variável no tempo

\subsubsection{Incentivos e penalizações}

Para que as metas estabelecidas tenham algum significado, é necessário estabelecer um regime de incentivos e penalizações com base no cumprimento ou não dessas metas.

As penalizações podem estar relacionadas com extensão de garantia, pagamentos de multas, substituição de equipamentos e até cancelamentos de contrato. Os incentivos podem estar relacionados com liberação de valores inicialmente retidos, antecipação de eventos de pagamento, e avaliações positivas para fornecimentos futuros.

O regime de incentivos e penalizações é baseado no registro diário de todas as perturbações do serviço que resultem em cancelamento, perda de tempo ou outro incidente que afete os objetivos da qualidade do serviço.

A operadora é encarregada de registrar e classificar esses eventos além fazer uma pré-atribuição de responsabilidade pela causa do evento. Tais eventos 
podem ser, por exemplo, falhas externas, falhas nas estações, falhas operacionais, falhas do material rodante, etc. Dentre as falhas do material rodante, há ainda que se verificar se a falha é imputável ao fabricante, à ação de vandalismo ou mesmo a erro operacional.

Ocorre então uma revisão dessa classificação entre os representantes das partes envolvidas (operadora, concessionária, fabricante, etc) para definir a responsabilidade final sobre cada falha. Os cálculos de incentivos e penalizações devem levar em conta as ocorrências que forem consensualmente definidas.

A Tabela 12 mostra um exemplo de como pode ser estabelecido um regime de incentivos e penalizações com base nas metas de MKBF do trem.

Neste exemplo, duas metas de MKBF foram estabelecidas para falhas do tipo $\mathrm{A}$, em dois diferentes períodos de observação, levando-se em conta um período de crescimento de confiabilidade. A medição é feita por intervalo de confiança, com um nível de confiança de $60 \%$, e com base nas falhas tipo $A$ ocorridas em cada período.

Tabela 12: Exemplo de incentivos e penalizações

\begin{tabular}{|c|c|c|c|}
\hline $\begin{array}{l}\text { Período } \\
\text { de } \\
\text { avaliação }\end{array}$ & $\begin{array}{c}\text { Intervalo de confiança do } \\
\qquad \mathrm{MKBF}_{\mathrm{A}} \\
{\left[\mathrm{MKBF}_{\text {min }}, \mathrm{MKBF}_{\text {máx }}\right]}\end{array}$ & $\begin{array}{l}\text { (I) Incentivo / (P) } \\
\text { Penalização }\end{array}$ & Valor do pagamento \\
\hline \multirow{3}{*}{ Período 1} & $\mathrm{MKBF}_{\text {máx(1) }}<\mathrm{MKBF}_{\text {objetivo(1) }}$ & $\begin{array}{l}\text { (P) Multa paga } \\
\text { pelo fabricante à } \\
\text { operadora }\end{array}$ & \multirow{3}{*}{$\$=\frac{M K B F_{\text {objetivo }(1)}-M K B F_{1}}{M K B F_{\text {objetivo }(1)}} \cdot k 1$} \\
\hline & $\mathrm{MKBF}_{\text {máx(1) }}>\mathrm{MKBF}_{\text {objetivo(1) }}$ & Nenhum & \\
\hline & $\mathrm{MKBF}_{\min (1)}>\mathrm{MKBF}_{\text {objetivo(1) }}$ & $\begin{array}{l}\text { (I) Antecipação de } \\
\text { evento de } \\
\text { pagamento }\end{array}$ & \\
\hline \multirow{3}{*}{ Período 2} & $\mathrm{MKBF}_{\text {máx(2) }}<\mathrm{MKBF}_{\text {objetivo(2) }}$ & $\begin{array}{l}\text { (P) Multa paga } \\
\text { pelo fabricante à } \\
\text { operadora }\end{array}$ & \multirow{3}{*}{$\$=\frac{M K B F_{\text {objetivo(2) }}-M K B F_{2}}{M K B F_{\text {objetivo(2) }}} \cdot k 2$} \\
\hline & $\mathrm{MKBF}_{\text {máx(2) }}>\mathrm{MKBF}_{\text {objetivo(2) }}$ & Nenhum & \\
\hline & $\mathrm{MKBF}_{\min (2)}>\mathrm{MKBF}_{\text {objetivo(2) }}$ & $\begin{array}{l}\text { (I) Antecipação de } \\
\text { evento de } \\
\text { pagamento }\end{array}$ & \\
\hline
\end{tabular}




\subsection{PLANO DO PROGRAMA DE CDMS}

Os requisitos do cliente determinam os objetivos a serem perseguidos na especificação, projeto, compra e manufatura do material rodante. Baseado nos requisitos da operadora, tanto padrões qualitativos como quantitativos e respectivas metas devem ser prescritos nesse plano para sistemas individuais e subsistemas que serão integrados no veículo. Além disso, deve ser previsto o atendimento das regras e práticas recomendadas em normas internacionais.

Para atender tais objetivos, é necessária uma abordagem apropriada pelas áreas de projeto, qualidade e manufatura. Os elementos funcionais que causam impacto na confiabilidade global dos trens devem ser identificados e relacionados.

O objetivo principal do Plano do Programa de Confiabilidade (PPC) é descrever a abordagem para assegurar que os níveis desejados de confiabilidade estejam inerentes em todo o processo. O PPC define a política, o escopo, a organização e os processos estabelecidos para a implementação do programa. Também determina as responsabilidades, o relacionamento com outras atividades de projeto, o cronograma, as normas e os métodos utilizados para assegurar o cumprimento com os requisitos contratuais e com as normas apropriadas.

O Plano do Programa de Confiabilidade é elaborado e conduzido pelo responsável de CDMS, o qual é parte integrante do time do projeto. A responsabilidade dos Engenheiros de CDMS inclui, (13) e (14):

- Efetuar a alocação de metas numéricas de CDMS, e assegurar que as tarefas são desenvolvidas de forma a alcançar tais metas;

- Promover a interface entre os departamentos de Projeto, Manufatura e Compras, verificando o desempenho e propondo modificações e ações corretivas quando necessário;

- Analisar o desempenho de CDMS dos sistemas e comparar os resultados com os requisitos contratuais;

- Fornecer suporte técnico para os departamentos de Projeto, Manufatura e Compras; 
- Reportar a evolução das atividades de CDMS para o Gerente de Projeto.

\subsubsection{Perfil da missão}

É importante definir, juntamente com o plano do programa de CDMS, as condições ambientais e das vias previstas para operação dos trens, assim como o uso que será feito dos mesmos.

No caso das condições ambientais, informações como temperaturas média e máxima, umidade relativa do ar, precipitação média de chuva e neve, altitude, etc, podem ser importantes para a confiabilidade de alguns equipamentos.

Da mesma forma, informações do perfil de via tais como extensão, inclinação, número de estações, etc, ajudam a definir a utilização do trem, tais como número de paradas e ciclos de abertura e fechamento de portas.

Por fim, a própria previsão de operação por parte do cliente deve ser considerada na definição do perfil da missão não apenas de cada trem, mas de toda a frota. Por exemplo, informações do período diário de operação, horários de pico e vale, tempo entre trens, percentual de utilização da frota em cada período, número máximo de trens em manutenção preventiva, etc.

O perfil da missão pode também levar em conta estudos realizados na fase de proposta ou mesmo no início do projeto, tais como simulações, desenhos, conceitos construtivos, etc.

Sem uma clara definição do perfil da missão e das condições nas quais o trem será submetido, o projeto poderá ser afetado negativamente de maneira a prejudicar o desempenho de CDMS. Logicamente, muitas vezes os aspectos ambientais e operacionais devem ser tratados prevendo o pior cenário. Todavia, é preferível detalhar todas as condições nas quais o trem estará sujeito, oferecendo assim recursos para o julgamento técnico para cada caso em particular, (13). 


\subsubsection{Requisitos para os fornecedores}

Os fornecedores de sub-sistemas têm grande influência no desempenho de CDMS do trem. Portanto, é essencial que os esforços de CDMS no projeto do trem sejam fortemente direcionados aos principais fornecedores, no que diz respeito ao desenvolvimento, projeto, manufatura e assistência técnica de seus produtos.

Para tal, é importante a participação efetiva dos fornecedores desde as fases iniciais da proposta, em parceria com o fabricante do trem, para que estejam cientes dos requisitos finais, do desempenho esperado e de que forma seus sistemas contribuem para os parâmetros globais de CDMS do trem.

Da mesma forma, é importante o fabricante tornar explícito ao seu cliente de que forma os fornecedores estão inseridos no contexto de CDMS dentro do projeto e como é gerenciada essa relação para proporcionar, da melhor maneira possível, o atendimento aos requisitos especificados.

\subsection{RELATÓRIOS DE ANÁLISE DE CDMS}

Durante o projeto do trem, as análises de CDMS devem ser corretamente documentadas e divulgadas entre os envolvidos no processo e, principalmente, para os responsáveis pelo gerenciamento do projeto.

A norma IEC 60863 (17) determina os tópicos que devem ser levados em conta na elaboração dos relatórios de predição de CDM. De forma resumida, esses relatórios devem conter como mínimo:

- Sumário;

- Propósito da predição;

- Objeto da predição;

- Características;

- Requisitos e condições;

- Análises;

- Modelos; 
- Fontes de dados;

- Princípios de cálculo;

- Resultados;

- Conclusões e recomendações;

Os relatórios de predição devem ser considerados nas tomadas de decisão quanto ao encaminhamento do projeto, análises de risco e negociações com o cliente.

\subsection{CUSTOS DE CDMS}

Alcançar altos índices de confiabilidade tem um custo elevado, principalmente em se tratando de um produto complexo como um trem e que, em algumas vezes, envolve inovação tecnológica. As técnicas de análise de CDMS requerem recursos como engenheiros treinados, gerenciamento das ações e do tempo, equipamentos e produtos para testes, ferramentas de análise, entre outros. Isso pode fazer parecer difícil de se justificar as despesas com CDMS, principalmente pelo fato da confiabilidade ser uma ciência probabilística. As pessoas geralmente ficam tentadas a confiar no projeto sem que sejam dedicados esforços específicos à CDMS. Todavia, a experiência mostra que os custos com CDMS são pagos pelos próprios ganhos no final do projeto. Quer seja pela melhoria do desempenho, reduzindo custos operacionais, ou ainda pela diminuição da quantidade de falhas, reduzindo os custos com retrabalhos, com multas por não cumprimento de metas, com atrasos na entrega, etc. Isso tudo sem se falar da imagem da empresa pode ser duramente afetada, (13).

Portanto, o quanto antes, no processo de desenvolvimento, for identificado e corrigido o modo de falha, menor será o custo associado a ele. Os esforços com CDMS devem ser conduzidos buscando eliminar o maior numero possível de problemas potenciais, desde as etapas preliminares de analise, revisões até os testes e entrada em operação. Da mesma forma, é sempre mais barato 
corrigir as causas dos problemas de produção do que conviver com as conseqüências em termos de custos de retrabalhos e falta de confiabilidade, (13). 


\section{ANÁLISES E FERRAMENTAS DE CDMS}

\subsection{ALOCAÇÃO DE METAS DE CONFIABILIDADE}

A alocação da confiabilidade consiste em se dividir a meta de confiabilidade global do trem, normalmente definida na Especificação Técnica (ET) do material rodante, e atribuir metas entre os subsistemas que compõem o trem, de forma que a meta global seja atendida.

Isso é necessário para facilitar as análises de cada subsistema possibilitando às equipes de projeto compreender e desenvolver relações entre as confiabilidades de componentes, equipamentos, subsistemas e do próprio material rodante. Além disso, praticamente obriga a engenharia de projeto a considerar a confiabilidade tanto quanto outros parâmetros do sistema, tais como peso, custo e desempenho.

Um outro benefício da alocação de metas é o fato de que a maioria dos subsistemas é fornecida por diferentes empresas a uma montadora que, por sua vez, integra os sistemas no trem. Cada subsistema possuindo metas individuais facilita a comunicação entre montadora e fornecedor, além de permitir um melhor acompanhamento e verificação de cumprimento das metas, podendo até ser estabelecidas penalidades por não cumprimento.

Do ponto de vista da integração dos sistemas, permite ainda um melhor gerenciamento da confiabilidade global do trem, possibilitando a tomada de ações corretivas conforme a evolução do programa de confiabilidade e facilitando análises de trade-off (ou "trocas compensatórias", em português) durante o projeto.

\subsubsection{Métodos de alocação da confiabilidade}

Para alocar as metas de confiabilidade nos itens que compõem um sistema, é necessário modelar a confiabilidade $R(t)$ ou um parâmetro equivalente 
(MTBF, MKBF, etc) do sistema de acordo com os parâmetros de confiabilidade dos itens que constituem o sistema e encontrar soluções para a inequação (4.1):

$$
R(t)=f\left(R_{i}(t), \ldots\right) \geq \text { metas_confiabilidade }
$$

$\mathrm{Na}$ teoria, um número infinito de soluções atende a essa inequação básica. O processo de alocação consiste em seguir uma rotina que leve a uma única solução ou, pelo menos, a um número limitado de soluções que representem metas alcançáveis e realistas, permitindo o cumprimento da meta global.

Para isso, é necessário inicialmente que se tenha o modelamento dos parâmetros de confiabilidade dos sub-sistemas. Esse modelamento pode ser feito com ferramentas tipo Diagrama de Blocos e Árvore de Falhas, por exemplo.

A Figura 11 mostra um fluxograma genérico do processo de alocação de metas da confiabilidade.

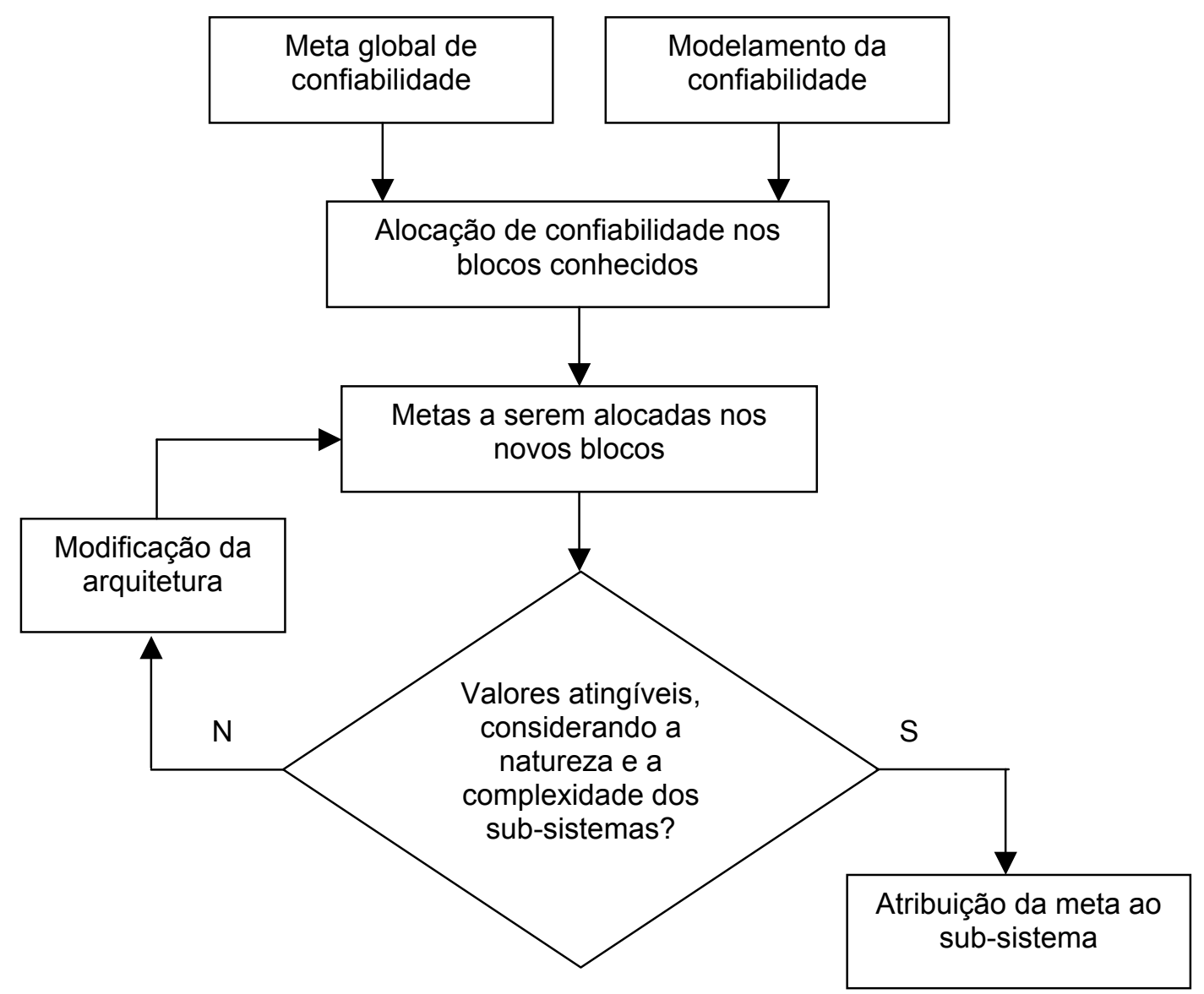

Figura 11: Fluxograma de alocação de metas de confiabilidade 
Para sistemas ou parte de sistemas que impliquem na aplicação do modelo serial de confiabilidade, é possível utilizar os seguintes métodos elementares:

- Método EQUAL (ou “igual”, em português)

- Método ARINC (Aeronautical Radio Incorporated)

- Método AGREE (Advisory Group on Reliability of Electronic Equipment)

- Método da avaliação da viabilidade dos objetivos

Os métodos mais comuns empregados na ferrovia são o ARINC e o da avaliação da viabilidade.

\subsubsection{Método EQUAL}

O método EQUAL é o mais simples e direto para se alocar as metas de confiabilidade entre os sistemas. Nesse método supõe-se que os subsistemas estão em série, as taxas de falha são constantes e que o tempo de missão do sistema é igual ao dos subsistemas. O objetivo é escolher $R_{i}$ tal que:

$$
R_{i}=\left(R_{\text {sys }}\right)^{\frac{1}{n}}
$$

Onde $R_{i}$ é a confiabilidade alocada ao subsistema i.

Porém, a maior deficiência desse método é justamente essa simplicidade, pois não diferencia os subsistemas de acordo com o grau de dificuldade para atendimento das metas alocadas, pois os considera com a mesma alocação de confiabilidade, (18) e (19). 
No método ARINC supõe-se que os subsistemas estão em série, as taxas de falha são constantes e que o tempo de missão do sistema é igual ao dos subsistemas. O objetivo é escolher $\lambda_{i}$ tal que:

$$
\sum_{i=1}^{n} \lambda_{i} \leq \lambda
$$

onde $\lambda_{i}$ é a taxa de falha alocada ao subsistema i e $\lambda$ é a taxa de falha global a ser atendida.

O método ARINC inclui, (18) e (19):

- Determinação das taxas $\lambda_{i}$, a partir de dados fornecidos, observados ou estimados;

- Atribuição de um fator de ponderação $\omega_{i}$ a cada subsistema, de acordo com as taxas de falha determinadas no passo anterior, onde $\omega$ i é dado por:

$$
\omega_{i}=\frac{\lambda_{i}}{\sum_{i=1}^{n} \lambda_{i}}
$$

- $\quad$ Atribuição da meta do sub-sistema, conforme equação 4.5.

$$
\lambda_{i}=\omega_{i} \cdot \lambda_{s}
$$

\subsubsection{Método AGREE}

O método AGREE é mais sofisticado e se baseia na complexidade do componente ou subsistema e considera explicitamente a relação entre o 
componente e a falha do sistema. A fórmula AGREE é utilizada para se determinar o MTBF de cada componente para que se atinja a confiabilidade do sistema. Supõe-se que os subsistemas estão em série, as taxas de falha são constantes e independentes entre si.

A complexidade do subsistema é definida em termos de módulos e suas conexões. O fator de ponderação de um subsistema é definido em termos de probabilidade de falhas do sistema, caso esse subsistema falhe. Um fator de ponderação igual a 1 (um) significa que o subsistema deve operar para que o sistema opere com sucesso. Um fator de ponderação igual a zero significa que a falha do subsistema não tem efeito na operação do sistema.

A alocação supõe que cada módulo presta uma contribuição igual ao sucesso do subsistema. Observando-se que $e^{t} \cong 1$-t quando $t$ for muito pequeno $(t<0,01)$, a taxa de falha alocada ao i-ésimo subsistema é dada por, (18):

$$
\lambda_{i}=\frac{N_{i} \cdot\left(-\ln \left(R^{*}(t)\right)\right.}{N \cdot \omega_{i} \cdot t_{i}}
$$

Onde:

$t=$ Tempo da missão;

$t_{i}=$ Tempo de operação do i-ésimo subsistema, durante t do sistema

$\left(0<\mathrm{t}_{\mathrm{i}} \leq \mathrm{t}\right)$;

$N_{i}=$ Número de módulos do i-ésimo subsistema;

$N=$ Número total de módulos no sistema $=\sum N_{i}$;

$\omega_{i}=$ fator de ponderação para o i-ésimo subsistema $=$ P [falha do sistema quando o subsistema i falhar];

$R^{*}(t)=$ Confiabilidade requerida para o sistema para o tempo de operação $t$ (missão);

A confiabilidade alocada ao i-ésimo subsistema para o tempo de operação $t_{i}$ é dada por:

$$
R_{i}\left(t_{i}\right)=1-\frac{1-\left(R^{*}(t)\right)^{\frac{N_{i}}{N}}}{\omega_{i}}
$$


Quando os valores de $\omega_{\mathrm{i}}$ estão muito abaixo de 1 (um), a fórmula AGREE conduz a valores distorcidos de alocação.

4.1.1.4 Método da avaliação da viabilidade dos objetivos

Essa técnica é principalmente usada para sistemas eletromecânicos nãoreparáveis que não possuam dados de retorno de experiências de campo. Os fatores de alocação dos subsistemas são computados como uma função de índices numéricos para:

- Complexidade do sistema: A complexidade é avaliada considerando o número provável de itens que compõem o sistema e julgada pela complexidade de montagem desses itens. Os sistemas recebem índices numéricos entre 1 e 10, de acordo com sua complexidade, sendo o valor 10 para os mais complexos.

- Estado da arte: Corresponde ao estado atual do progresso tecnológico e da engenharia aplicada. Os sistemas recebem índices numéricos entre 1 e 10, sendo o valor 10 para os sistemas com tecnologias e aplicações ainda pouco utilizadas.

- Tempo de operação: Os sistemas recebem índices de 1 a 10, de acordo com o tempo de utilização dentro da missão global do trem, sendo 10 para os itens que operam durante toda a missão.

- Ambiente: As condições ambientais também recebem pesos entre $1 \mathrm{e}$ 10 , sendo o valor 10 para aqueles sujeitos às condições ambientais mais severas para sua confiabilidade.

Esses valores são atribuídos pelo engenheiro de projeto ou por um grupo de engenheiros, em um processo de discussões e votação, baseado no conhecimento e experiência de cada um.

A alocação das metas é então realizada de forma análoga ao método ARINC, porém com os fatores de ponderação $\left(\omega_{i}\right)$ calculados com base na proporção do produto dos índices numéricos atribuídos para cada um dos critérios mencionados, ou seja: 


$$
\begin{aligned}
& C_{i}=r_{1 i} \cdot r_{2 i} \cdot r_{3 i} \cdot r_{4 i} \\
& \omega_{i}=\frac{C_{i}}{\sum C_{i}} \\
& \lambda_{i}=\omega_{i} \cdot \lambda_{s}
\end{aligned}
$$

onde:

$r_{1 i}$ a $r_{4 i}$ : valores de 1 a 10 para os 4 critérios de cada subsistema.

\subsubsection{MTBF mínimo dos equipamentos}

Sempre que for especificado um critério de falha sistemática, é possível estabelecer o MTBF mínimo dos equipamentos utilizando apenas a quantidade de itens instalados na frota e o período de garantia contratual (ver item 3.6.2.3).

Porém, mesmo que não seja especificado esse critério, é possível estabelecê-lo internamente, como método de alocação, em conjunto com os outros métodos mencionados. Nesse caso deve-se definir o percentual a partir do qual a falha do componente torna-se sistemática do ponto de vista do fabricante, considerando os custos e riscos associados.

Há ainda uma outra forma de se estabelecer o MTBF mínimo dos componentes. Seguindo os processos de alocação descritos, pode-se aprofundar cada vez mais a alocação até se obter o nível desejado. Por exemplo, com base na alocação feita para um sistema, distribuem-se as metas convenientemente entre os principais equipamentos que o compõem. Da mesma forma, com base nas metas estabelecidas para o equipamento, faz-se a alocação das metas para os módulos internos, componentes, etc.

Nesse processo todo de alocação, é importante comparar as alocações feitas para cada sistema ou equipamento, com as metas contratuais (se houver) e também com as experiências passadas de tal forma que seja possível saber se as 
metas globais e individuais são alcançáveis ou não e também onde devem ser concentrados os esforços para melhoria da confiabilidade.

\subsection{PREDIÇÃO DA CONFIABILIDADE DE COMPONENTES}

A predição ou estimação da confiabilidade consiste em se prever a confiabilidade do sistema, através de modelagem, cálculos e análises, com o intuito de se comparar possíveis soluções de engenharia e escolher a que melhor atenda aos requisitos. Não necessariamente são obtidos valores precisos na predição de confiabilidade, porém para efeitos comparativos - entre os sub-sistemas e mesmo entre sistemas distintos - a predição é muito importante.

Da mesma forma, como normalmente o fabricante deve cumprir determinadas metas de confiabilidade, as técnicas de predição possibilitam perceber o quão distante de tais metas se está e se é necessário algum plano de ação para que as metas sejam atendidas.

Em suma, a técnica de predição da confiabilidade não é necessariamente sempre efetiva em termos quantitativos. Contudo, ainda que existam diferenças entre a confiabilidade real e a confiabilidade predita, essa técnica é útil por permitir identificar e segregar os poucos itens de projeto vitais daqueles vários itens triviais.

A predição da confiabilidade é um processo contínuo que começa nas fases iniciais do ciclo de vida do produto, quando dados preliminares existem apenas em papel, e evolui através das demais etapas de desenvolvimento do produto.

É uma técnica que se justifica por ajudar a gerar um produto final mais confiável, desde que usada corretamente e entendidas as suas limitações. A predição da confiabilidade é útil para (entre outros):

- Avaliar a exeqüibilidade do projeto;

- Estabelecer objetivos de confiabilidade;

- Estimar a confiabilidade total do projeto a partir dos componentes e

- Detectar áreas de problemas; 


\subsubsection{Limitações fundamentais da predição da confiabilidade}

\subsubsection{Predições no campo da engenharia}

Na engenharia e na ciência, de uma forma geral, são utilizados modelos matemáticos para a predição de parâmetros. Por exemplo, a dissipação de potência em um resistor pode ser predita utilizando-se a lei de Ohm, potência = tensão $x$ corrente. Esses modelos são válidos dentro de um domínio apropriado, ou seja, sob determinadas condições.

Todavia, para os propósitos do dia a dia, esses modelos determinísticos atendem bem às necessidades, levando-se em conta os aspectos práticos de medição de erros e tolerâncias.

Porém, enquanto muitas leis da física, por questões de simplificação e praticidade, podem ser tratadas de forma determinística, seus mecanismos reais são estocásticos. Por exemplo, a pressão de um gás em um reservatório fechado é função da movimentação de um número muito grande de moléculas. O Teorema do Limite Central, permite que seja feito uso dos efeitos médios da energia cinética molecular para predizer o parâmetro conhecido por pressão.

Para um modelo matemático ser aceito como base para predição científica, ele deve ser baseado numa teoria que explique seu relacionamento. Também é necessário que tal modelo seja baseado em definições claras dos parâmetros usados. Além disso, os modelos devem sempre possibilitar a repetição dos eventos, (13) e (16).

\subsubsection{Predições no campo da confiabilidade}

O conceito de estabelecer modelos matemáticos para predição de confiabilidade, da mesma forma como é feito em outros campos da engenharia e da ciência, é um apelo natural e desperta muita atenção. Por exemplo, a taxa de falhas 
de um componente eletrônico baseada em parâmetros como temperatura e outros fatores de estresse. Modelos similares são desenvolvidos para componentes não eletrônicos e até mesmo para software. Algumas vezes esses modelos são simples como um valor fixo, corrigido por fatores multiplicativos, já alguns outros são bastante complexos, levando em conta os vários fatores considerados prováveis de afetarem a confiabilidade.

Assim como outros modelos preditivos de engenharia, esses modelos são baseados em considerações que possam afetar o parâmetro de interesse, no caso a confiabilidade, ou seja, a ocorrência da falha. Todavia, a validade dessa abordagem é severamente limitada, em termos de predição de confiabilidade.

Um modelo tal qual a lei de Ohm é confiável (no sentido literal da palavra), porque não há dúvidas quanto à circulação de corrente quando uma tensão é aplicada sobre um resistor. Porém, enquanto um componente como um resistor possui propriedades tais como resistência, massa, etc, todos parâmetros claros e mensuráveis, é muito improvável estabelecer modelos de confiabilidade intrínseca que atendam tal critério.

A falha, ou ausência de falha, é altamente dependente de ações e percepções humanas, o que nem sempre ocorre com as leis da natureza. Isso, portanto, representa a limitação fundamental do conceito de predição de confiabilidade utilizando-se modelos matemáticos.

Uma outra limitação severa é proveniente do fato de que os modelos de confiabilidade são geralmente baseados em análise de dados estatísticos passados. Muitos mais dados e informações seriam necessários para se estabelecer uma relação estatística que confirme uma teoria determinística, e ainda assim haveria incertezas devido ao fato da amostra raramente ser representativa em relação à população total.

Há que se ter muito cuidado em se fazer predições baseadas em dados passados a menos que se tenha certeza de que as condições presentes, e que possam afetar o comportamento futuro, não mudarão. Há que se levar em conta também o esforço contínuo de algumas empresas na melhoria da qualidade e da confiabilidade, de forma que a predição baseada em dados passados pode ser demasiadamente pessimista. 
A predição de confiabilidade para um sistema contendo vários itens é mais precisa que para um pequeno sistema e certamente em relação a um item individual. É importante destacar que as variações da confiabilidade dos itens são de magnitudes muito maiores que as variações da confiabilidade de sistemas.

A simples apresentação de predições de confiabilidade, sem que esses pontos estejam claros entre os interlocutores, pode minar a credibilidade da engenharia de confiabilidade, em particular devido ao fato de que freqüentemente os sistemas alcançam níveis de confiabilidade muito mais altos que as predições, ainda que isso não seja uma regra, pois também podem ficar bastante aquém das predições, (13).

\subsubsection{Abordagem prática}

Apesar de identificadas as limitações fundamentais dos modelos de predição e da utilização de dados, existe a necessidade de se predizer a confiabilidade de sistemas. É possível efetuar predições razoavelmente confiáveis sob certas circunstâncias. São elas:

- Os sistemas são similares aos sistemas já desenvolvidos, implementados e utilizados anteriormente, de forma que as experiências passadas possam ser consideradas;

- O novo sistema não envolve risco tecnológico demasiadamente elevado;

- O sistema será produzido em grandes quantidades, trata-se de um sistema complexo, será utilizado por um longo período ou ainda uma combinação desses fatores;

- Existe um forte comprometimento para se alcançar a confiabilidade predita, como prioridade de projeto.

A predição da confiabilidade não assegura que os valores de confiabilidade sejam alcançados. Não é uma demonstração assim como um cálculo de dissipação de potência, baseado em leis físicas. Por outro lado, deve ser usada 
como base para o estabelecimento de objetivos e identificação de pontos problemáticos de maneira comparativa. Isso só é possível se houver comprometimento humano.

Segundo O'Connor (13), “as predições devem sempre levar em conta os objetivos e aspectos gerenciais relacionados, tais como comprometimento e riscos associados. Se o gerenciamento não considera os esforços de confiabilidade, as predições tornam-se um exercício sem significado".

Outro ponto importante a ser destacado é o fato de que a obtenção de altos índices de confiabilidade não implica necessariamente em custos significativamente mais altos.

\subsubsection{Predições conforme normas e bancos de dados}

\subsubsection{MIL-HDBK 217}

A norma MIL-HDBK-217 (20) apresenta 2 (dois) métodos para estimar a confiabilidade dos equipamentos eletrônicos durante o projeto. Esses métodos são conhecidos como Parts Count (contagem dos componentes) e Part Stress (análise das solicitações). Em ambos os casos, o modelo parte de uma taxa de falhas típica para o componente e essa taxa de falhas é então corrigida por fatores multiplicativos.

O método Parts Count requer menos informações e pode ser aplicado nas etapas preliminares do projeto. O método Part Stress requer informação mais detalhada e aplica-se nas últimas etapas de projeto, em que os circuitos e configurações finais estão sendo definidos.

- Parts Count

O método Parts Count simplesmente soma as taxas de falha estimadas dos componentes de uma montagem. Essa técnica assume modelo de confiabilidade em série. 
A taxa de falha de cada componente pode ser estimada usando a taxa de falhas típica do componente $\lambda_{g i}$, modificada por um fator de qualidade $\pi_{q i}$. A taxa de falhas total do equipamento pode ser então calculada:

$$
\lambda_{\text {Equip }}=\sum_{i=1}^{m} n_{i} \cdot\left(\lambda_{g} \cdot \pi_{Q}\right)_{i}
$$

Onde:

- $\quad \lambda_{\text {Equip: }}$ Taxa de falhas total do equipamento;

- $\quad$ m: Número de diferentes tipos de componente;

- $\quad n_{\mathrm{i}}$ : Número de componentes do tipo i;

- $\quad \lambda_{g}$ : Taxa de falhas genérica para cada tipo de componente (função da complexidade e do ambiente de uso);

- $\quad \pi_{\mathrm{Q}}$ : Fator de qualidade;

- Part Stress

O método Part Stress é um cálculo similar para estimação das taxas de falha de componentes individuais. Esse método utiliza a seguinte expressão:

$$
\lambda_{p}=\lambda_{b} \cdot \pi_{Q} \cdot \pi_{e}
$$

Onde:

- $\quad \lambda_{p}$ : Estimação da taxa de falha do componente individual;

- $\quad \lambda_{b}$ : Taxa de falha base para o tipo específico de componente;

- $\quad \pi_{\mathrm{Q}}$ : Fator de qualidade;

$-\quad \pi_{e}:$ Fator ambiental;

Os modelos desse método são específicos de cada tipo de componente e tecnologia. Por exemplo, o modelo para relés é:

$$
\lambda_{p}=\lambda_{b} \cdot \pi_{L} \cdot \pi_{C} \cdot \pi_{C Y C} \cdot \pi_{F} \cdot \pi_{Q} \cdot \pi_{e}
$$


Onde:

- $\quad \lambda_{p}$ : Estimação da taxa de falha do componente individual;

- $\quad \lambda_{b}$ : Taxa de falha base para o tipo específico de componente;

- $\quad \pi_{\mathrm{L}}$ : Fator de carga;

- $\pi_{\mathrm{C}}$ : Fator construtivo;

- $\quad \pi_{\mathrm{CYC}}$ : Fator de ciclos de operação;

- $\pi_{\mathrm{F}}$ : Fator de tipo;

- $\pi_{\mathrm{Q}}$ : Fator de qualidade;

- $\pi_{e}:$ Fator ambiental;

\subsubsection{UTE 80-810}

A norma UTE80-810 (21) é uma norma Francesa similar à MIL-HDBK-217 (20), no que se refere ao método Part Stress para componentes eletrônicos. Os modelos de ambas as normas possuem pequenas diferenças entre si.

Isso leva a valores de taxa de falha diferentes se calculados por uma ou outra norma. Porém não significa necessariamente um problema se levarmos em conta as limitações das predições de confiabilidade e as utilizarmos adequadamente.

\subsubsection{NPRD-95}

O relatório NPRD-95 (22) é um documento emitido pelo Centro de Análises de Confiabilidade (RAC) dos EUA com a publicação de dados de confiabilidade compilados de relatórios técnicos de entidades governamentais e não governamentais americanas, além dos fabricantes.

Esse documento fornece dados de taxa de falha de uma grande variedade de tipos de componentes, incluindo componentes mecânicos, eletromecânicos, componentes eletrônicos discretos e montagens. Fornece tanto um 
resumo como dados detalhados classificados por tipo, nível de qualidade, ambiente e fonte de dados.

Os dados contidos representam uma compilação da experiência de campo em aplicações militares, comerciais e industriais e se concentra em itens não cobertos pela MIL-HDBK-217 (20). As tabelas de dados incluem descrição dos itens, níveis de qualidade, ambientes de aplicação, estimativas pontuais da taxa de falha, fontes de dados, número de falhas observadas, total de horas operacionais (ou total de distância percorrida, no caso de veículos terrestres), e características detalhadas dos componentes.

- Interpretação dos dados

Conforme descrito no próprio relatório NPRD-95 (22), os dados apresentados nesse documento representam uma estimação da taxa de falhas esperada e o valor verdadeiro estará dentro de algum intervalo de confiança em torno desse valor. O método tradicional de identificação dos limites de confiança para distribuição exponencial de vida de componentes tem sido a distribuição QuiQuadrado. Essa distribuição conta com a observação de falhas em uma população homogênea.

Deve-se notar que essas precisões são aplicáveis para prever a taxa de falha de componentes e que a confiança aumenta quando as distribuições estatísticas de componentes são combinadas em módulos ou sistemas.

É assumido que as distribuições estatísticas dos componentes presentes nesse documento sejam exponenciais. Porém, muitos itens para os quais são apresentados dados, não seguem a distribuição exponencial, pois apresentam características de desgaste ou uma taxa de falha crescente no tempo.

Embora a distribuição real possa ser Weibull ou lognormal, pode-se considerar que os tempos de falha seguem uma distribuição exponencial de confiabilidade, se um tempo longo o suficiente tenha sido decorrido. Isso é verdadeiro sob a condição de que os componentes sejam substituídos na ocorrência de falha. Para ilustrar isso, a Figura 12 mostra a taxa de falha aparente para uma população de componentes com distribuição Weibull e que são substituídos em caso de falha. 


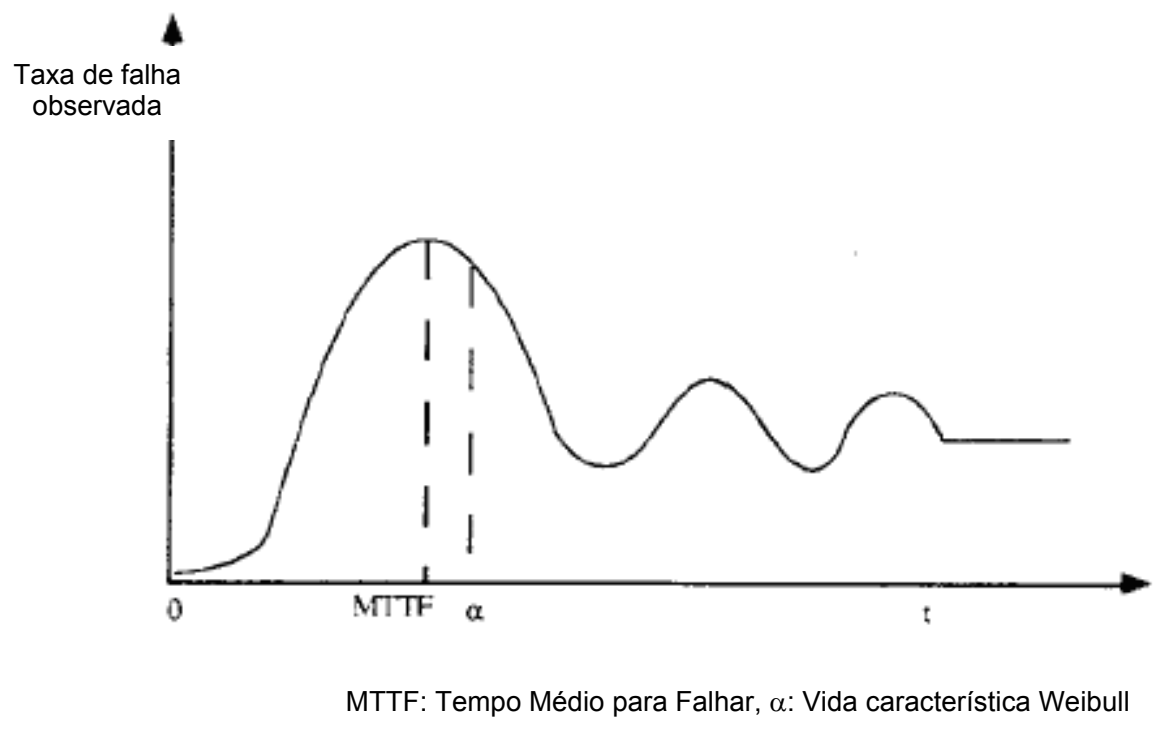

Figura 12: Taxa de falhas aparente de um sistema reparável, (22)

No instante $\mathrm{t}=0$ todos os itens de uma população estão funcionando normalmente. À medida que o tempo de operação aumenta, os itens vão sendo substituídos ao falhar e a taxa de falhas aumenta gradativamente. A taxa de falhas diminui à medida que a maioria dos itens vai sendo substituída por itens novos. A população dos itens substituídos segue o mesmo processo exceto pelo fato de que o desvio na segunda distribuição é maior em virtude dos "instantes zeros" de cada item estarem distribuídos no tempo. Esse processo continua até que o instante zero de cada item seja suficientemente aleatório e resulte em uma distribuição exponencial aparente. O tempo aproximado para se atingir esse valor assintótico é uma função de $\beta$ dada na Tabela 13. O valor assintótico da taxa de falhas é $1 / \alpha$ ao invés de $\beta,(22)$.

Tabela 13: Tempo em que o valor assintótico é atingido, (22)

\begin{tabular}{|c|c|}
\hline$\beta$ & Assíntota \\
\hline 2 & $1,0 \times \alpha$ \\
\hline 4 & $2,4 \times \alpha$ \\
\hline 6 & $4,2 \times \alpha$ \\
\hline 8 & $7,0 \times \alpha$ \\
\hline
\end{tabular}


Uma vez que o MTTF é mais freqüentemente utilizado que a característica de vida, essa relação deve ser entendida. A razão $\alpha / M T T F$ é uma função de $\beta$ e é dada na Tabela 14 .

Tabela 14: Razão $\alpha / M T T F$ em função de $\beta$, (22)

\begin{tabular}{|c|c|}
\hline $\boldsymbol{\beta}$ & $\boldsymbol{\alpha} / \mathbf{M T T F}$ \\
\hline 1 & 1,00 \\
\hline 2 & 1,15 \\
\hline 2,5 & 1,12 \\
\hline 3 & 1,10 \\
\hline 4 & 1,06 \\
\hline
\end{tabular}

É visível, portanto, que o período de tempo no qual os dados são coletados é muito importante. Por exemplo, se os dados são coletados do tempo zero até um tempo que seja fração de $\alpha$, a taxa de falhas será crescente nesse período e a taxa de falhas média será muito menor que o valor assintótico. Por outro lado, se os dados forem coletados durante um período de tempo após ter atingido o valor assintótico, a taxa de falhas será constante e terá o valor $1 / \alpha$.

O relatório NPRD-95 (22) mostra ainda como se obter os parâmetros de vida da distribuição Weibull, baseado nos dados apresentados, quando se analisa individualmente algum item e por um tempo menor que $\alpha$, porém não será tratado aqui já que o sistema "Material Rodante" é um sistema complexo (em relação ao número de itens), pressupõe manutenção, e seu tempo de vida útil é normalmente maior ou igual a 25 anos.

Essas considerações são válidas principalmente porque o foco desse trabalho é a confiabilidade do Material Rodante. Deve-se ter extremo cuidado para se fazer as mesmas considerações quando se tratar da Segurança, pois outros fatores devem ser incluídos na análise.

A Figura 13 mostra um exemplo de apresentação de dados da NPRD-95 (22) em inglês, tal como sua versão original. Os itens são classificados por sua descrição em ordem alfabética. Além disso, também são classificados por nível de qualidade e ambientes onde os itens foram testados. Pode-se então obter uma estimativa pontual da taxa de falhas com base no tempo total acumulado e a quantidade de falhas observadas durante esse período. 


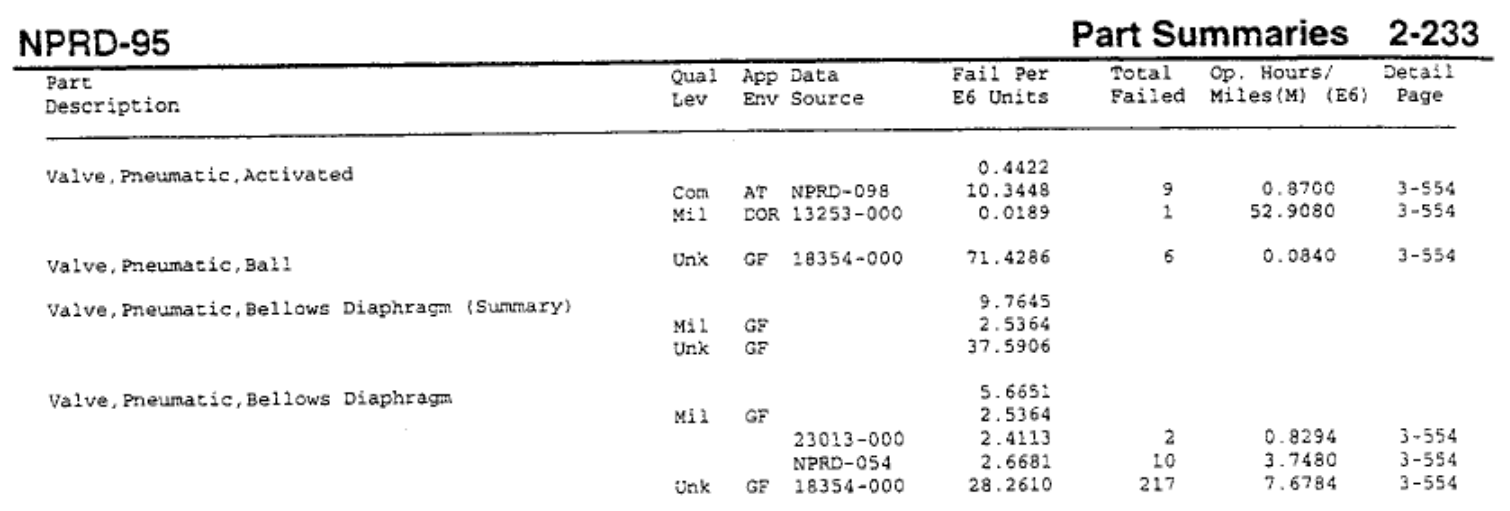

Figura 13: Exemplo de apresentação de dados da NPRD95

\subsubsection{Análise da solicitação e resistência}

O procedimento clássico em projetos mecânicos e estruturais é dimensionar um componente com resistência suficiente para suportar a pior solicitação à qual for submetido.

Uma vez que as falhas nem sempre são relacionadas apenas com 0 tempo, são necessárias técnicas de comparação de solicitação e resistência além da determinação quantitativa da confiabilidade. O conceito de análise de solicitaçãoresistência nos projetos leva em conta o fato de que os valores de solicitação aos quais os itens estão submetidos e suas resistências não são valores pontuais, mas uma faixa de valores estatisticamente distribuída com uma probabilidade de ocorrência associada a cada valor nessa faixa. As faixas de valores podem ser descritas por funções de densidade de probabilidade apropriadas. É necessário ter o conhecimento prévio dessas distribuições para se proceder com esse tipo de análise.

Com ambas as distribuições definidas, a confiabilidade é o complemento da probabilidade da solicitação imposta ser maior que a resistência suportada pelo item. Esse valor pode ser determinado analiticamente, graficamente, por integração numérica ou por técnicas de simulação, como Monte Carlo. A Figura 14 ilustra a 
região de probabilidade de falha através da área hachurada, onde a solicitação é maior que a resistência.

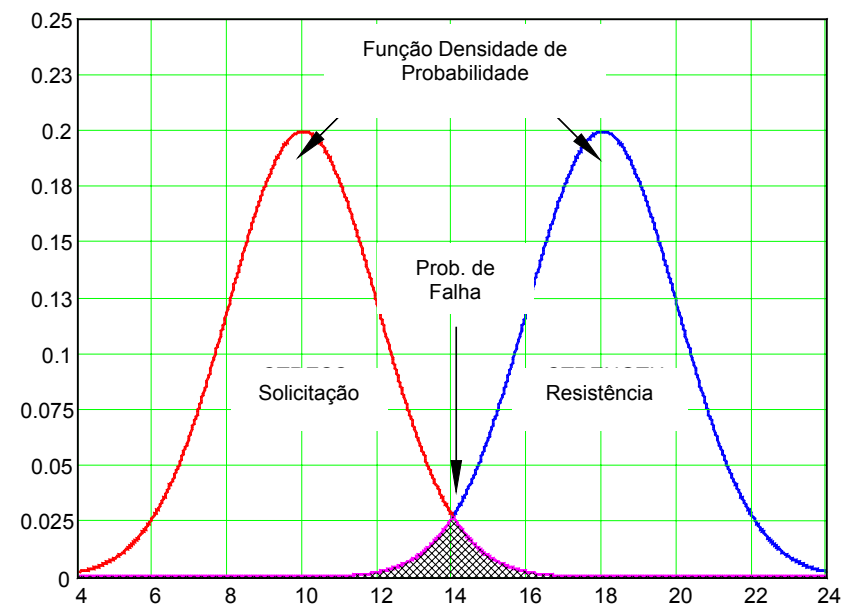

Figura 14: Representação da probabilidade de falha

De fato, essa é apenas uma representação esquemática das distribuições e da probabilidade de falha.

O que ocorre é que a probabilidade das diversas combinações de valores de solicitação e resistência é, na verdade, uma função espacial representada na Figura 15.

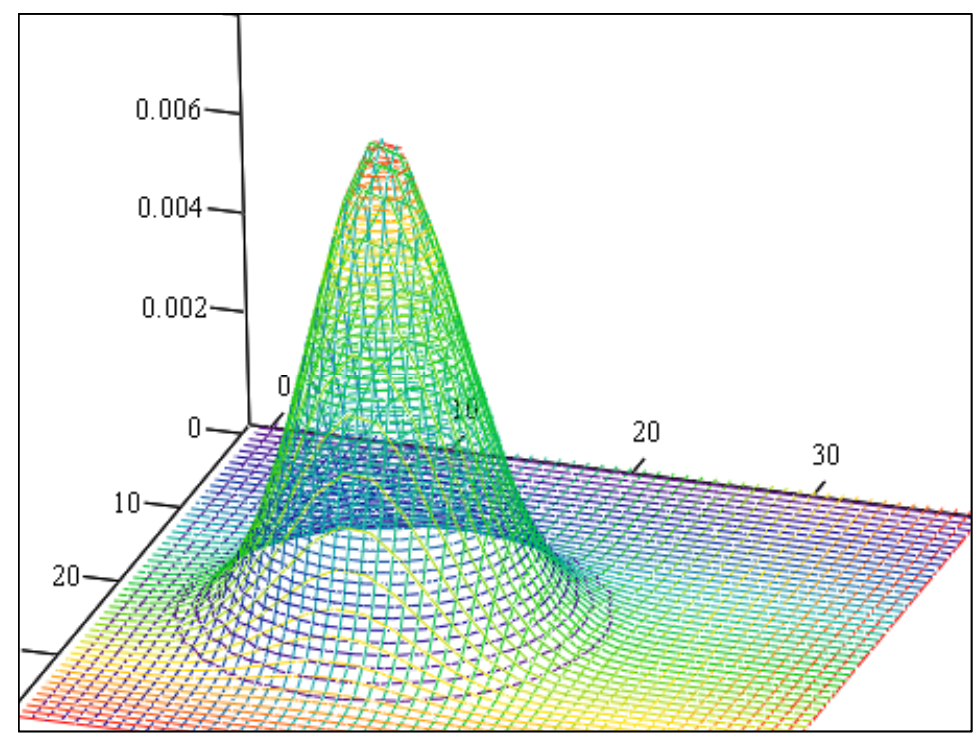

pdf

Figura 15: Função densidade de probabilidade 
A falha ocorre, quando a solicitação é maior que a resistência. Portanto há um plano que divide essa figura em duas partes, conforme Figura 16.

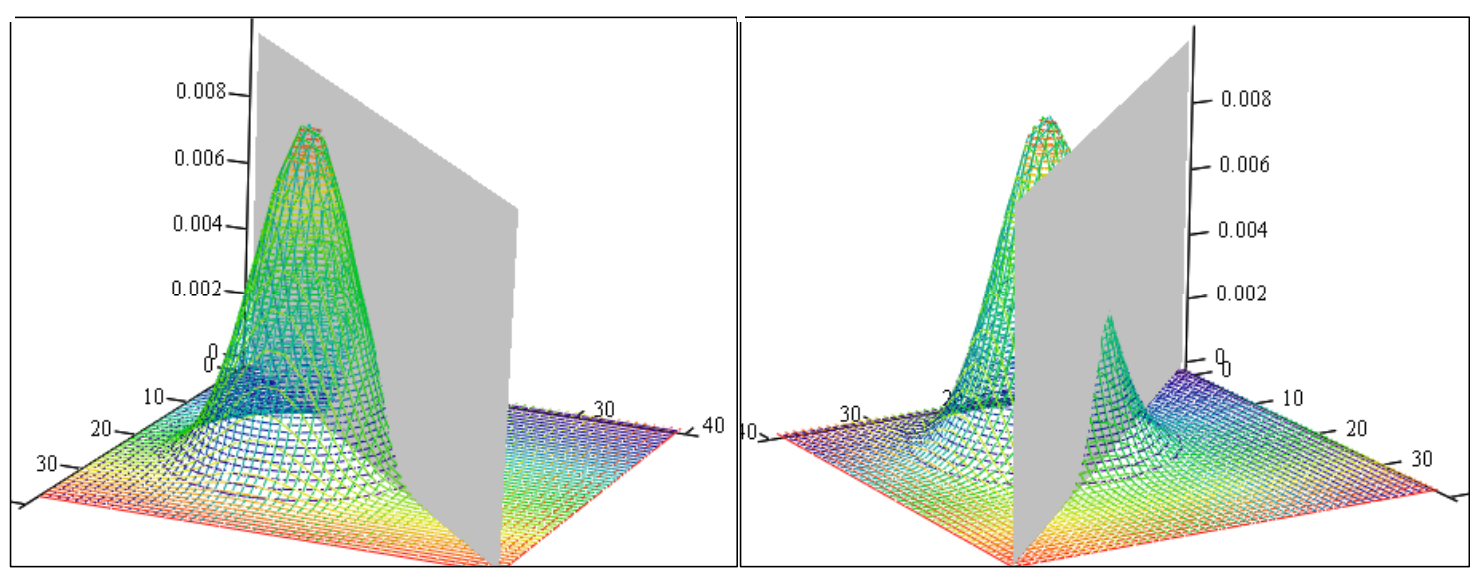

pdf , plano

pdf, plano

Figura 16: Plano quando solicitação = resistência

O volume maior representa a confiabilidade e o volume menor a probabilidade de falha. $O$ volume total da figura deve ser sempre igual a 1.

Desde que os eventos sejam mutuamente independentes, pode-se usar a regra do produto para se calcular a probabilidade de falha.

$$
F(x, y)=\int_{-\infty}^{\infty}\left(\int_{-\infty}^{y} \operatorname{Re}(x) \cdot d x\right) \cdot S(y) \cdot d y
$$

Onde $\operatorname{Re}(x)$ é a f.d.p. da resistência e $S(y)$ é a f.d.p. da solicitação.

Porém, como não existem solicitações e resistências menores que zero, a equação 4.14 se torna igual a:

$$
F(x, y)=\int_{0}^{\infty}\left(\int_{0}^{y} \operatorname{Re}(x) \cdot d x\right) \cdot S(y) \cdot d y
$$




\subsubsection{Ensaios de confiabilidade}

Uma das maneiras mais eficientes para obtenção de valores de confiabilidade de componentes é através da observação do desempenho real de itens iguais ou similares àqueles que se pretende utilizar no novo projeto.

Isso pode ser feito através da execução de ensaios planejados, visando a observação de determinado parâmetro que evidencie a falha do item, que pode ser um componente, um equipamento ou mesmo um sistema.

Basicamente, as etapas para realização de um ensaio de confiabilidade consistem de, (13) (18):

- Planejamento;

- Realização dos ensaios;

- Análise dos resultados;

\subsubsection{Planejamento dos testes}

Os ensaios de confiabilidade, comparativamente a outros ensaios de desempenho, têm custos relativamente elevados além de necessitarem de um tempo elevado para suas realizações. Além disso, muitas vezes, a interrupção não programada dos ensaios pode comprometer os dados já coletados. Por essas razões, o planejamento dos testes deve começar o quanto antes no processo de desenvolvimento do projeto.

O planejamento dos ensaios deve conter todas as informações necessárias à execução dos testes, coleta e interpretação dos dados, de acordo com os objetivos do ensaio. Deve conter ainda informações quanto à estrutura necessária para a realização dos testes, considerando:

- Logística, como apoio administrativo, cronograma, etc;

- Equipamentos e Instrumentos de medição que serão utilizados;

- Instalações e condições físicas e ambientais;

- Recursos humanos e respectivas competências; 
As condições e níveis de solicitação aos quais estarão submetidos os componentes, assim como o desempenho mínimo que possibilite a caracterização e a classificação das falhas devem estar muitos bem definidos para que os testes não sejam invalidados, (13) (18).

4.2.4.2 Realização dos testes e coleta de dados

O procedimento de ensaio deve ser definido no plano, porém geralmente consiste em se submeter os itens ao ciclo de ensaio especificado, medir o tempo relevante de ensaio e contar as falhas relevantes, somados sucessivamente para todos os itens do ensaio. Quando um item falhar, deverá ser reparado ou substituído, e retornado ao ensaio, (23).

Tão importante quanto a realização dos testes é a coleta dos dados que deve ser feita de forma organizada, sistemática, detalhada e efetiva. Para mais detalhes, ver a seção sobre FRACAS (4.10).

\subsubsection{Uso de retorno de experiências}

Os ensaios de confiabilidade podem ser efetuados não só através de experimentos isolados de laboratório mas, principalmente, através da observação do comportamento de dados de campo. Isso faz com que a amostra utilizada seja significativa e esteja sob condições de ensaio que mais se aproximem da realidade, além é claro da otimização de custos. 


\subsubsection{Estimação pontual}

Uma estimativa pontual é um valor numérico único que representa o valor verdadeiro, não conhecido, de um parâmetro estatístico, tal como a taxa de falhas. Geralmente a estimativa por ponto considerada nesse caso é o valor observado, (24).

- Dados Não Censurados

Quando todos os itens de uma amostra são testados até a falha, diz-se que se obteve uma amostra completa. A estimação pontual do $\operatorname{MTBF}(\hat{\theta})$ é a simples divisão do tempo total de teste pela quantidade de falhas, ou seja, a média aritmética dos tempos até a falha.

$$
\hat{\theta}=\frac{T}{f}
$$

Sendo,

$T$ : Tempo total acumulado no teste por todas as unidades

f: Número total de falhas que ocorreram

No caso da amostra completa, o número total de falhas é igual ao tamanho da amostra.

- Dados Censurados

Ensaios com amostras censuradas são interrompidos após um determinado tempo ou quando um certo número de falhas tenha ocorrido.

Se o teste de vida terminar num instante específico $t_{i}$, quando podem ter ocorrido menos falhas do que o tamanho da amostra, tem-se um teste de vida com censura ou interrupção do tipo I. Na censura do tipo I, o número de falhas e seus respectivos tempos são variáveis aleatórias.

Diz-se que foi realizado um teste de vida com censura ou interrupção do tipo II, quando o ensaio terminar no instante em que ocorrer um particular número de falhas $\mathrm{f}$. Na censura do tipo II o número de falhas é considerado fixo e as variáveis 
aleatórias são os instantes em que ocorrem as falhas. As equações apresentadas na seqüência deste texto foram obtidas nas referências (12), (18), (19), (24) e (25).

- Censura tipo I, ensaio COM reposição:

$$
\hat{\theta}=\frac{n \cdot T}{f}
$$

Onde:

n: Tamanho da amostra;

T: Tempo de teste estabelecido;

f: Número total de falhas;

- Censura tipo I, ensaio SEM reposição:

$$
\hat{\theta}=\frac{\sum_{i=1}^{f} t_{i}+(n-f) \cdot T}{f}
$$

Onde:

$n$ : Tamanho da amostra;

T: Tempo de teste estabelecido;

$f$ : Número total de falhas;

$t_{i}$ : Tempo da i-ésima falha;

- Censura tipo II, ensaio COM reposição:

$$
\hat{\theta}=\frac{n \cdot t_{i}}{f}
$$

Onde:

$n$ : Tamanho da amostra;

$f$ : Número total de falhas;

$t_{i}$ : Tempo da i-ésima falha; 
- Censura tipo II, ensaio SEM reposição:

$$
\hat{\theta}=\frac{\sum_{i=1}^{f} t_{i}+(n-f) \cdot t_{u}}{f}
$$

Onde:

$n$ : Tamanho da amostra;

$f$ : Número total de falhas;

$t_{i}$ : Tempo da i-ésima falha;

$t_{u}$ : Tempo da última falha;

- Censura múltipla, ensaio SEM reposição:

Nesse caso, além das $f$ unidades que falharem e não forem repostas, outras $r$ unidades foram descartadas do teste por uma razão qualquer.

$$
\hat{\theta}=\frac{\sum_{i=1}^{f} t_{i}+\sum_{j=1}^{r} t_{j}+(n-f-r) \cdot t^{*}}{f}
$$

Onde:

$n$ : Tamanho da amostra;

f: Número total de falhas;

$r$ : Unidades descartadas;

$t_{i}$ : Tempo da i-ésima falha;

$t_{j}$ : Tempo de operação até o descarte;

$t^{*}$ : Tempo de teste estabelecido (se do tipo I) ou tempo da última falha (se do tipo II); 
4.2.4.5 Estimação por intervalo de confiança

Os limites de confiança definem um intervalo de confiança em torno da estimativa por ponto, o qual inclui o verdadeiro valor do parâmetro que está sendo estimado com uma certa probabilidade, o nível de confiança.

O intervalo de confiança será mais estreito quanto maior o tempo acumulado de ensaio e o número de falhas e também quanto menor o nível de confiança desejado.

O intervalo de confiança pode ser unilateral ou bilateral. No caso do intervalo de confiança unilateral é dado o limite de confiança superior ou inferior. No caso do intervalo bilateral, são dados os dois limites. As expressões para estes intervalos, listados na seqüência do texto, são apresentadas nas referências (18) e (19).

- Censura Tipo I:

Para um ensaio censurado do Tipo I, o intervalo de confiança BILATERAL para a estimativa do $\operatorname{MTBF}(\hat{\theta})$ da população é:

$$
P\left(\frac{2 \cdot T}{\chi_{\left(\frac{\alpha}{2}\right),(2 \cdot f+2)}^{2}} \leq \hat{\theta} \leq \frac{2 \cdot T}{\chi_{\left(1-\frac{\alpha}{2}\right),(2 \cdot f)}^{2}}\right)=1-\alpha=N C
$$

Onde:

$T$ : Tempo total acumulado de operação dos itens;

f: Número de falhas;

NC: Nível de confiança, entre 0 e 1;

$\chi^{2}$ : Distribuição Qui-quadrado;

Para um ensaio censurado do Tipo I, o intervalo de confiança UNILATERAL para a estimativa do $\operatorname{MTBF}(\hat{\theta})$ da população é:

$$
P\left(\frac{2 \cdot T}{\chi_{(\alpha),(2 \cdot f+2)}^{2}} \leq \hat{\theta}\right)=1-\alpha=N C
$$


Onde:

T: Tempo total acumulado de operação dos itens;

f: Número de falhas;

NC: Nível de confiança, entre 0 e 1 ;

$\chi^{2}$ : Distribuição Qui-quadrado;

- Censura Tipo II:

Para um ensaio censurado do Tipo II, o intervalo de confiança BILATERAL para a estimativa do $\operatorname{MTBF}(\hat{\theta})$ da população é:

$$
P\left(\frac{2 \cdot T}{\chi_{\left(\frac{\alpha}{2}\right),(2 \cdot f)}^{2}} \leq \hat{\theta} \leq \frac{2 \cdot T}{\chi_{\left(1-\frac{\alpha}{2}\right),(2 \cdot f)}^{2}}\right)=1-\alpha=N C
$$

Onde:

T: Tempo total acumulado de operação dos itens;

$f$ : Número de falhas;

NC: Nível de confiança, entre 0 e 1;

$\chi^{2}$ : Distribuição Qui-quadrado;

Para um ensaio censurado do Tipo II, o intervalo de confiança UNILATERAL para a estimativa do $\operatorname{MTBF}(\hat{\theta})$ da população é:

$$
P\left(\frac{2 \cdot T}{\chi_{(\alpha),(2 \cdot f)}^{2}} \leq \hat{\theta}\right)=1-\alpha=N C
$$

Onde:

$T$ : Tempo total acumulado de operação dos itens;

f: Número de falhas;

NC: Nível de confiança, entre 0 e 1;

$\chi^{2}$ : Distribuição Qui-quadrado; 


\subsubsection{Predição da confiabilidade de sistemas redundantes}

Um sistema redundante geralmente apresenta confiabilidade e disponibilidade maiores que os sistemas em série. As principais configurações de redundância são, (26):

- Paralelo: geralmente feita de itens idênticos e independentes uns dos outros;

- $\mathrm{k}$ de n: pelo menos "k" itens de " $\mathrm{n}$ " devem funcionar satisfatoriamente;

- Redundância passiva: itens são dispostos nominalmente em paralelo, porém só entram em operação após a ocorrência de uma falha.

- Redes: Arranjos mais elaborados que simples configurações em paralelo ou k de $n$;

Ver item 4.3 para mais detalhes sobre sistemas redundantes e as equações dos diversos arranjos.

\subsection{DIAGRAMA DE BLOCOS}

Nos itens anteriores foi discutida a abordagem de análise da confiabilidade de cada item dos sistemas individualmente. Durante o projeto, é importante estimar a confiabilidade final de um sistema completo contendo vários itens.

O modelamento da confiabilidade de um sistema através de diagramas de blocos permite que seja calculada a confiabilidade do sistema com base nas confiabilidades individuais dos itens que o compõem.

Os diagramas de blocos de confiabilidade não necessariamente representam as configurações físicas, elétricas ou funcionais dos componentes, equipamentos ou módulos. Trata-se de uma representação gráfica do interrelacionamento dos itens do ponto de vista da confiabilidade global do sistema. Pode 
também ser interpretado como um diagrama de fluxo, da entrada para a saída do sistema, onde cada elemento do sistema é representado por um bloco, (18) e (25).

A simbologia empregada no uso de diagramas de bloco de confiabilidade é descrita na norma IEC 61078 (27).

\subsubsection{Sistema em série}

O sistema em série pode ser entendido como um sistema que não possui redundância, ou seja, cada elemento do sistema deve operar para que o sistema opere adequadamente. Isso ocorre nos elementos que não são tolerantes a falhas e, portanto, a falha de qualquer item leva à falha do sistema. A confiabilidade do sistema é menor que a confiabilidade do item menos confiável.

Isso faz com que o sistema em série seja a abordagem mais conservadora, em termos de confiabilidade, quanto ao modelamento de um sistema. E justamente por ser a abordagem mais conservadora, as primeiras predições de confiabilidade efetuadas no início do projeto seguem esse modelo.

As equações listadas na seqüência deste texto foram obtidas das referências (13), (18), (28), (29) e (30).

- Representação

A representação gráfica de um sistema em série é feita conforme ilustrado na Figura 17.

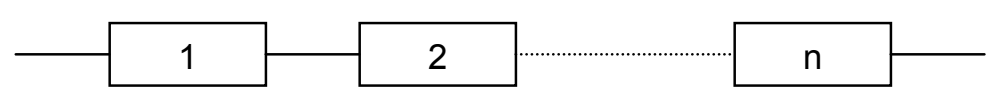

Figura 17: Sistema em série

- Cálculo da confiabilidade

A confiabilidade de um sistema em série é a probabilidade de todos os seus elementos operarem sem falhas, ou seja, o produto das confiabilidades dos itens que compõem o sistema. 


$$
R_{s}(t)=R_{1}(t) \cdot R_{2}(t) \cdot \ldots \cdot R_{n}(t)
$$

Genericamente:

$$
R_{s}(t)=\prod_{i=1}^{n} R_{i}(t)
$$

Quando os componentes forem idênticos:

$$
R_{s}(t)=[R(t)]^{n}
$$

- Cálculo da taxa de falhas e/ou MTBF

O MTBF de um sistema $\left(M T B F_{s}\right)$ é obtido através da integração da função confiabilidade:

$$
\operatorname{MTBF}_{s}=\int_{0}^{\infty} R(t) d t
$$

No caso particular de itens independentes e com distribuição exponencial dos tempos de falha, a taxa de falhas do sistema pode ser calculada através da somatória das taxas de falha dos itens:

$$
\lambda_{s}=\sum_{i=1}^{n} \lambda_{i}
$$

Quando os componentes forem idênticos:

$$
\lambda_{s}=n \cdot \lambda
$$

Em ambos os casos:

$$
\mathrm{MTBF}_{\mathrm{s}}=\frac{1}{\lambda_{\mathrm{s}}}
$$




\subsubsection{Sistema em paralelo}

No sistema em paralelo, basta que pelo menos um de seus elementos funcione para que o sistema opere adequadamente. A confiabilidade do sistema é maior que a confiabilidade do item mais confiável.

As equações listadas na seqüência deste texto foram obtidas nas referências (13), (18), (26), (28), (29) e (30).

- Representação

A representação gráfica de um sistema em paralelo é feita conforme ilustrado na Figura 18.

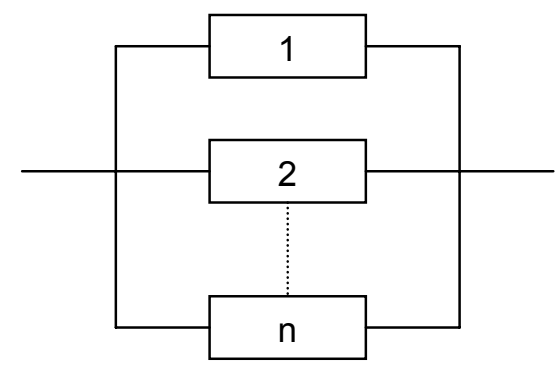

Figura 18: Sistema em paralelo

- Cálculo da confiabilidade

A confiabilidade de um sistema em paralelo é a probabilidade de que ao menos um de seus elementos opere sem falhas, ou seja, o complemento do produto das probabilidades de falha dos itens que compõem o sistema.

$$
R_{s}(t)=1-\left[\left(1-R_{1}(t)\right) \cdot\left(1-R_{2}(t)\right) \cdot \ldots \cdot\left(1-R_{n}(t)\right)\right]
$$

Genericamente:

$$
R_{s}(t)=1-\prod_{i=1}^{n}\left(1-R_{i}(t)\right)
$$

Quando os componentes forem idênticos:

$$
R_{s}(t)=1-[1-R(t)]^{n}
$$


- Cálculo da taxa de falhas e/ou MTBF

O MTBF de um sistema $\left(M T B F_{s}\right)$ é obtido através da integração da função confiabilidade:

$$
M T B F_{s}=\int_{0}^{\infty} R(t) d t
$$

No caso particular de itens idênticos, independentes e com distribuição exponencial de confiabilidade, o MTBF do sistema pode ser calculado através de:

$$
\text { MTBF }_{s}=\int_{0}^{\infty}\left[1-\left(1-e^{-\lambda \cdot t}\right)^{n}\right] d t \quad, \lambda>0
$$

Dessa forma, o MTBF de uma configuração redundante em paralelo de 2 itens idênticos e independentes, com taxa de falhas constante, seria igual a:

$$
\begin{aligned}
& \operatorname{MTBF}_{s}=\int_{0}^{\infty}\left[1-\left(1-e^{-\lambda \cdot t}\right)^{2}\right] d t \\
& M_{T} F_{s}=\frac{3}{2 \cdot \lambda}=\frac{3}{2} \cdot M T B F_{\text {item }}
\end{aligned}
$$

ou seja, 1,5 vez maior que o MTBF de cada item, se considerado individualmente. Uma forma prática de se efetuar esse cálculo é utilizar os resultados da Tabela 15 como fatores multiplicativos a serem aplicados sobre o MTBF dos itens individualmente, em função do número de itens em paralelo.

Tabela 15: MTBF no arranjo em paralelo

\begin{tabular}{|c|c|c|}
\hline Itens em paralelo & MTBF resultante & Fator multiplicativo \\
\hline 1 & $1 \times \mathrm{MTBF}_{\text {item }}$ & 1,000 \\
\hline 2 & $3 / 2 \times \mathrm{MTBF}_{\text {item }}$ & 1,500 \\
\hline 3 & $11 / 6 \times \mathrm{MTBF}_{\text {item }}$ & 1,833 \\
\hline 4 & $25 / 12 \times \mathrm{MTBF}_{\text {item }}$ & 2,083 \\
\hline 5 & $137 / 60 \times \mathrm{MTBF}_{\text {item }}$ & 2,283 \\
\hline 6 & $49 / 20 \times \mathrm{MTBF}_{\text {item }}$ & 2,450 \\
\hline 7 & $363 / 140 \times \mathrm{MTBF}_{\text {item }}$ & 2,593 \\
\hline 8 & $761 / 280 \times \mathrm{MTBF}_{\text {item }}$ & 2,718 \\
\hline
\end{tabular}




\subsubsection{Sistema $\mathrm{k}$ de $\mathrm{n}$}

O sistema $\mathrm{k}$ de $\mathrm{n}$ é o caso genérico dos anteriores. Nele é necessário que "k" entre os " $\mathrm{n}$ " itens estejam funcionando para que o sistema opere adequadamente. Os sistemas em série e em paralelo são casos particulares do sistema $\mathrm{k} / \mathrm{n}$, em que $\mathrm{k}=\mathrm{n}$ e $\mathrm{k}=1$, respectivamente.

As equações listadas na seqüência deste texto foram obtidas nas referências (13), (18) e (26).

- Representação

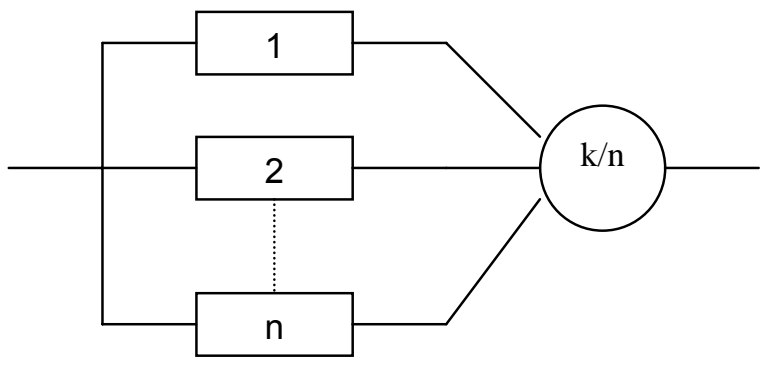

Figura 19: Sistema k de $\mathbf{n}$

- Cálculo da confiabilidade

Para o caso de n elementos idênticos e independentes, pode-se aplicar a equação binomial para calcular a confiabilidade do sistema, ou seja, a probabilidade de que pelo menos $\mathrm{k}$ entre os $\mathrm{n}$ elementos operem sem falhas.

$$
R_{s}(t)=\sum_{i=k}^{n}\left[\left(\begin{array}{l}
n \\
i
\end{array}\right) \cdot R(t)^{i} \cdot(1-R(t))^{n-i}\right]
$$

sendo que:

$$
\left(\begin{array}{l}
n \\
i
\end{array}\right)=\frac{n !}{(n-i) ! i !}
$$


Caso as confiabilidades dos itens sejam diferentes, então o cálculo deve ser feito de acordo com o teorema de Bayes. Nesse caso é mais fácil proceder com o cálculo utilizando o método da tabela verdade. Ver itens 4.3 .6 e 4.6 para mais detalhes.

- Cálculo da taxa de falhas e/ou MTBF

O MTBF de um sistema $\left(M T B F_{s}\right)$ é obtido através da integração da função confiabilidade:

$$
M T B F_{s}=\int_{0}^{\infty} R(t) d t
$$

No caso particular de itens idênticos, independentes e com distribuição exponencial de confiabilidade, o MTBF do sistema pode ser calculado através de:

$$
\operatorname{MTBF}_{s}=\frac{1}{\lambda} \cdot \sum_{i=k}^{n}\left(\frac{1}{i}\right)
$$

Da mesma maneira, um cálculo prático do MTBF de uma configuração redundante do tipo k de $\mathrm{n}$ é apresentado na Tabela 16.

Tabela 16: MTBF no arranjo $k$ de $n$

\begin{tabular}{|c|c|c|c|}
\hline \multicolumn{2}{|l|}{ Itens redundantes } & \multirow{2}{*}{ MTBF resultante } & \multirow{2}{*}{ Fator multiplicativo } \\
\hline k & $\mathbf{n}$ & & \\
\hline 1 & 2 & $3 / 2 \times \mathrm{MTBF}_{\text {item }}$ & 1,5 \\
\hline 1 & 3 & $11 / 6 \times \mathrm{MTBF}_{\text {item }}$ & 1,833 \\
\hline 1 & 4 & $25 / 12 \times \mathrm{MTBF}_{\text {item }}$ & 2,083 \\
\hline 1 & 5 & $137 / 60 \times \mathrm{MTBF}_{\text {item }}$ & 2,283 \\
\hline 1 & 6 & $49 / 20 \times \mathrm{MTBF}_{\text {item }}$ & 2,450 \\
\hline 2 & 3 & $5 / 6 \times \mathrm{MTBF}_{\text {item }}$ & 0,833 \\
\hline 2 & 4 & $13 / 12 \times \mathrm{MTBF}_{\text {item }}$ & 1,083 \\
\hline 2 & 5 & $77 / 60 \times \mathrm{MTBF}_{\text {item }}$ & 1,283 \\
\hline 2 & 6 & $29 / 20 \times \mathrm{MTBF}_{\text {item }}$ & 1,450 \\
\hline 3 & 4 & $7 / 12 \times \mathrm{MTBF}_{\text {item }}$ & 0,583 \\
\hline 3 & 5 & $47 / 60 \times \mathrm{MTBF}_{\text {item }}$ & 0,783 \\
\hline 3 & 6 & $19 / 20 \times \mathrm{MTBF}_{\text {item }}$ & 0,950 \\
\hline 4 & 5 & $9 / 20 \times \mathrm{MTBF}_{\text {item }}$ & 0,450 \\
\hline 4 & 6 & $37 / 60 \times \mathrm{MTBF}_{\text {item }}$ & 0,617 \\
\hline 5 & 6 & $11 / 30 \times \mathrm{MTBF}_{\text {item }}$ & 0,367 \\
\hline
\end{tabular}




\subsubsection{Sistema em paralelo com cobertura de falhas}

Cobertura de falhas é a medida da habilidade do sistema em se recuperar dada a ocorrência de falhas. O que caracteriza a recuperação de falha é a continuação do desempenho da função principal do sistema, integral ou parcialmente, após a ocorrência de uma falha.

Isso pode ser feito por uma simples re-configuração automática do sistema ou ainda pela recuperação de informações evitando-se que dados sejam corrompidos. Em função disso, esta técnica é mais usada em sistemas e equipamentos digitais, ainda que os conceitos envolvidos sejam válidos para outras áreas, (28), (29) e (31).

- Representação

A representação gráfica de um sistema em paralelo com cobertura de falhas é a mesma adotada para os sistemas em paralelo convencional, conforme Figura 18.

- Cálculo da confiabilidade

A confiabilidade de um sistema de dois itens em paralelo com cobertura de falhas é a probabilidade de que um de seus elementos opere sem falhas ou que, em caso de falha do primeiro, essa falha seja detectada pelo segundo e que o mesmo opere sem falhas.

Sendo "c" a cobertura da falha, e que corresponde a probabilidade de detecção de falha do módulo 1 em um sistema de dois módulos, a confiabilidade pode ser expressa por:

$$
R_{s}(t)=R_{1}(t)+c_{1} \cdot R_{2}(t) \cdot\left(1-R_{1}(t)\right)
$$

Genericamente, quando os componentes forem idênticos:

$$
R_{s}(t)=R(t) \cdot \sum_{i=0}^{n-1} c^{i} \cdot(1-R(t))^{i}
$$


- Cálculo da taxa de falhas e/ou MTBF

O MTBF de um sistema $\left(M T B F_{s}\right)$ é obtido através da integração da função confiabilidade:

$$
\operatorname{MTBF}_{s}=\int_{0}^{\infty} R(t) d t
$$

No caso particular de itens idênticos, independentes e com distribuição exponencial de confiabilidade, o MTBF do sistema pode ser calculado através de:

$$
\mathrm{MTBF}_{\mathrm{s}}=\frac{1}{\lambda \cdot c} \cdot \sum_{i=1}^{n} \frac{c^{i}}{i}
$$

\subsubsection{Redundância passiva}

Neste caso apenas um elemento executa a função requerida, enquanto $n$ subsistemas estão desativados, porém prontos para entrar em operação. $O(s)$ elemento(s) redundante(s) somente entra $(m)$ em operação no caso de falha do primeiro. A redundância passiva implica no uso de um dispositivo que detecte a ocorrência da falha e realize a operação de desativar o elemento em falha e colocar em funcionamento os elementos redundantes.

As equações listadas na seqüência deste texto foram obtidas nas referências (12), (18), (19), (30) e (32).

- Representação

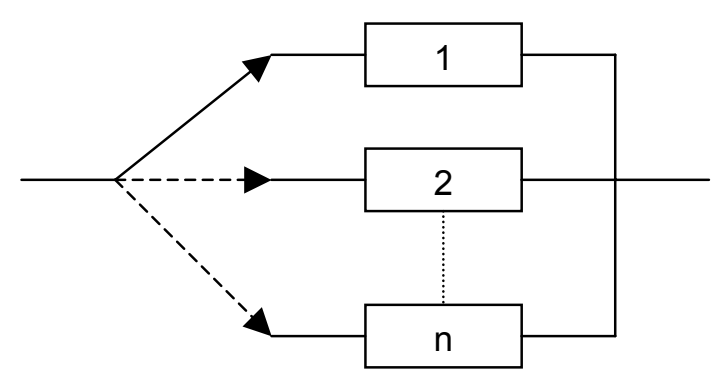

Figura 20: Redundância passiva com chaveamento perfeito 


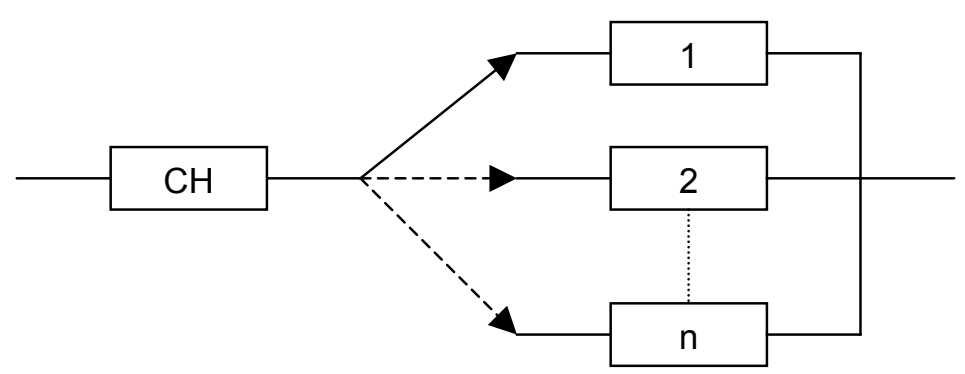

Figura 21: Redundância passiva com chaveamento imperfeito

- Cálculo da confiabilidade

No caso de chaveamento perfeito com " $k$ " itens em funcionamento simultâneo dentre " $n$ " itens idênticos com distribuição exponencial de confiabilidade:

$$
R_{s}(t)=e^{-k \cdot \lambda \cdot t} \cdot \sum_{i=0}^{n-k} \frac{(k \cdot \lambda \cdot t)^{i}}{i !}
$$

Quando k=1 e $n=2$ :

$$
R_{s}(t)=e^{-\lambda \cdot t} \cdot(1+\lambda \cdot t)
$$

Para o caso de chaveamento imperfeito com " $k$ " itens em funcionamento simultâneo dentre " $n$ " itens idênticos com distribuição exponencial de confiabilidade, e sendo $R_{c h}$ a confiabilidade do chaveamento:

$$
R_{s}(t)=e^{-k \cdot \lambda \cdot t} \cdot \sum_{i=0}^{n-k} \frac{\left(k \cdot \lambda \cdot t \cdot R_{c h}\right)^{i}}{i !}
$$

Quando k=1 e $n=2$ :

$$
R_{s}(t)=e^{-\lambda \cdot t} \cdot\left(1+\lambda \cdot t \cdot R_{c h}\right)
$$

- Cálculo da taxa de falhas e/ou MTBF

O MTBF de um sistema $\left(M T B F_{s}\right)$ é obtido através da integração da função confiabilidade: 


$$
\mathrm{MTBF}_{s}=\int_{0}^{\infty} R(t) d t
$$

No caso particular de itens idênticos, independentes, com distribuição exponencial de confiabilidade e chaveamento perfeito, o MTBF do sistema pode ser calculado através de:

$$
M T B F_{s}=\frac{n}{\lambda}
$$

\subsubsection{Sistemas complexos}

Para determinar a confiabilidade de sistemas complexos, basta resolvêlos parte a parte e combinar adequadamente as confiabilidades dos elementos considerados com os modelos apresentados até então.

Entretanto, há casos de maior complexidade onde esses modelos não poderão ser aplicados. Nesse caso pode-se empregar o teorema de Bayes. Para isso, é necessário que se escolha um componente estratégico na configuração de confiabilidade do sistema, de forma que sua eliminação permita o funcionamento, mesmo que degradado, do sistema, (18), (19) e (30).

O teorema de Bayes pode ser enunciado da seguinte forma:

"A probabilidade de falha do sistema é a probabilidade do sistema falhar dado que o componente escolhido está funcional, multiplicado pela confiabilidade do componente, mais a probabilidade do sistema falhar dado que o componente escolhido está em falha, multiplicado pela probabilidade de falha do componente".

Por exemplo, no sistema complexo da Figura 22, escolhe-se o componente "C" como elemento estratégico. 


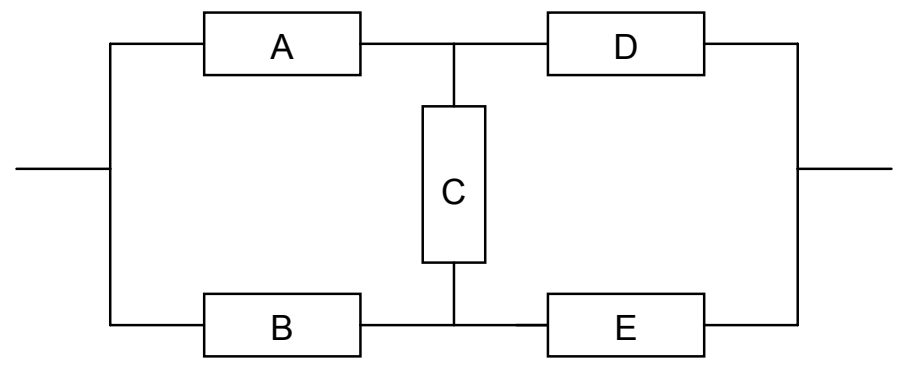

Figura 22: Exemplo de sistema complexo

Situação 1: A confiabilidade do sistema é dada pela probabilidade do sistema operar dado que o componente " $\mathrm{C}$ " falha, ou seja, a resolução do diagrama da Figura 23:

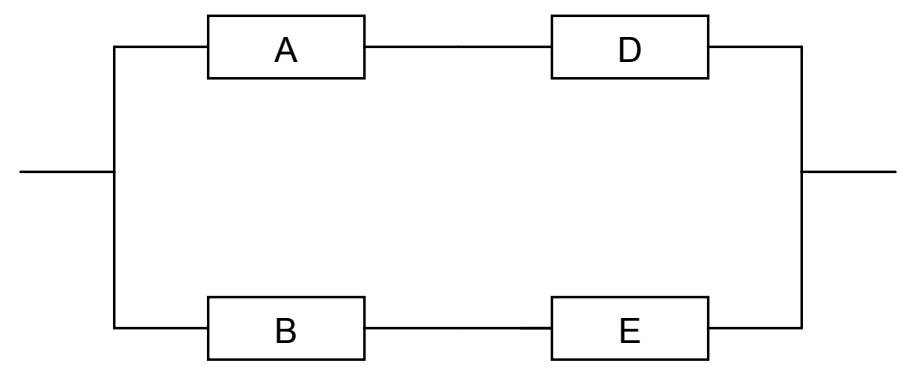

Figura 23: Situação 1

Situação 2: A confiabilidade do sistema é dada pela probabilidade do sistema operar dado que o componente "C" opera, ou seja, a resolução do diagrama da Figura 24:

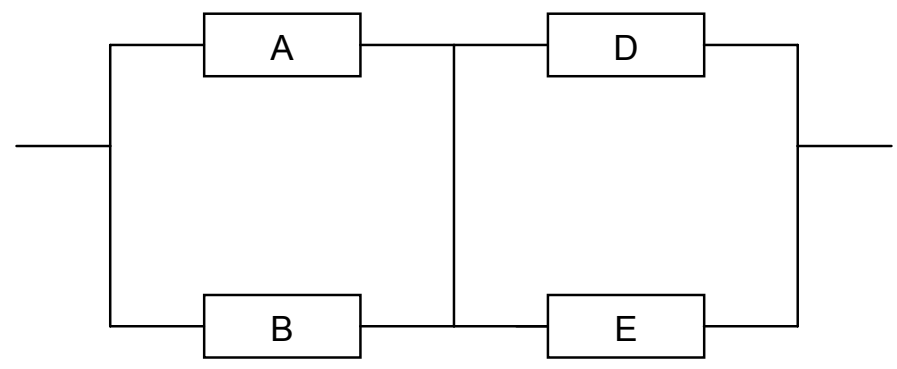

Figura 24: Situação 2

Dessa forma a confiabilidade do sistema como um todo é a soma das confiabilidades obtidas nas situações 1 e 2 . 


\subsubsection{Sistemas com carga distribuída}

Os sistemas com carga distribuída são sistemas em paralelo com itens idênticos onde ambos estão ativos durante a operação. A diferença nesse tipo de sistema é que a falha de um dos itens faz com que o item sobrevivente suporte toda a carga que era antes distribuída. Isso faz com que a taxa de falha do item sobrevivente aumente devido a essa distribuição de carga, (19) e (30).

- Cálculo da confiabilidade

A confiabilidade de sistemas de dois itens com carga distribuída é dada por:

$$
R(t)=e^{-2 \cdot \lambda_{I} \cdot t}+\frac{2 \cdot \lambda_{I}}{\left(2 \cdot \lambda_{I}-\lambda_{I I}\right)} \cdot\left(e^{-\lambda_{I I} \cdot t}-e^{-2 \cdot \lambda_{I} \cdot t}\right)
$$

Onde:

$\lambda_{\text {I }}$ : Taxa de falha de cada item quando ambos estão funcionando;

$\lambda_{11}$ : Taxa de falha do item sobrevivente, após a falha de um deles.

Quando $2 \lambda_{I}=\lambda_{I I}$, o denominador fica nulo, causando uma função indeterminada. Nesse caso a equação 4.52 deve ser modificada para:

$$
R(t)=e^{-2 \cdot \lambda_{I} \cdot t}+2 \cdot \lambda_{I} \cdot t \cdot e^{-\lambda_{I I} \cdot t}
$$

\subsubsection{Falhas de modo comum}

Falhas de modo comum são falhas que podem afetar mais de um elemento de um sistema redundante. A identificação e a avaliação das falhas de modo comum é muito importante uma vez que, geralmente, possuem confiabilidade menor que a do sistema redundante, quando considerados apenas seus elementos principais. É importante também eliminar as possíveis fontes de falha de modo comum ou, pelo menos, reduzir suas probabilidades de ocorrência, (13). 
No caso do modelamento por diagrama de blocos, as falhas de modo comum podem ser representadas por blocos virtuais em série com o trecho redundante do sistema. Ver 4.3.1.

Alguns exemplos de fontes potenciais de falhas de modo comum:

- Sistemas de chaveamento para ativar elementos redundantes passivos;

- Sistemas de sensoriamento para detecção de falhas;

- Sistemas indicadores de avisos e alertas de falha;

- Falhas de alimentação elétrica ou pneumática;

- Interferências eletromagnéticas;

- Condições ambientais como temperatura, umidade, etc;

- Vibrações;

- Falhas de software;

- Erros humanos como ações indevidas ou deficientes de manutenção e operação;

\subsubsection{Falhas dependentes}

Falhas dependentes são aquelas provocadas pela ocorrência de uma outra falha no próprio elemento ou, geralmente, em outro elemento do sistema. A ocorrência da primeira falha faz com que as taxas de falha dos demais itens do sistema sejam alteradas, (13).

No caso do modelamento de falhas dependentes, é necessário que se tenha conhecimento prévio e detalhado dos mecanismos de falha dos itens que resultam em falhas dependentes. Na representação por diagrama de blocos, a maneira mais prática e eficiente é elaborar outro diagrama, baseado no original, considerando a existência da primeira falha e com as taxas de falha dos demais itens devidamente modificadas em função da falha existente. 


\subsection{FMEA/FMECA}

Análise de Modos de Falha e seus Efeitos (FMEA) é um procedimento de análise que consiste em avaliar cada item do sistema, considerando como esse item pode falhar e de que forma essas falhas afetam a operação do sistema. Trata-se de uma análise estruturada, lógica e sistemática. A identificação dos possíveis modos de falha dos componentes e a determinação dos seus efeitos na operação do sistema ajudam o analista a desenvolver um entendimento mais aprofundado da integração entre os componentes do sistema. Isso propicia a melhoria do projeto através de mudanças para eliminar ou mitigar efeitos de falha indesejados.

Algumas normas como a MIL-STD-1629 (33), a IEC-60812 (34) e a J1739 (35) definem essa metodologia de análise em detalhes.

A diferença entre FMEA e FMECA é que o segundo inclui também uma avaliação da probabilidade de ocorrência do modo de falha e uma classificação quanto à severidade.

O primeiro passo é a decomposição do sistema em sua estrutura analítica possibilitando uma visualização detalhada do sistema e de que forma seus componentes estão agrupados em sub-sistemas, módulos, equipamentos, etc. Essa decomposição do sistema em sua estrutura analítica, os diagramas de bloco e esquemas funcionais auxiliam na elaboração da análise.

O próximo passo consiste em se identificar os modos de falha, ou seja, as formas pelas quais cada componente pode falhar. Para cada modo de falha são determinados os efeitos que ele exerce sobre o sistema. Os efeitos são determinados em pelo menos 3 níveis distintos - no equipamento ou no módulo onde ocorreu a falha, no sub-sistema ao qual o componente pertence, e no funcionamento do próprio trem. Além disso, pode-se ainda determinar as conseqüências dos modos de falha para a segurança operacional.

A Figura 25 ilustra algumas atividades típicas de FMECA relacionadas com o ciclo de vida de um projeto. 


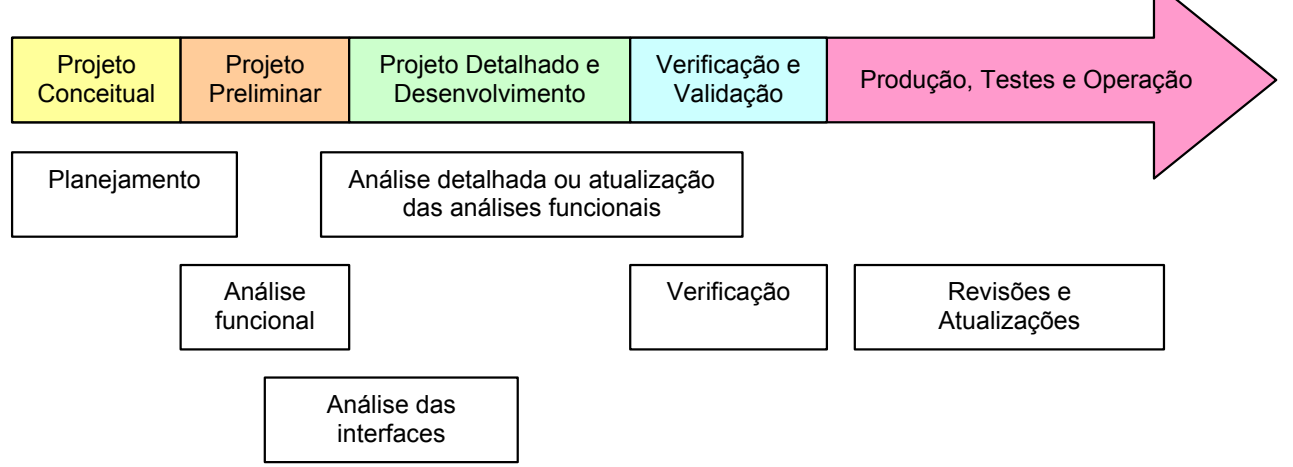

Figura 25: Atividades típicas de FMECA em um projeto

\subsubsection{Metodologia}

A metodologia de FMECA é baseada em uma abordagem de análise hierárquica e indutiva. $\mathrm{O}$ analista deve determinar como cada modo de falha possível afeta a operação e, quando for o caso, a segurança do sistema. O procedimento básico consiste de:

- Identificar todos os modos de falha dos itens;

- Determinar o efeito para cada modo de falha, localmente (equipamento, módulo), no próprio sistema, e na operação trem e/ou dos demais sistemas;

- Determinar também, quando for o caso, o efeito na segurança operacional;

- Classificar a falha de acordo com seus efeitos na operação do sistema e no cumprimento da missão;

- Determinar a probabilidade de ocorrência da falha;

- Identificar como o modo de falha pode ser detectado (isso é particularmente importante para sistemas tolerantes a falha);

- Se necessário, identificar as ações de gerenciamento para modificação de projeto para eliminar o modo de falha ou, se não for possível, mitigar ou mesmo compensar seus efeitos; 
As análises de FMECA são registradas através de planilhas específicas as quais são organizadas de forma a facilitar a leitura dos campos além de proporcionar rastreabilidade aos documentos utilizados para análise. Geralmente essas planilhas incluem:

- Identificação e descrição do componente a ser analisado;

- Função do componente;

- Modos de falha do componente;

- Causa da falha;

- Os efeitos no equipamento, no sistema, no trem (funcionais) e na segurança do trem;

- Classificação da severidade da falha e probabilidade de ocorrência;

- Modo de detecção da falha;

- Modo de gerenciamento da falha;

- Notas gerais;

$\mathrm{Na}$ FMECA, as falhas são geralmente analisadas uma a uma como se fosse a única falha do sistema. Todavia, quando a falha é latente ou não é detectável, ou ainda se o item for redundante, a análise pode ser estendida para se determinar os efeitos de outra falha que, combinada com a primeira, possa resultar em uma situação indesejável. Todas as falhas simples constatadas durante a análise e que tenham conseqüências indesejáveis devem ser destacadas na planilha para que ações apropriadas sejam tomadas, (36).

\subsubsection{O processo de FMECA}

Durante as fases conceitual e preliminar do projeto, a FMECA serve principalmente para verificar a adequação dos requisitos do sistema. Durante a fase do projeto detalhado, é usado para verificar o cumprimento dos requisitos. Durante as fases de verificação e validação, ajuda a manter a integridade do sistema no controle de alterações de projeto. Por fim, durante a fase de produção e operação, 
serve como guia para capturar dados de campo, no desenvolvimento de procedimentos e como suporte à manutenção, (36).

\subsubsection{Planejamento}

Deve-se planejar cuidadosamente o escopo da análise para atender aos requisitos do programa e proporcionar um processo que identifique as deficiências do projeto de forma que as ações corretivas ou mitigatórias possam ser tomadas a tempo. Um planejamento adequado deve contemplar os requisitos do sistema, incluindo os modos operacionais, funções, níveis de desempenho desejados, condições ambientais, requisitos regulatórios e de segurança, (36).

- Análise das bibliotecas

Durante o processo de planejamento, é importante definir as bibliotecas com as descrições dos modos de falha e conseqüências. Tais bibliotecas ajudam a controlar o processo de análise e a assegurar a consistência da terminologia, tipos de modo de falha considerados, etc. entre todos os analistas (incluindo aqueles que venham a entrar no projeto posteriormente). Também proporcionam um direcionamento quanto ao nível de detalhe da análise e, ao mesmo tempo, garante uma uniformidade na documentação gerada. As seguintes bibliotecas devem ser desenvolvidas para elaboração eficiente de FMECAS:

- Modos de falha para cada tipo de componente. Para componentes eletrônicos, podem ser usadas tabelas, tais como da Figura 26, extraída da norma MIL-HDBK-338B (37). Para equipamentos completos (caixa-preta) e outros tipos de componente, deve-se definir os modos de falha funcionais e de interface.

- Descrição dos modos operacionais;

- Efeitos que cada modo de falha provoca no sistema e no trem;

- Tabela de severidade;

- Tabela de detecção de falha; 


\begin{tabular}{|l|l|c|}
\hline DEVICE TYPE & FAllURE MODE & MODE PROBABILITY $(\alpha)$ \\
\hline Diode, SCR & Short & .98 \\
& Open & .02 \\
\hline Diode, Small Signal & Parameter Change & .58 \\
& Open & .24 \\
& Short & .18 \\
\hline Diode, Thyristor & Failed Off & .45 \\
& Short & .40 \\
& Open & .10 \\
& Failed On & .05 \\
\hline Diode, Triac & Failed Off & .90 \\
& Failed On & .10 \\
\hline Diode, Zener, Voltage & Parameter Change & .69 \\
Reference & Open & .18 \\
& Short & .13 \\
\hline Diode, Zener, Voltage & Open & .45 \\
Regulator & Parameter Change & .35 \\
& Short & .20 \\
\hline Electric Motor, AC & Winding Failure & .31 \\
& Bearing Failure & .28 \\
& Fails to Run, After Start & .23 \\
& Fails to Start & .18 \\
\hline Fuse & Fails to Open & .49 \\
& Slow to Open & .43 \\
& Premature Open & .08 \\
\hline
\end{tabular}

Figura 26: Exemplo de tabela de modos de falha

- Análise dos defeitos funcionais

A análise dos defeitos funcionais é realizada na fase conceitual do projeto para verificar se os recursos necessários para contornar os riscos de projeto são suficientes.

- Análise dos defeitos de interface

A análise dos defeitos de interface é focada na determinação das características de falha nas interconexões entre sub-sistemas, tais como cabos e conectores, tubulação pneumática, conexões mecânicas, etc.

- Análise detalhada dos defeitos

A análise detalhada dos defeitos é usada para verificar se o projeto cumpre os requisitos do sistema para:

- Falhas simples que possam causar perdas das funções;

- Capacidade de detecção de falhas;

- Isolação de falhas; 


\subsubsection{Priorização}

Um FMECA, mesmo em sistemas de tamanho moderado, geralmente resulta na identificação de centenas de modos de falha potenciais cujos efeitos podem variar de quase imperceptíveis até catastróficos. Em função disso, é necessário priorizar os mais importantes para ações corretivas. A maioria das técnicas de priorização está relacionada com o vetor severidade $\mathrm{x}$ probabilidade, porém algumas consideram também o custo da falha, (36).

\section{5 ÁRVORE DE FALHAS}

A árvore de falhas é uma representação gráfica organizada das condições que contribuem para ocorrência de falhas de um evento definido, chamado de evento topo. A representação é feita de forma que possa ser entendida, analisada e, se necessário, re-arranjada para facilitar a identificação de:

- Fatores que afetam as características de confiabilidade e o desempenho do sistema, como por exemplo, modos de falha, erros de operação, condições ambientais, falhas de software, etc;

- Requisitos ou especificações conflitantes que possam afetar um desempenho confiável do sistema;

- Eventos de modo comum, ou seja, aqueles que afetam mais de um componente do sistema, neutralizando o benefício das redundâncias;

A análise de árvore de falhas é basicamente um método dedutivo que visa identificar as causas ou combinação de causas que possam levar ao evento topo definido. A análise é basicamente qualitativa, porém, dependendo das condições, pode também ser quantitativa.

A discussão do método apresentado na seqüência deste texto é um resumo do conteúdo das referências (12), (19) e (38). 


\subsubsection{Objetivos}

Existem várias razões para se realizar uma análise de árvore de falhas independentemente ou em conjunto com outras análises, como por exemplo:

- Identificação das causas ou combinação de causas que levam ao evento topo;

- Determinação de se a confiabilidade de um sistema em particular atende a um requisito especificado;

- Demonstração de que considerações feitas em outras análises, em relação à independência de sistemas e não-relevâncias de falhas, não são violadas;

- Determinação dos fatores que mais afetam a confiabilidade e, conseqüentemente, os pontos de melhoria do sistema.

- Identificação de eventos de modo comum, que afetam mais de um componente do sistema.

\subsubsection{Aplicação}

A árvore de falhas é particularmente adequada para a análise de sistemas complexos que possuam várias funcionalidades ou sub-sistemas.

De forma a utilizar efetivamente a árvore de falhas como um método de análise de sistemas, o procedimento deve consistir no mínimo dos seguintes passos:

- Definição do escopo de análise;

- Familiarização com o projeto, funções e operação do sistema;

- Definição do evento;

- Construção da árvore de falhas;

- Análise lógica da árvore de falhas;

- Elaboração de relatório com os resultados da análise; 
Para que a análise de árvore de falhas seja conduzida com sucesso é necessário que se tenha um bom conhecimento prévio do sistema. Todavia, alguns sistemas podem ser tão complexos e difíceis de serem analisados que é necessário uma divisão de tarefas entre os envolvidos no projeto.

O desenvolvimento da árvore de falhas começa com a definição do evento topo. O evento topo é a saída da primeira porta lógica, enquanto os eventos de entrada identificam possíveis causas e condições para ocorrência do evento topo. Cada evento de entrada pode ser um evento de saída de outra porta lógica de nível hierárquico inferior na análise, e assim sucessivamente.

\subsubsection{Construção da árvore de falhas}

Os símbolos mais comuns empregados na construção de árvores de falhas estão representados na Tabela 17, baseada na norma IEC 61025 (38).

Tabela 17: Símbolos empregados em FTA (continua)

\begin{tabular}{|c|c|c|}
\hline Símbolo & Descrição & Aplicação \\
\hline & $\begin{array}{c}\text { Bloco de descrição de } \\
\text { evento }\end{array}$ & $\begin{array}{c}\text { Nome ou descrição do evento, código do } \\
\text { evento e a probabilidade de ocorrência } \\
\text { quando necessário) devem ser inseridos } \\
\text { dentro deste símbolo. }\end{array}$ \\
\hline Evento básico & \begin{tabular}{c} 
Evento que não pode ser subdividido \\
\hline
\end{tabular} & $\begin{array}{c}\text { Evento para o qual não foi feita análise } \\
\text { mais detalhada, geralmente quando é } \\
\text { considerado desnecessário ou não se } \\
\text { possui informação suficiente no momento, } \\
\text { deixando o evento para análise futura. }\end{array}$ \\
\hline & $\begin{array}{c}\text { Evento analisado } \\
\text { separadamente }\end{array}$ & $\begin{array}{c}\text { Evento que é analisado em outra árvore de } \\
\text { falha }\end{array}$ \\
\hline
\end{tabular}


Tabela 17: Símbolos empregados em FTA (continuação)

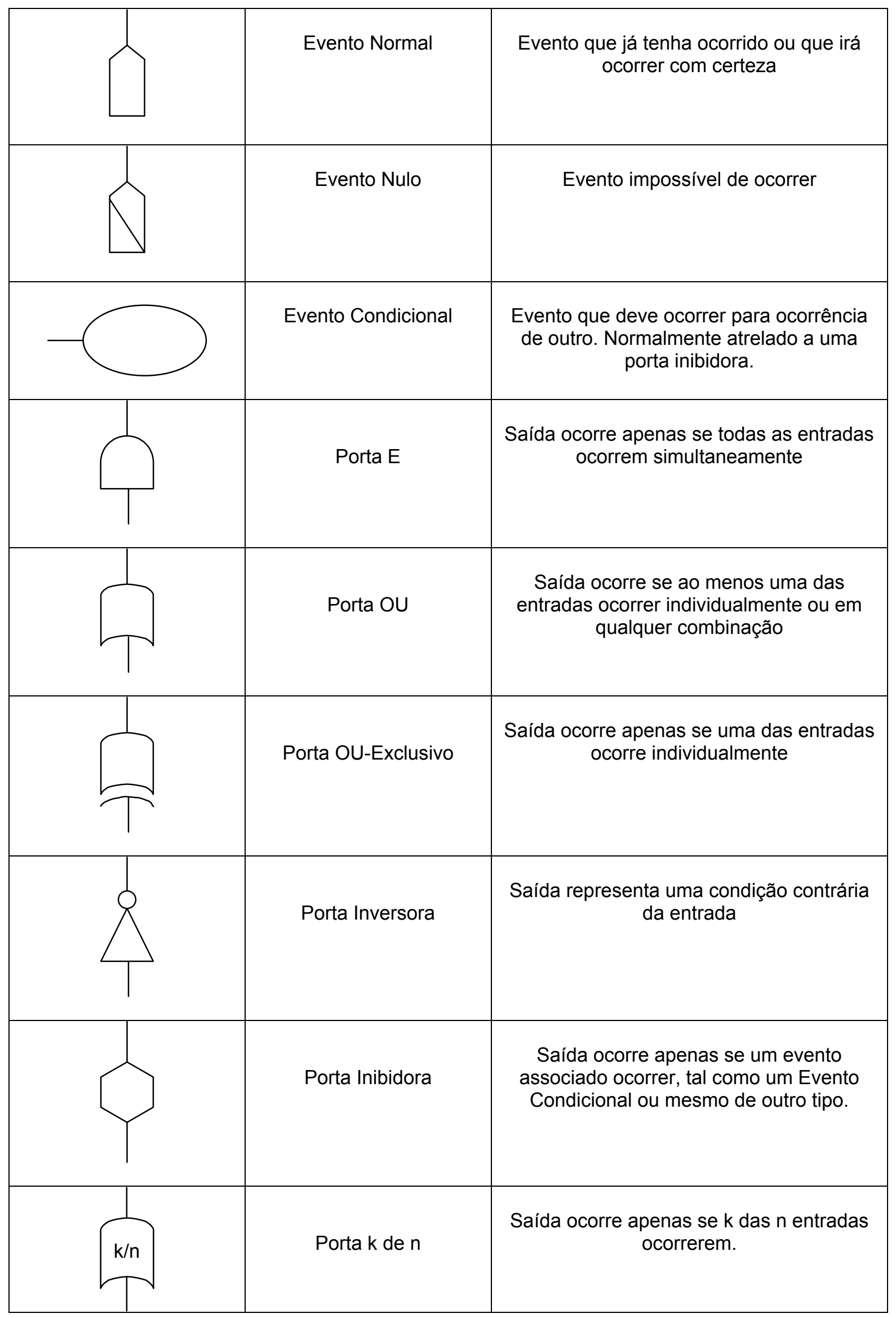


Tabela 17: Símbolos empregados em FTA (conclusão)

\begin{tabular}{|c|c|c|}
\hline & Porta Geral & $\begin{array}{c}\text { Símbolo geral cuja função deve ser definida } \\
\text { dentro do símbolo }\end{array}$ \\
\hline
\end{tabular}

\subsubsection{Avaliação da árvore de falhas}

\subsubsection{Análise lógica}

Três técnicas básicas são usadas para análises lógicas: investigação, redução booleana e determinação dos cortes mínimos.

- Investigação:

É uma análise qualitativa que inclui uma revisão da estrutura da árvore de falhas, identificação de eventos comuns e uma procura por ramificações independentes. Em alguns casos, as informações obtidas com essa investigação, podem ser suficientes para eliminar a necessidade de análises adicionais.

- Redução booleana:

Redução booleana é usada para avaliação dos efeitos de eventos comuns, ou seja, eventos que ocorrem em diferentes ramos, onde a ocorrência do evento topo não depende de uma seqüência temporal de eventos.

- Método dos cortes mínimos:

Corte mínimo é a combinação da menor quantidade de falhas primárias que, se todas ocorrerem simultaneamente, o evento topo também ocorrerá. Pode-se determinar mais de um corte mínimo por sistema. Em geral, isso é feito através da resolução da equação lógica da árvore de falhas. 
4.5.4.2 Análises numéricas

O propósito das análises numéricas é obter uma avaliação quantitativa da probabilidade de ocorrência do evento topo ou de um conjunto de eventos. As análises numéricas também são usadas para complementar as análises lógicas. Para realização dos cálculos probabilísticos, é necessária obtenção de dados de predição da confiabilidade dos componentes.

\subsubsection{Identificação dos elementos}

Cada evento da árvore de falhas deve ser identificado de forma única e que possam ser facilmente referenciados na documentação e localizados quando necessário.

Apenas um evento topo pode ser associado a uma dada árvore de falhas.

Se vários eventos em uma árvore de falhas referem-se a diferentes modos de falha do mesmo item, tais elementos devem ser identificados de forma a distinguí-los. Ao mesmo tempo, deve ficar claro que se trata de diferentes eventos de um mesmo item.

Se um evento ocorre em diferentes pontos de uma mesma árvore de falhas, tais ocorrências devem receber a mesma identificação. Todavia, eventos similares que envolvam itens diferentes devem receber identificações distintas.

Cada porta lógica de um diagrama possui apenas uma saída, mas pode possuir mais de uma entrada. 


\subsubsection{Exemplo de FTA}

A Figura 27 mostra um exemplo simplificado de FTA para o evento topo "Trem sem captação de energia". A equação booleana desse exemplo seria expressa por:

$$
E T_{1}=P_{1} \quad E \quad\left(P_{2} \quad O U \quad C\right)
$$

ou ainda:

$$
E T_{1}=P_{1} \times\left(P_{2}+C\right)
$$

Sendo,

$E T_{1}$ : Evento Topo 1 - "Trem sem captação de energia"

$P_{1}$ : Falha do Pantógrafo 1

$\mathrm{P}_{2}$ : Falha do Pantógrafo 2

C: Falha do Equipamento de Controle

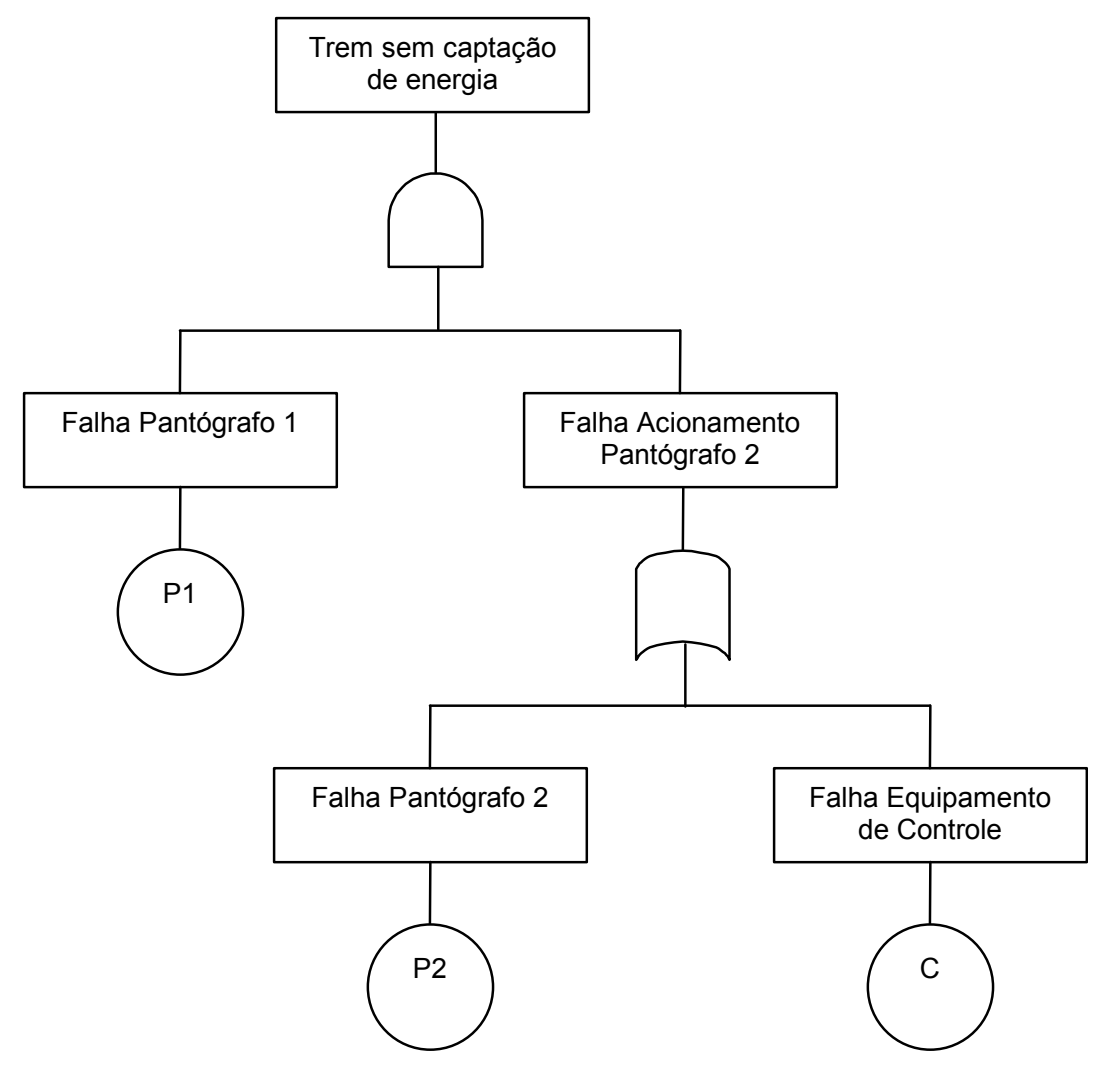

Figura 27: Exemplo de FTA 
Pode-se identificar dois cortes mínimos nesse FTA. São eles:

- $P_{1} \times P_{2}$

- $P_{1} \times C$

De forma que a ocorrência de qualquer um deles leva a ocorrência do evento topo.

\subsubsection{Relatório}

Os itens básicos de um relatório devem ser:

- Objetivo e escopo;

- Descrição do sistema;

- Considerações;

- Definição de falhas e critérios;

- Resultados e conclusões;

Além disso, também podem ser inseridas informações complementares como diagramas de bloco ou funcional dos circuitos, síntese dos dados de confiabilidade dos componentes e respectivas fontes.

\subsection{MÉTODO DA TABELA VERDADE}

Assim como o teorema de Bayes, o método da tabela verdade também pode ser usado para resolver sistemas complexos. Esse método funciona através da enumeração de todas as combinações binárias possíveis entre os elementos dos sistemas, sendo componente funcionando $=1$ (um) e componente em falha $=0$ (zero). São calculadas apenas as probabilidades das combinações que resultem no funcionamento do sistema. A confiabilidade do sistema, por sua vez, é a soma das probabilidades das combinações de sucesso, (19). 


\subsubsection{Exemplo de aplicação da tabela verdade}

Seja o sistema complexo apresentado na Figura 22 (página 117), com os seguintes valores de confiabilidade dos seus componentes:

- $\mathrm{R}_{\mathrm{A}}=0,9$

- $\mathrm{R}_{\mathrm{B}}=0,8$

- $\mathrm{R}_{\mathrm{C}}=0,7$

- $\mathrm{R}_{\mathrm{D}}=0,6$

- $\mathrm{R}_{\mathrm{E}}=0,5$

A confiabilidade do sistema, através do teorema de Bayes (ver item 4.3.6), é igual a:

$$
\begin{aligned}
& R_{s}=R_{\text {situação_1 }}+R_{\text {situaç̃o_ }_{2}} \\
& R_{s}=0,3 \cdot[1-(1-0,9 \cdot 0,6) \cdot(1-0,8 \cdot 0,5)]+0,7 \cdot[(1-0,1 \cdot 0,2) \cdot(1-0,4 \cdot 0,5)] \\
& R_{s}=0,766
\end{aligned}
$$

Esse mesmo sistema pode ser resolvido pelo método da tabela verdade, enumerando todas as possíveis combinações de estado de seus componentes e avaliando o estado final do sistema, se funcional ou em falha. A Tabela 18 ilustra melhor como isso pode ser feito.

Por exemplo, na combinação número 14 o cálculo da probabilidade é dado por:

$$
\begin{aligned}
& P(14)=P\left(A_{\text {falha }}\right) \cdot P\left(B_{\text {func }}\right) \cdot P\left(C_{\text {func }}\right) \cdot P\left(D_{\text {falha }}\right) \cdot P\left(E_{\text {func }}\right) \\
& P(14)=0,1 \times 0,8 \times 0,7 \times 0,4 \times 0,5=0,0112
\end{aligned}
$$

A confiabilidade do sistema é dada então pela somatória das probabilidades das combinações de sucesso, ou seja, $R=0,766$. 
Tabela 18: Exemplo de uso da tabela verdade

\begin{tabular}{|c|c|c|c|c|c|c|c|}
\hline Elemento & $A$ & B & C & $\mathrm{D}$ & $E$ & Sucesso? & \multirow{5}{*}{$\begin{array}{l}\text { Prob. de } \\
\text { sucesso }\end{array}$} \\
\hline $\mathrm{P}$ (funcionar) & 0,9 & 0,8 & 0,7 & 0,6 & 0,5 & \multirow{4}{*}{$\begin{array}{l}0 \text { - não } \\
1 \text { - sim }\end{array}$} & \\
\hline $\mathrm{P}$ (falha) & 0,1 & 0,2 & 0,3 & 0,4 & 0,5 & & \\
\hline \multirow{2}{*}{$\begin{array}{l}\text { Combinação } \\
\text { número }\end{array}$} & \multicolumn{5}{|c|}{$\begin{array}{c}\text { Estado: } \\
(0 \text { - falha / } 1 \text { - funcional })\end{array}$} & & \\
\hline & $A$ & $B$ & $\mathrm{C}$ & $\mathrm{D}$ & $E$ & & \\
\hline 1 & 0 & 0 & 0 & 0 & 0 & 0 & 0 \\
\hline 2 & 0 & 0 & 0 & 0 & 1 & 0 & 0 \\
\hline 3 & 0 & 0 & 0 & 1 & 0 & 0 & 0 \\
\hline 4 & 0 & 0 & 0 & 1 & 1 & 0 & 0 \\
\hline 5 & 0 & 0 & 1 & 0 & 0 & 0 & 0 \\
\hline 6 & 0 & 0 & 1 & 0 & 1 & 0 & 0 \\
\hline 7 & 0 & 0 & 1 & 1 & 0 & 0 & 0 \\
\hline 8 & 0 & 0 & 1 & 1 & 1 & 0 & 0 \\
\hline 9 & 0 & 1 & 0 & 0 & 0 & 0 & 0 \\
\hline 10 & 0 & 1 & 0 & 0 & 1 & 1 & 0,0048 \\
\hline 11 & 0 & 1 & 0 & 1 & 0 & 0 & 0 \\
\hline 12 & 0 & 1 & 0 & 1 & 1 & 1 & 0,0072 \\
\hline 13 & 0 & 1 & 1 & 0 & 0 & 0 & 0 \\
\hline 14 & 0 & 1 & 1 & 0 & 1 & 1 & 0,0112 \\
\hline 15 & 0 & 1 & 1 & 1 & 0 & 1 & 0,0168 \\
\hline 16 & 0 & 1 & 1 & 1 & 1 & 1 & 0,0168 \\
\hline 17 & 1 & 0 & 0 & 0 & 0 & 0 & 0 \\
\hline 18 & 1 & 0 & 0 & 0 & 1 & 0 & 0 \\
\hline 19 & 1 & 0 & 0 & 1 & 0 & 1 & 0,0162 \\
\hline 20 & 1 & 0 & 0 & 1 & 1 & 1 & 0,0162 \\
\hline 21 & 1 & 0 & 1 & 0 & 0 & 0 & 0 \\
\hline 22 & 1 & 0 & 1 & 0 & 1 & 1 & 0,0252 \\
\hline 23 & 1 & 0 & 1 & 1 & 0 & 1 & 0,0378 \\
\hline 24 & 1 & 0 & 1 & 1 & 1 & 1 & 0,0378 \\
\hline 25 & 1 & 1 & 0 & 0 & 0 & 0 & 0 \\
\hline 26 & 1 & 1 & 0 & 0 & 1 & 1 & 0,0432 \\
\hline 27 & 1 & 1 & 0 & 1 & 0 & 1 & 0,0648 \\
\hline 28 & 1 & 1 & 0 & 1 & 1 & 1 & 0,0648 \\
\hline 29 & 1 & 1 & 1 & 0 & 0 & 0 & 0 \\
\hline 30 & 1 & 1 & 1 & 0 & 1 & 1 & 0,1008 \\
\hline 31 & 1 & 1 & 1 & 1 & 0 & 1 & 0,1512 \\
\hline 32 & 1 & 1 & 1 & 1 & 1 & 1 & 0,1512 \\
\hline & & & & & & $\mathrm{R}=$ & 0,7660 \\
\hline
\end{tabular}

\subsection{LISTA DE ITENS CRÍTICOS}

A lista de itens críticos (LIC) é uma síntese dos itens identificados pelas análises cujas falhas afetam significativamente a confiabilidade (ou a segurança) do 
sistema, ou ainda que envolvam um nível considerável de incerteza. O propósito da LIC é destacar esses itens e priorizar as ações para redução de riscos.

A LIC é inicialmente baseada nas análises de projeto, porém deve ser atualizada ao longo do ciclo de vida do desenvolvimento levando-se em conta os resultados dos testes, as mudanças de projeto, retorno de experiências de campo, etc.

A LIC é um documento que deve ser atribuída importância fundamental para o gerenciamento e tomadas de decisão e deve ser baseada no principio de gerenciamento por exceções, uma vez que está relacionada com problemas específicos de confiabilidade (ou de segurança).

Além disso, essa lista não deve ser muito extensa. De fato não é recomendável que essa lista tenha mais que 10 itens por sistema. Os itens devem ser classificados por ordem de criticidade ou por probabilidade de falha, de forma que as atenções de gerenciamento se concentrem sobre os itens mais importantes. Isso pode ser graficamente representado por um gráfico de Pareto.

\subsubsection{Análise de Pareto}

O principio da análise de Pareto visa separar os poucos itens mais significativos dos muitos de menor relevância na confiabilidade global do sistema. Com a analise de Pareto, pode-se determinar como resolver a maior parte dos problemas de confiabilidade atuando sobre um número reduzido de itens, ajudando a otimizar os custos de mitigação de problemas, (13) e (19).

A Figura 28 mostra um exemplo de gráfico de Pareto. 


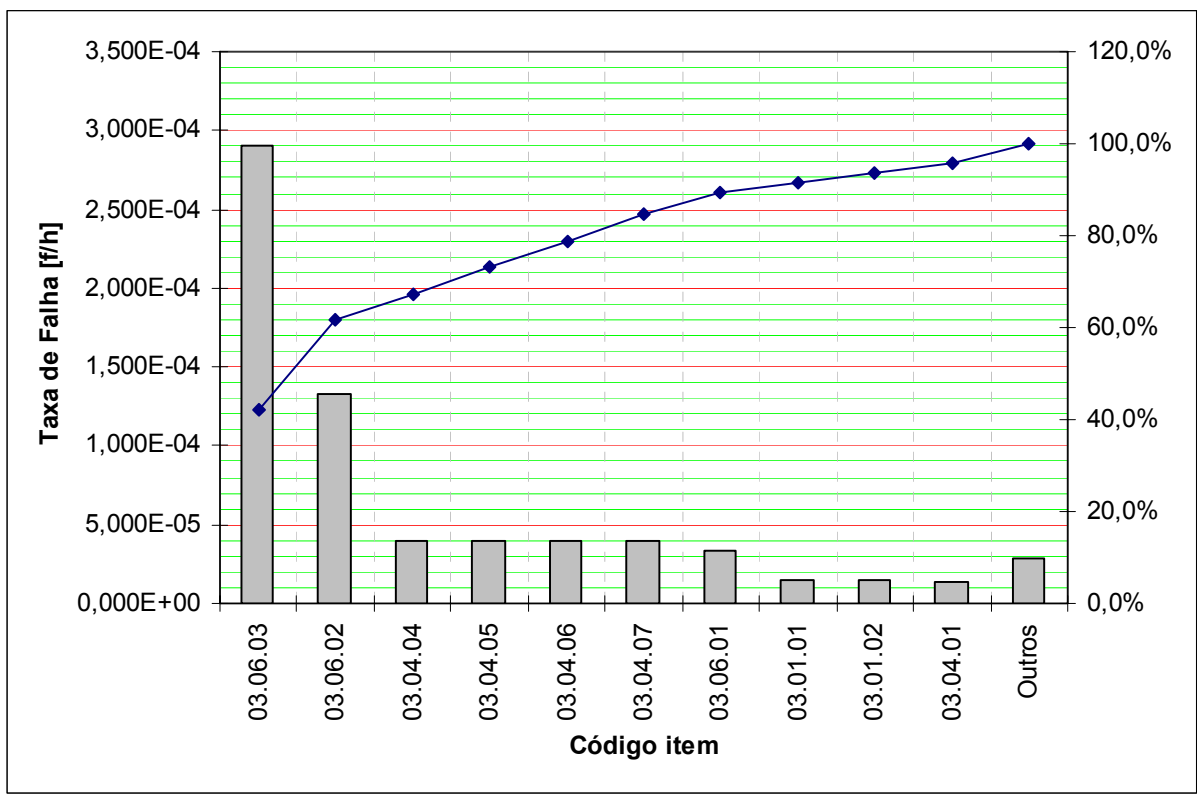

Figura 28: Exemplo de gráfico de Pareto

\subsection{CÁlCULO DE SOBRESSALENTES}

É possível avaliar a probabilidade de se ter itens sobressalentes suficientes disponíveis em campo para cobrir falhas dos equipamentos durante períodos específicos de missão. Para tal pode-se fazer uso da distribuição de Poisson.

Para utilizar a lei de Poisson são necessárias as seguintes considerações:

- Taxa de falhas constantes;

- Substituição do item defeituoso por um item sobressalente sem qualquer efeito colateral;

- O estoque de sobressalentes é completado somente no final da missão;

Através da lei de Poisson, a probabilidade de se obter $k$ falhas ou menos em um dado período de tempo é igual a, (18):

$$
P(x \leq k)=\sum_{x=0}^{k} \frac{(\lambda \cdot t)^{k}}{k !} \cdot e^{-\lambda \cdot t}
$$


onde:

$\lambda$ : taxa de falha;

$t$ : período de tempo considerado;

$k$ : número de falhas

A probabilidade de falta de material em estoque é então dada por:

$$
P(\text { falta_material })=1-P(x \leq k)
$$

No caso da probabilidade de falta de material ser um valor especificado pelo cliente, é possível definir $\mathrm{k}$ tal que:

$$
P(\text { falta_material })=(1-P(x \leq k)) \leq P(\text { especificada })
$$

Geralmente o tempo é definido em função do tempo necessário para repor um item em caso de falha do mesmo, considerando os tempos logísticos envolvidos nesse processo.

\subsection{MONITORAMENTO DA CONFIABILIDADE EM CAMPO}

O monitoramento da confiabilidade em campo é, uma das etapas mais importantes do processo de gerenciamento da confiabilidade. Somente através do monitoramento é possível determinar o cumprimento ou não das metas de confiabilidade estabelecidas no início do projeto. Porém mais do que isso, o monitoramento proporciona um excelente retorno de experiências que realimentam projetos futuros, além de contribuir para a validação dos processos e esforços com a confiabilidade durante o projeto, (13), (18).

\subsubsection{Procedimento de seguimento operacional da confiabilidade}

Antes da entrada em operação deve-se estabelecer entre a operadora e o fabricante um procedimento de seguimento operacional da confiabilidade, onde 
deverão estar descritas as principais considerações envolvidas com essa etapa. Os principais pontos a serem cobertos por esse plano são:

- Estrutura analítica do produto utilizada para apontamento das falhas;

- Características do software que será utilizado para registro das falhas;

- Referências às cláusulas contratuais e documentos e estudos relacionados ao projeto;

- Metodologia de entrada dos dados de falha no sistema e respectiva classificação;

- Procedimento estatístico utilizado para apuração dos índices de confiabilidade;

- Formato dos relatórios periódicos de acompanhamento da confiabilidade;

- Identificação das responsabilidades;

\subsubsection{Registro e consolidação de falhas}

Geralmente, as falhas apontadas no sistema devem passar por uma reavaliação e consolidação entre os representantes da operadora e do fabricante. Isso é feito em reuniões periódicas com o intuito de verificar as falhas registradas uma a uma e compará-las com os critérios e com os planos de seguimento operacional.

Tal verificação é necessária para se corrigir eventuais erros de apontamento e/ou classificação das falhas, além de se excluírem eventos decorrentes de vandalismo, por exemplo.

Essa "purificação" dos dados evita que os cálculos dos índices carreguem erros implícitos que possam provocar tomadas de decisão e ações equivocadas. 


\subsubsection{Relatórios periódicos e comparação com as metas}

A cada período estabelecido no procedimento de seguimento operacional da confiabilidade (mensal, bimestral, trimestral, semestral, etc) deve ser gerado um relatório para acompanhamento dos índices de confiabilidade, sua evolução ao longo do tempo e comparação com as metas estabelecidas. Com base nesses relatórios são tomadas decisões de aplicação ou não de multas, extensões de garantia, retrabalhos para melhoria da confiabilidade ou simplesmente de emissão de certificado de aceitação definitiva dos trens e encerramento de garantia.

\subsubsection{Crescimento da confiabilidade}

Em um programa de crescimento da confiabilidade, o projeto do produto é analisado para se determinar se algum de seus componentes e respectivas interfaces possui fraquezas potenciais quando sujeito às condições operacionais e ambientais esperadas. Podem ser comparados resultados da análise de projeto com as metas de confiabilidade e feitas recomendações quanto às melhorias necessárias.

Todos os métodos analíticos de confiabilidade podem ser aplicados, incluindo testes especificamente planejados para detectar modos de falha potenciais, principalmente onde a análise seria muito complexa, ou provável de produzir resultados incertos. Modos de falha com as maiores probabilidades de ocorrência e as respectivas causas são identificados como pontos para melhoria do projeto, e a confiabilidade do novo sistema, após as modificações, é então reavaliada. Dessa maneira, o progresso é registrado e é monitorado o crescimento da confiabilidade.

Fraquezas no produto em uso normalmente são desconhecidas até que se manifestem através de falhas. Porém, uma fraqueza pode ser criada muito tempo antes da ocorrência de uma falha observável, em função de um erro humano em alguma operação na montagem, do dimensionamento inadequado de componente 
tal que o submeta a solicitações severas. Além disso, as franquezas podem ser inerentes de um material ou ainda geradas por um processo cuja qualidade não esteja totalmente sob controle.

O número de fraquezas presentes é influenciado por:

- Precisão na especificação ou na previsão das condições ambientais e operacionais;

- Nível de inovação, complexidade ou criticidade do projeto, dos processos industriais ou da utilização;

- Restrições como cronogramas e orçamentos de desenvolvimento e de produção inadequados.

- Habilidade e nível de treinamento do pessoal envolvido, especialmente do pessoal de projeto;

Fraquezas residuais são normalmente relacionadas com a variação aleatória das características do item ou de seus componentes. Os fatores mencionados também contribuem para a incidência de fraquezas residuais, mas isso pode ser reduzido por treinamentos e processos de controle da qualidade.

O modelamento do crescimento da confiabilidade permite que sejam feitas estimativas quantitativas da confiabilidade futura medidas ao término de um programa de crescimento da confiabilidade, ou em instantes intermediários, durante a evolução do programa, possibilitando a determinação da, (39):

- Taxa de falha ou MTBF instantâneo em um determinado instante no programa;

- Taxa de falha ou MTBF extrapolado em algum instante futuro;

- Taxa de falha ou MTBF projetado após implementações de modificações ou melhorias.

É possível estender o programa de crescimento da confiabilidade mesmo com o produto em campo. Uma revisão detalhada dos dados de falha de campo, pode revelar problemas relacionados ao projeto não descoberto em análises e testes. Pode-se então melhorar a confiabilidade dos produtos similares no futuro. $O$ monitoramento cuidadoso dos dados de campo relacionados com falhas particulares e o não re-aparecimento sistemático delas são evidências de que as ações definidas foram introduzidas com sucesso na melhoria da confiabilidade do produto. 


\subsubsection{Método Duane}

O modelo usado freqüentemente para processo de crescimento da confiabilidade é método Duane. Essencialmente, este modelo provê uma aproximação determinística para crescimento de confiabilidade tal que o MTBF de sistema em função das horas operacionais se comporta como uma reta quando traçado em papel Di-Log, ou seja, quando ambos os eixos possuem escalas logarítmicas. Quer dizer, a variação no MTBF durante desenvolvimento é proporcional a $\mathrm{T}$ onde $\mathrm{T}$ é o tempo operacional acumulado e a taxa de crescimento corresponde à velocidade com que são encontradas falhas e feitas mudanças para eliminar suas causas básicas, (18) e (39).

Seja:

$\theta_{a}(T)$ : MTBF acumulado no tempo T

$\theta_{0}$ : MTBF no início do desenvolvimento $\left(\mathrm{T}_{0}\right)$

$\alpha$ : Coeficiente de crescimento - indica o esforço para melhoria do projeto

O método de Duane estabelece a seguinte relação para MTBF versus tempo:

$$
\theta_{a}(T)=\theta_{0} \cdot\left(\frac{T}{T_{0}}\right)^{\alpha}
$$

Como ao fim de cada período de avaliação interessa também saber o MTBF neste instante $\left(\theta_{i}(T)\right)$ :

$$
\theta_{i}(T)=\frac{1}{1-\alpha} \cdot \theta_{a}(T)
$$




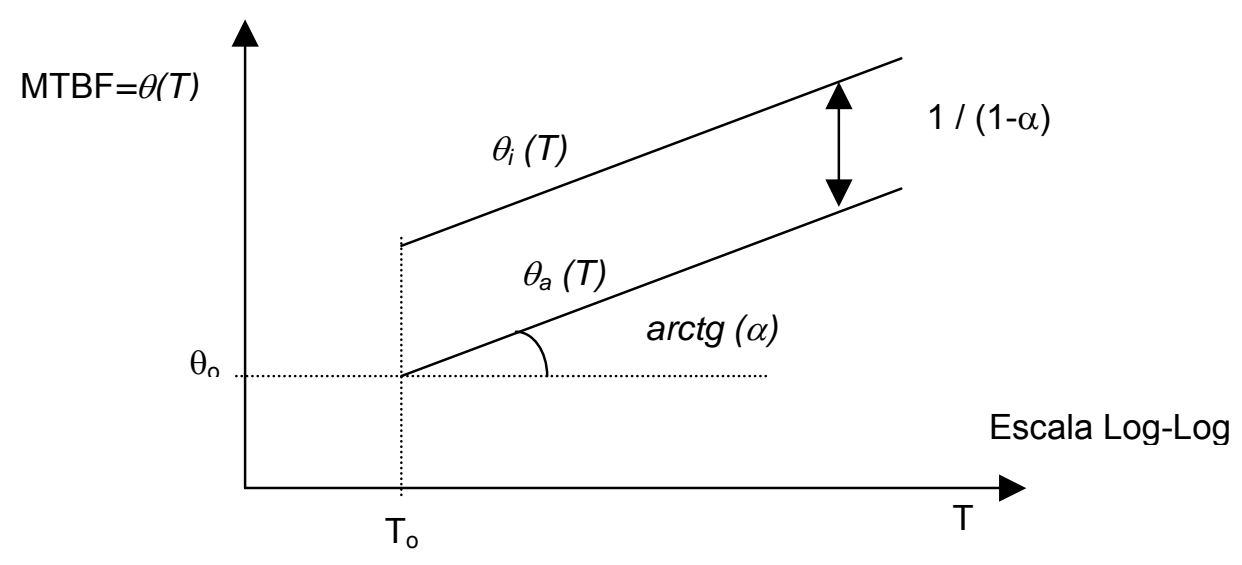

Figura 29: Crescimento da confiabilidade

O coeficiente de crescimento $\alpha$ pode ser expresso por:

$$
\alpha=\frac{\Delta M T B F}{\Delta T}
$$

A interpretação de $\alpha$ pode ser feita como o grau de esforço necessário para se alcançar o MTBF esperado. Esse conceito é ilustrado através da Tabela 19, baseada em experiências passadas com alguns projetos.

Tabela 19: Tabela de avaliação da taxa de crescimento necessária

\begin{tabular}{|c|c|}
\hline$\alpha$ & Grau de esforço necessário \\
\hline Até 0,2 & Não são necessários esforços significativos para alcançar a meta. \\
\hline De 0,2 até 0,4 & $\begin{array}{r}\text { Pequenos esforços de engenharia, tais como pequenas modificações pontuais } \\
\text { e cuidados de manutenção, são suficientes para alcançar a meta. }\end{array}$ \\
\hline De 0,4 até 0,7 & $\begin{array}{c}\text { Necessidade de investigações e procedimentos precisos, envolvendo } \\
\text { modificações de projeto e/ou cuidados especiais de manutenção e operação. }\end{array}$ \\
\hline Acima de 0,7 & $\begin{array}{c}\text { Meta dificilmente será alcançada sem modificações maiores no projeto ou sem } \\
\text { que ocorram pagamentos de penalizações. Uma revisão técnica das metas e } \\
\text { de como foram estabelecidas, além é claro do próprio projeto, é recomendável } \\
\text { nesse caso e deve ser feita o mais cedo possível no ciclo de vida do projeto. }\end{array}$ \\
\hline
\end{tabular}




\subsection{FRACAS}

FRACAS é a sigla para Sistema de Análise de Relatórios de Falha e Ações Corretivas, do Inglês Failure Reporting Analysis and Corrective Actions System.

O propósito do FRACAS é coletar dados de falha, proporcionar meios para determinar os índices de confiabilidade e as causas das falhas, além de documentar as ações corretivas. É essencial que as falhas ocorridas durante o processo de desenvolvimento e na operação dos trens sejam registradas e analisadas para assegurar a correta interpretação da confiabilidade e verificar se a mesma é alcançada e sustentada. O FRACAS deve fornecer informação essencial sobre O QUÊ falhou, COMO falhou, PORQUÊ falhou e de que maneira as falhas futuras podem ser evitadas, (37).

As fontes de dados de falhas podem ser testes de verificação de projeto, testes de produção, testes nos fornecedores e, principalmente, dados de campo como testes de comissionamento e operação.

O FRACAS é um processo importante no qual a qualidade e a confiabilidade de um produto podem ser seguidos medidos e melhorados. Segundo levantamento realizado em 1995 pela RAC (Reliability Analysis Center) dos Estados Unidos, empresas conhecidas por fornecer produtos altamente confiáveis identificaram o FRACAS como sendo um dos elementos mais importantes em seus programas de confiabilidade. Como pode ser visto na Tabela $20,88,3 \%$ dos entrevistados consideram FRACAS como a atividade mais importante em um programa de confiabilidade. Conforme destacado pela RAC, o FRACAS recebeu o maior percentual devido a sua capacidade de fornecer a causa raiz da falha e informações de ação corretiva realimentando o processo e melhorando, portanto, a confiabilidade do projeto, (40) e (41). 
Tabela 20: Atividades mais importantes de confiabilidade, (41).

\begin{tabular}{|c|c|c|}
\hline Ordem & Atividade & $\%$ \\
\hline 1 & FRACAS & 88,3 \\
\hline 2 & Revisões de Projeto & 83,8 \\
\hline 3 & Controle dos Fornecedores & 72,1 \\
\hline 4 & Controle de Qualidade & 71,2 \\
\hline 5 & FMECA & 70,3 \\
\hline 6 & Testes de Confiabilidade & 68,5 \\
\hline 7 & Predições & 62,2 \\
\hline 8 & Testes, Análises e Reparos & 59,5 \\
\hline 9 & Análises térmicas & 58,6 \\
\hline
\end{tabular}

\subsubsection{Sistema de Ciclo Fechado}

Para proporcionar tais características e benefícios aos vários grupos de trabalho dentro da empresa, o FRACAS deve ser um sistema de ciclo fechado que seja configurável, flexível e gradual. Isso significa que todas as falhas e defeitos reportados devem ser inseridos no FRACAS de uma maneira apropriada e controlada de forma que possam ser analisadas e as ações corretivas possam ser identificadas, implementadas e verificadas. O conhecimento obtido desse processo deve retornar ao projeto, manufatura, teste e manutenção de forma que a qualidade e a confiabilidade possam ser melhoradas.

A norma MIL-HDBK-338B (37) indica as principais etapas de um FRACAS de ciclo fechado. Tipicamente, isso consiste dos seguintes passos:

- Observação da falha durante a operação ou teste;

- Documentação da falha, incluindo no mínimo:

- Localização da falha

- Data e hora da falha

- Referência do sistema/equipamento em falha

- Número de série do sistema/equipamento em falha

- Modelo do sistema/equipamento em falha

- Sintomas de falha observados

- Identificação da pessoa que observou a falha

- Todas as condições significativas existentes no momento da falha 
- Verificação e confirmação da falha observada inicialmente;

- Isolação da falha, localizando o menor item substituível/reparável dentro do sistema/equipamento;

- Substituição do item suspeito por um conhecidamente bom e teste do sistema/equipamento para assegurar-se de que o item instalado de fato corrige a falha originalmente reportada;

- Re-teste do item suspeito para verificar que o mesmo se encontra defeituoso.

- Análise do item defeituoso para estabelecer o mecanismo de falha interno responsável pelo modo de falha observado;

- Procura por dados existentes relacionados à ocorrência de falhas similares no item em questão, levando em conta o modo e o mecanismo da falha.

- Estabelecimento das causas raízes com base nos dados obtidos nos dois últimos passos;

- Determinar as ações corretivas necessárias, tais como mudanças de projeto, de processo, de procedimentos, etc. para prevenir a recorrência da falha. A decisão a respeito das ações corretivas adequadas deve ser tomada por uma equipe interdisciplinar, envolvendo projeto, processo, qualidade, manutenção e assistência técnica;

- Incorporação da ação corretiva recomendada em um sistema/equipamento para teste;

- Re-teste do sistema/equipamento com as ações corretivas incorporadas;

- Após teste e revisão dos parâmetros apropriados, determinar se a ação corretiva proposta é efetiva.

Após a constatação da eficácia da ação corretiva proposta, a mesma é incorporada nos novos itens e, quando aplicável, no restante da frota já existente.

A Figura 30 ilustra esse processo na forma de fluxograma. 


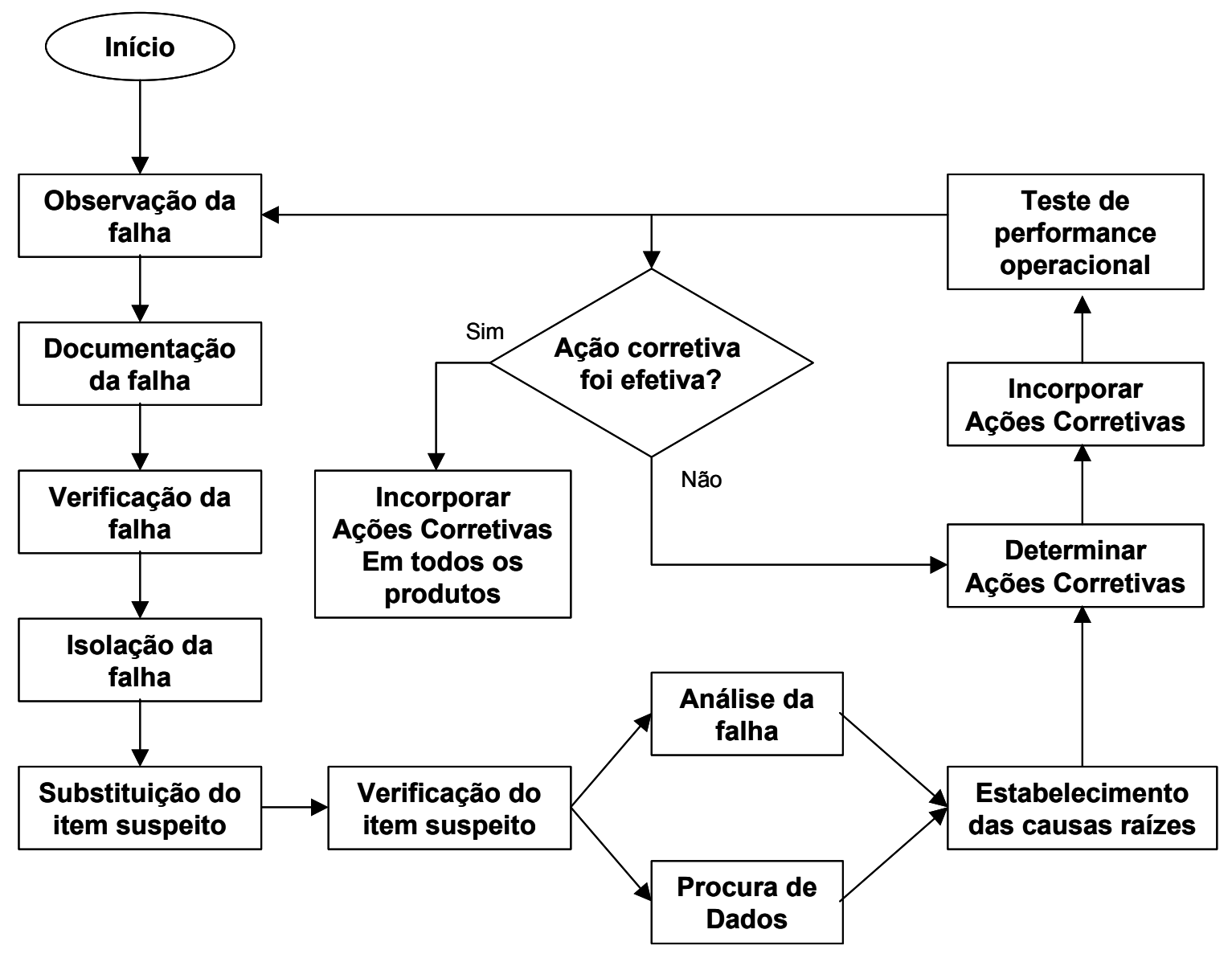

Figura 30: FRACAS - Ciclo Fechado, (37).

Existem vários elementos chave que fazem com que o ciclo do FRACAS seja efetivo. São eles:

- A disciplina na escrita do relatório deve ser mantida de tal forma a produzir uma descrição precisa da ocorrência e identificação da falha;

- As atribuições adequadas de prioridades e decisões nas análises de falhas devem ser realizadas pelo pessoal competente com o auxílio dos engenheiros de projeto, processo, manutenção e qualidade;

- O status de todas as falhas deve ser conhecido. É de vital importância que a análise da falha seja prioridade e que as ações corretivas sejam implementadas o mais rapidamente possível;

- A causa raiz de cada falha deve ser entendida. Sem esse entendimento, não há como seguir com ações corretivas logicamente associadas. 
- Devem existir meios de tabular as informações de falha para determinação de tendências e tempos médios entre falhas dos elementos do sistema. Devem também existir meios de gerenciamento e visualização do status das falhas e das ações corretivas;

O sistema deve proporcionar um alto nível conformidade no gerenciamento técnico dos resultados das análises de falha, na integridade e completude das ações corretivas, e na prevenção de recorrências.

\subsubsection{Sistemática no registro de falhas}

Normalmente o fabricante adota uma organização de engenharia da confiabilidade, a qual é responsável por instituir e gerenciar o FRACAS. Essa organização estabelece as políticas, as diretrizes e monitora o status das investigações de falhas no FRACAS. As organizações internas de inspeção, testes e assistência técnica, incluindo engenharia de confiabilidade e engenharia de qualidade, são responsáveis pela abertura dos relatórios de falha prontamente, logo que são observadas.

O FRACAS deve ser alimentado com todos os problemas que ocorrem durante inspeções, testes e trabalhos em campo, usando-se um procedimento estabelecido para o armazenamento preciso das informações de falhas. As pessoas responsáveis pela alimentação dos relatórios de falhas no FRACAS devem ser treinadas para obter os dados requeridos com precisão. Para facilitar a alimentação dos relatórios de falhas, os formulários de entrada devem ser desenvolvidos de acordo com o processo utilizado. Uma vez que um relatório de falhas é criado, o analista responsável deve ser informado de sua existência. 


\subsubsection{Formulários}

Para o sucesso do FRACAS, é imperativo que os relatórios de falha e resultados das ações corretivas sejam corretamente documentados. Além disso, os formulários de registro de falha e de ações corretivas devem ser projetados para atender às necessidades do desenvolvimento individual de sistemas e do programa de produção assim como as responsabilidades da organização, requisitos e limitações dos fabricantes.

\subsubsection{Coleta e armazenamento de dados}

A manutenção de registros precisos e atualizados através da implementação do FRACAS proporciona uma base crescente de experiências. Essa base de experiências, consistindo de falhas em teste e ações corretivas, não é apenas útil para os projetos correntes, mas também pode ser aplicado no desenvolvimento de novos projetos. Além disso, os dados de experiências passadas podem ser utilizados para:

- Avaliar e monitorar a confiabilidade;

- Realizar análises e avaliações comparativas;

- Determinar a efetividade das ações de qualidade e confiabilidade;

- Identificar componentes críticos e áreas problemáticas;

- Contabilizar o histórico de taxas de falha para predição da confiabilidade em novos projetos (ao invés de utilizar predições pela MIL-HDBK-217 (20), por exemplo).

A necessidade de se acessar informação atualizada sobre incidentes de uma maneira organizada facilmente justifica o uso de um software dedicado a essa finalidade. Os benefícios de um FRACAS informatizado incluem a capacidade do sistema para, (40) e (41):

- Armazenar dados sobre incidentes, análises e ações corretivas em um banco de dados de tal forma que essa informação possa ser usada 
para determinar a causa raiz de uma falha e detectar suas tendências históricas;

- Identificar, selecionar e priorizar os incidentes que estejam sob análise;

- Documentar as ações corretivas que são identificadas, implementadas e verificadas para prevenir a recorrência de uma falha crítica;

- Proporcionar ao pessoal apropriado um acesso periódico a todos os incidentes relevantes, análises e ações corretivas, de forma a gerar crescimento de confiabilidade e decisões pró-ativas para prevenir a ocorrência de problemas similares em projetos ou serviços futuros, (fechando o ciclo);

Ao avaliar um software FRACAS, outras características importantes a serem observadas incluem a capacidade de:

- Personalizar a estrutura e os requisitos do FRACAS de maneira a considerar o tipo de produto/serviço oferecido e a natureza do mercado no qual compete;

- Estabelecer e registrar o tempo de teste acumulado e o tempo operacional de todos os equipamentos durante o desenvolvimento e a operação comercial, de tal forma que esses registros possam ser usados para o cálculo das taxas de falha, custos e tendências associadas;

- Oferecer registros detalhados e gráficos para a exploração das tendências de falha e geração de relatórios de acompanhamento e gerenciais;

- Implementar um FRACAS de ciclo fechado amplo que possa suportar uma gama ilimitada de aplicações e um fluxo de trabalho personalizado;

Quando um FRACAS de ciclo fechado é implementado, o sistema inclui provisões para assegurar que as ações corretivas efetivas sejam tomadas adequadamente. A informação coletada do FRACAS pode facilmente ser aplicada nos projetos futuros para assegurar melhor confiabilidade dos produtos, serviços, 
processos ou aplicações de software. A utilização de tal sistema permite auditorias de acompanhamento para revisar os incidentes em aberto, análises e datas das ações corretivas, e facilmente perceber atrasos e implementações indevidas facilitando o gerenciamento do processo como um todo, (37).

Um bom software de FRACAS permite a melhora continua da confiabilidade do produto, através da captura, otimização e entrega de todos incidentes relevantes, assim como informações de análises e ações corretivas ao pessoal adequado.

\subsubsection{Análise de dados}

Um analista examina a informação inserida em um relatório de falhas, determina a causa raiz da falha e identifica os fatores contribuintes. Os métodos para análises das causas raízes vão desde simples investigações das circunstâncias envolvendo uma falha até análises laboratoriais sofisticadas de itens defeituosos. Uma vez que o analista tenha estabelecido a causa raiz e os fatores contribuintes, deve-se desenvolver as ações corretivas de acordo com essas análises. Conforme o número de registros no FRACAS cresce, o analista pode levantar os dados históricos de falhas similares ou relacionadas para ajudar a definir a ação corretiva apropriada. Uma vez que a ação corretiva seja definida, o FRACAS deve alertar o técnico responsável pela sua execução, (37) e (40).

Do ponto de vista da avaliação da confiabilidade, os dados de falha são usados para:

- Determinar a distribuição de probabilidades do tempo para falhar e estimar seus parâmetros (se já não forem conhecidos);

- Determinar uma estimativa pontual de um parâmetro específico de confiabilidade. Por exemplo MTBF;

- Determinar um intervalo de confiança que se acredita conter o valor real do parâmetro; 


\subsubsection{Cálculo de MTBF de campo}

Através da utilização de dados reais de trens em operação, tais como número de falhas, número de reparos, número de chamadas, tempo de operação e fora de serviço, tempo para reparar, distância percorrida, etc., valores como MTBF, taxa de falhas, e MTTR podem ser calculados.

O FRACAS pode ser uma ferramenta para a coleta de dados qualitativos importantes assim como para o cálculo de parâmetro quantitativos como MTBF, taxa de falha e confiabilidade. Para se obter resultados quantitativos significativos do FRACAS, a coleta de dados do período operacional (tempo, distância ou número de ciclos) é uma tarefa considerada crítica.

O método de inserção de dados de período operacional pode ser de 3 tipos, (40):

\section{- Tempo Calendário:}

Se as datas reais de início e de término de operação são conhecidas, então o tempo calendário pode ser usado para computar o tempo total de utilização.

Os dados coletados de campo incluem a data em que o item foi posto em serviço, a data em que falhou e as horas diárias que ele opera. Esse tipo de informação pode ser usado para determinar o tempo operacional de cada item e o tempo operacional total da frota em uso. Esse tempo e o número total de falhas imputáveis aos itens podem ser usados para calcular o MTBF.

Considere que 5 itens tenham sido instalados e os seguintes dados tenham sido coletados:

Tabela 21: Exemplo de registro com "Tempo Calendário"

\begin{tabular}{|c|c|c|c|c|}
\hline Item & $\begin{array}{c}\text { Data de } \\
\text { Instalação }\end{array}$ & Data da Falha & $\begin{array}{c}\text { Horas por dia de } \\
\text { operação }\end{array}$ & $\begin{array}{c}\text { Tempo } \\
\text { operacional (h) }\end{array}$ \\
\hline 1 & $01 / 06 / 04$ & $02 / 06 / 04$ & 12 & 12 \\
\hline 2 & $01 / 06 / 04$ & ${ }^{*}$ & 12 & 168 \\
\hline 3 & $01 / 06 / 04$ & $10 / 06 / 04$ & 12 & 108 \\
\hline 4 & $01 / 06 / 04$ & $14 / 06 / 04$ & 10 & 130 \\
\hline 5 & $01 / 06 / 04$ & $*$ & 10 & 140 \\
\hline
\end{tabular}

O asterisco $\left(^{*}\right)$ indica que o item não falhou até a data de coleta da falha. Embora não tenha sido registrada falha no item, seu tempo operacional afeta o 
MTBF global. Para os itens 2 e 5 da Tabela 21, a data final assumida é 15/06/04. Aproximações utilizando a distribuição Qui-Quadrado podem ser feitas nesses casos onde não são registradas falhas.

Note que a aquisição das datas de entrada em operação e de ocorrência das falhas resultam em uma estimativa de MTBF mais precisa. Quando o modelo de registro por tempo calendário é usado, deve-se determinar as datas e horas de início e término de operação.

- Tempo Equivalente:

Se os momentos iniciais de início e término de operação são conhecidos de uma outra forma que não seja tempo, como ciclos, milhas, quilômetros, etc., esses valores podem ser usados para calcular o tempo operacional com a utilização de fatores de conversão apropriados ( $\mathrm{km} / \mathrm{h}$, ciclos/minuto, etc.).

Os dados coletados de campo incluem, por exemplo, o número total de ciclos antes da falha e o número médio de ciclos por hora. Esse tipo de informação pode ser usado para determinar o tempo operacional para os itens em serviço. Esse dado de tempo, juntamente com os dados de falha, pode então ser usado para determinar o MTBF.

Considere 5 itens em serviço e que os seguintes dados tenham sido coletados:

Tabela 22: Exemplo de registro com "Tempo Equivalente"

\begin{tabular}{|c|c|c|c|c|}
\hline Item & Ciclos no início & Ciclos na falha & Ciclos / hora & $\begin{array}{c}\text { Tempo } \\
\text { Operacional (h) }\end{array}$ \\
\hline 1 & 0 & 100 & 50 & 2 \\
\hline 2 & 0 & 150 & 25 & 6 \\
\hline 3 & 0 & 200 & 40 & 5 \\
\hline 4 & 0 & 100 & 10 & 10 \\
\hline 5 & 0 & 400 & 10 & 40 \\
\hline
\end{tabular}

O modelo de registro de tempo equivalente também funciona para registro do tempo operacional de itens cuja aplicação seja medida em distância (por exemplo, em quilômetro, onde um fator de conversão dado em km/h é necessário). 
- Tempo Transcorrido:

Se um item possui um medidor de algum parâmetro indicativo do tempo operacional, como um horímetro, o valor medido pode ser usado como o tempo real de operação.

Os dados coletados de campo incluem o tempo total transcorrido antes da falha, considerando uma operação constante. Esse tipo de informação pode ser usado para determinar o tempo operacional dos itens em serviço. Esse dado de tempo, juntamente com os dados de falha, pode então ser usado para determinar o MTBF.

Considere 5 itens em serviço e que os seguintes dados tenham sido coletados:

Tabela 23: Exemplo de registro com "Tempo Transcorrido"

\begin{tabular}{|c|c|}
\hline Item & $\begin{array}{c}\text { Tempo } \\
\text { Operacional (h) }\end{array}$ \\
\hline 1 & 4808 \\
\hline 2 & 2412 \\
\hline 3 & 7216 \\
\hline 4 & 1208 \\
\hline 5 & 2412 \\
\hline
\end{tabular}




\section{CASOS EXEMPLO}

Neste capítulo serão apresentados alguns exemplos de aplicação das análises descritas no capítulo 4 .

Um projeto de material rodante leva, em média, entre 18 e 36 meses considerando proposta, projeto, fabricação, entrega do primeiro trem e testes de validação. Se for levado em conta o período de garantia, que é geralmente de 24 a 36 meses, o tempo total de uma obra entre a assinatura do contrato e o término da garantia pode chegar a algo em torno de 72 meses.

As particularidades de cada obra fazem com que nem sempre seja possível a aplicação de todas as técnicas apresentadas neste trabalho. Por isso é importante a especificação de CDMS de maneira adequada, levando-se em conta o que foi discutido no item 3.6. Tão importante quanto uma boa especificação é a elaboração por parte do fabricante de um Plano do Programa de Confiabilidade específico para cada obra, conforme descrito no item 3.7.

Em função desses aspectos, os exemplos aqui apresentados não se referem a uma única obra completa, o que seria melhor do ponto de vista didático, mas sim a uma amostragem de algumas situações reais vividas em diversas obras. Portanto, os exemplos não necessariamente estão relacionados entre si, mas abordam os aspectos práticos a que se propõem.

Além disso, por questões éticas e de preservação das empresas envolvidas, o nome das obras, assim como dos fornecedores de sistemas e das operadoras, serão omitidos. 


\subsection{EXEMPLO 1: ALOCAÇÃO DE METAS DE CONFIABILIDADE}

\subsubsection{Descrição}

Durante a fase de proposta de uma determinada obra, com base na especificação técnica elaborada pela operadora, notou-se a necessidade de alocação das metas de confiabilidade entre os sub-sistemas que compõem o trem.

Essa alocação é necessária para a elaboração do Plano do Programa de Confiabilidade que, por sua vez, determinará as metas dos fornecedores dos respectivos sub-sistemas, além de demonstrar à operadora qual será a abordagem de projeto do ponto de vista de CDMS.

A operadora não estabeleceu metas para os sub-sistemas do trem. $O$ fabricante será cobrado através de multas e/ou extensão de garantia pelo não cumprimento das metas globais, ou seja, considerando todos os sub-sistemas do trem.

Mesmo que o fabricante seja cobrado pelo cumprimento das metas globais e não pelas metas de cada sub-sistema, é importante que essas metas sejam repartidas entre os sub-sistemas para facilitar a condução do projeto e as discussões com os fornecedores. As metas de cada sub-sistema podem, dessa maneira, ser repassadas aos respectivos fornecedores, reduzindo o risco de não cumprimento da meta global por parte da montadora.

Os principais sub-sistemas do trem em questão, e que terão metas específicas de confiabilidade, são:

- Portas

- Tração

- Interface com condutor

- Comunicação de voz e dados (Data-bus)

- Freio

- Caixa

- Suprimento elétrico

- Suprimento de ar 
- Ventilação

- Conforto

- Truque

- Engate

Totalizando 12 sistemas.

\subsubsection{Metas globais de confiabilidade}

A operadora especificou as metas de confiabilidade estabelecendo dois tipos de falha:

- Falha tipo A:

- Falhas que provocam evacuação e/ou reboque dos trens;

- Falhas que provocam a retirada iminente do trem de operação por seus próprios meios;

- Meta: 250.000 carro-quilômetro

- Falha Tipo B:

- Demais falhas que se manifestem durante a operação do trem e que não afetem o critério de falha tipo $A$;

Meta: 8.000 carro-quilômetro

Nota-se ainda que as metas são especificadas em carro-quilômetro. Significa dizer que a apuração futura dos índices se fará acumulando a quilometragem de cada carro do trem. Neste exemplo o projeto consiste de trens de 3 carros, sendo dois motorizados com cabine e um reboque. 


\subsubsection{Método de alocação}

Conforme fluxograma da Figura 11, o processo de alocação tem como entradas principais a meta global de confiabilidade e o modelamento do sistema. A primeira foi definida na própria especificação técnica da operadora. O modelamento da confiabilidade dos sistemas é considerado como sendo em série.

Tenta-se inicialmente a alocação das metas através do método EQUAL (ver item 4.1.1.1).

Para os valores de MKBF especificados, tem-se as seguintes taxas de falhas Tipo $A\left(\lambda_{A}\right)$ e Tipo $B\left(\lambda_{B}\right)$ :

$$
\begin{aligned}
& \lambda_{A}=\frac{1}{M K B F_{A}}=\frac{1}{250.000}=4 \cdot 10^{-6} \quad f / k m=4 \quad F P M K \\
& \text { e } \\
& \lambda_{B}=\frac{1}{M K B F_{B}}=\frac{1}{8.000}=1,25 \cdot 10^{-4} \quad f / k m=125 \quad F P M K
\end{aligned}
$$

Por se tratar de sistemas em série e com distribuição exponencial de confiabilidade, pode-se calcular a alocação no método EQUAL através da equação 4.31, ou seja:

$$
\begin{aligned}
& \lambda_{s}=n \cdot \lambda \\
& \lambda=\frac{\lambda_{s}}{n}
\end{aligned}
$$

Portanto,

$$
\begin{aligned}
& \lambda_{A}=\frac{4 \cdot 10^{-6}}{12}=3,333 \cdot 10^{-7} \\
& \text { e } \\
& \lambda_{B}=\frac{1,25 \cdot 10^{-4}}{12}=1,042 \cdot 10^{-5}
\end{aligned}
$$

Os valores de MKBF ficariam iguais a: 


$$
M K B F_{A}=\frac{1}{\lambda_{A}}=\frac{1}{3,333 \cdot 10^{-7}}=3.000 .000 \mathrm{~km}
$$

e

$$
\mathrm{MKBF}_{B}=\frac{1}{\lambda_{B}}=\frac{1}{1,042 \cdot 10^{-5}}=96.000 \mathrm{~km}
$$

Com esse método, chega-se a seguinte tabela de alocação:

\begin{tabular}{|c|c|c|c|c|}
\hline \multirow{2}{*}{ SISTEMA } & \multicolumn{2}{|c|}{ FALHA TIPO A } & \multicolumn{2}{|c|}{ FALHA TIPO B } \\
\hline & $\lambda(\mathbf{f} / \mathbf{k m})$ & MKBF & $\lambda(\mathbf{f} / \mathbf{k m})$ & MKBF \\
\hline Portas & 3,333E-07 & 3.000 .000 & 1,042E-05 & 96.000 \\
\hline Tração & 3,333E-07 & 3.000 .000 & 1,042E-05 & 96.000 \\
\hline $\begin{array}{c}\text { Interface com o } \\
\text { condutor } \\
\end{array}$ & 3,333E-07 & 3.000 .000 & 1,042E-05 & 96.000 \\
\hline Data Bus & 3,333E-07 & 3.000 .000 & 1,042E-05 & 96.000 \\
\hline Freio & 3,333E-07 & 3.000 .000 & 1,042E-05 & 96.000 \\
\hline Caixa & 3,333E-07 & 3.000 .000 & 1,042E-05 & 96.000 \\
\hline $\begin{array}{c}\text { Suprimento } \\
\text { elétrico }\end{array}$ & 3,333E-07 & 3.000 .000 & 1,042E-05 & 96.000 \\
\hline $\begin{array}{c}\text { Suprimento de } \\
\text { ar }\end{array}$ & 3,333E-07 & 3.000 .000 & 1,042E-05 & 96.000 \\
\hline Ventilação & 3,333E-07 & 3.000 .000 & 1,042E-05 & 96.000 \\
\hline Conforto & 3,333E-07 & 3.000 .000 & 1,042E-05 & 96.000 \\
\hline Truque & 3,333E-07 & 3.000 .000 & 1,042E-05 & 96.000 \\
\hline Engate & 3,333E-07 & 3.000 .000 & 1,042E-05 & 96.000 \\
\hline TOTAIS & 4,000E-06 & 250.000 & 1,250E-04 & 8.000 \\
\hline
\end{tabular}

Tabela 24: Alocação pelo método EQUAL

Porém, é possível afirmar através da experiência e de dados históricos de outras obras semelhantes, que metas de $3.000 .000 \mathrm{~km}$ para falhas tipo A e 96.000 $\mathrm{km}$ para falhas tipo B para todos os sistemas faria com que alguns sistemas, alcançassem suas metas muito facilmente, como truque e engate, por exemplo. Em contrapartida, outros sistemas como portas e tração jamais alcançariam as metas. Nota-se através desse exemplo que o método EQUAL não é o mais apropriado para a alocação das metas de confiabilidade entre sistemas. De maneira geral, esse 
método é mais aplicável quando se trata de alocação de confiabilidade entre componentes semelhantes dentro de um pequeno módulo, por exemplo.

Recorre-se então ao método ARINC (ver item 4.1.1.2) que, conforme mencionado no item 4.1 é, juntamente com o método da avaliação da viabilidade (ver item 4.1.1.4), o mais empregado na ferrovia.

Com base em histórico de outras obras similares, tem-se uma proporção aproximada de falhas entre os sistemas do trem $\left(\omega_{\mathrm{i}}\right)$. Esses valores estão indicados na Figura 31 para falhas tipo A e na Figura 32 para falhas tipo B.

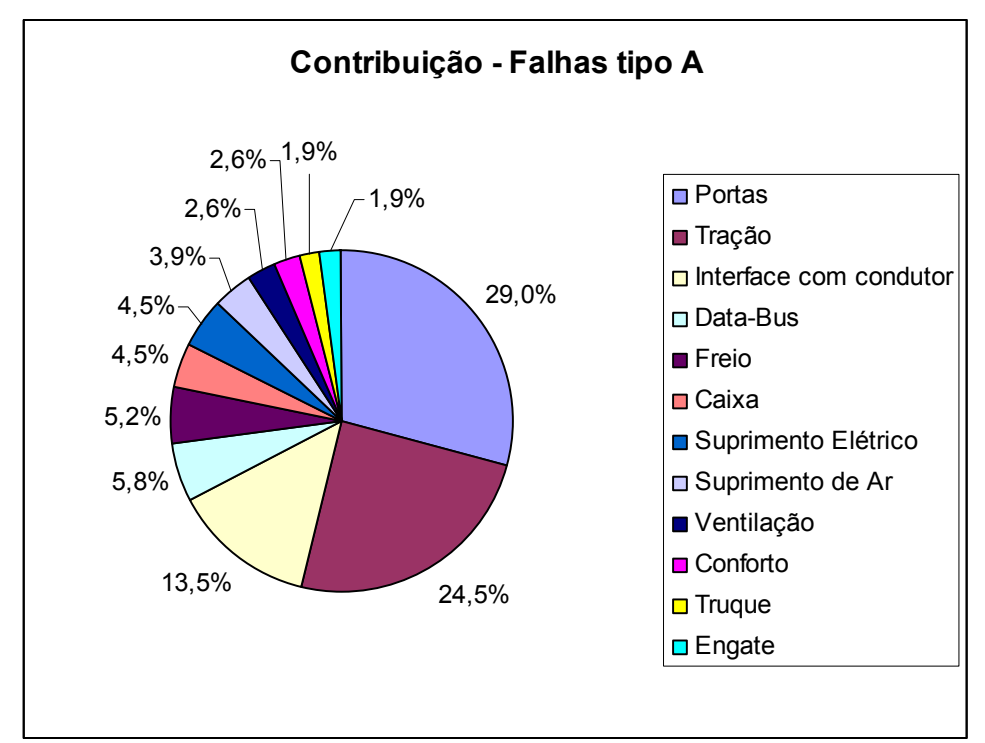

Figura 31: Contribuição por sistema - Falhas tipo A

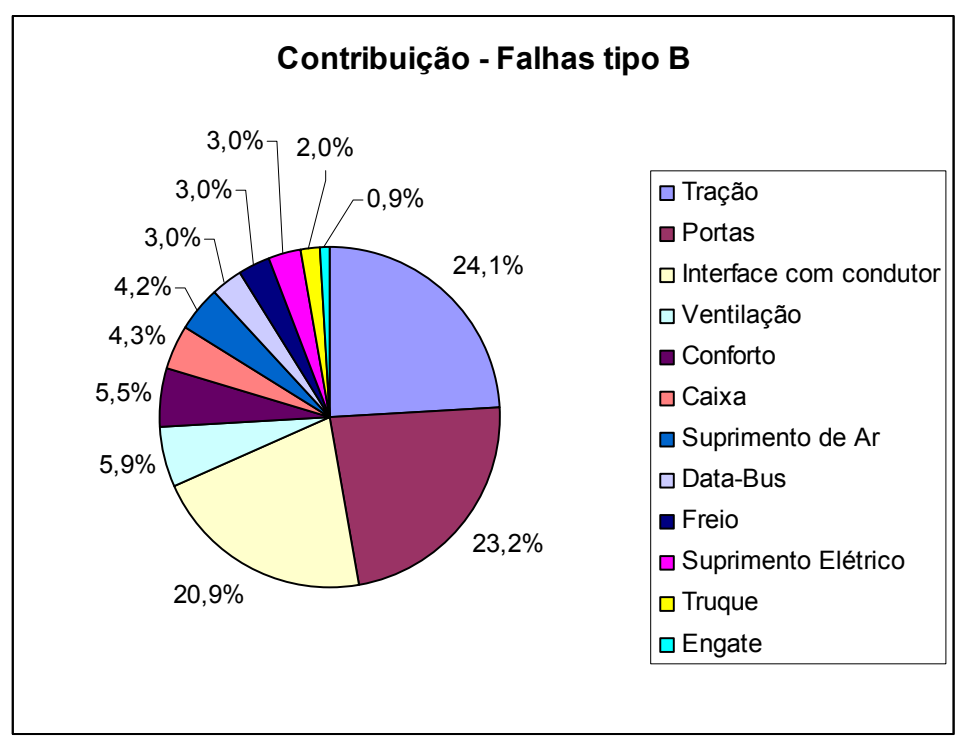

Figura 32: Contribuição por sistema - Falhas tipo B 
Utilizando-se essa proporção como fator de ponderação, calcula-se a meta de cada sistema, através da equação 4.5 .

$$
\lambda_{i}=\omega_{i} \cdot \lambda_{s}
$$

\subsubsection{Resultados}

O resultado desse processo de alocação está apresentado na Tabela 25 para falhas tipo A e na Tabela 26 para falhas tipo $B$.

Comparam-se então essas metas com os valores alcançados em sistemas equivalentes de obras semelhantes. Neste exemplo, os valores obtidos foram considerados possíveis de serem alcançados sem grandes problemas. Caso algum valor fosse demasiadamente difícil de ser alcançado, poderia-se então recorrer ao método da avaliação da viabilidade dos objetivos (ver item 4.1.1.4) em conjunto com o método ARINC até que se obtivessem valores considerados aceitáveis e possíveis de serem alcançados.

Tabela 25: Alocação para falhas tipo A

\begin{tabular}{|l|c|c|c|}
\cline { 2 - 4 } \multicolumn{1}{c|}{} & \multicolumn{2}{c|}{ MKBF $_{\text {objetivo }}$} & 250.000 \\
\cline { 2 - 4 } \multicolumn{1}{c|}{ Sistema } & \multicolumn{2}{c|}{$\lambda_{\text {objetivo }}$} & $4,00 \mathrm{E}-06$ \\
\hline Portas & $29,0 \%$ & $1,16 \mathrm{E}-06$ & 861.111 \\
\hline Tração & $24,5 \%$ & $9,81 \mathrm{E}-07$ & 1.019 .737 \\
\hline Interface com condutor & $13,5 \%$ & $5,42 \mathrm{E}-07$ & 1.845 .238 \\
\hline Data-Bus & $5,8 \%$ & $2,32 \mathrm{E}-07$ & 4.305 .556 \\
\hline Freio & $5,2 \%$ & $2,06 \mathrm{E}-07$ & 4.843 .750 \\
\hline Caixa & $4,5 \%$ & $1,81 \mathrm{E}-07$ & 5.535 .714 \\
\hline Suprimento Elétrico & $4,5 \%$ & $1,81 \mathrm{E}-07$ & 5.535 .714 \\
\hline Suprimento de Ar & $3,9 \%$ & $1,55 \mathrm{E}-07$ & 6.458 .333 \\
\hline Ventilação & $2,6 \%$ & $1,03 \mathrm{E}-07$ & 9.687 .500 \\
\hline Conforto & $2,6 \%$ & $1,03 \mathrm{E}-07$ & 9.687 .500 \\
\hline Truque & $1,9 \%$ & $7,74 \mathrm{E}-08$ & 12.916 .667 \\
\hline Engate & $1,9 \%$ & $7,74 \mathrm{E}-08$ & 12.916 .667 \\
\hline TOTAL & $\mathbf{1 0 0 , 0} \%$ & $\mathbf{4 , 0 0 E}-06$ & $\mathbf{2 5 0 . 0 0 0}$ \\
\hline
\end{tabular}


Tabela 26: Alocação para falhas tipo B

\begin{tabular}{|l|c|c|r|}
\cline { 2 - 4 } \multicolumn{1}{c|}{} & \multicolumn{2}{c|}{ MKBF $_{\text {objetivo }}$} & \multicolumn{1}{c|}{8.000} \\
\cline { 2 - 4 } \multicolumn{1}{c|}{ Sistema } & \multicolumn{2}{c|}{$\lambda_{\text {objetivo }}$} & $1,25 \mathrm{E}-04$ \\
\hline Tração & $24,1 \%$ & $3,01 \mathrm{E}-05$ & \multicolumn{1}{c|}{ MKBF } \\
\hline Portas & $23,2 \%$ & $2,90 \mathrm{E}-05$ & 34.485 \\
\hline Interface com condutor & $20,9 \%$ & $2,61 \mathrm{E}-05$ & 38.278 \\
\hline Ventilação & $5,9 \%$ & $7,38 \mathrm{E}-06$ & 135.593 \\
\hline Conforto & $5,5 \%$ & $6,88 \mathrm{E}-06$ & 145.455 \\
\hline Caixa & $4,3 \%$ & $5,38 \mathrm{E}-06$ & 186.047 \\
\hline Suprimento de Ar & $4,2 \%$ & $5,25 \mathrm{E}-06$ & 190.476 \\
\hline Data-Bus & $3,0 \%$ & $3,75 \mathrm{E}-06$ & 266.667 \\
\hline Freio & $3,0 \%$ & $3,75 \mathrm{E}-06$ & 266.667 \\
\hline Suprimento Elétrico & $3,0 \%$ & $3,75 \mathrm{E}-06$ & 266.667 \\
\hline Truque & $2,0 \%$ & $2,50 \mathrm{E}-06$ & 400.000 \\
\hline Engate & $\mathbf{0 , 9} \%$ & $1,13 \mathrm{E}-06$ & 888.889 \\
\hline TOTAL & $\mathbf{1 0 0 , 0} \%$ & $\mathbf{1 , 2 5 E}-04$ & $\mathbf{8 . 0 0 0}$ \\
\hline
\end{tabular}

\subsubsection{MTBF mínimo dos equipamentos}

Supondo que cada trem rode em média $100.000 \mathrm{~km}$ por ano e com velocidade média de $37 \mathrm{~km} / \mathrm{h}$ (valores especificados pela operadora), é possível calcular o MTBF mínimo de qualquer equipamento instalado no trem para que a cláusula contratual de falha sistemática $(<10 \%)$ seja atendida. O período de garantia é estabelecido para 2 anos. Ver item 3.6.2.3.

O MTBF mínimo de um equipamento que opera durante $100 \%$ do tempo de operação do trem, é calculado da seguinte forma:

$$
M T B F_{\text {min_eq }}=\frac{t}{0,105}=\frac{\frac{2 \cdot 100000}{37}}{0,105}=51480
$$


Já um determinado item que opere $50 \%$ do tempo de operação do trem, seu MTBF mínimo deveria ser igual a:

$$
M T B F_{\text {min_eq }_{-}}=\frac{t}{0,105}=\frac{\left(\frac{2 \cdot 100000}{37}\right) \cdot 0,5}{0,105}=25740
$$

Com isso, é possível definir para esse projeto, uma curva de MTBF mínimo em função do percentual do tempo em que o item opera no trem.

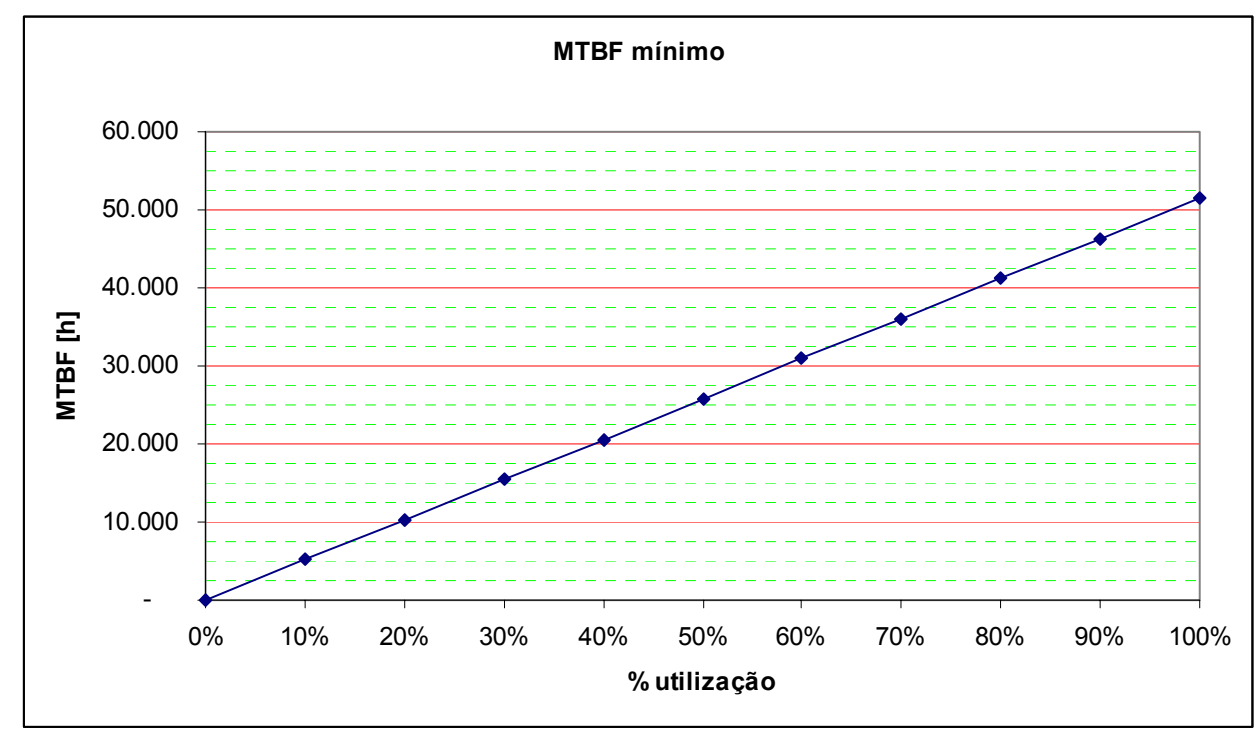

Figura 33: Curva de MTBF mínimo

Portanto, cada item instalado no trem deverá atender a esse critério de MTBF mínimo, independentemente do MTBF do sistema. Logicamente, se para atender o MTBF do sistema o item necessitar de um MTBF diferente, prevalece como meta o de maior valor.

\subsubsection{Recomendações}

Após o processo de alocação de metas e determinação do MTBF mínimo dos componentes, tais informações devem ser inseridas nas especificações de 
fornecimento dos sub-sistemas, as quais são instrumento contratual de negociação técnica entre a montadora e seus fornecedores.

\subsection{EXEMPLO 2: PREDIÇÃO DA CONFIABILIDADE}

\subsubsection{Descrição}

Em uma outra obra, com o projeto já iniciado, a equipe de CDMS realiza a predição de confiabilidade dos sistemas, em parceria com os respectivos fornecedores, buscando avaliar a perspectiva de cumprimento com as metas estabelecidas e destacar quais são os itens críticos para confiabilidade.

O presente exemplo ilustra esse processo para o sistema de Suprimento Elétrico.

\subsubsection{Metas de confiabilidade do sistema}

Em um processo similar ao apresentado no Exemplo 1, o sistema de Suprimento Elétrico teve suas metas definidas da seguinte maneira:

- $\mathrm{MKBF}_{\mathrm{A}}=600.000 \mathrm{~km}\left(\mathrm{FPMK}_{\mathrm{A}}=1,67\right)$

- $\mathrm{MKBF}_{\mathrm{B}}=125.000 \mathrm{~km}\left(\mathrm{FPMK}_{\mathrm{B}}=8,00\right)$

- $\mathrm{MKBF}_{\mathrm{C}}=60.000 \mathrm{~km}\left(\mathrm{FPMK}_{\mathrm{C}}=16,67\right)$

- $\mathrm{MKBF}_{\mathrm{A}+\mathrm{B}+\mathrm{C}}=37.975 \mathrm{~km}\left(\mathrm{FPMK}_{\mathrm{A}+\mathrm{B}+\mathrm{C}}=26,34\right)$

Essas metas foram alocadas para trens de 4 carros em trem-quilômetro (diferentemente do Exemplo 1 em que as metas estavam em carro-quilômetro).

$\mathrm{Na}$ obra em questão, são definidos 3 tipos de falha - A, B e C, da seguinte forma: 
- Falha tipo A: Falhas que afetam a circulação do trem, paralisando ou prejudicando completamente a operação. O trem não tem mais condições de trafegar e é evacuado e retirado de operação imediatamente. - Operação Impossível);

- Falha tipo B: Falhas que afetam parcialmente a circulação do trem, paralisando ou prejudicando parcialmente a operação, com atrasos superiores a 6 minutos. $O$ trem possui condições de trafegar até o final da via por seus próprios meios para ser retirado de operação.

- Falha tipo C: São as falhas que não afetam a circulação dos trens. O trem tem condições de cumprir a programação do dia ou pode aguardar em operação por uma programação de parada, desde que não provoque atrasos na operação superiores a 6 minutos. Falhas encontradas na manutenção preventiva também são consideradas como tipo C.

No Plano do Programa de Confiabilidade, foram detalhados os critérios de classificação de falhas para cada sistema do trem, de acordo com as definições de cada tipo de falha. No caso específico do sistema de Suprimento Elétrico, os critérios estabelecidos estão descritos na Tabela 27.

Tabela 27: Classificação de falhas - Suprimento elétrico

\begin{tabular}{|c|l|c|c|c|}
\hline \multirow{2}{*}{ SISTEMA } & CATEGORIA DE FALHA & TIPO A (Significante) & TIPO B (Maior) & TIPO C (Menor) \\
\cline { 2 - 5 } & \multicolumn{1}{|c|}{ EFEITO NA OPERAÇÃo } & $\begin{array}{c}\text { Operação Impossível } \\
\text { (Evacuação elou reboque) }\end{array}$ & $\begin{array}{c}\text { Operação Emergencial 1 } \\
\text { (Término da volta - } \\
\text { desempenho degradado) }\end{array}$ & $\begin{array}{c}\text { Operação Emergencial 2 } \\
\text { (Programação de parada) }\end{array}$ \\
\hline $\begin{array}{c}\text { Suprimento } \\
\text { Elétrico }\end{array}$ & $\begin{array}{l}\text { Alimentação Corrente } \\
\text { Alternada (CA) }\end{array}$ & $\begin{array}{c}\text { Perda total da alimentação } \\
\text { CA do trem (100\%) }\end{array}$ & $\begin{array}{c}\text { Perda parcial (inferior à } \\
100 \%) \text { da alimentação CA do } \\
\text { trem }\end{array}$ & $\begin{array}{c}\text { Falhas que não provocam } \\
\text { perdas de alimentação }\end{array}$ \\
\hline $\begin{array}{c}\text { Suprimento } \\
\text { Elétrico }\end{array}$ & $\begin{array}{l}\text { Alimentação Corrente } \\
\text { Contínua (CC) }\end{array}$ & $\begin{array}{c}\text { Perda Total da alimentação } \\
\text { CC do trem (100\%) }\end{array}$ & $\begin{array}{c}\text { Perda parcial (inferior à } \\
100 \%) \text { da alimentação CC do } \\
\text { trem }\end{array}$ & $\begin{array}{c}\text { Falhas que não provocam } \\
\text { perdas de alimentação }\end{array}$ \\
\hline
\end{tabular}

\subsubsection{Estrutura analítica do sistema}

O primeiro passo é desmembrar o sistema em seus itens e quantidades, até o nível em que é feita a manutenção no trem. Isso está relacionado com o 
conceito de Item Substituível em Linha (LRU) e Item Substituível em Bancada (SRU). Dessa forma, tem-se a chamada estrutura analítica do sistema, a qual será base tanto para as análises de predição durante o projeto como para apuração dos índices de falha quando o trem já estiver em operação.

A Tabela 28 mostra a estrutura analítica do sistema de Suprimento Elétrico e a respectiva quantidade de cada item.

Tabela 28: Estrutura analítica - Suprimento Elétrico

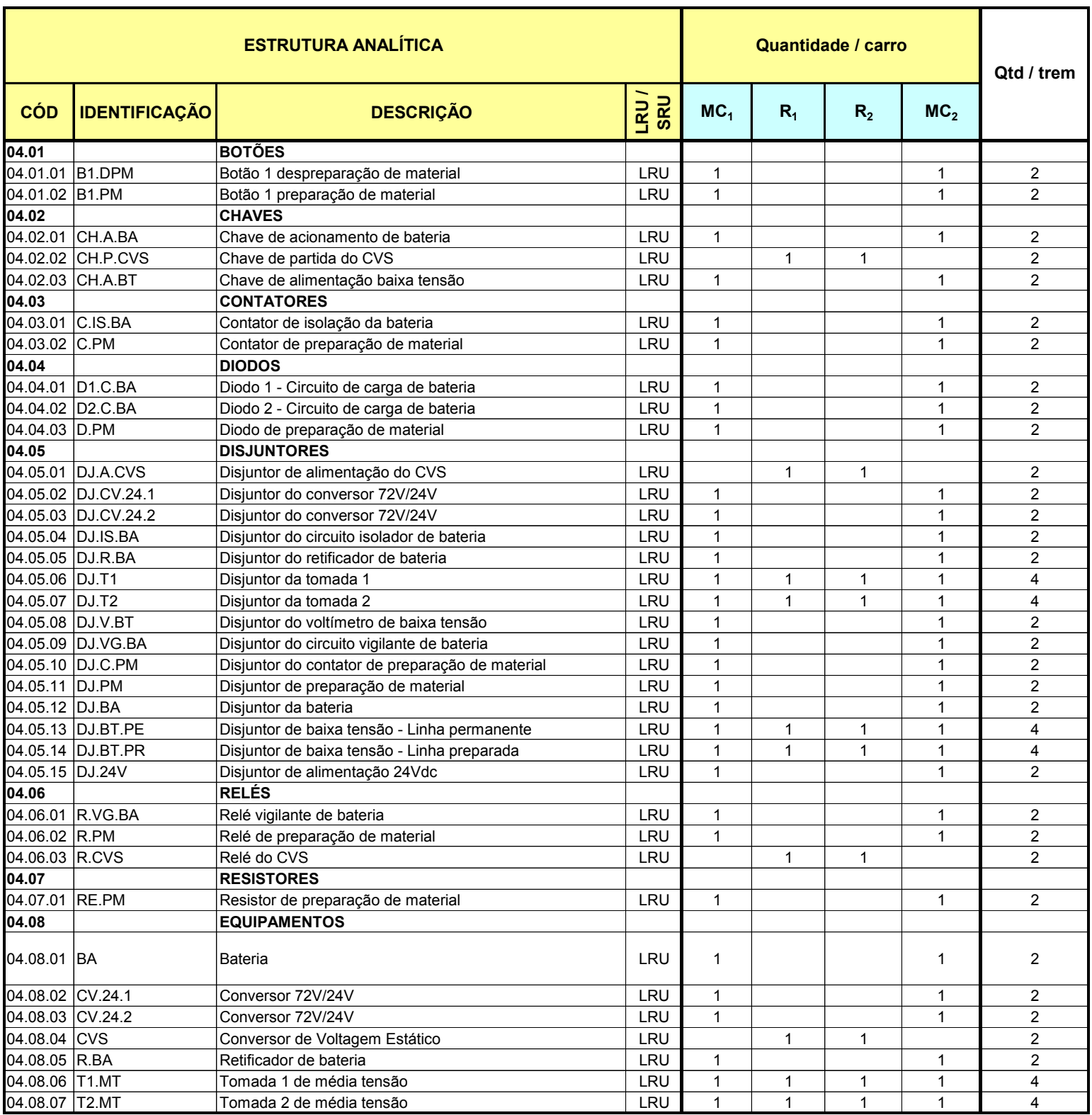




\subsubsection{Determinação da confiabilidade dos componentes}

Para os itens classificados como LRU, são calculados os valores de MTBF baseando-se, sempre que possível, na seguinte ordem de prioridade:

- Informações reais de campo de falhas ocorridas nos componentes idênticos aos que serão usados no novo projeto;

- Informações reais de campo de falhas ocorridas em componentes similares aos que serão usados no novo projeto;

- Informações de resultados de ensaios de vida realizados em componentes idênticos ou similares aos que serão usados no novo projeto;

- Informações de banco de dados e guias tais como (20) e (22);

- Estimação por avaliação de especialistas e comparação com outros sistemas.

A fonte de informação do MTBF de cada item deve ser mencionada, assim como também deve ser mencionado se o item já foi provado em operação ou não. A Tabela 29 mostra como isso pode ser feito. Pode-se notar que alguns itens foram baseados em dados de campo (Projeto "X"), outros em informações de bancos de dados como a MIL-HDBK-217 (20) e NPRD 95 (22), ou ainda em informações dos fornecedores dos equipamentos (Fornecedor "A"). Os itens identificados como "OBJETIVADO" são aqueles para os quais não se dispunha no momento de dados suficientes e, portanto, foi feita uma avaliação técnica para estabelecer o MTBF mínimo do componente de maneira a não exceder as metas do sistema. 
Tabela 29: Valores de MTBF e fonte de informação

\begin{tabular}{|c|c|c|c|c|}
\hline \multicolumn{2}{|c|}{ ESTRUTURA ANALÍTICA } & \multirow{2}{*}{$\begin{array}{c}\text { MTBF } \\
{[\mathrm{h}]}\end{array}$} & \multirow{2}{*}{$\begin{array}{c}\text { Provado em } \\
\text { operação? } \\
\text { [S/N] }\end{array}$} & \multirow{2}{*}{$\begin{array}{c}\text { Fonte de } \\
\text { Informação }\end{array}$} \\
\hline CÓD & IDENTIFICAÇÃO & & & \\
\hline \multicolumn{5}{|l|}{04.01} \\
\hline 04.01 .01 & B1.DPM & 387.684 & $\mathrm{~s}$ & Projeto "X" \\
\hline 04.01 .02 & B1.PM & 775.368 & $\mathrm{~s}$ & Projeto "X" \\
\hline \multicolumn{5}{|c|}{\begin{tabular}{|l|l}
04.02 & \\
\end{tabular}} \\
\hline 04.02 .01 & CH.A.BA & 303.155 & $\mathrm{~s}$ & Projeto "X" \\
\hline 04.02 .02 & CH.P.CVS & 303.155 & $\mathrm{~S}$ & Projeto "X" \\
\hline 04.02 .03 & CH.A.BT & 303.155 & $\mathrm{~S}$ & Projeto "X" \\
\hline \multicolumn{5}{|c|}{\begin{tabular}{l|l}
04.03 & \\
\end{tabular}} \\
\hline 04.03 .01 & C.IS.BA & 387.684 & $\mathrm{~s}$ & Projeto "X" \\
\hline 04.03 .02 & C.PM & 387.684 & $\mathrm{~S}$ & Projeto "X" \\
\hline \multicolumn{5}{|c|}{\begin{tabular}{|l|l|}
04.04 & \\
\end{tabular}} \\
\hline 04.04 .01 & D1.C.BA & 49.225 .195 & $\mathrm{~N}$ & MIL-HDBK-217F \\
\hline 04.04 .02 & D2.C.BA & 49.225 .195 & $\mathrm{~N}$ & MIL-HDBK-217F \\
\hline 04.04 .03 & D.PM & 49.225 .195 & $\mathrm{~N}$ & MIL-HDBK-217F \\
\hline \multicolumn{5}{|c|}{\begin{tabular}{|l|l|}
04.05 & \\
\end{tabular}} \\
\hline 04.05 .01 & DJ.A.CVS & 4.040 .754 & $\mathrm{~s}$ & Projeto "X" \\
\hline 04.05 .02 & DJ.CV.24.1 & 4.040 .754 & $\mathrm{~S}$ & Projeto "X" \\
\hline 04.05 .03 & DJ.CV.24.2 & 404.754 & $\mathrm{~s}$ & Projeto "X" \\
\hline 04.05 .04 & DJ.IS.BA & 4.040 .754 & $\mathrm{~S}$ & Projeto "X" \\
\hline 04.05 .05 & DJ.R.BA & 505.258 & S & Projeto "X" \\
\hline 04.05 .06 & DJ.T1 & 4.040 .754 & S & Projeto "X" \\
\hline 04.05 .07 & DJ.T2 & 4.040 .754 & $\mathrm{~S}$ & Projeto "X" \\
\hline 04.05 .08 & DJ.V.BT & 4.040 .754 & $\mathrm{~S}$ & Projeto "X" \\
\hline 04.05 .09 & DJ.VG.BA & 4.040 .754 & $\mathrm{~S}$ & Projeto "X" \\
\hline 04.05 .10 & DJ.C.PM & 4.040 .754 & $\mathrm{~S}$ & Projeto "X" \\
\hline 04.05 .11 & DJ.PM & 4.040 .754 & $\mathrm{~S}$ & Projeto "X" \\
\hline 04.05 .12 & DJ.BA & 535.000 & $\mathrm{~N}$ & MIL-HDBK-217F \\
\hline 04.05 .13 & DJ.BT.PE & 535.000 & $\mathrm{~N}$ & MIL-HDBK-217F \\
\hline 04.05 .14 & DJ.BT.PR & 535.000 & $\mathrm{~N}$ & MIL-HDBK-217F \\
\hline 04.05 .15 & DJ.24V & 535.000 & $\mathrm{~N}$ & MIL-HDBK-217F \\
\hline \multicolumn{5}{|c|}{\begin{tabular}{l|l}
04.06 & \\
\end{tabular}} \\
\hline 04.06 .01 & R.VG.BA & 709.684 & $\mathrm{~N}$ & MIL-HDBK-217F \\
\hline 04.06 .02 & R.PM & 1.906 .104 & $\mathrm{~N}$ & MIL-HDBK-217F \\
\hline 04.06 .03 & R.CVS & 709.684 & $\mathrm{~N}$ & MIL-HDBK-217F \\
\hline \multicolumn{5}{|c|}{\begin{tabular}{|l|l|}
04.07 & \\
\end{tabular}} \\
\hline 04.07.01 & RE.PM & 629.026 & $\mathrm{~N}$ & MIL-HDBK-217F \\
\hline \multicolumn{5}{|c|}{\begin{tabular}{|l|l}
04.08 & \\
\end{tabular}} \\
\hline 04.08 .01 & BA & 613.459 & $N$ & $\begin{array}{c}\text { NPRD-95 - Battery } \\
18354-000\end{array}$ \\
\hline 04.08 .02 & CV.24.1 & 17.000 & $\mathrm{~N}$ & OBJETIVADO \\
\hline 04.08 .03 & CV.24.2 & 17.000 & $\mathrm{~N}$ & OBJETIVADO \\
\hline 04.08 .04 & CVS & 14.653 & $\mathrm{~N}$ & Fornecedor "A" \\
\hline 04.08 .05 & R.BA & 31.387 & $\mathrm{~N}$ & Fornecedor "A" \\
\hline 04.08 .06 & T1.MT & 19.415 .213 & $\mathrm{~N}$ & MIL-HDBK-217F \\
\hline 04.08 .07 & T2.MT & 19.415 .213 & $\mathrm{~N}$ & MIL-HDBK-217F \\
\hline
\end{tabular}




\subsubsection{Cálculo do MTBF dos itens}

- Projeto " $X$ "

Os itens indicados na Tabela 29 cuja fonte de informação é mencionada como Projeto "X", tiveram seu MTBF calculados com base em características construtivas e de operação dos trens que fazem parte desse projeto, e na observação dos itens instalados quanto a apresentação de falhas.

Por exemplo, o item 04.05.01 corresponde a um disjuntor monofásico, em operação no Projeto "X", com as seguintes características:

- $\quad$ Total de itens do mesmo tipo instalados por trem no Projeto "X": 91

- Total de trens na frota: 60

- Quilometragem acumulada pela frota em um determinado período: 3.197.000 trem-km.

- Número de falhas observadas no período: 4

- Velocidade média da frota observada no período: $18 \mathrm{~km} / \mathrm{h}$

Através da equação 4.17 é possível calcular a estimativa de MKBF desse item:

$$
\begin{aligned}
& \hat{\theta}=\frac{n \cdot T}{f} \\
& \hat{\theta}=\frac{91 \times 3.197 .000}{4}=72.731 .750 \mathrm{~km}
\end{aligned}
$$

onde $n \cdot T$ é a quilometragem acumulada pelos disjuntores desse tipo na frota.

Calcula-se então o MTBF do item, através de equação 3.4, levando-se em conta a velocidade média da frota em circulação:

$$
M T B F=\frac{M K B F}{V C}=\frac{72.731 .750}{18}=4.040 .650 h
$$


- MIL-HDBK-217-F

Os itens indicados na Tabela 29 cuja fonte de informação é mencionada como MIL-HDBK-217-F, tiveram seu MTBF calculados com base na norma de mesmo código (20).

Por exemplo, o item 04.06.01 corresponde a um relé, para o qual a norma citada define a seguinte equação para cálculo da taxa de falhas (ver equação 4.13):

$$
\lambda_{p}=\lambda_{b} \cdot \pi_{L} \cdot \pi_{C} \cdot \pi_{C Y C} \cdot \pi_{F} \cdot \pi_{Q} \cdot \pi_{e}
$$

Para cada fator multiplicativo a norma apresenta uma tabela que deve ser consultada de acordo com as características construtivas e operacionais do componente. Neste caso específico, foram obtidos os seguintes fatores:

$\lambda_{b}=0,0075$ (Taxa de falha base na temperatura de $25^{\circ} \mathrm{C}$ );

$\pi_{L}=1,07528$ (Fator de carga, para uma carga resistiva de 2,155 A e contato com capacidade para $10 \mathrm{~A}$ de corrente);

$$
\begin{aligned}
& \pi_{C}=5,5 \text { (Relé com } 4 \text { contatos reversíveis); } \\
& \pi_{C Y C}=1 \text { (freqüência de atuação menor que } 10 \text { ciclos por hora); } \\
& \pi_{F}=2 \text { (Tipo magnético - média potência); } \\
& \pi_{Q}=2,9 \text { (Qualidade comercial) } \\
& \pi_{E}=\sqrt{2 \cdot 15} \text { (Fator ambiental - Média geométrica entre fatores terrestres }
\end{aligned}
$$

fixo e móvel)

Calcula-se assim a taxa de falhas $\lambda$ do componente:

$$
\begin{aligned}
& \lambda_{p}=\lambda_{b} \cdot \pi_{L} \cdot \pi_{C} \cdot \pi_{C Y C} \cdot \pi_{F} \cdot \pi_{Q} \cdot \pi_{e} \\
& \lambda_{p}=0,0075 \cdot 1,07528 \cdot 5,5 \cdot 1 \cdot 2 \cdot 2,9 \cdot \sqrt{2 \cdot 15} \\
& \lambda_{p}=1,409078 \quad \mathrm{FPMH}
\end{aligned}
$$

que resulta em um MTBF de:

$$
M T B F=\frac{1}{\lambda_{p}}=\frac{1}{1,409078 \cdot 10^{-6}}=709.684 \quad h
$$


- NPRD-95

O único item indicado na Tabela 29 cuja fonte de informação é mencionada como NPRD-95, teve seu MTBF obtido com base no documento de mesmo código (22), através de consulta direta.

- Fornecedor "A"

Os itens indicados na Tabela 29 cuja fonte de informação é mencionada como Fornecedor "A", tiveram seu MTBF estimados pelo fornecedor com base em experiências, dados de campo, ensaios, etc.

\subsubsection{Contribuição para cada tipo de falha}

Através de análises mais detalhadas como FMECA, determinam-se os percentuais de contribuição de cada componente para cada tipo de falha, levando-se em conta os efeitos provocados no trem por cada modo de falha do item, além dos critérios definidos na especificação técnica e do Plano do Programa de Confiabilidade (ver Exemplo 4).

A Tabela 30 mostra um exemplo de apresentação da contribuição percentual de cada item da estrutura para cada tipo de falha. 
Tabela 30: Contribuição por tipo de falha

\begin{tabular}{|c|c|c|c|c|}
\hline \multicolumn{2}{|c|}{ ESTRUTURA ANALÍTICA } & \multicolumn{3}{|c|}{$\begin{array}{c}\text { Contribuição por tipo de falha } \\
{[\%]}\end{array}$} \\
\hline Cód & IDENTIFICAÇÃO & $\mathbf{A}$ & B & C \\
\hline \multicolumn{5}{|l|}{04.01} \\
\hline 04.01 .01 & B1.DPM & 20,0 & & 80,0 \\
\hline 04.01 .02 & B1.PM & & & 100,0 \\
\hline \multicolumn{5}{|c|}{\begin{tabular}{|l|l|}
04.02 & \\
\end{tabular}} \\
\hline 04.02 .01 & CH.A.BA & & 74,5 & 25,5 \\
\hline 04.02 .02 & CH.P.CVS & & 74,5 & 25,5 \\
\hline 04.02 .03 & CH.A.BT & & 6,3 & 93,7 \\
\hline \multicolumn{5}{|c|}{\begin{tabular}{|l|l|}
04.03 & \\
\end{tabular}} \\
\hline 04.03 .01 & C.IS.BA & & & 100,0 \\
\hline 04.03 .02 & C.PM & & 55,0 & 45,0 \\
\hline \multicolumn{5}{|c|}{\begin{tabular}{|l|l|}
04.04 & \\
\end{tabular}} \\
\hline 04.04.01 & D1.C.BA & & 29,0 & 71,0 \\
\hline 04.04 .02 & D2.C.BA & & & 100,0 \\
\hline 04.04 .03 & D.PM & & & 100,0 \\
\hline \multicolumn{5}{|c|}{\begin{tabular}{|l|l|}
04.05 &
\end{tabular}} \\
\hline 04.05 .01 & DJ.A.CVS & & 51,0 & 49,0 \\
\hline 04.05 .02 & DJ.CV.24.1 & & 51,0 & 49,0 \\
\hline 04.05 .03 & DJ.CV.24.2 & & 51,0 & 49,0 \\
\hline 04.05 .04 & DJ.IS.BA & & & 100,0 \\
\hline 04.05 .05 & DJ.R.BA & & 51,0 & 49,0 \\
\hline 04.05 .06 & DJ.T1 & & & 100,0 \\
\hline 04.05 .07 & DJ.T2 & & & 100,0 \\
\hline 04.05 .08 & DJ.V.BT & & & 100,0 \\
\hline 04.05 .09 & DJ.VG.BA & & & 100,0 \\
\hline 04.05 .10 & DJ.C.PM & & 51,0 & 49,0 \\
\hline 04.05 .11 & DJ.PM & & & 100,0 \\
\hline 04.05 .12 & DJ.BA & & & 100,0 \\
\hline 04.05 .13 & DJ.BT.PE & 25,5 & & 74,5 \\
\hline 04.05 .14 & DJ.BT.PR & & 51,0 & 49,0 \\
\hline 04.05 .15 & DJ.24V & 51,0 & & 49,0 \\
\hline \multicolumn{5}{|c|}{\begin{tabular}{|l|l|}
04.06 & \\
\end{tabular}} \\
\hline 04.06 .01 & R.VG.BA & & & 100,0 \\
\hline 04.06 .02 & R.PM & & & 100,0 \\
\hline 04.06 .03 & R.CVS & & 81,0 & 19,0 \\
\hline \multicolumn{5}{|c|}{\begin{tabular}{|l|l|}
04.07 & \\
\end{tabular}} \\
\hline 04.07 .01 & RE.PM & & & 100,0 \\
\hline \multicolumn{5}{|c|}{\begin{tabular}{|l|l|}
04.08 & \\
\end{tabular}} \\
\hline 04.08.01 & BA & & 100,0 & \\
\hline 04.08 .02 & CV.24.1 & & & 100,0 \\
\hline 04.08 .03 & CV.24.2 & & & 100,0 \\
\hline 04.08 .04 & CVS & & 75,0 & 25,0 \\
\hline 04.08 .05 & R.BA & & 100,0 & \\
\hline 04.08 .06 & T1.MT & & & 100,0 \\
\hline 04.08 .07 & T2.MT & & & 100,0 \\
\hline
\end{tabular}




\subsubsection{Cálculo das taxas de falha}

A taxa de falha de cada componente é obtida calculando-se o inverso de seu MTBF. A taxa de falhas de cada componente refletida no trem depende da quantidade instalada desse componente, ou seja, é o produto da taxa de falhas do componente pela sua quantidade.

Para a obtenção da taxa de falhas tipo A, B ou C de cada componente, multiplica-se a taxa de falhas desse componente refletida no trem pelo percentual de contribuição para cada tipo de falha.

A Tabela 31 mostra um exemplo desses cálculos. Os valores de contribuição percentual são aqueles já apresentados anteriormente, na Tabela 30.

Para obtenção das taxas de falha globais do sistema, basta somar as colunas $\lambda_{A}, \lambda_{B}$ e $\lambda_{C}$ da Tabela 31 . Isso só é possível pois o sistema é considerado em série e seus itens com taxa de falhas constante.

O resultado da predição do sistema é apresentado na Tabela 32, assim como as respectivas conversões em diferentes unidades. A velocidade média da frota utilizada para as conversões foi estimada no Plano do Programa de Confiabilidade e é de $19,7 \mathrm{~km} / \mathrm{h}$. 
Tabela 31: Taxas de falha distribuídas por tipo de falha

\begin{tabular}{|c|c|c|c|c|c|c|c|c|}
\hline \multicolumn{2}{|c|}{ ESTRUTURA ANALÍTICA } & \multirow{2}{*}{ Qtd / trem } & \multirow{2}{*}{$\begin{array}{l}\text { MTBF } \\
{[\mathrm{h}]}\end{array}$} & \multicolumn{2}{|c|}{$\frac{\lambda}{[\text { falhas } / h \text { ] }}$} & \multicolumn{3}{|c|}{$\lambda($ Trem) } \\
\hline Cód & IDENTIFICAÇÃO & & & Componente & Trem & $\lambda_{\mathrm{A}}$ & $\lambda_{B}$ & $\lambda_{c}$ \\
\hline \multicolumn{9}{|c|}{\begin{tabular}{|l|l}
04.01 & \\
\end{tabular}} \\
\hline 04.01 .01 & B1.DPM & 2 & 387.684 & $2,579 \mathrm{E}-06$ & $5,159 \mathrm{E}-06$ & $1,032 \mathrm{E}-06$ & & $4,127 \mathrm{E}-06$ \\
\hline 04.01 .02 & B1.PM & 2 & 775.368 & $1,290 \mathrm{E}-06$ & $2,579 \mathrm{E}-06$ & & & $2,579 \mathrm{E}-06$ \\
\hline \multicolumn{9}{|c|}{\begin{tabular}{|l|l|}
04.02 & \\
\end{tabular}} \\
\hline 04.02 .01 & CH.A.BA & 2 & 303.155 & $3,299 \mathrm{E}-06$ & $6,597 \mathrm{E}-06$ & & 4,915E-06 & 1,682E-06 \\
\hline 04.02 .02 & CH.P.CVS & 2 & 303.155 & $3,299 \mathrm{E}-06$ & $6,597 \mathrm{E}-06$ & & 4,915E-06 & $1,682 \mathrm{E}-06$ \\
\hline 04.02 .03 & CH.A.BT & 2 & 303.155 & $3,299 \mathrm{E}-06$ & $6,597 \mathrm{E}-06$ & & $4,156 \mathrm{E}-07$ & $6,182 \mathrm{E}-06$ \\
\hline \multicolumn{9}{|c|}{\begin{tabular}{l|l}
04.03 & \\
\end{tabular}} \\
\hline 04.03 .01 & C.IS.BA & 2 & 387.684 & $2,579 \mathrm{E}-06$ & $5,159 \mathrm{E}-06$ & & & 5,159E-06 \\
\hline 04.03 .02 & C.PM & 2 & 387.684 & $2,579 \mathrm{E}-06$ & $5,159 \mathrm{E}-06$ & & 2,837E-06 & $2,321 \mathrm{E}-06$ \\
\hline \multicolumn{9}{|c|}{\begin{tabular}{|l|l|}
04.04 & \\
\end{tabular}} \\
\hline 04.04 .01 & D1.C.BA & 2 & 49.225 .195 & $2,031 \mathrm{E}-08$ & $4,063 \mathrm{E}-08$ & & $1,178 \mathrm{E}-08$ & $2,885 \mathrm{E}-08$ \\
\hline 04.04 .02 & D2.C.BA & 2 & 49.225 .195 & $2,031 \mathrm{E}-08$ & $4,063 \mathrm{E}-08$ & & & 4,063E-08 \\
\hline 04.04 .03 & D.PM & 2 & 49.225 .195 & $2,031 \mathrm{E}-08$ & 4,063E-08 & & & 4,063E-08 \\
\hline \multicolumn{9}{|c|}{\begin{tabular}{|l|l|}
04.05 & \\
\end{tabular}} \\
\hline 04.05 .01 & DJ.A.CVS & 2 & 4.040 .754 & $2,475 \mathrm{E}-07$ & $4,950 \mathrm{E}-07$ & & $2,524 \mathrm{E}-07$ & $2,425 \mathrm{E}-07$ \\
\hline 04.05 .02 & DJ.CV.24.1 & 2 & 4.040 .754 & $2,475 \mathrm{E}-07$ & $4,950 \mathrm{E}-07$ & & $2,524 \mathrm{E}-07$ & $2,425 \mathrm{E}-07$ \\
\hline 04.05 .03 & DJ.CV.24.2 & 2 & 404.754 & $2,471 \mathrm{E}-06$ & $4,941 \mathrm{E}-06$ & & $2,520 \mathrm{E}-06$ & $2,421 \mathrm{E}-06$ \\
\hline 04.05 .04 & DJ.IS.BA & 2 & 4.040 .754 & $2,475 \mathrm{E}-07$ & $4,950 \mathrm{E}-07$ & & & $4,950 \mathrm{E}-07$ \\
\hline 04.05 .05 & DJ.R.BA & 2 & 505.258 & $1,979 \mathrm{E}-06$ & $3,958 \mathrm{E}-06$ & & $2,019 \mathrm{E}-06$ & $1,940 \mathrm{E}-06$ \\
\hline 04.05 .06 & DJ.T1 & 4 & 4.040 .754 & $2,475 \mathrm{E}-07$ & $9,899 \mathrm{E}-07$ & & & $9,899 \mathrm{E}-07$ \\
\hline 04.05 .07 & DJ.T2 & 4 & 4.040 .754 & $2,475 \mathrm{E}-07$ & $9,899 \mathrm{E}-07$ & & & $9,899 \mathrm{E}-07$ \\
\hline 04.05 .08 & DJ.V.BT & 2 & 4.040 .754 & $2,475 \mathrm{E}-07$ & $4,950 \mathrm{E}-07$ & & & $4,950 \mathrm{E}-07$ \\
\hline 04.05 .09 & DJ.VG.BA & 2 & 4.040 .754 & $2,475 \mathrm{E}-07$ & $4,950 \mathrm{E}-07$ & & & $4,950 \mathrm{E}-07$ \\
\hline 04.05 .10 & DJ.C.PM & 2 & 4.040 .754 & $2,475 \mathrm{E}-07$ & $4,950 \mathrm{E}-07$ & & $2,524 \mathrm{E}-07$ & $2,425 \mathrm{E}-07$ \\
\hline 04.05 .11 & DJ.PM & 2 & 4.040 .754 & $2,475 \mathrm{E}-07$ & $4,950 \mathrm{E}-07$ & & & $4,950 \mathrm{E}-07$ \\
\hline 04.05 .12 & DJ.BA & 2 & 535.000 & $1,869 \mathrm{E}-06$ & $3,738 \mathrm{E}-06$ & & & $3,738 \mathrm{E}-06$ \\
\hline 04.05 .13 & DJ.BT.PE & 4 & 535.000 & $1,869 \mathrm{E}-06$ & $7,477 \mathrm{E}-06$ & 1,907E-06 & & $5,570 \mathrm{E}-06$ \\
\hline 04.05 .14 & DJ.BT.PR & 4 & 535.000 & 1,869E-06 & 7,477E-06 & & 3,813E-06 & $3,664 \mathrm{E}-06$ \\
\hline 04.05 .15 & DJ.24V & 2 & 535.000 & 1,869E-06 & $3,738 \mathrm{E}-06$ & 1,907E-06 & & 1,832E-06 \\
\hline \multicolumn{9}{|c|}{\begin{tabular}{|l|l|}
04.06 & \\
\end{tabular}} \\
\hline 04.06 .01 & R.VG.BA & 2 & 709.684 & 1,409E-06 & $2,818 \mathrm{E}-06$ & & & $2,818 \mathrm{E}-06$ \\
\hline 04.06 .02 & R.PM & 2 & 1.906 .104 & $5,246 \mathrm{E}-07$ & 1,049E-06 & & & $1,049 \mathrm{E}-06$ \\
\hline 04.06 .03 & R.CVS & 2 & 709.684 & $1,409 \mathrm{E}-06$ & $2,818 \mathrm{E}-06$ & & $2,283 \mathrm{E}-06$ & $5,354 \mathrm{E}-07$ \\
\hline \multicolumn{9}{|c|}{\begin{tabular}{|l|l|}
04.07 & \\
\end{tabular}} \\
\hline 04.07 .01 & RE.PM & 2 & 629.026 & 1,590E-06 & $3,180 \mathrm{E}-06$ & & & $3,180 \mathrm{E}-06$ \\
\hline \multicolumn{9}{|l|}{04.08} \\
\hline 04.08 .01 & BA & 2 & 613.459 & $1,630 \mathrm{E}-06$ & $3,260 \mathrm{E}-06$ & & $3,260 \mathrm{E}-06$ & \\
\hline 04.08 .02 & CV.24.1 & 2 & 17.000 & $5,882 \mathrm{E}-05$ & $1,176 \mathrm{E}-04$ & & & $1,176 \mathrm{E}-04$ \\
\hline 04.08 .03 & CV.24.2 & 2 & 17.000 & $5,882 \mathrm{E}-05$ & $1,176 \mathrm{E}-04$ & & & $1,176 \mathrm{E}-04$ \\
\hline 04.08 .04 & CVS & 2 & 14.653 & $6,825 \mathrm{E}-05$ & $1,365 \mathrm{E}-04$ & & $1,024 \mathrm{E}-04$ & $3,412 \mathrm{E}-05$ \\
\hline 04.08 .05 & R.BA & 2 & 31.387 & $3,186 \mathrm{E}-05$ & $6,372 \mathrm{E}-05$ & & $6,372 \mathrm{E}-05$ & \\
\hline 04.08 .06 & T1.MT & 4 & 19.415.213 & $5,151 \mathrm{E}-08$ & $2,060 \mathrm{E}-07$ & & & $2,060 \mathrm{E}-07$ \\
\hline 04.08 .07 & T2.MT & 4 & 19.415.213 & $5,151 \mathrm{E}-08$ & $2,060 \mathrm{E}-07$ & & & $2,060 \mathrm{E}-07$ \\
\hline
\end{tabular}

Tabela 32: Resultados da predição

\begin{tabular}{|c|c|c|c|c|}
\hline & $\begin{array}{c}\text { MTBF } \\
{[\mathbf{h}]}\end{array}$ & $\begin{array}{c}\lambda \\
{[\mathbf{f} / \mathbf{h}]}\end{array}$ & $\begin{array}{c}\text { MKBF } \\
{[\mathbf{~ k m}]}\end{array}$ & $\begin{array}{c}\text { FPMK } \\
{\left[\lambda \times \mathbf{1 0}^{\mathbf{6}}\right]}\end{array}$ \\
\hline Falha tipo A: & 206.405 & $4,845 \mathrm{E}-06$ & 4.066 .171 & 0,246 \\
\hline Falha tipo B: & 5.159 & $1,938 \mathrm{E}-04$ & 101.633 & 9,839 \\
\hline Falha tipo C: & 3.076 & $3,251 \mathrm{E}-04$ & 60.596 & 16,503 \\
\hline Falha tipo A+B+C: & 1.909 & $5,238 \mathrm{E}-04$ & 37.611 & 26,588 \\
\hline
\end{tabular}




\subsubsection{Apresentação e interpretação dos resultados}

A predição completa de confiabilidade do sistema está na Figura 34 . Pode-se notar na Figura 35 que as predições para os tipos de falha A e C estão dentro das metas porém, para o tipo de falha B o valor limite foi ultrapassado, não atendendo à meta estabelecida. Conseqüentemente, o valor total das falhas também ultrapassou o limite estabelecido.

Na Figura 36 e na Figura 37, está representada a contribuição de cada tipo de falha. A maior contribuição de falha é do tipo $B$, seguido da falha tipo $C$, cujo valor está praticamente no limite estabelecido. A falha tipo A apresentou contribuição mínima nas falhas.

A Figura 38 mostra um gráfico de Pareto com os itens que mais contribuem para falhas do tipo A. Nota-se que existem somente 3 itens contribuindo para este tipo de falha, onde somente os dois primeiros representam $78 \%$ do total. Os itens são o 04.05 .13 (Disjuntor Baixa Tensão Linha Permanente), 04.05.15 (Disjuntor Alimentação 24VDC) e 04.01 .01 (Botão de Despreparação do Material) e, portanto, são os itens a serem melhorados em uma eventual tentativa de redução da taxa de falha do tipo A.

Na Figura 39 podemos verificar que existem dois itens que se destacam na contribuição para este tipo de falha e, juntos, representam $85 \%$ do total de falhas tipo B. São eles o 04.08.04 (CVS) e o 04.08.05 (Retificador de Bateria). Em caso de melhoria da taxa de falha tipo B estes são os itens a serem melhorados.

A Figura 40 mostra um gráfico de pareto com os 10 itens que mais contribuem para falhas tipo C. Nota-se que os itens 04.08 .02 (Conversor 1 72/24VDC) e 04.08.03 (Conversor 2 72/24VDC) representam aproximadamente $72 \%$ das falhas desse tipo e, portanto são os principais itens a serem melhorados em uma eventual tentativa de redução da taxa de falhas tipo $\mathrm{C}$.

A Figura 41 mostra um gráfico de Pareto com os 10 itens que mais contribuem para a taxa de falhas global do sistema. Nota-se que há uma participação homogênea dos 10 primeiros itens, onde juntos respondem por aproximadamente $70 \%$ das falhas desse tipo. Os 5 primeiros itens, que respondem por $41 \%$ do total, são 04.05 .13 (Disjuntor Baixa Tensão Linha Permanente), 
04.05.14 (Disjuntor Baixa Tensão Linha Preparada), 04.02.01 (Chave de Acionamento Bateria), 04.02.02 (Chave Partida CVS) e 04.02.03 (Chave Alimentação Baixa Tensão) e são os principais itens a serem melhorados em uma eventual tentativa de redução da taxa de falhas global do sistema. 


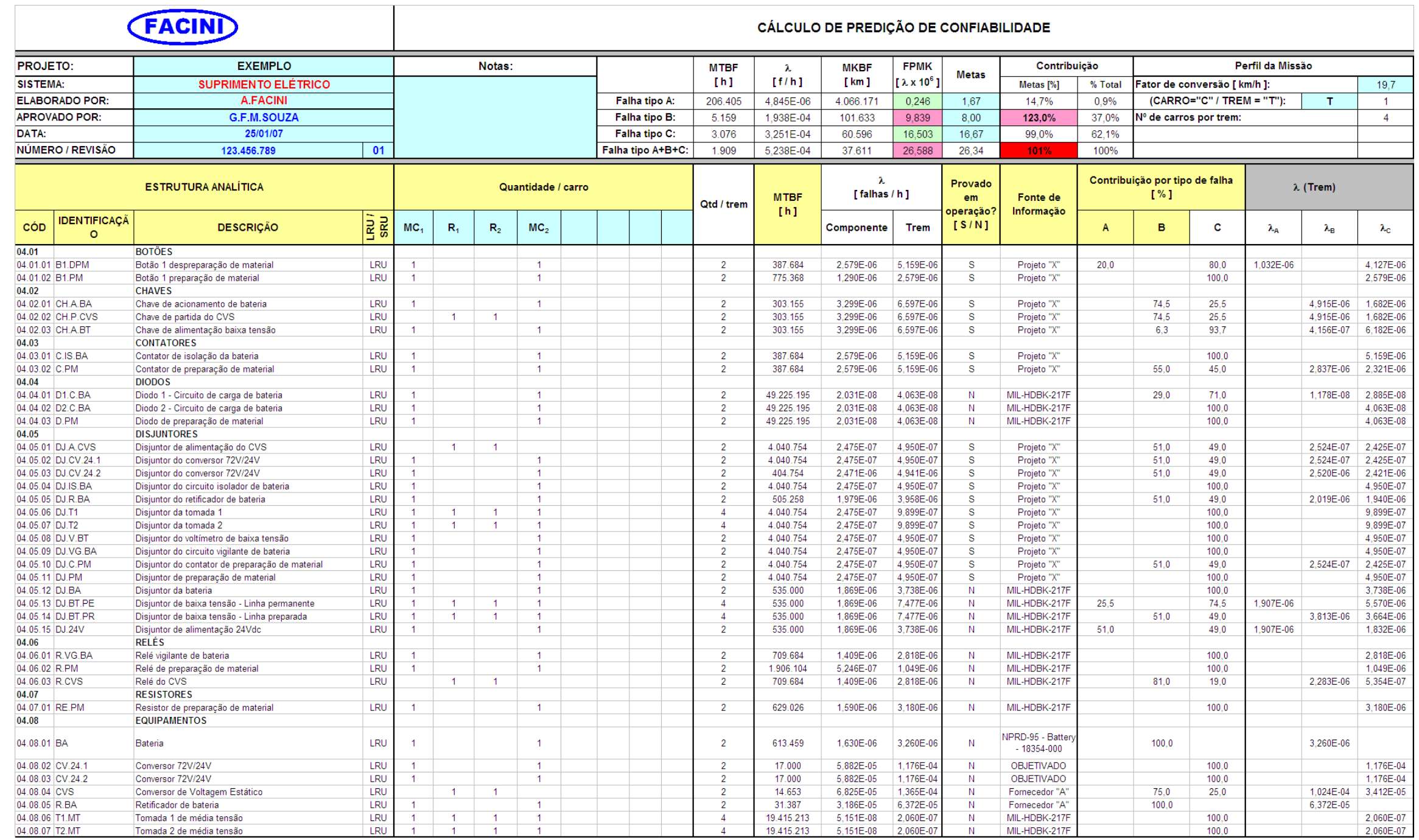

Figura 34: Planilha de predição de confiabilidade 


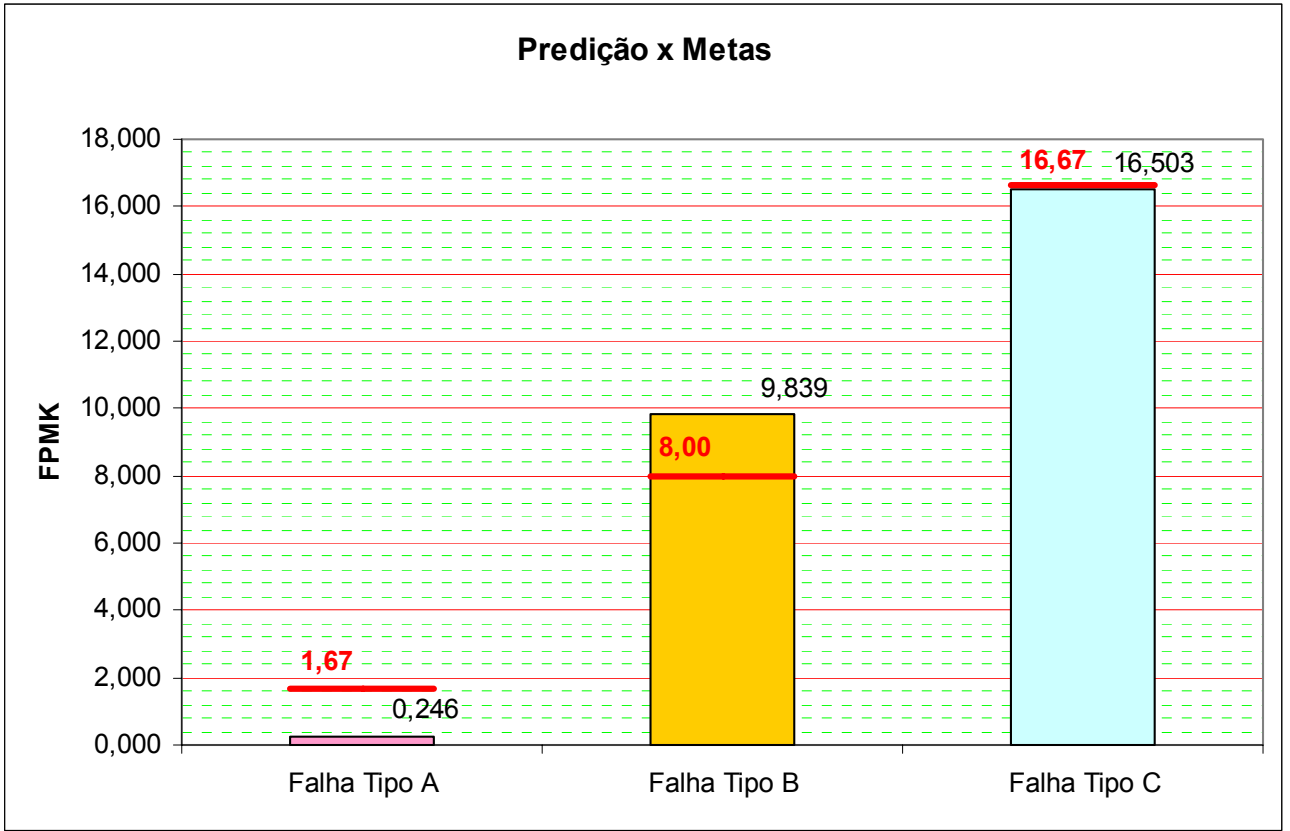

Figura 35: Predição x Metas

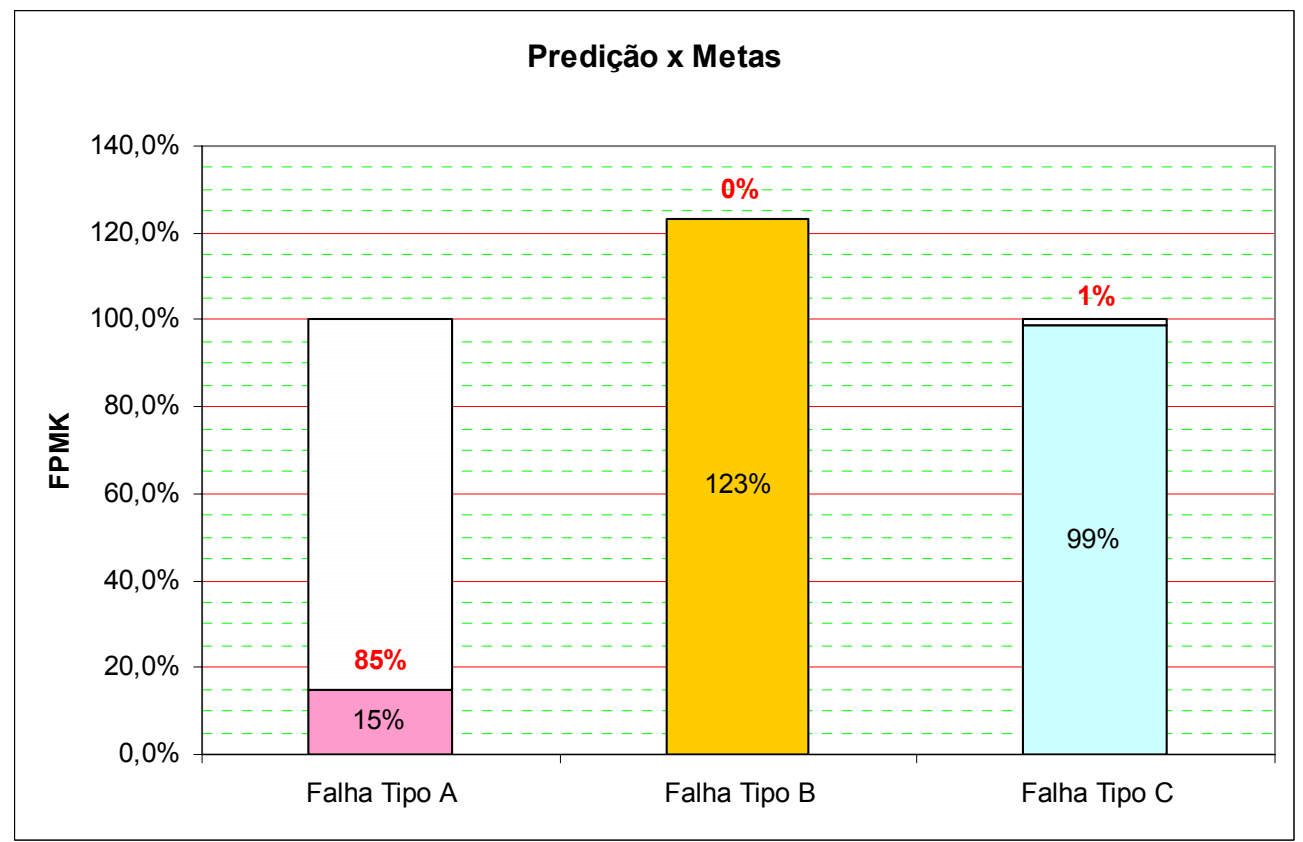

Figura 36: Predição x Metas 


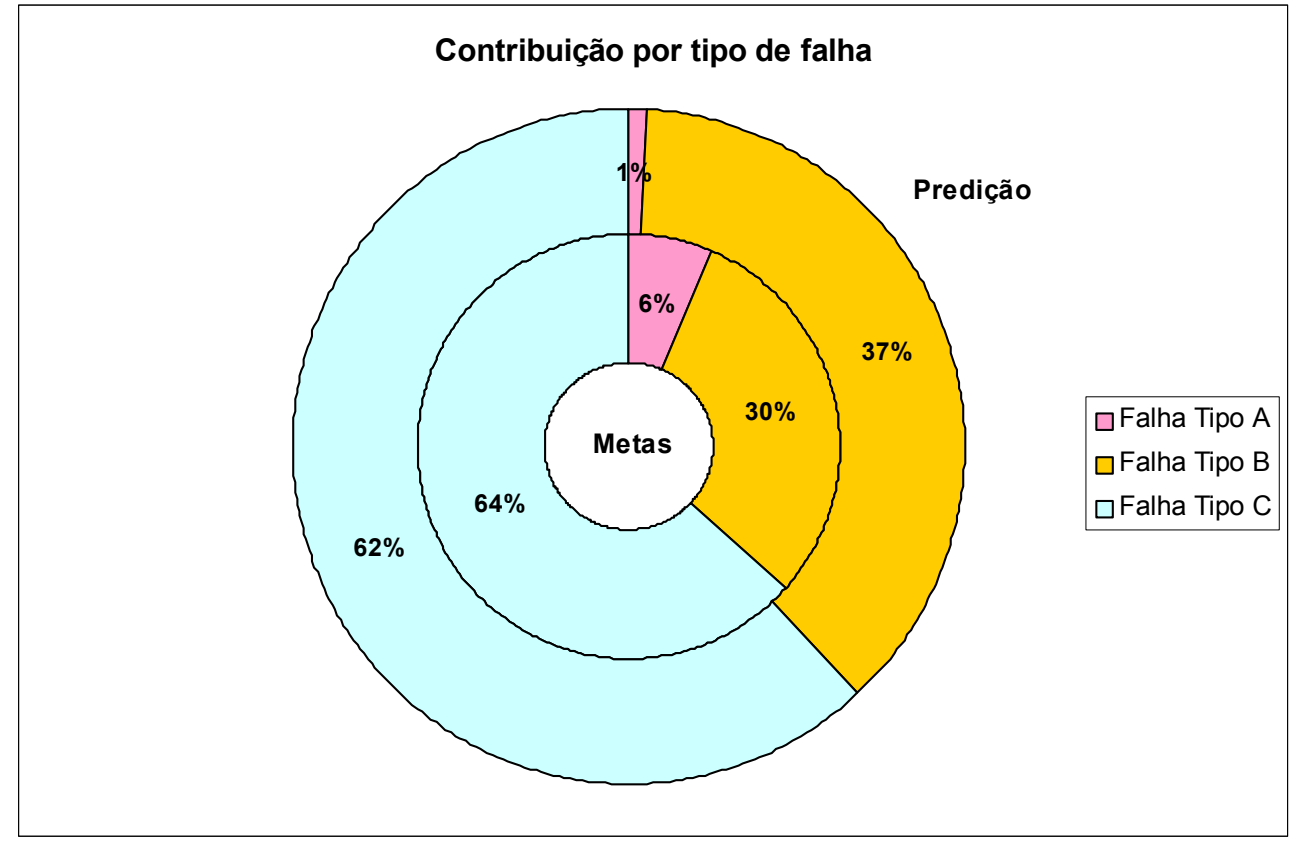

Figura 37: Contribuição por tipo de falha

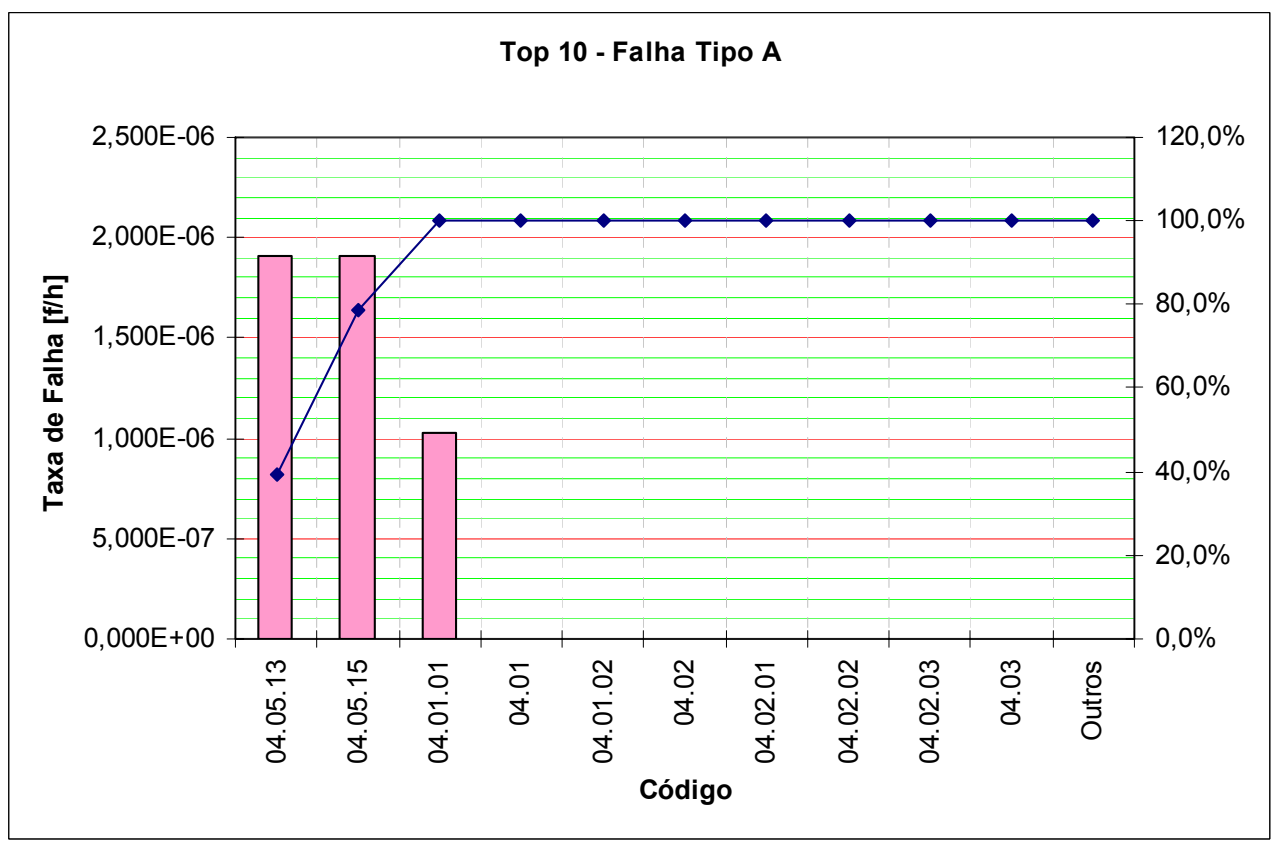

Figura 38: TOP 10 - Falha tipo A 


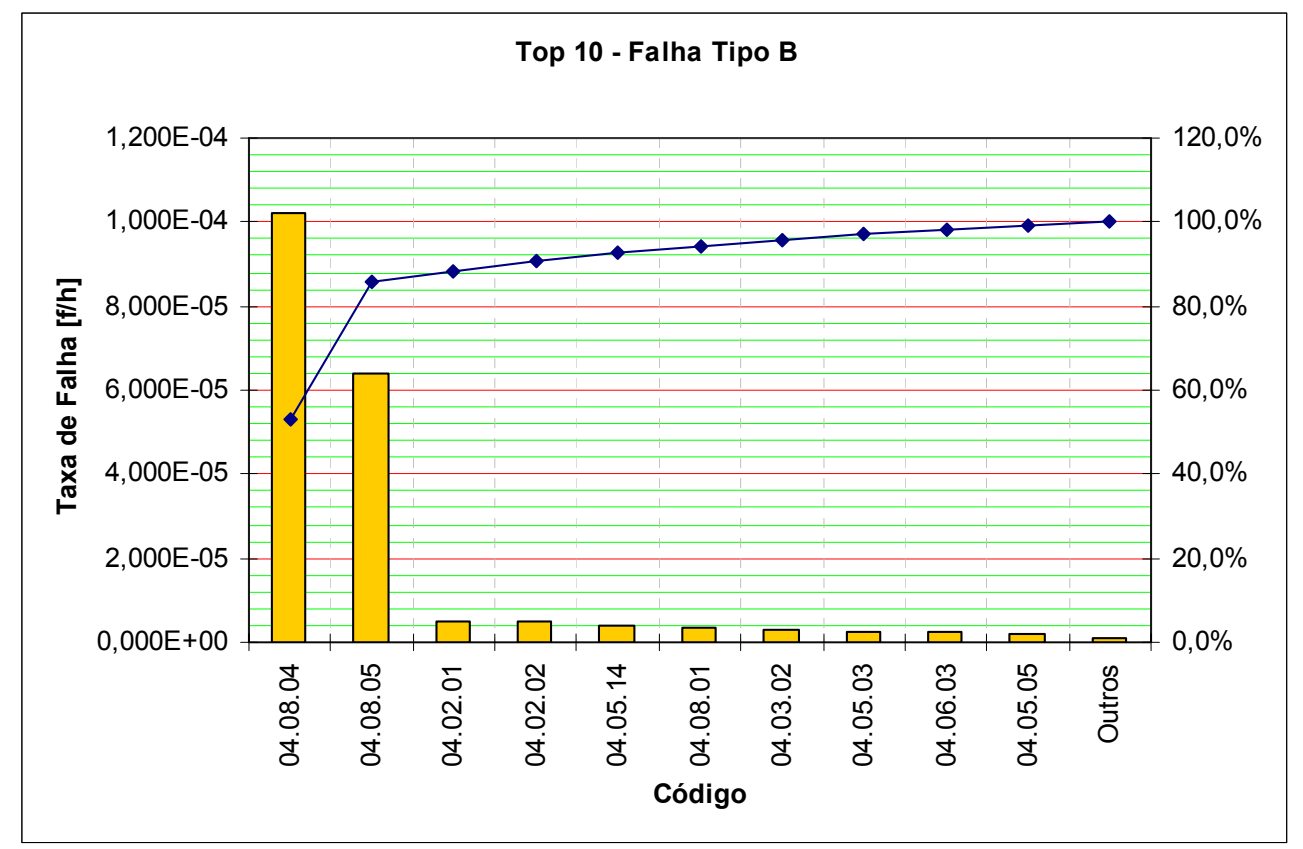

Figura 39: TOP 10 - Falha tipo B

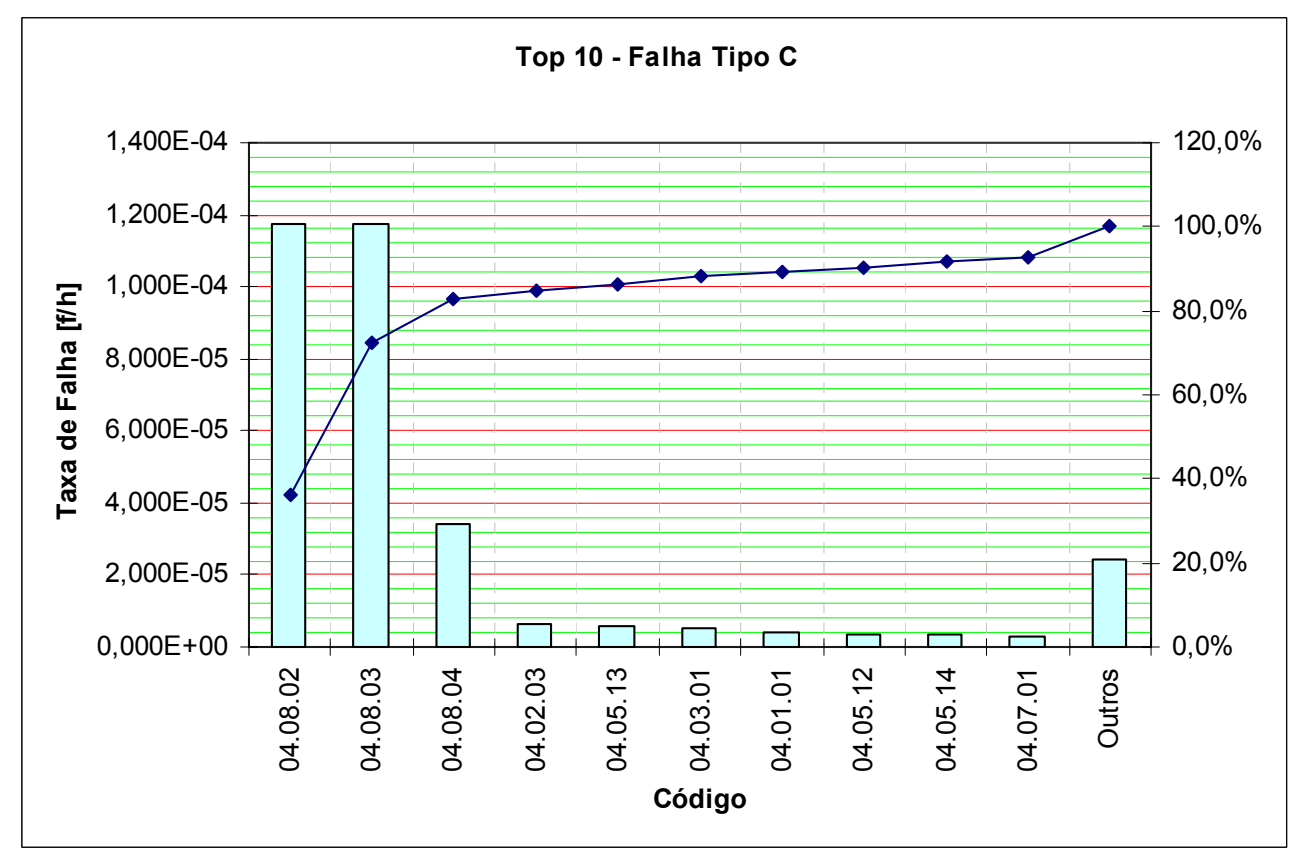

Figura 40: TOP 10 - Falha tipo C 


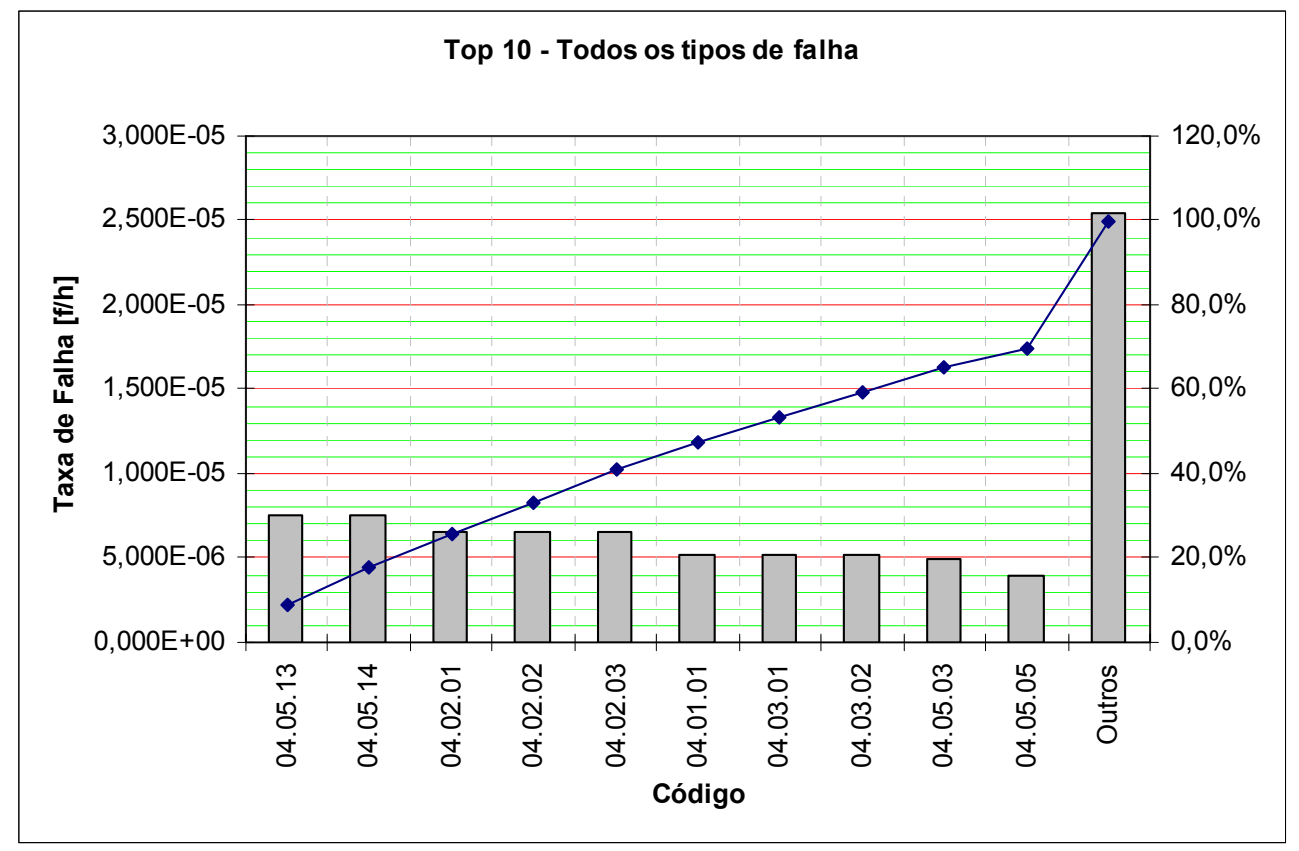

Figura 41: TOP 10 - Todos os tipos de falha

\subsubsection{Recomendações}

Para que a meta de confiabilidade proposta para a falha do tipo B seja alcançada e, conseqüentemente também a meta global do sistema, devem ser tomadas ações no sentido de melhorar o MTBF do item 04.08.04, Conversor de Voltagem Estático, o qual apresenta um valor baixo nesta predição.

Foram feitas simulações e conclui-se que para atender às metas estabelecidas o valor de MTBF do item 04.08.04 deve ser igual ou superior a 23.000 horas, ou seja, deve haver um acréscimo de $57 \%$ sobre o valor atual. O fabricante do item deve ser informado para que tome as devidas ações de maneira a alcançar essa meta. 


\subsection{EXEMPLO 3: ANÁLISE DE SOLICITAÇÃO E RESISTÊNCIA}

\subsubsection{Descrição}

Este exemplo ilustra a integração entre as áreas de confiabilidade e segurança dentro de um projeto. Ainda que o assunto específico segurança não tenha sido abordado de uma forma mais completa neste trabalho, a segurança dos sistemas é significativamente afetada pela sua confiabilidade.

Em um estudo mais abrangente de segurança, constatou-se a necessidade de demonstração de que a probabilidade de falha de um cabo de aço que realiza o intertravamento entre alavancas do controlador mestre no console do trem, seja menor que $1 \times 10^{-9}$.

Apenas para ilustrar melhor o funcionamento desse intertravamento, existem três alavancas no console de condução do trem em um dado projeto. Uma para selecionar o esforço de tração e frenagem demandado pelo operador e outras duas, conjugadas entre si, que determinam o sentido de direção (frente ou ré) e o modo de condução (manual, automático e neutro). O cabo de aço em questão faz com que sejam evitadas comutações das alavancas em situações que possam causar situações inseguras, como por exemplo a inversão do sentido de marcha sem que o trem esteja em modo de operação manual.

Dentro de um sistema, a taxa de falhas do cabo de aço é demasiadamente pequena, o que faz com que a mesma seja desprezível para predição da confiabilidade do sistema. Porém, por ser um item que pode afetar a segurança, o estudo de confiabilidade se faz necessário como suporte para as argumentações que comprovarão a segurança do trem. O modo de falha indesejado é a ruptura do cabo, que faria com que os intertravamentos de segurança fossem eliminados.

O projeto seguiu as recomendações do fabricante do cabo de aço quanto à instalação do mesmo, incluindo raio de curvatura, carga recomendada, forma de fixação, etc. Além disso são previstas inspeções periódicas para verificar a existência de anomalias nesse dispositivo, como atrito excessivo, por exemplo, que 
poderia comprometer a resistência do cabo com o rompimento progressivo dos fios do cabo. Com estas considerações, o estudo fica restrito à ruptura do cabo devido à solicitação imposta.

A técnica mais apropriada nesse caso é o da solicitação e resistência, conforme descrito no item 4.2.3 deste trabalho.

\subsubsection{Dados de entrada}

De acordo com o procedimento descrito em 4.2.3, é necessário que se conheçam as distribuições de probabilidades da solicitação imposta ao cabo e da sua resistência. Em termos práticos, por se tratar de itens mecânicos e com base em situações semelhantes estudadas anteriormente, assume-se que ambas as distribuições possuam distribuição normal.

Dessa forma, é necessário conhecer a média e o desvio padrão da solicitação e da resistência para se determinar as funções densidade de probabilidade.

Os dados de resistência foram obtidos do catálogo do fabricante. A carga recomendada $(22,7 \mathrm{~kg})$ foi considerada como média da distribuição e, em função do desconhecimento do valor real, o desvio padrão foi assumido como $15 \%$ desse valor, ou seja $3,4 \mathrm{~kg}$.

Os dados de solicitação foram obtidos diretamente do dispositivo, no qual foram realizadas algumas medições da carga aplicada ao cabo de aço quando da comutação das alavancas. A média e desvio padrão encontrados foram de 0,2 e 0,1 Kgf respectivamente.

\subsubsection{Cálculo e resultados}

- Solicitação:

- Média: $\quad \mu_{S}=0,2 \mathrm{kgf}$ 
- Desvio Padrão: $\quad \sigma_{s}=0,1 \mathrm{kgf}$

- f.d.p.:

$$
S(x)=\left(\frac{1}{\sqrt{2 \cdot \pi} \cdot \sigma_{S}}\right) \cdot e^{-0,5 \cdot\left[\frac{\left(x-\mu_{S}\right)}{\sigma_{S}}\right]^{2}}
$$

- Resistência:

- Média:

$$
\mu_{R}=22,7 \quad \mathrm{kgf}
$$

- Desvio Padrão:

$$
\sigma_{R}=3,405 \mathrm{kgf}
$$

- f.d.p.:

$$
\operatorname{Re}(x)=\left(\frac{1}{\sqrt{2 \cdot \pi} \cdot \sigma_{R}}\right) \cdot e^{-0,5 \cdot\left[\frac{\left(x-\mu_{R}\right)}{\sigma_{R}}\right]^{2}}
$$

Através da equação 4.15 , calcula-se a probabilidade de falha:

$$
\begin{aligned}
& F(x, y)=\int_{0}^{\infty}\left(\int_{0}^{y} \operatorname{Re}(x) \cdot d x\right) \cdot S(y) \cdot d y \\
& F(x, y)=6,802 \cdot 10^{-12}
\end{aligned}
$$

\subsubsection{Recomendações e considerações}

De acordo com os cálculos realizados, ficou demonstrado que a probabilidade de falha do mesmo por ruptura é inferior a $10^{-9}$, o que, conforme os demais estudos de segurança é suficiente para garantir a segurança do dispositivo.

Uma análise de sensibilidade foi realizada para se identificar a influência do desvio padrão da resistência na probabilidade de falha. A Figura 42 mostra o resultado dessa análise. Nota-se que com um desvio padrão a partir de $17,2 \%$, a probabilidade de falha passa a ser maior que o valor especificado de $10^{-9}$. 


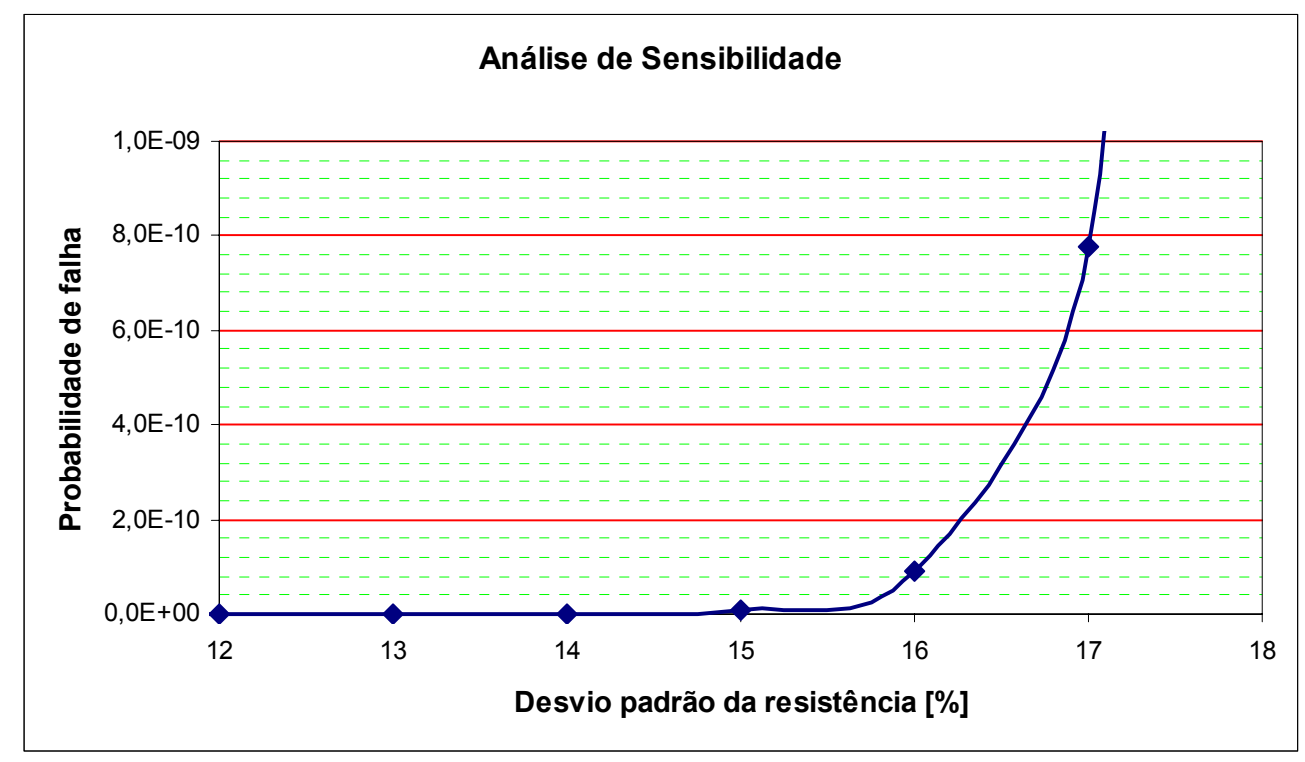

Figura 42: Análise de Sensibilidade

Para efeitos didáticos, de uma maneira geral, supondo que a meta não tivesse sido alcançada, seria possível estabelecer recomendações típicas baseandose nos 4 parâmetros de entrada da análise de solicitação e resistência de forma a reduzir a probabilidade de falha, ou em outras palavras, aumentar a confiabilidade. São elas:

- Aumentar a resistência média - Basicamente através do dimensionamento e da seleção de materiais com maior resistência. Alguns fatores limitantes são geralmente tamanho, peso e custo.

- Reduzir a solicitação média - Ocasionalmente a solicitação média pode ser reduzida com pequenas modificações no projeto, ou nos procedimentos operacionais sem que 0 desempenho seja significativamente afetado.

- Diminuir a variação da solicitação - A variação da solicitação é geralmente difícil de ser controlada. Todavia, a distribuição de solicitação pode ser efetivamente truncada através da inclusão de dispositivos que limitem as condições de uso, tais como sensores, fusíveis, etc.

- Diminuir a variação da resistência - A variação natural da resistência de item para item pode ser reduzida através da melhoria do processo produtivo e de um controle de qualidade mais rigoroso. 


\subsection{EXEMPLO 4: FMECA}

\subsubsection{Descrição}

Durante a fase de detalhamento de um projeto, realizam-se análises aprofundadas dos modos de falha dos componentes, avaliando os efeitos provocados nos demais componentes do sistema, assim como no funcionamento e na segurança do trem. De acordo com o que foi discutido no item 4.4, as análises do tipo FMECA são adequadas para isso. Conforme mencionado no exemplo 2, esse tipo de análise também se presta à determinação dos percentuais de contribuição para cada tipo de falha.

Análises FMECA são geralmente extensas e trabalhosas por natureza (ver item 4.4), portanto, neste exemplo será abordado um sistema denominado "Caixa - Miscelâneas" devido ao seu tamanho relativamente reduzido. Esse sistema compreende basicamente itens como:

- Limpador de pára brisa;

- Esguicho d'água;

- Buzina e itens relacionados;

- Retrovisores automáticos;

\subsubsection{Premissas do Plano de Confiabilidade e Segurança}

Nas especificações técnicas da operadora, os tipos de falha são definidos da seguinte maneira:

- FALHA TIPO A (SIGNIFICANTE): Falhas que afetam a circulação do trem, paralisando ou prejudicando completamente a operação. O trem não tem mais condições de trafegar e é evacuado e retirado de operação imediatamente. 
- FALHA TIPO B (MAIOR): Falhas que afetam parcialmente a circulação do trem, paralisando ou prejudicando parcialmente a operação, com atrasos superiores a 6 minutos. O trem possui condições de trafegar até o final da via por seus próprios meios para ser retirado de operação.

- FALHA TIPO C (MENOR): São as falhas que não afetam a circulação dos trens. O trem tem condições de cumprir com a programação do dia ou pode aguardar em operação por uma programação de parada, desde que não provoque atrasos na operação superiores a 6 minutos. Falhas encontradas na manutenção preventiva também são consideradas como do tipo $\mathrm{C}$.

O Plano do Programa de Confiabilidade, definido no início do projeto, define detalhadamente a classificação de cada tipo de falha para cada sistema, considerando seu desempenho. Após algumas rodadas de apresentações e discussões, esse Plano fora aprovado pela operadora. No caso específico do sistema "Caixa - Miscelâneas", chegou-se à seguinte classificação:

Tabela 33: Classificação de falhas - CAIXA - Miscelâneas

\begin{tabular}{|c|c|c|c|c|}
\hline \multirow{2}{*}{ SISTEMA } & CATEGORIA DE FALHA & TIPO A (Significante) & TIPO B (Maior) & TIPO C (Menor) \\
\cline { 2 - 5 } & EFEITO NA OPERAÇÃo & $\begin{array}{c}\text { Operação Impossível } \\
\text { (Evacuação e/ou reboque) }\end{array}$ & $\begin{array}{c}\text { Operação Emergencial 1 } \\
\text { (Término da volta - } \\
\text { desempenho degradado) }\end{array}$ & $\begin{array}{c}\text { Operação Emergencial 2 } \\
\text { (Programação de parada) }\end{array}$ \\
\hline Caixa & $\begin{array}{l}\text { Pára-brisa, limpador de pára- } \\
\text { brisa e esguicho d'água; }\end{array}$ & - & $\begin{array}{c}\text { Perda do limpador de pára } \\
\text { brisa do lado do condutor, } \\
\text { falha do pára-brisa } \\
\text { (quebrado, solto) }\end{array}$ & $\begin{array}{c}\text { Perda do limpador de pára } \\
\text { brisa do lado do carona, } \\
\text { perda total do esquicho } \\
\text { d'água }\end{array}$ \\
\hline Caixa & Buzina (sistema); & - & Perda total da buzina & $\begin{array}{c}\text { Perda parcial da buzina } \\
\text { (menor intensidade sonora) }\end{array}$ \\
\hline Caixa & Espelho externo e quebra-sol; & - & $\begin{array}{c}\text { Falha no espelho externo e } \\
\text { no quebra-sol }\end{array}$ \\
\hline
\end{tabular}

Nota-se que, de acordo com essa definição, não existem falhas do tipo A nesse sistema.

O Plano do Programa de Segurança define as categorias de severidade, conforme a Tabela 34. Define também as categorias de freqüência conforme a Tabela 35, a matriz de risco e aceitabilidades conforme a Tabela 36, e as ações a serem tomadas para cada categoria de risco conforme a Tabela 37. 
Tabela 34: Severidade

\begin{tabular}{|c|c|c|c|}
\hline $\begin{array}{c}\text { Descrição da } \\
\text { severidade do } \\
\text { perigo }\end{array}$ & $\begin{array}{c}\text { Categoria da } \\
\text { severidade do } \\
\text { perigo }\end{array}$ & Consequência ao pessoal ou ambiente & $\begin{array}{c}\text { Consequência ao } \\
\text { serviço }\end{array}$ \\
\hline CATATRÓFICO & I & $\begin{array}{l}\text { Fatalidades e/ou ferimentos múltiplos } \\
\text { severos e/ou maiores danos ao ambiente. }\end{array}$ & Perda de todo o sistema \\
\hline CRÍTICO & II & $\begin{array}{l}\text { Fatalidade simples e/ou ferimentos severos } \\
\text { e/ou danos significativos ao ambiente }\end{array}$ & $\begin{array}{l}\text { Perda de grande parte } \\
\text { do sistema }\end{array}$ \\
\hline MARGINAL & III & $\begin{array}{c}\text { Ferimentos menores e/ou ameaça } \\
\text { significante ao ambiente }\end{array}$ & $\begin{array}{c}\text { Danos severos ao } \\
\text { sistema }\end{array}$ \\
\hline INSIGNIFICANTE & IV & Possível pequenos ferimentos & $\begin{array}{l}\text { Danos pequenos ao } \\
\text { sistema }\end{array}$ \\
\hline
\end{tabular}

Tabela 35: Freqüência

\begin{tabular}{|c|c|c|c|c|c|}
\hline \multicolumn{2}{|c|}{ Categoria } & Descrição & $\begin{array}{l}\text { Probabilidade de } \\
\text { falha em } 1 \mathrm{~h} \\
\qquad \mathrm{~F}(\mathrm{t}) \mid \mathrm{t}=1 \mathrm{~h}\end{array}$ & $\begin{array}{c}\text { Taxa de falha } \\
\text { tolerável } \\
\text { THR (f/h) }\end{array}$ & $\begin{array}{l}\text { Tempo médio entre eventos } \\
\text { MTBE (h) }\end{array}$ \\
\hline A & Frequente & $\begin{array}{l}\text { Provável que ocorra com } \\
\text { frequência. O perigo será } \\
\text { experimentado continuamente }\end{array}$ & $F(t)>10^{-3}$ & $\mathrm{THR}>10^{-3}$ & MTBE $<1000$ \\
\hline B & Provável & $\begin{array}{l}\text { Ocorrerá diversas vezes. O } \\
\text { perigo pode ser esperado } \\
\text { ocorrer com frequência }\end{array}$ & $10^{-3}>\mathrm{F}(\mathrm{t})>10^{-5}$ & $10^{-3}>$ THR $>10^{-5}$ & $100000<$ MTBE $<1000$ \\
\hline $\mathrm{D}$ & Remota & $\begin{array}{l}\text { Provável ocorrer alguma vez no } \\
\text { ciclo de vida do sistema. A } \\
\text { ocorrência do perigo pode ser } \\
\text { razoavelmente esperada }\end{array}$ & $10^{-6}>\mathrm{F}(\mathrm{t})>10^{-8}$ & $10^{-6}>$ THR $>10^{-8}$ & $100000000<\mathrm{MTBE}<1000000$ \\
\hline$E$ & Improvável & $\begin{array}{c}\text { Improvável ocorrência, mas } \\
\text { possível. Pode-se assumir que } \\
\text { o perigo pode excepcionalmente } \\
\text { ocorrer }\end{array}$ & $10^{-8}>\mathrm{F}(\mathrm{t})>10^{-9}$ & $10^{-8}>$ THR $>10^{-9}$ & $1000000000<\mathrm{MTBE}<100000000$ \\
\hline $\mathrm{F}$ & Inacreditável & $\begin{array}{l}\text { Extremamente improvável de } \\
\text { ocorrer. Pode ser assumido que } \\
\text { o perigo não pode ocorrer }\end{array}$ & $F(t)<10^{-9}$ & THR $<10^{-9}$ & MTBE > 1000000000 \\
\hline
\end{tabular}


Tabela 36: Matriz de Risco

\begin{tabular}{|c|c|c|c|c|}
\hline $\begin{array}{c}\text { Frequência de ocorrência } \\
\text { de um evento perigoso }\end{array}$ & \multicolumn{4}{|c|}{ Nível de Risco } \\
\hline Frequente & Indesejável & Intolerável & Intolerável & Intolerável \\
\hline Provável & Tolerável & Indesejável & Intolerável & Intolerável \\
\hline Ocasional & Tolerável & Indesejável & Indesejável & Intolerável \\
\hline Remota & Desprezível & Tolerável & Indesejável & Indesejável \\
\hline Improvável & Desprezível & Desprezível & Tolerável & Tolerável \\
\hline Inacreditável & Desprezível & Desprezível & Desprezível & Desprezível \\
\hline & Insignificante & Marginal & Crítico & Catastrófico \\
\cline { 2 - 5 } & \multicolumn{2}{|c|}{ Nível de Severidade da Consequência do Perigo } \\
\hline
\end{tabular}

Tabela 37: Ações a serem tomadas para cada categoria de risco

\begin{tabular}{|c|l|}
\hline Categoria do Risco & \multicolumn{1}{|c|}{ Ações a serem aplicadas contra cada categoria } \\
\hline Intolerável & Deve ser eliminado \\
\hline Indesejável & $\begin{array}{l}\text { Só deve ser aceito quando a redução do risco é impraticável e } \\
\text { Autoridade Regulatória de Segurança, como apropriado }\end{array}$ \\
\hline Tolerável & $\begin{array}{l}\text { Aceitável com adequado controle e com o consentimento da } \\
\text { Autoridade Ferroviária }\end{array}$ \\
\hline Desprezível & Aceitável com/sem o consentimento da Autoridade ferroviária \\
\hline
\end{tabular}




\subsubsection{Metodologia de análise}

Assim como nas predições, o primeiro passo é estabelecer a estrutura analítica do sistema. Essa estrutura, assim como a respectiva numeração de identificação dos itens deve ser exatamente a mesma na predição, no FMECA e também, futuramente, no apontamento de falhas ocorridas em campo.

Para cada item da estrutura analítica classificado como LRU, define-se a função do mesmo e, com base em banco de dados como o da figura 26, definem-se os modos de falha de cada componente e os respectivos percentuais de contribuição.

A Tabela 38 mostra um exemplo com uma parte da estrutura analítica do sistema. Note que componentes com mais de um modo de falha aparecem tantas vezes quantos forem os modos de falha, ou seja, cada linha da tabela corresponde a um modo de falha. 
Tabela 38: Estrutura analítica - Sistema Caixa - Miscelâneas

\begin{tabular}{|c|c|c|c|c|c|c|c|}
\hline \multicolumn{5}{|c|}{ ESTRUTURA ANALÍTICA } & \multirow[b]{2}{*}{ Função } & \multirow[b]{2}{*}{ Modo de falha } & \multirow[b]{2}{*}{$\alpha$} \\
\hline ID & CÓD. & Identificação & Descrição & 总 & & & \\
\hline 1 & 01.01 .01 & DJ.B.LP & $\begin{array}{c}\text { Disjuntor da bomba do limpador de } \\
\text { parabrisa }\end{array}$ & LRU & $\begin{array}{c}\text { Proteger o circuito da } \\
\text { bomba do limpador } \\
\text { de parabrisa }\end{array}$ & Abre sem estímulo & 0,51 \\
\hline 2 & 01.01 .01 & DJ.B.LP & $\begin{array}{c}\text { Disjuntor da bomba do limpador de } \\
\text { parabrisa }\end{array}$ & LRU & $\begin{array}{c}\text { Proteger o circuito da } \\
\text { bomba do limpador } \\
\text { de parabrisa }\end{array}$ & Não abre & 0,49 \\
\hline 3 & 01.01 .02 & DJ.BZ & Disjuntor da buzina & LRU & $\begin{array}{c}\text { Proteger a } \\
\text { eletroválvula da } \\
\text { buzina }\end{array}$ & Abre sem estímulo & 0,51 \\
\hline 5 & 01.01 .03 & DJ.LP & Disjuntor dos limpadores de parabrisa & LRU & $\begin{array}{l}\text { Proteger o circuito } \\
\text { acionador do motor } \\
\text { do limpador de } \\
\text { parabrisa }\end{array}$ & Abre sem estímulo & 0,51 \\
\hline 6 & 01.01 .03 & DJ.LP & Disjuntor dos limpadores de parabrisa & LRU & $\begin{array}{l}\text { Proteger o circuito } \\
\text { acionador do motor } \\
\text { do limpador de } \\
\text { parabrisa }\end{array}$ & Não abre & 0,49 \\
\hline 7 & 01.01 .04 & DJ.RT & Disjuntor dos retrovisores & LRU & $\begin{array}{c}\text { Proteger o circuito do } \\
\text { retrovisor }\end{array}$ & Abre sem estímulo & 0,51 \\
\hline
\end{tabular}

Para cada modo de falha são analisados os efeitos no componente, no sistema e no funcionamento do trem.

A Tabela 39 mostra o resultado dessa análise para uma parte da estrutura analítica. 
Tabela 39: Efeito dos modos de falha

\begin{tabular}{|c|c|c|c|c|c|}
\hline \multicolumn{2}{|c|}{$\begin{array}{l}\text { ESTRUTURA } \\
\text { ANALÍTICA }\end{array}$} & \multirow[b]{2}{*}{ Modo de falha } & \multicolumn{3}{|c|}{ Efeito da falha } \\
\hline ID & CóD. & & Componente & Sistema & Trem - Funcionamento \\
\hline 1 & 01.01 .01 & Abre sem estímulo & Contato aberto & $\begin{array}{c}\text { Sem alimentação para acionar } \\
\text { a bomba B.LP }\end{array}$ & $\begin{array}{c}\text { Carro MC sem esguicho } \\
\text { d'água }\end{array}$ \\
\hline 2 & 01.01 .01 & Não abre & Contato sempre fechado & $\begin{array}{l}\text { Sem proteção para a bomba } \\
\text { B.LP }\end{array}$ & Nenhum \\
\hline 3 & 01.01 .02 & Abre sem estímulo & Contato aberto & $\begin{array}{l}\text { Sem alimentação para acionar } \\
\text { a eletroválvula da buzina }\end{array}$ & Buzina sem acionamento \\
\hline 4 & 01.01 .02 & Não abre & Contato sempre fechado & $\begin{array}{l}\text { Sem proteção para } \\
\text { eletroválvula da buzina }\end{array}$ & Nenhum \\
\hline 5 & 01.01 .03 & Abre sem estímulo & Contato aberto & $\begin{array}{l}\text { Circuito de comando do motor } \\
\text { sem alimentação }\end{array}$ & $\begin{array}{l}\text { Limpador de parabrisa não } \\
\text { funciona }\end{array}$ \\
\hline 6 & 01.01 .03 & Não abre & Contato sempre fechado & $\begin{array}{c}\text { Sem proteção para o motor } \\
\text { M.LP }\end{array}$ & Nenhum \\
\hline 7 & 01.01 .04 & Abre sem estímulo & Contato aberto & $\begin{array}{l}\text { Eletroválvulas dos retrovisores } \\
\text { sem acionamento }\end{array}$ & Retrovisores não funcionam \\
\hline 8 & 01.01 .04 & Não abre & Contato sempre fechado & $\begin{array}{l}\text { Sem proteção para as } \\
\text { eletroválvulas dos retrovisores }\end{array}$ & Nenhum \\
\hline 9 & 01.01 .05 & Abre sem estímulo & Contato aberto & $\begin{array}{c}\text { Desembaçador sem } \\
\text { acionamento }\end{array}$ & Retrovisores não funcionam \\
\hline 10 & 01.01 .05 & Não abre & Contato sempre fechado & $\begin{array}{l}\text { Sem proteção para o } \\
\text { Desembaçador }\end{array}$ & Nenhum \\
\hline
\end{tabular}

Com base no efeito causado ao funcionamento do trem e na Tabela 33, classifica-se o tipo de falha correspondente.

A Tabela 40 mostra uma parte dessa classificação. 
Tabela 40: Determinação dos tipos de falha

\begin{tabular}{|c|c|c|c|}
\hline \multicolumn{2}{|c|}{$\begin{array}{l}\text { ESTRUTURA } \\
\text { ANALÍTICA }\end{array}$} & \multicolumn{2}{|l|}{ Efeito da falha } \\
\hline ID & CÓD. & Trem - Funcionamento & $\begin{array}{l}\text { Tipo de } \\
\text { falha }\end{array}$ \\
\hline 1 & 01.01 .01 & $\begin{array}{c}\text { Carro MC sem esguicho } \\
\text { d'água }\end{array}$ & C \\
\hline 2 & 01.01 .01 & Nenhum & C \\
\hline 3 & 01.01 .02 & Buzina sem acionamento & B \\
\hline 4 & 01.01 .02 & Nenhum & C \\
\hline 5 & 01.01 .03 & $\begin{array}{l}\text { Limpador de parabrisa não } \\
\text { funciona }\end{array}$ & B \\
\hline 6 & 01.01 .03 & Nenhum & C \\
\hline 7 & 01.01 .04 & Retrovisores não funcionam & C \\
\hline 8 & 01.01 .04 & Nenhum & C \\
\hline 9 & 01.01 .05 & Retrovisores não funcionam & C \\
\hline 10 & 01.01 .05 & Nenhum & C \\
\hline
\end{tabular}

Da mesma forma, avaliam-se os efeitos dos modos de falha para a segurança do trem e classificam-se as severidades de cada modo de falha, de acordo com a Tabela 34.

A Tabela 41 mostra o resultado dessa análise para alguns itens da estrutura analítica e a respectiva classificação de severidade. 
Tabela 41: Efeitos na segurança

\begin{tabular}{|c|c|c|c|c|}
\hline \multicolumn{2}{|c|}{$\begin{array}{l}\text { ESTRUTURA } \\
\text { ANALÍTICA }\end{array}$} & \multirow[b]{2}{*}{ Modo de falha } & Efeito da falha & \multirow[b]{2}{*}{ Severidade } \\
\hline ID & CÓD. & & Trem - Segurança & \\
\hline 1 & 01.01 .01 & Abre sem estímulo & $\begin{array}{l}\text { Visibilidade possivelmente } \\
\text { prejudicada }\end{array}$ & IV \\
\hline 2 & 01.01 .01 & Não abre & $\begin{array}{l}\text { Pode ocorrer queima da fiação } \\
\text { em caso de sobrecorrente }\end{array}$ & III \\
\hline 3 & 01.01 .02 & Abre sem estímulo & Sem sinal sonoro de alerta & IV \\
\hline 4 & 01.01 .02 & Não abre & $\begin{array}{l}\text { Pode ocorrer queima da fiação } \\
\text { em caso de sobrecorrente }\end{array}$ & III \\
\hline 5 & 01.01 .03 & Abre sem estímulo & $\begin{array}{l}\text { Visibilidade prejudicada em } \\
\text { caso de chuva e/ou visibilidade } \\
\text { possivelmente prejudicada } \\
\text { pela impossibilidade de } \\
\text { limpeza do parabrisa }\end{array}$ & IV \\
\hline 6 & 01.01 .03 & Não abre & $\begin{array}{l}\text { Pode ocorrer queima da fiação } \\
\text { em caso de sobrecorrente }\end{array}$ & III \\
\hline 7 & 01.01 .04 & Abre sem estímulo & Visibilidade prejudicada & IV \\
\hline 8 & 01.01 .04 & Não abre & $\begin{array}{l}\text { Pode ocorrer queima da fiação } \\
\text { em caso de sobrecorrente }\end{array}$ & III \\
\hline 9 & 01.01 .05 & Abre sem estímulo & Sem efeito & IV \\
\hline 10 & 01.01 .05 & Não abre & $\begin{array}{c}\text { Pode ocorrer queima da fiação } \\
\text { em caso de sobrecorrente }\end{array}$ & III \\
\hline
\end{tabular}

Com base na predição de confiabilidade de cada item da estrutura analítica, determina-se o MTBF dos componentes.

De acordo com a Tabela 35 a categoria de freqüência da falha é estabelecida com base na sua probabilidade de ocorrência em uma hora. Como se trata de itens independentes, em série e com taxa de falha constante esse cálculo pode ser feito da seguinte maneira:

$$
F(t)=1-e^{(-\lambda \cdot \alpha \cdot t)}=1-e^{\left(\frac{-\alpha \cdot t}{M T B F}\right)}
$$

Para $t=1 \mathrm{~h}$ :

$$
F(1)=1-e^{\left(\frac{-\alpha}{M T B F}\right)}
$$


Por exemplo, no caso do primeiro item da Tabela 42, a probabilidade de falha em uma hora é igual a:

$$
\begin{aligned}
& F(1)=1-e^{\left(\frac{-\alpha}{M T B F}\right)} \\
& F(1)=1-e^{\left(\frac{-0,51}{4.040 .754}\right)}=1,26214 \cdot 10^{-7}
\end{aligned}
$$

Determina-se então a categoria de freqüência (Tabela 35) e a aceitabilidade do risco (Tabela 36).

Conforme mencionado no exemplo 2, é possível obter o percentual de contribuição para cada tipo de falha de cada item do FMECA. Por exemplo, o item 01.01 .03 (ID 5 e 6 da Tabela 42) possui dois modos de falha, sendo que a ocorrência de um deles é considerado como falha do tipo B e a ocorrência do outro modo é considerado falha do tipo $\mathrm{C}$. Os percentuais de contribuição desses modos são respectivamente $51 \%$ e $49 \%$. Para itens com vários modos de falha, cuja classificação afete mais de um tipo de falha, o estabelecimento dos percentuais de contribuição é feito pela somatória dos percentuais de cada modo de falha que possuam a mesma classificação. A somatória dos percentuais de cada componente deve sempre totalizar $100 \%$.

Nota-se que em alguns itens, como o 01.01.04, todos os seus modos de falha são de um mesmo tipo. Nesse caso, o percentual a ser considerado é de $100 \%$ para falhas do tipo $\mathrm{C}$. 
Tabela 42: Classificação da aceitabilidade do risco

\begin{tabular}{|c|c|c|c|c|c|c|c|c|c|}
\hline \multicolumn{2}{|c|}{$\begin{array}{c}\text { ESTRUTURA } \\
\text { ANALÍTICA }\end{array}$} & \multirow[b]{2}{*}{ Modo de falha } & \multirow{2}{*}{\begin{tabular}{|c}
$\begin{array}{c}\text { Efeito da } \\
\text { falha }\end{array}$ \\
$\begin{array}{c}\text { Tipo de } \\
\text { falha }\end{array}$
\end{tabular}} & \multirow[b]{2}{*}{ Severidade } & \multirow[b]{2}{*}{ MTBF } & \multirow[b]{2}{*}{$\alpha$} & \multirow[b]{2}{*}{$F(t)$} & \multirow[b]{2}{*}{ Freq. } & \multirow{2}{*}{$\begin{array}{c}\text { Aceitabilidade do } \\
\text { risco }\end{array}$} \\
\hline ID & CóD. & & & & & & & & \\
\hline 1 & 01.01 .01 & Abre sem estímulo & C & IV & 4.040 .754 & 0,51 & 1,26214E-07 & D & Desprezível \\
\hline 2 & 01.01 .01 & Não abre & C & III & 4.040 .754 & 0,49 & $1,21264 \mathrm{E}-07$ & D & Tolerável \\
\hline 3 & 01.01 .02 & Abre sem estímulo & B & IV & 4.040 .754 & 0,51 & 1,26214E-07 & D & Desprezível \\
\hline 4 & 01.01 .02 & Não abre & C & III & 4.040 .754 & 0,49 & 1,21264E-07 & D & Tolerável \\
\hline 5 & 01.01 .03 & Abre sem estímulo & B & IV & 4.040 .754 & 0,51 & $1,26214 \mathrm{E}-07$ & D & Desprezível \\
\hline 6 & 01.01 .03 & Não abre & C & III & 4.040 .754 & 0,49 & $1,21264 \mathrm{E}-07$ & D & Tolerável \\
\hline 7 & 01.01 .04 & Abre sem estímulo & C & IV & 4.040 .754 & 0,51 & $1,26214 \mathrm{E}-07$ & D & Desprezível \\
\hline 8 & 01.01 .04 & Não abre & C & III & 4.040 .754 & 0,49 & $1,21264 \mathrm{E}-07$ & D & Tolerável \\
\hline 9 & 01.01 .05 & Abre sem estímulo & C & IV & 4.040 .754 & 0,51 & $1,26214 \mathrm{E}-07$ & D & Desprezível \\
\hline 10 & 01.01 .05 & Não abre & C & III & 4.040 .754 & 0,49 & 1,21264E-07 & D & Tolerável \\
\hline
\end{tabular}

As planilhas de FMECA também podem ser utilizadas para a determinação dos modos de detecção de cada modo de falha e para a determinação de ações de gerenciamento da falha, tais como modificação de projeto, manutenção periódica, procedimentos de operação, etc.(ver Tabela 43). 
Tabela 43: Modos de detecção e gerenciamento da falha

\begin{tabular}{|c|c|c|c|c|}
\hline \multicolumn{2}{|c|}{$\begin{array}{l}\text { ESTRUTURA } \\
\text { ANALÍTICA }\end{array}$} & \multirow{2}{*}{ Modo de falha } & \multirow{2}{*}{$\begin{array}{c}\text { Modo de Detecção } \\
\text { Descrição }\end{array}$} & \multirow{2}{*}{$\begin{array}{c}\text { Gerenciamento da Falha } \\
\text { Descrição }\end{array}$} \\
\hline ID & CÓD. & & & \\
\hline 1 & 01.01 .01 & Abre sem estímulo & Sem esguicho d'água & $\begin{array}{l}\text { Este item deve ser verificado } \\
\text { nas Inspeções Periódicas }\end{array}$ \\
\hline 2 & 01.01 .01 & Não abre & Sem detecção & NA \\
\hline 3 & 01.01 .02 & Abre sem estímulo & Buzina não funciona & $\begin{array}{l}\text { Este item deve ser verificado } \\
\text { nas Inspeções Periódicas }\end{array}$ \\
\hline 4 & 01.01 .02 & Não abre & Sem detecção & NA \\
\hline 5 & 01.01 .03 & Abre sem estímulo & Limpador de parabrisa não funciona & $\begin{array}{l}\text { Este item deve ser verificado } \\
\text { nas Inspeções Periódicas }\end{array}$ \\
\hline 6 & 01.01 .03 & Não abre & Sem detecção & NA \\
\hline 7 & 01.01 .04 & Abre sem estímulo & Retrovisores não funcionam & $\begin{array}{c}\text { Este item deve ser verificado } \\
\text { nas Inspeções Periódicas }\end{array}$ \\
\hline 8 & 01.01 .04 & Não abre & Sem detecção & NA \\
\hline 9 & 01.01 .05 & Abre sem estímulo & Desembaçador sem acionamento & $\begin{array}{l}\text { Este item deve ser verificado } \\
\text { nas Inspeções Periódicas }\end{array}$ \\
\hline 10 & 01.01 .05 & Não abre & Sem detecção & NA \\
\hline
\end{tabular}

\subsubsection{Apresentação e interpretação dos resultados}

O FMECA completo do sistema está na Figura 43 e na Figura 44. Os resultados das colunas "Tipo de Falha" e " $\alpha$ " são exportados para a tabela de predição de confiabilidade. Para tipos de falha iguais de um mesmo componente, seus percentuais de contribuição são somados. 


\begin{tabular}{|c|c|c|c|c|c|c|c|c|c|c|c|c|c|c|c|c|c|c|c|c|c|c|c|c|}
\hline & & FAC & INII & & & & & & & & $E C A$ & LISE DOS MO & 80 & HAE & $y=$ & $s$ & eircos & & & & & & & \\
\hline & $\begin{array}{l}\text { PRoNe } \\
\text { STSTE }\end{array}$ & & 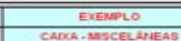 & & imroo & & & FHECA & SIstrem canta-Msec & EQMUEAS & & & & & & & & & 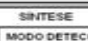 & & & & & \\
\hline & 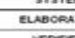 & & AEAGEA & & & & & & & & & & $n$ & 41 & $F$ & $a_{0}$ & 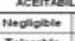 & $\frac{1006}{30}$ & 10 & 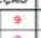 & 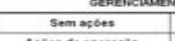 & & & \\
\hline & 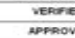 & & $\begin{array}{l}\text { GFusoven } \\
\text { EPrusp }\end{array}$ & & & & & & & & & & $:$ & 13 & $\begin{array}{c}E \\
0\end{array}$ & 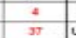 & 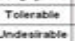 & $\frac{22}{2}$ & $\frac{m}{\text { To }}$ & & 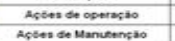 & & 13 & \\
\hline & Dare & & seoser & & & & & & & & & & ! & $\circ$ & c & 8 & mesolitersite & 2 & $\begin{array}{l}\text { To } \\
\text { op } \\
\text { of }\end{array}$ & $=$ & 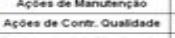 & & & \\
\hline & mever. & & rasestion & $a$ & & & & & & & & & $=$ & $\circ$ & 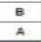 & 5 & & & $\begin{array}{l}\mathrm{Es}_{\mathrm{Fs}} \\
\mathrm{Fs}\end{array}$ & & 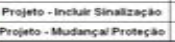 & 5 & $\div$ & \\
\hline & & Estrauru & pessuevitica & & & & 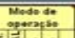 & & & incosens & & & & & & & & & & & 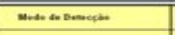 & & 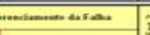 & \\
\hline • & $c 00$. & 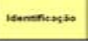 & onentiss & 产至 & ramsto & & 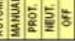 & cansenen- & $=$ & 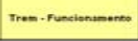 & Thesen & 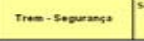 & & mise & - & $\rightarrow$ & sion & $=$ & $+\infty$ & $\omega$ & 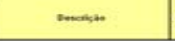 & $\omega$ & 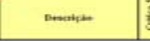 & \\
\hline & artere & wose & $=0$ & $\infty$ & \pm & $-m$ & $x=$ & 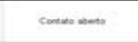 & sentomis & 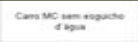 & $=$ & Dats & N & $\operatorname{sense}$ & $\because$ & sxuen & 。 & n & $=$ & $\infty$ & 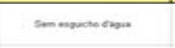 & , & 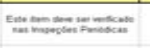 & \\
\hline 2 & oroter & wess & - & $\infty$ & \pm & $-\infty$ & $x \times x$ & $-1-2$ & 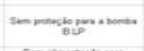 & - & $=$ & $=$ & $=$ &. $\operatorname{senses}$ & $\infty$ & 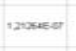 & 。 & $\infty$ & $=$ & $\infty$ & smonst & & m & \\
\hline & arem & DUEF & 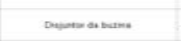 & $\infty$ & $\Xi$ & - & $x \times x$ & cosencos & $=$ & $-n$ & . & 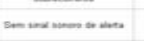 & N & .coess & $\approx$ & isuen & . & no & - & $\infty$ & 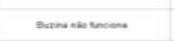 & $=$ & $=-x$ & \\
\hline 4 & arome & Dine & 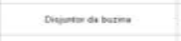 & w & 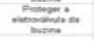 & $=-\infty$ & $x \times x$ & 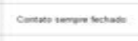 & 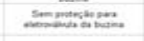 & - & . & 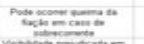 & . & cosese & $\infty$ & rescues: & 。 & $\infty$ & 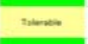 & $\infty$ & sumest & & ne & $\underline{m e s}$ \\
\hline & ortows & wo & & $\infty$ & $=$ & $-\infty$ & $x \times x$ & $\operatorname{cosen}-\infty$ & $c_{n-1}=-1$ & $-x=$ & a & 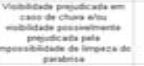 & $\approx$ & $\operatorname{coses} x$ & 0.51 & mines & D & $\infty$ & 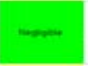 & $\infty$ & 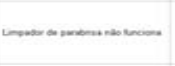 & 3 & 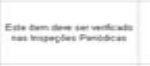 & \\
\hline 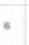 & orom & ars & - & w & $\ldots$ & $=-$ & $x \times x$ & cestronst & 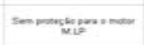 & - & c & 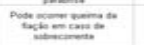 & $=$ & .000 & $\infty$ & rowese & 。 & $\infty$ & $=$ & $\infty$ & $=m$ & & ne & 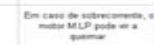 \\
\hline & aronese & arert & 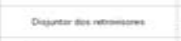 & $\infty$ & $=$ & $-\infty-\infty$ & $x \times x$ & consens & 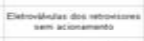 & - & c & 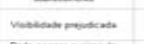 & * &. $\operatorname{senses}$ & 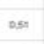 & swes: & 。 & no & 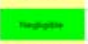 & $\infty$ & 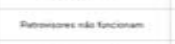 & , & Ex=-10 & \\
\hline 3 & orotses & ORT & naverm- & $\infty$ & $=m$ & $-\infty$ & $x \times x$ & 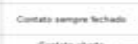 & somsipan. & - & c & 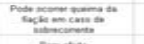 & - & toess & $\infty$ & insues & . & $\infty$ & 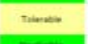 & $\infty$ & sommessen & & se & $=$ \\
\hline & 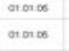 & weses & $=0$ & 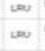 & 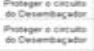 & $-\infty$ & $\begin{array}{l}x \times x \\
x \times x \times\end{array}$ & -1 & 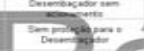 & & 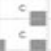 & $n=$ & $\approx$ &. $\cos s$ & $\infty$ & toued & : & $\infty$ & $=$ & $\infty$ & $=0$ & : & $=1$ & \\
\hline & arosen & mise & 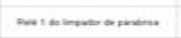 & $\infty$ & $=$ & $=0$ & $x \times x$ & $=$ & & & & -7 & 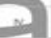 & $=\infty$ & $=0$ & $x$ & $=$ & ne & 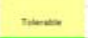 & $\infty$ & $=0$ & $=$ & $=-1=$ & \\
\hline & $\theta \cos \theta$ & nt. & 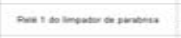 & $\infty$ & $=$ & $=$ & $x \times x$ & -1 & $=c$ & & & $s-1$ & 2 & $=\infty$ & $0 x$ & froes & 。 & no & $-\infty$ & $\infty$ & 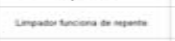 & , & $=-1=$ & \\
\hline 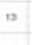 & arosen & Pise & 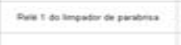 & $\infty$ & $=$ & $\infty$ & $x=$ & cosentensing & 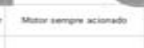 & $y=x$ & $c$ & $=$ & " & $=\infty$ & $\therefore$ & 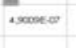 & 。 & no & $m$ & $\infty$ & 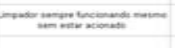 & , & 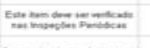 & $=$ \\
\hline 5 & artenes & pase & mots & $\infty$ & ton & $=$ & $x \times x$ & costents & $=$ & 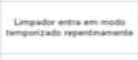 & c & $=-$ & N & $=2$ & ex & men & 。 & $\infty$ & $m$ & $\infty$ & $=$ & ' & $=-5=$ & $=$ \\
\hline$=8$ & atomese & Novs & $-m$ & $\infty$ & : & cons & $x \times x$ & $-\infty$ & $-m-\infty$ & $x=$ & . & $=-$ & n & 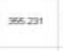 & a.s & ssesesen & 。 & no & - & $\infty$ & $m=-$ & , & 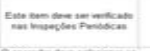 & -ration \\
\hline 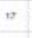 & starot & 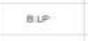 & 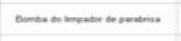 & 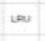 & $\ldots$ & ventert & $x \times x$ & ventam & $x=$ & $x$ & $=$ & 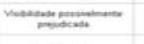 & 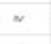 & 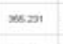 & ose & 20 ansex & $c$ & me & $=$ & $\infty$ & 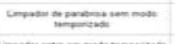 & $=$ & $-1=$ & \\
\hline e & ananer & sto & - & 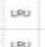 & - & nencens & $\times \times x$ & noresces & - & 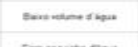 & & $-m$ & & $\alpha$ & 0.12 & shenes & & no & - & $\infty$ & $=$ & $=$ & 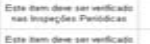 & $=0$ \\
\hline$=$ & oreater & 81 & 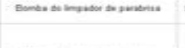 & - & tons & 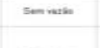 & $x \times x$ & $=$ & $=$ & 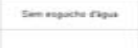 & c & $=$ & n & 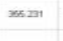 & ox & Des & D & $\infty$ & - & $\infty$ & -1 & , & 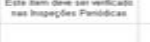 & 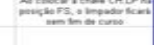 \\
\hline$=$ & ormat का & $n$ & 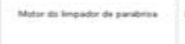 & 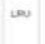 & $=$ & $\infty$ & $\times \times \times$ & $\infty$ & $=$ & +1 & * & $\because$ & N & $=\infty$ & , & $20 x=x$ & $=$ & ผ & $+\infty$ & $\infty$ & 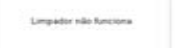 & $=$ & 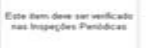 & \\
\hline & ormate & mosins & 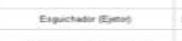 & $\infty$ & $=$ & samer & $x \times x$ & bese & $=$ & senomes & c & $\frac{1}{5}$ & $\sim$ & $n$ & , & severies & & $m$ & $n-$ & $\infty$ & smanement & $=$ & 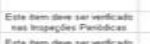 & \\
\hline$m$ & onsarese & $x=1600$ & 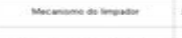 & $=0$ & $=$ & onesen- & $\times \times \times$ & (anch & $=$ & $-1=$ & A & $=$ & N & , 0000 & & spowes & . & e & $=$ & $\approx$ & 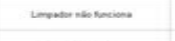 & $=$ & $=-5=$ & \\
\hline$z$ & onsemat & n & tinn-mann & 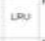 & $=$ & - & $x \times x$ & $=-\infty$ & $-m$ & $x=$ & * & $=-\infty-m-\infty$ & N & 3004000 & oss & , seserer & 。 & no & $=$ & $\infty$ & somenters & 3 & 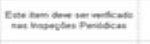 & \\
\hline & andasen & $\Rightarrow$ & n-mingengen & $\infty$ & $=$ & $=$ & $x \times x$ & -5 & sominten & $x=$ & . & $=-$ & N & $\sin m$ & $\infty .8$ & $=$ & D & no & - & $\infty$ & 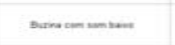 & ' & 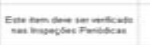 & \\
\hline & 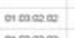 & & mastins & 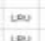 & $=$ & vens & $x \times x$ & & $=$ & 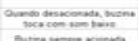 & $\therefore$ & $=$ & $\approx$ & $\infty$ & $\approx$ & & & 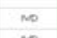 & -1 & $\infty$ & & & $=-1-1$ & \\
\hline & 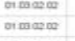 & & 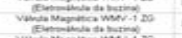 & 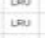 & 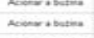 & $=-\infty$ & $\begin{array}{l}x=x \\
x \times x\end{array}$ & $=$ & & 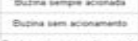 & ? & 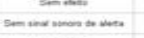 & $\mathrm{N}$ & & 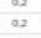 & & & no & $=$ & $\infty$ & sententes & & 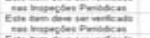 & \\
\hline & 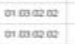 & 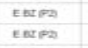 & 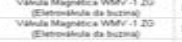 & 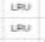 & $x-5=$ & $=$ & $\begin{array}{l}x \times x \\
x \times x \\
x \times x\end{array}$ & $=$ & 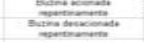 & $=$ & $\therefore$ & $=-$ & $\approx$ & & o.t. & & : & 央 & $=$ & $\infty$ & $\operatorname{sen} x+1$ & $x^{*}$ & 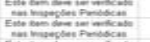 & \\
\hline & 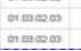 & $n$ & Déminsosone & $\infty$ & $=-1$ & $=-$ & $\begin{array}{l}x \times x \\
x \times x \times x\end{array}$ & 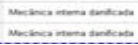 & $\sin =1-$ & $=-$ & $\dot{c}$ & $x-\infty$ & N & $=0000$ & $\infty$ & nener & : & $\infty$ & $=$ & $\infty$ & sonste & : & $=5$ & \\
\hline
\end{tabular}

Figura 43: Planilha FMECA (1/2) 


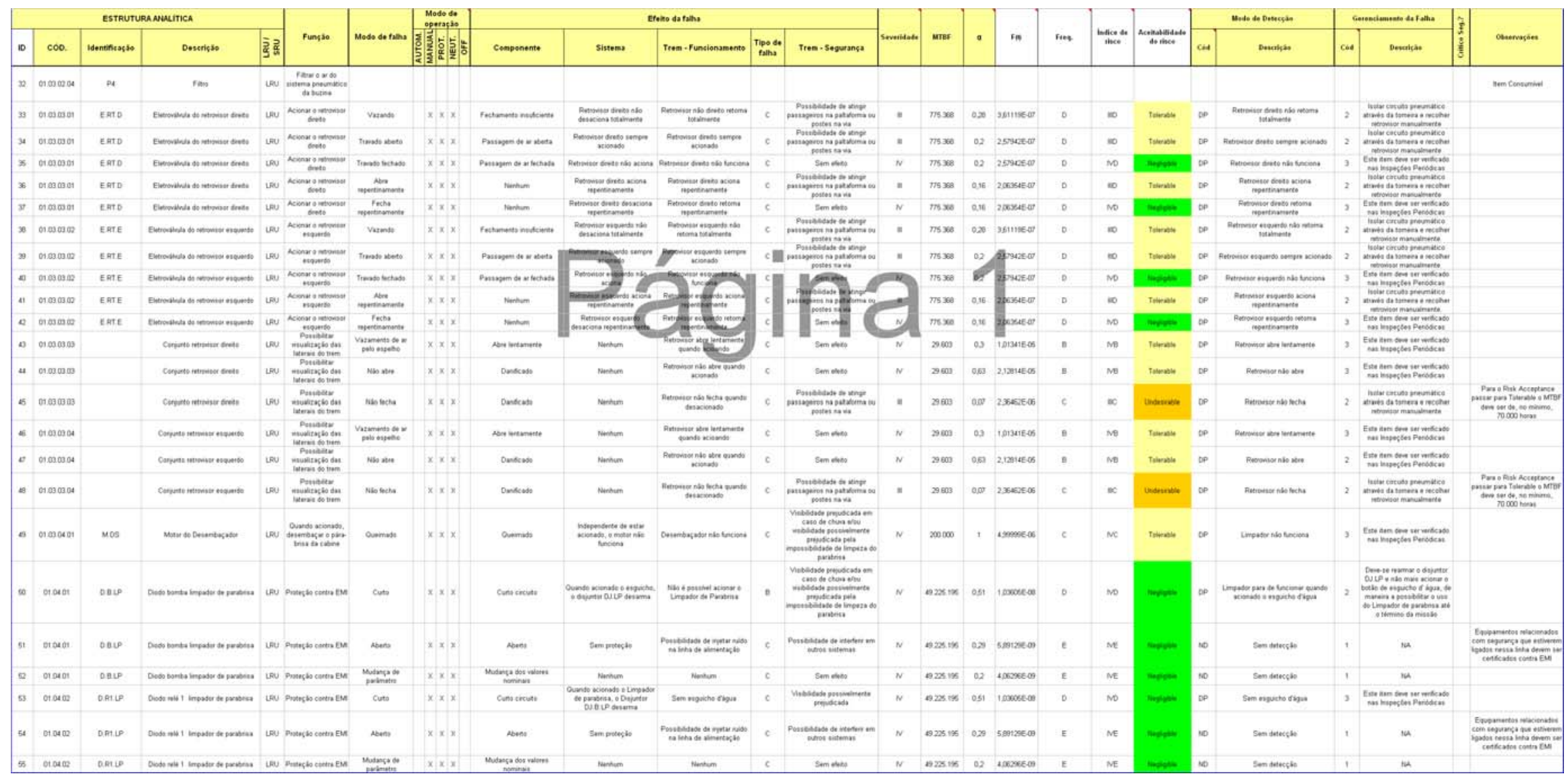

Figura 44: Planilha FMECA (2/2) 
Além disso, o FMECA aplica-se também para análises de segurança, considerando-se falhas simples. Pode-se notar na Figura 45 a quantidade de riscos classificados em cada uma das categorias. Na Figura 46 pode-se perceber que nenhum dos riscos identificados é do tipo I ou II. A Figura 47 mostra as quantidades de falha por categoria de freqüência.

A Figura 48 mostra a quantidade de falhas de acordo com a aceitabilidade. Notam-se 2 itens indesejáveis relacionados às linhas 45 e 48 do FMECA. Isso ocorre pois, caso o retrovisor automático falhe de modo a não permitir seu fechamento, corre-se o risco de atingir pessoas na plataforma ou mesmo postes ao longo da via.

Da mesma forma, constam no FMECA análises de modo de detecção da falha e gerenciamento da mesma. Os resultados estão na Figura 49 e na Figura 50.

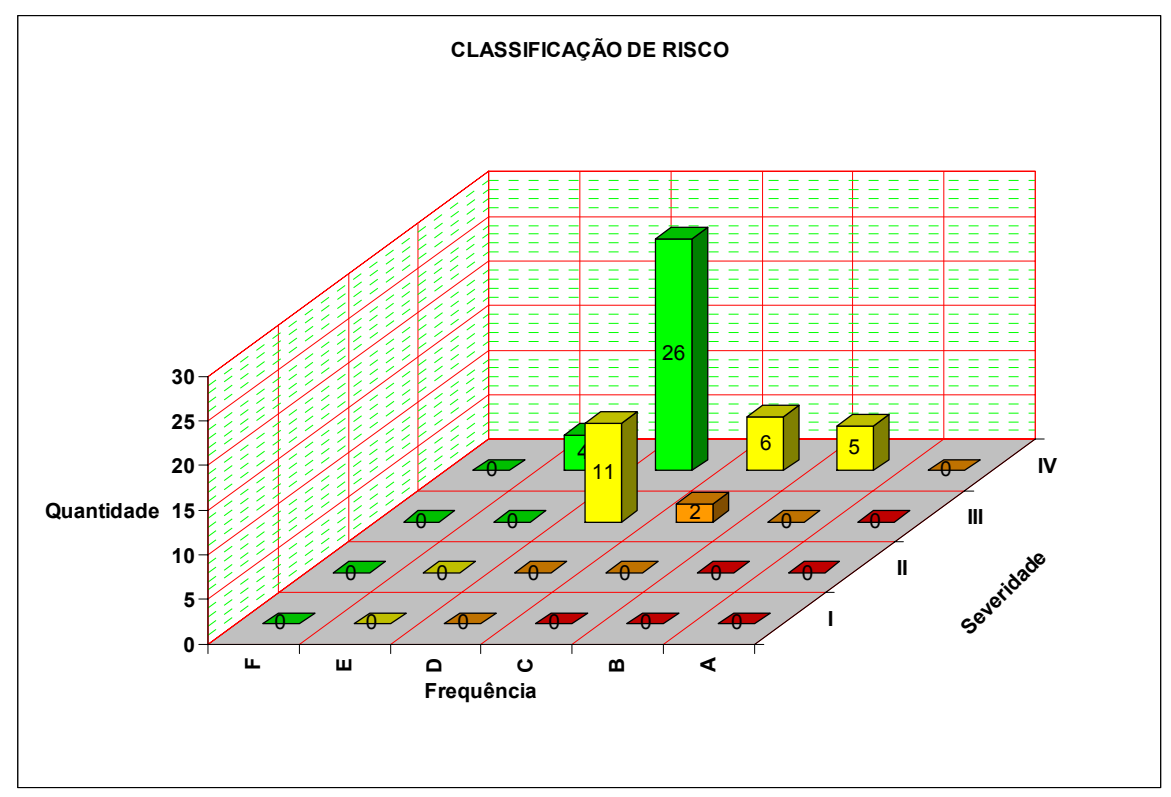

Figura 45: Matriz de risco resultante 


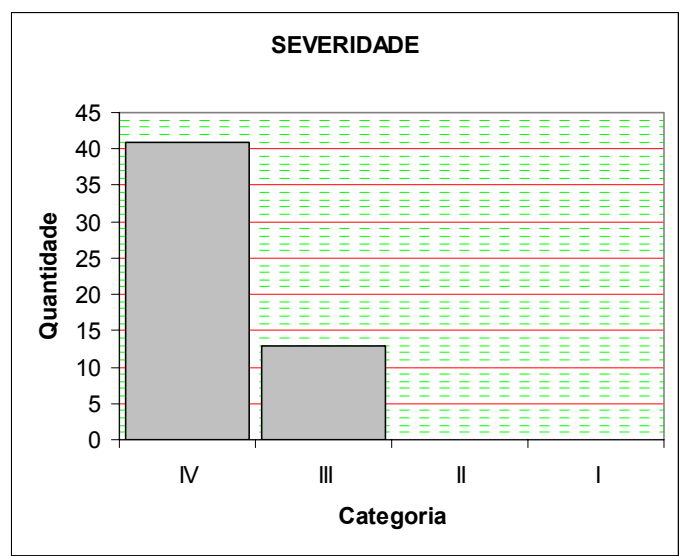

Figura 46: Severidade das falhas - resultado

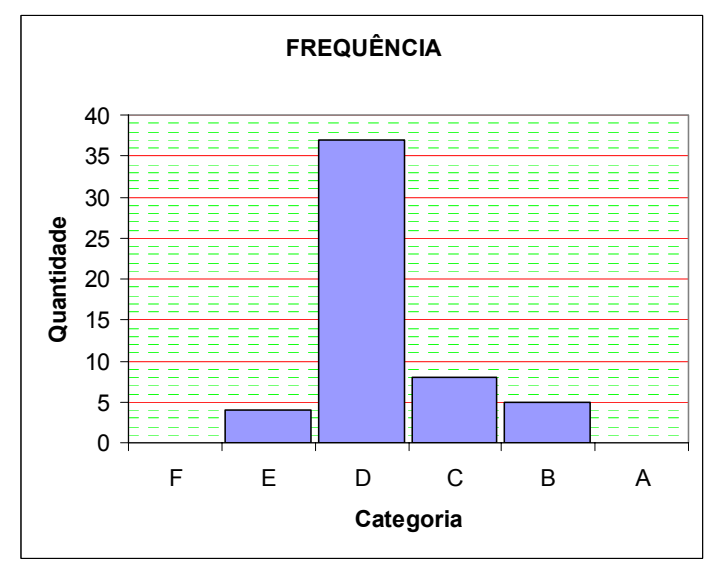

Figura 47: Freqüência das falhas - resultado
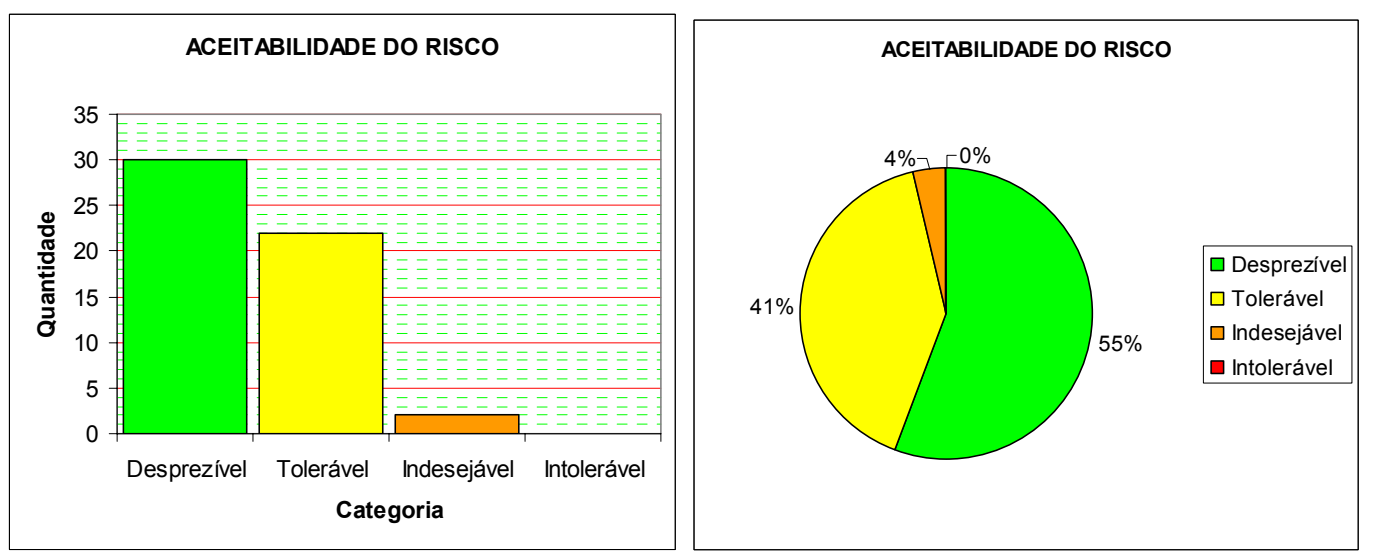

Figura 48: Aceitabilidade dos riscos - resultado 

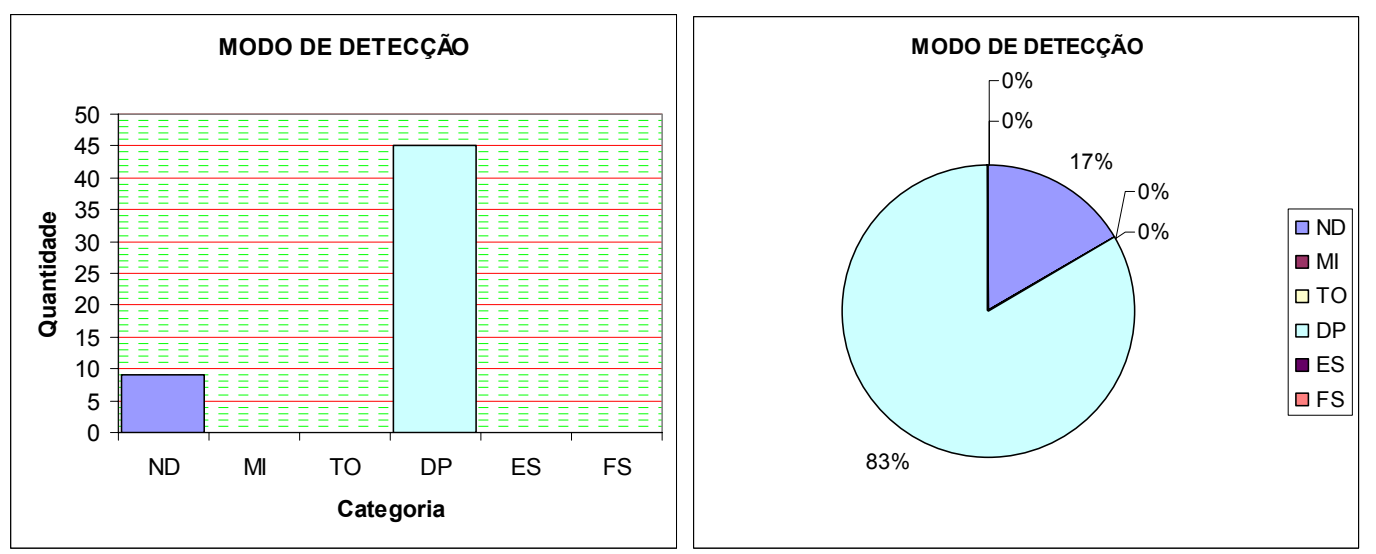

Figura 49: Modos de detecção - resultado

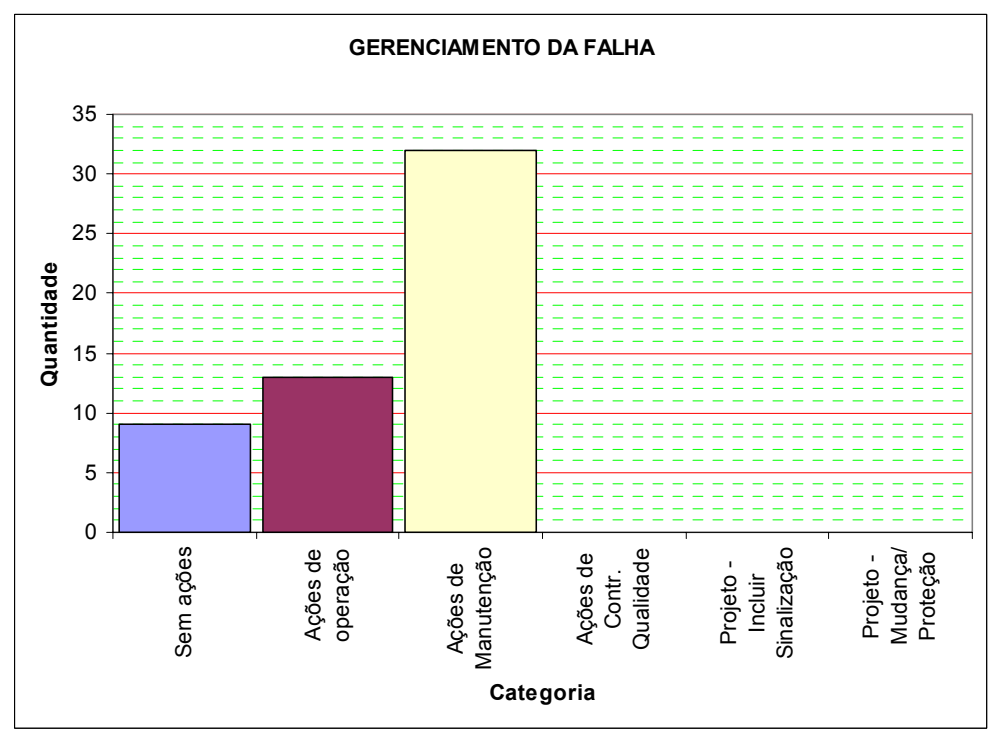

Figura 50: Gerenciamento das falhas - resultado

\subsection{EXEMPLO 5: CÁLCULO DE SOBRESSALENTES}

\subsubsection{Descrição}

Em um determinado projeto, antes dos testes de tipo e da entrada em operação comercial, inicia-se o planejamento da manutenção pelas equipes responsáveis. Dentre as atividades de CDMS que podem ser utilizadas como 
suporte a esse planejamento, o cálculo de itens sobressalentes é uma das mais importantes.

Neste exemplo será apresentada uma demonstração de cálculo de sobressalentes necessários à manutenção de um sistema do trem, durante o período de garantia, levando-se em conta o tempo para reposição do item no estoque, sua taxa da falhas e a quantidade total de itens instalados na frota. Para tal, será considerado o sistema de iluminação de uma determinada frota de trens de metrô. Essa frota consiste de 12 trens de 4 carros, sendo 2 carros motorizados com cabine e 2 carros reboques por trem.

\subsubsection{Requisitos da especificação técnica}

A especificação define que a quantidade de itens sobressalentes disponível nas oficinas de manutenção seja corretamente dimensionada de forma que atenda a demanda em caso de falha no trem. O risco aceitável de falta de material deve ser menor ou igual a $2 \%$ no período de um ano.

A especificação determina ainda que tal dimensionamento seja feito com base nos estudos de CDMS.

\subsubsection{Metodologia de análise}

Com base na estrutura analítica definida nos estudos de CDMS desse sistema e também com base no tamanho da frota, determina-se a quantidade total de itens de um mesmo tipo instalados na frota. A Tabela 44 mostra como isso pode ser feito. 
Tabela 44: Quantidade de itens na frota

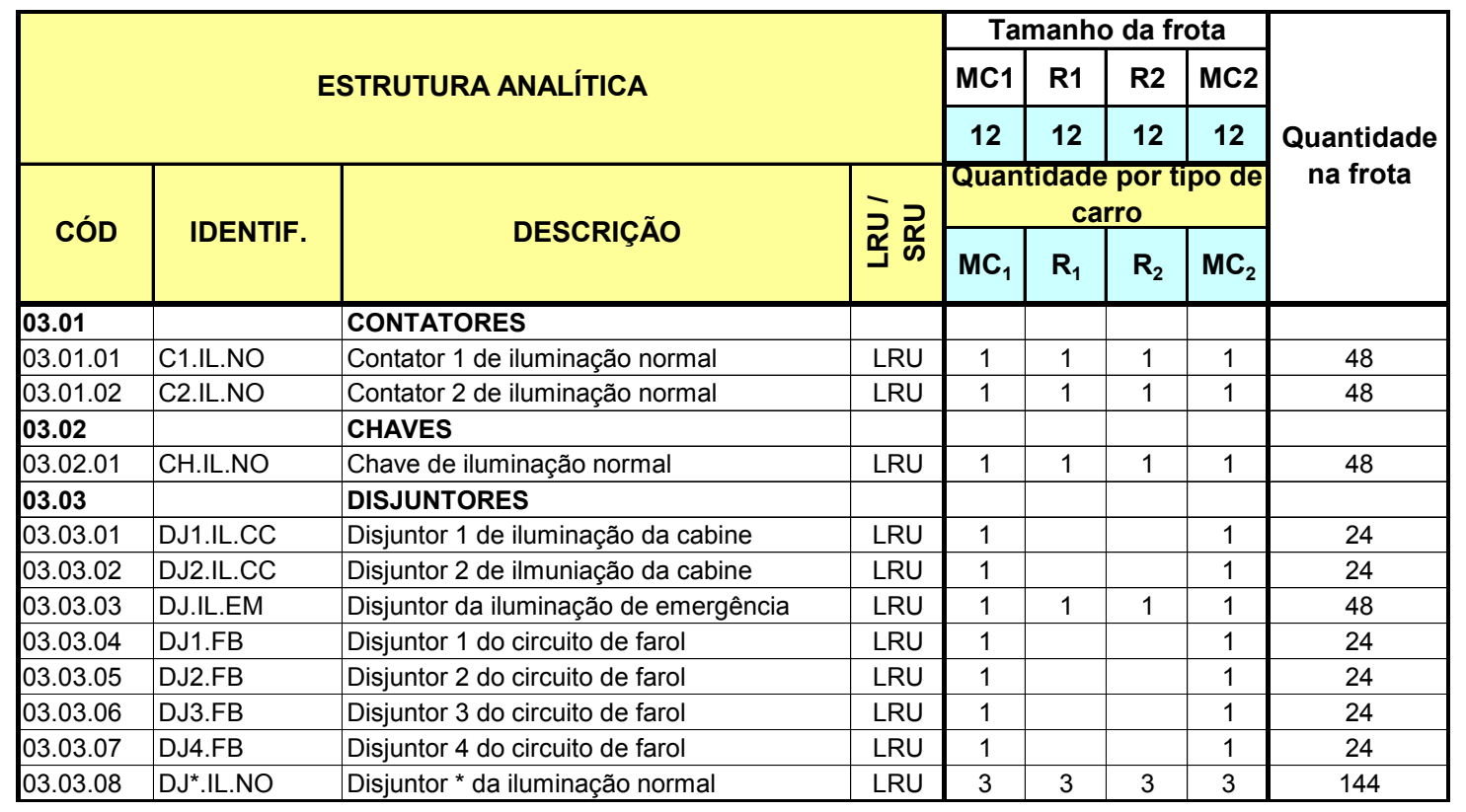

Por exemplo, o item 03.03.01 (disjuntor 1 de iluminação da cabine) está instalado apenas nos carros Mc1 e Mc2. Como existem 12 carros Mc1 e 12 carros Mc2, o total desse item instalado na frota é de $1 \times 12+1 \times 12=24$ itens.

Através de contatos com os fornecedores e experiências anteriores, estima-se o tempo de reposição de um item em estoque. Essa estimativa deve considerar o tempo desde a retirada do item do estoque para utilização no trem até a chegada de um item novo, ou mesmo reparado, para que fique novamente disponível em estoque. Isso inclui os tempos de colocação de pedido de compras/reparo, transportes, desembaraço de importação/exportação, etc.

A Tabela 45 ilustra um trecho da estrutura analítica do sistema com a determinação dos tempos para reposição, dado em meses. 
Tabela 45: Tempo para reposição do item

\begin{tabular}{|c|c|c|c|}
\hline \multicolumn{2}{|c|}{$\begin{array}{l}\text { ESTRUTURA } \\
\text { ANALÍTICA }\end{array}$} & \multirow{2}{*}{$\begin{array}{l}\text { Quantidade } \\
\text { na frota }\end{array}$} & \multirow{2}{*}{$\begin{array}{c}\text { Tempo } \\
\text { para } \\
\text { reposição } \\
\text { ("Lead } \\
\text { time") } \\
\text { [months] }\end{array}$} \\
\hline CÓD & IDENTIF. & & \\
\hline \multicolumn{4}{|l|}{03.01} \\
\hline 03.01 .01 & C1.IL.NO & 48 & 3,0 \\
\hline 03.01 .02 & C2.IL.NO & 48 & 3,0 \\
\hline \multicolumn{4}{|l|}{03.02} \\
\hline 03.02 .01 & CH.IL.NO & 48 & 3,0 \\
\hline \multicolumn{4}{|l|}{03.03} \\
\hline 03.03 .01 & DJ1.IL.CC & 24 & 3,0 \\
\hline 03.03 .02 & DJ2.IL.CC & 24 & 3,0 \\
\hline 03.03 .03 & DJ.IL.EM & 48 & 3,0 \\
\hline 03.03 .04 & DJ1.FB & 24 & 3,0 \\
\hline 03.03 .05 & DJ2.FB & 24 & 3,0 \\
\hline 03.03 .06 & DJ3.FB & 24 & 3,0 \\
\hline 03.03 .07 & DJ4.FB & 24 & 3,0 \\
\hline 03.03 .08 & DJ*.IL.NO & 144 & 3,0 \\
\hline
\end{tabular}

Para cada item determina-se o valor de MTBF obtido nas predições de confiabilidade (ver exemplo 2). Calcula-se então a taxa de falhas, a confiabilidade e a probabilidade de falha no período de reposição determinado. A Tabela 46 mostra o resultado desses cálculos.

Por exemplo, o item 03.01.01 teve como predição um MTBF de 277.778 h. A taxa de falhas é obtida calculando-se o inverso desse valor, por se tratar de itens independentes e com taxa de falhas constante, ou seja:

$$
\lambda=\frac{1}{M T B F}=\frac{1}{277.778}=3,6 \cdot 10^{-6} \quad f / h
$$


Tabela 46: Cálculo da confiabilidade no período

\begin{tabular}{|c|c|c|c|c|c|c|c|}
\hline \multicolumn{2}{|c|}{$\begin{array}{c}\text { ESTRUTURA } \\
\text { ANALÍTICA }\end{array}$} & \multirow{2}{*}{$\begin{array}{c}\text { Quantidade } \\
\text { na frota }\end{array}$} & \multicolumn{4}{|c|}{ Confiabilidade } & \multirow{2}{*}{$\begin{array}{c}\text { Tempo } \\
\text { para } \\
\text { reposição } \\
\text { ("Lead } \\
\text { time") } \\
\text { [months] }\end{array}$} \\
\hline CÓD & IDENTIF. & & $\begin{array}{c}\text { MTBF } \\
{[\mathrm{h}]}\end{array}$ & $\begin{array}{c}\lambda \\
{[\mathbf{f} / \mathbf{h}]}\end{array}$ & $R(t)$ & $F(t)$ & \\
\hline \multicolumn{8}{|l|}{03.01} \\
\hline 03.01 .01 & C1.IL.NO & 48 & 277.778 & 3,600E-06 & $99,280 \%$ & $0,720 \%$ & 3,0 \\
\hline 03.01 .02 & C2.IL.NO & 48 & 277.778 & $3,600 \mathrm{E}-06$ & $99,280 \%$ & $0,720 \%$ & 3,0 \\
\hline \multicolumn{8}{|l|}{03.02} \\
\hline 03.02 .01 & CH.IL.NO & 48 & 1.263 .145 & 7,917E-07 & $99,841 \%$ & $0,159 \%$ & 3,0 \\
\hline \multicolumn{8}{|l|}{03.03} \\
\hline 03.03 .01 & DJ1.IL.CC & 24 & 4.040 .754 & $2,475 \mathrm{E}-07$ & $99,950 \%$ & $0,050 \%$ & 3,0 \\
\hline 03.03 .02 & DJ2.IL.CC & 24 & 4.040 .754 & $2,475 \mathrm{E}-07$ & $99,950 \%$ & $0,050 \%$ & 3,0 \\
\hline 03.03 .03 & DJ.IL.EM & 48 & 4.040 .754 & $2,475 \mathrm{E}-07$ & $99,950 \%$ & $0,050 \%$ & 3,0 \\
\hline 03.03 .04 & DJ1.FB & 24 & 4.040 .754 & $2,475 \mathrm{E}-07$ & $99,950 \%$ & $0,050 \%$ & 3,0 \\
\hline 03.03 .05 & DJ2.FB & 24 & 4.040 .754 & $2,475 \mathrm{E}-07$ & $99,950 \%$ & $0,050 \%$ & 3,0 \\
\hline 03.03 .06 & DJ3.FB & 24 & 4.040 .754 & $2,475 \mathrm{E}-07$ & $99,950 \%$ & $0,050 \%$ & 3,0 \\
\hline 03.03 .07 & DJ4.FB & 24 & 4.040 .754 & $2,475 \mathrm{E}-07$ & $99,950 \%$ & $0,050 \%$ & 3,0 \\
\hline 03.03 .08 & DJ*.IL.NO & 144 & 4.040 .754 & $2,475 \mathrm{E}-07$ & $99,950 \%$ & $0,050 \%$ & 3,0 \\
\hline
\end{tabular}

O perfil da missão, estabelecido no plano do programa de confiabilidade, define que o tempo médio operacional por ano é de 8030 horas por trem. Com essa informação, pode-se calcular a confiabilidade do item durante o período de reposição. No caso do mesmo item 03.01.01, a confiabilidade durante 3 meses é de:

$$
R(t)=e^{(-\lambda \cdot t)}=e^{\left(\frac{-t}{M T B F}\right)}
$$

O tempo $\mathrm{t}$ corresponde à média de horas operacionais em 3 meses, ou seja:

$$
R(t)=e^{\left(\frac{-8030 \cdot \frac{3}{12}}{277.778}\right)}=0,9928=99,28 \%
$$

A probabilidade de falha de cada um dos 48 itens nesse período é:

$$
F(t)=1-R(t)=1-0,9928=0,0072=0,72 \%
$$

A quantidade de itens sobressalentes necessários é calculada utilizandose a equação 4.54 .

$$
P(x \leq k)=\sum_{x=0}^{k} \frac{(\lambda \cdot t)^{k}}{k !} \cdot e^{-\lambda \cdot t}
$$


onde o objetivo é calcular $k$ tal que a probabilidade de falta de material seja menor ou igual a $2 \%$. Isso pode ser feito através de um processo progressivo de cálculo, estabelecendo valores inteiros à variável $k$ e avaliando o resultado até que se obtenha o menor valor de $k$ que atenda ao requisito de probabilidade menor ou igual a $2 \%$.

Por exemplo, para o mesmo componente citado (03.01.01), o cálculo da quantidade de sobressalentes está detalhado na Tabela 47.

Tabela 47: Cálculo detalhado de sobressalentes

\begin{tabular}{|l|c|c|}
\hline $\mathrm{k}=0$ & $P(x \leq 0)=\sum_{x=0}^{0} \frac{(\lambda \cdot t)^{0}}{0 !} \cdot e^{-\lambda \cdot t}=e^{-\lambda \cdot t}=e^{-3,6 \cdot 10^{-6} \cdot 8030 \cdot \frac{3}{12} \cdot 48}=0,293=29,3 \%$ & $\begin{array}{c}\text { Não } \\
\text { atende }\end{array}$ \\
\hline $\mathrm{k}=1$ & $P(x \leq 1)=\sum_{x=0}^{1} \frac{(\lambda \cdot t)^{1}}{1 !} \cdot e^{-\lambda \cdot t}=4,8 \%$ & $\begin{array}{c}\text { Não } \\
\text { atende }\end{array}$ \\
\hline $\mathrm{k}=2$ & $P(x \leq 2)=\sum_{x=0}^{2} \frac{(\lambda \cdot t)^{2}}{2 !} \cdot e^{-\lambda \cdot t}=0,5 \%$ & Atende \\
\hline
\end{tabular}

Portanto, para esse componente, determina-se a quantidade de 2 itens sobressalentes para que atenda ao requisito especificado.

Geralmente esses cálculos são feitos através de programação para agilizar o processo. A Tabela 48 ilustra um trecho da estrutura analítica com as quantidades de sobressalentes já calculadas para um risco menor que $2 \%$ e para um risco menor que $10 \%$. 
Tabela 48: Cálculo de sobressalentes

\begin{tabular}{|c|c|c|c|c|c|c|c|c|c|}
\hline \multicolumn{2}{|c|}{$\begin{array}{c}\text { ESTRUTURA } \\
\text { ANALITICA }\end{array}$} & \multirow{3}{*}{$\begin{array}{c}\text { Quantidade } \\
\text { na frota }\end{array}$} & \multicolumn{4}{|c|}{ Confiabilidade } & \multirow{3}{*}{$\begin{array}{l}\text { Tempo } \\
\text { para } \\
\text { reposição } \\
\text { ("Lead } \\
\text { time") } \\
\text { [months] }\end{array}$} & \multicolumn{2}{|c|}{$\begin{array}{l}\text { Número de } \\
\text { sobressalentes } \\
\text { recomendados para um } \\
\text { risco menor que: }\end{array}$} \\
\hline \multirow{2}{*}{ CÓD } & \multirow{2}{*}{ IDENTIF. } & & \multirow{2}{*}{$\begin{array}{c}\text { MTBF } \\
{[\mathrm{h}]}\end{array}$} & \multirow{2}{*}{$\begin{array}{c}\lambda \\
{[f / h]}\end{array}$} & \multirow{2}{*}{$R(t)$} & \multirow{2}{*}{$F(t)$} & & & \\
\hline & & & & & & & & $2,0 \%$ & $10,0 \%$ \\
\hline 03.01 & & & & & & & & - & - \\
\hline 03.01 .01 & C1.IL.NO & 48 & 277.778 & $3,600 \mathrm{E}-06$ & $99,280 \%$ & $0,720 \%$ & 3,0 & 2,0 & 1,0 \\
\hline 03.01 .02 & C2.IL.NO & 48 & 277.778 & $3,600 \mathrm{E}-06$ & $99,280 \%$ & $0,720 \%$ & 3,0 & 2,0 & 1,0 \\
\hline 03.02 & & & & & & & & - & - \\
\hline 03.02 .01 & CH.IL.NO & 48 & 1.263 .145 & 7,917E-07 & $99,841 \%$ & $0,159 \%$ & 3,0 & 1,0 & - \\
\hline 03.03 & & & & & & & & - & - \\
\hline 03.03 .01 & DJ1.IL.CC & 24 & 4.040 .754 & $2,475 \mathrm{E}-07$ & $99,950 \%$ & $0,050 \%$ & 3,0 & - & - \\
\hline 03.03 .02 & DJ2.IL.CC & 24 & 4.040 .754 & $2,475 \mathrm{E}-07$ & $99,950 \%$ & $0,050 \%$ & 3,0 & - & - \\
\hline 03.03 .03 & DJ.IL.EM & 48 & 4.040 .754 & $2,475 \mathrm{E}-07$ & $99,950 \%$ & $0,050 \%$ & 3,0 & 1,0 & - \\
\hline 03.03 .04 & DJ1.FB & 24 & 4.040 .754 & $2,475 \mathrm{E}-07$ & $99,950 \%$ & $0,050 \%$ & 3,0 & - & - \\
\hline 03.03 .05 & DJ2.FB & 24 & 4.040 .754 & $2,475 \mathrm{E}-07$ & $99,950 \%$ & $0,050 \%$ & 3,0 & - & - \\
\hline 03.03 .06 & DJ3.FB & 24 & 4.040 .754 & $2,475 \mathrm{E}-07$ & $99,950 \%$ & $0,050 \%$ & 3,0 & - & - \\
\hline 03.03 .07 & DJ4.FB & 24 & 4.040 .754 & $2,475 \mathrm{E}-07$ & $99,950 \%$ & $0,050 \%$ & 3,0 & - & - \\
\hline 03.03 .08 & DJ*.IL.NO & 144 & 4.040 .754 & 2,475E-07 & $99,950 \%$ & $0,050 \%$ & 3,0 & 1,0 & - \\
\hline
\end{tabular}

Eventualmente, dependendo dos acordos firmados entre operadora e montadora e também entre montadora e seus fornecedores, podem existir os chamados lotes de consignação de materiais, que nada mais são que materiais de propriedade dos fornecedores que são disponibilizados para uso da operadora durante um determinado período, de forma a cobrir a necessidade de materiais para manutenção.

É necessário, portanto, verificar se as quantidades informadas pelo fornecedor atendem à demanda de materiais com base nas informações de CDMS e qual seria o risco de aceitação dessas quantidades. Isso facilita a tomada de decisões quanto à solicitação de alteração de quantidades, ou complementação dos itens por conta da própria montadora, ou ainda a simples aceitação do risco, por exemplo. A Tabela 49 ilustra isso para um trecho da estrutura analítica. 
Tabela 49: Risco de falta de materiais

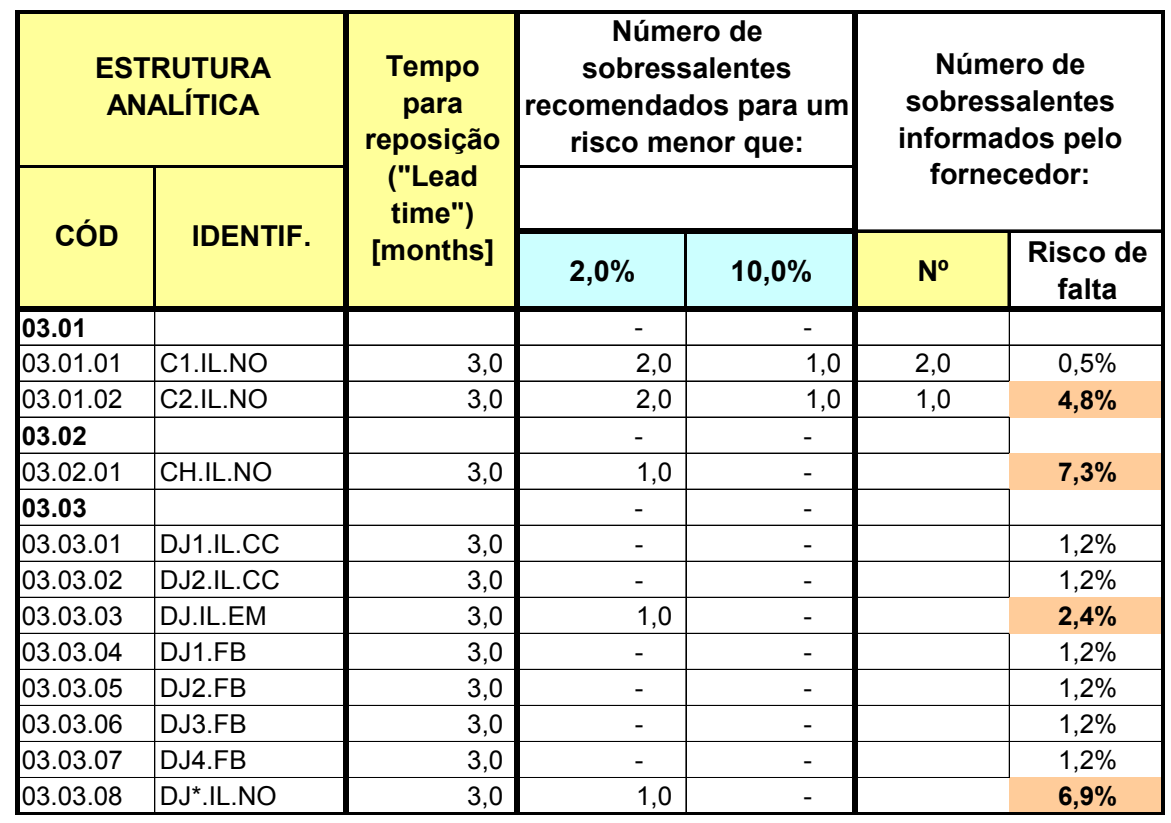

\subsubsection{Apresentação dos resultados}

A Figura 51 apresenta a planilha completa com o cálculo das quantidades de itens sobressalentes para o sistema de iluminação.

\subsubsection{Recomendações}

Conforme mencionado anteriormente, o cálculo de sobressalentes visa proporcionar informações suficientes e adequadas para dar suporte às tomadas de decisão referentes ao planejamento da manutenção, negociação com fornecedores, etc. As recomendações possíveis podem variar bastante de caso para caso, mas de uma maneira geral estarão sempre relacionadas com a aceitação ou não do risco, com a modificação de quantidades ou com o estabelecimento de metas de confiabilidade que possibilitem a redução das necessidades de sobressalentes. Relatórios específicos podem ser elaborados com as recomendações adequadas para cada item, por sistema ou por fornecedor. 


\begin{tabular}{|c|c|c|c|c|c|c|c|c|c|c|c|c|c|c|c|c|c|c|c|}
\hline & $C$ & FACIND & & & & & & & & & CÁLCULC & JE SOBR & SSALEI & ENTES & & & & & \\
\hline & PROJETO:| & EXEMPLO & & & & & Nota & & & & & & & Perfil da & Missäo & & & & \\
\hline & SISTEMA: & ILUMINAÇÃO & & & & & & & & Horas of & eracionais & ano $[\mathrm{h}]:$ & 8030 & & & & & & \\
\hline ELABC & ORADO POR: & A.FACINI & & & com, & ponen & ntes 03 & 3.04.02, & 03.04.05, & & & & & & & & & & \\
\hline APR & OVADO POR: & G.F.M.SOUZA & & & .06 & $\begin{array}{l}03 \\
\text { eis }\end{array}$ & 1.07 säc & $\begin{array}{l}\text { oitens } \\
\text { se mot }\end{array}$ & & & & & & & & & & & \\
\hline & DATA: & $26 / 01 / 07$ & & & & & $\begin{array}{l}\text { poress } \\
\text { lo de M }\end{array}$ & $\begin{array}{l}\text { MTBF. } \\
\text { MTE. }\end{array}$ & & & & & & & & & & & \\
\hline NÚMER & 20/REVISÄO & 123.456 .789 & 00 & & & & & & & & & & & & & & & & \\
\hline & & & & & & & manho & da frota & & & & & & & & & & & \\
\hline & & STRUTURA ANALITICA & & MC1 & R1 & R2 & MC2 & & & & & Confiabilid & & & & ress & & & \\
\hline & & & & 12 & 12 & 12 & 12 & & & Quantidade & & & & & $\begin{array}{l}\text { reposiçäa } \\
\text { res }\end{array}$ & $\begin{array}{l}\text { Tecoment } \\
\text { um risco m }\end{array}$ & $\begin{array}{l}\text { nos qua } \\
\text { nor que: }\end{array}$ & inform & pelo \\
\hline & ADENTIE & & & & & antidac & ide por & It tipo de & carro & na frota & MTBF & & & & $\begin{array}{l}\text { ("Lead } \\
\text { time") }\end{array}$ & & & & \\
\hline $\operatorname{coD}$ & IDENTIF. & DESCRIÇAO & 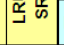 & $\mathrm{Mc}_{1}$ & $R_{1}$ & $\mathrm{R}_{2}$ & $\mathrm{MC}_{2}$ & & & & {$[\mathrm{~h}]$} & {$[f / h]$} & $R(t)$ & $F(t)$ & & $2,0 \%$ & $10,0 \%$ & $\mathrm{~N}^{\circ}$ & $\begin{array}{c}\text { Riscode } \\
\text { falta }\end{array}$ \\
\hline $\begin{array}{l}03.01 \\
03.01 .01\end{array}$ & C1.LNO & $\begin{array}{l}\text { CONTATORES } \\
\text { Contator } 1 \text { de iluminacẵo normal }\end{array}$ & LRU & & 1 & 1 & 1 & & & 48 & 277.778 & $3.600 E-06$ & & $0.720 \%$ & 3.0 & 2.0 & 1.0 & 2.0 & Tanta \\
\hline 030.102 & C2.l.NO & 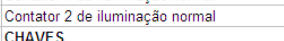 & LRU & 1 & 1 & 1 & 1 & & & 48 & 277.778 & $3.600 E-06$ & $99.280 \%$ & $0.720 \%$ & 3.0 & 2.0 & 1.0 & 1.0 & $4,8 \%$ \\
\hline 00.02 .01 & CH.ILNO & 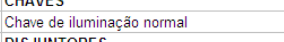 & LRU & 1 & 1 & 1 & 1 & & & 48 & 1.263 .145 & $7.917 E-07$ & $99.841 \%$ & $0,159 \%$ & 3.0 & 1.0 & & & $7,3 \%$ \\
\hline $\begin{array}{l}03.03 \\
03.03 .01\end{array}$ & DJ1.L.CC & $\begin{array}{l}\text { DISJUNTORES } \\
\text { Disijuntor 1 de iluminanăăo da cabine }\end{array}$ & LRU & 1 & & 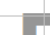 & & 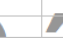 & & $\equiv$ & 4.040 .754 & $2,4756-07$ & & & 3.0 & 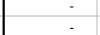 & & & $12 \%$ \\
\hline 03.03 .02 & & Disjuntor 2 de ilmuniaçăa da cabine & LRU & 1 & & & 1 & & & 24 & 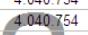 & $2,475 E-07$ & $99,950 \%$ & & 3,0 & & & & $\begin{array}{l}\frac{1,2 \%}{1.2 \%} \\
1\end{array}$ \\
\hline 03.03 .03 & DJ.LEM & Disjuntor da iluminaç̧̃âo de emergência & & & 1 & & & & & 46 & 4.040 .754 & $2,475 E-07$ & $99,950 \%$ & $0,050 \%$ & 3,0 & 1.0 & & & $2,4 \%$ \\
\hline 03.03 .04 & DJ1.FB & Disjuntor 1 do circuito de farol & LRU & 1 & & 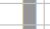 & 1 & $c$ & & 24 & 4.0407754 & $2.475 E-07$ & $99,950 \%$ & $0,050 \%$ & 3,0 &. & & & $1,2 \%$ \\
\hline 03.03 .05 & DJ2FB & Disjuntor 2 do circuito de farol & LRU & 1 & & & 1 & & & & 4.040 .754 & $2.475 E-07$ & $99,950 \%$ & $0,050 \%$ & 3,0 & - & & & $1,2 \%$ \\
\hline 03.03 .06 & DJ3.FB & 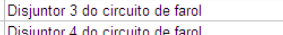 & LRU & 1 & & 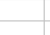 & 1 & & 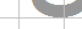 & 24 & $\begin{array}{l}4.040 .754 \\
404754\end{array}$ & 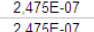 & $99,950 \%$ & $0.050 \%$ & 3,0 & - & & & $1,2 \%$ \\
\hline 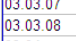 & $\begin{array}{l}\text { DSFFB } \\
\text { DJ"L.NO }\end{array}$ & 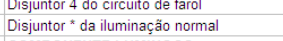 & LRU & $\frac{1}{3}$ & 3 & 3 & $\frac{1}{3}$ & & & ${ }_{144}^{24}$ & $\begin{array}{l}4.040 .754 \\
4.040 .754\end{array}$ & $\begin{array}{l}2.475 E-07 \\
2.475--07\end{array}$ & 999,950\% & $0.050 \%$ & $\begin{array}{l}3,0 \\
3,0\end{array}$ & 1.0 & & & $\begin{array}{l}1,2 \% \\
6,9 \%\end{array}$ \\
\hline $\begin{array}{l}03.04 \\
030401\end{array}$ & FB1 1 & $\begin{array}{l}\text { COMPONENTE LUMINOSO } \\
\text { Fare }\end{array}$ & IRU & 1 & & & 1 & & & 24 & 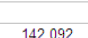 & C.38E-06 & $1000000 \%$ & & 3,0 & & & & \\
\hline $\begin{array}{l}0.304 .01 \\
03.04 .02\end{array}$ & $\begin{array}{l}F B 1 \\
F B 2\end{array}$ & 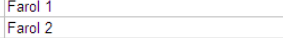 & $\begin{array}{l}\text { LRU } \\
R Q\end{array}$ & $\frac{1}{1}$ & & & $\frac{1}{1}$ & & & 24 & $\begin{array}{l}142.092 \\
112092\end{array}$ & $\begin{array}{l}7.033 E E-06 \\
7.0385-06\end{array}$ & $\begin{array}{l}100.000 \% \\
9.134 \%\end{array}$ & $1.866 \%$ & 4.0 & 20 & 10 & & \\
\hline 03.04 .03 & LF.NO: & Iluminaçåo normal & CONS & 32 & 32 & 32 & 32 & & & 1536 & & & & & & & & & \\
\hline & LB.1 & & LRU & & & & 1 & & & 24 & 50.000 & $2,000 E-05$ & $94.787 \%$ & $5.213 \%$ & 4.0 & 4.0 & & & \\
\hline & LB.2 2 & amento & LRU & 1 & & & 1 & & & 24 & 50.000 & & $94.787 \%$ & $5.213 \%$ & 4,0 & 4.0 & 3.0 & 5.0 & $0.2 \%$ \\
\hline 03.04 .06 & LC. 1 & & LRU & 1 & & & 1 & & & 24 & & $2,000 E-05$ & $94,787 \%$ & $5,213 \%$ & 4.0 & 4.0 & 3,0 & 5.0 & $0.2 \%$ \\
\hline 03.04 .07 & LC.2 & Luz 2 de cauda & LRU & 1 & & & 1 & & & 24 & 50.000 & $2,000 E-05$ & $94,787 \%$ & $5.213 \%$ & 4.0 & 4.0 & 3.0 & 5.0 & $0.2 \%$ \\
\hline 003.04 .08 & & & $\begin{array}{c}\text { cons } \\
\text { cons }\end{array}$ & 4 & 8 & & 4 & & & 966 & & & & & & & & & \\
\hline $\begin{array}{l}030409.09 \\
03.04 .10\end{array}$ & $\begin{array}{l}\text { LFEM." } \\
\text { SPOT* }\end{array}$ & 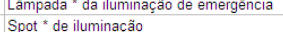 & $\begin{array}{l}\text { cons } \\
\text { cons }\end{array}$ & $\frac{8}{2}$ & 8 & 8 & $\frac{8}{2}$ & & & 384 & & & & & & & & & \\
\hline 03.04 .11 & LUM." "E & 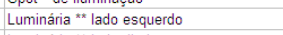 & LRU & 1 & 1 & 1 & 1 & & & 48 & & & & & & $\cdot$ & & & \\
\hline 03.04 .12 & & Luminária " lac & LRU & 1 & 1 & 1 & 1 & & & & & & & & & & & & \\
\hline 3.04.13 33 & LUM.1CC & Luminarial $1 \mathrm{da}$ & LRU & 1 & & & 1 & & & 24 & & & & & & & & & \\
\hline & LUM.2CC & & LRU & 1 & & & 1 & & & 24 & & & & & & & & & \\
\hline 03.04 .15 & LUM.3.3CC & Lunináára 3 da & LRU & 1 & & & 1 & & & 24 & & & & & & 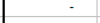 & & & \\
\hline & LUM. $4 c c$ & $\begin{array}{l}\text { Lumnanala } 4 \mathrm{~d} \\
\text { RELÉs }\end{array}$ & LRU & 1 & & & & & & & & & & & & & & & \\
\hline 03.05 .01 & RFB & le farol & LRU & 1 & & & 1 & & & 24 & 4.973 .236 & $2.011 E-07$ & $99,960 \%$ & $0,040 \%$ & 3,0 & $\cdot$ & & & $1.0 \%$ \\
\hline & & Inve & LRU & 4 & & & 4 & & & 96 & 241482 & 4.141E-06 & $98.624 \%$ & $1376 \%$ & 50 & 40 & 3.0 & 3.0 & $4,6 \%$ \\
\hline 03.06 .02 & I.EM. & or * de liuminaçăo & LRU & & 8 & 8 & 8 & & & 384 & & & $24 \%$ & 1.37 & 5.0 & 11.0 & 8.0 & 10.0 & $\%$ \\
\hline 33.06 .03 & RNO:" & Reator * - iluminaçăon normal do saläo & LRU & 16 & 18 & 18 & 16 & & & 816 & 440.000 & & $99.242 \%$ & $0,758 \%$ & 5,0 & 12,0 & 9,0 & 10,0 & $5,2 \%$ \\
\hline 3.06 .04 & TFF.FB & Trafo do circuito de farol & LRU & & 1 & & & & & & 445.408 & $2.245 E-06$ & $99.252 \%$ & $0.748 \%$ & & 2.0 & 1.0 & 1.0 & $5,1 \%$ \\
\hline
\end{tabular}

Figura 51: Planilha de sobressalentes 


\subsection{EXEMPLO 6: MONITORAMENTO DA CONFIABILIDADE}

\subsubsection{Descrição}

Uma determinada frota já em operação após projeto, testes e comissionamento, é observada para levantamento de informações de confiabilidade. Os dados de campo são coletados mensalmente e consolidados entre fabricante e operadora. A equipe de manutenção divulga mensalmente um relatório contendo as informações relevantes para o cálculo dos índices de confiabilidade.

\subsubsection{Metas globais de confiabilidade}

A operadora especificou as metas de confiabilidade estabelecendo dois tipos de falha:

- Falha do tipo A:

- Falhas que provocam evacuação e/ou reboque dos trens;

- Falhas que provocam a retirada iminente do trem da operação por seus próprios meios;

- Meta: 250.000 carro-quilômetro

- Falha do Tipo B:

- Demais falhas que se manifestem durante a operação do trem e que não afetem o critério de falha do tipo $A$;

Meta: 9.000 carro-quilômetro

\subsubsection{Metodologia de análise}


Ainda na fase de projeto, durante as análises de CDMS, são estabelecidas as estruturas analíticas de cada sistema do trem. Como já foi mencionado, essas estruturas são utilizadas desde as etapas iniciais de projeto até o acompanhamento da operação em campo. O que não significa que as mesmas não possam sofrer revisões ao longo do projeto.

Todas as estruturas analíticas dos sistemas são consolidadas em uma única, a qual também é comumente chamada de arborização, e que deve ser inserida em um software de monitoramento (FRACAS) para que sejam computadas as falhas ocorridas em campo e comparadas com as metas e, quando necessário, com os estudos realizados durante a fase de projeto.

O apontamento das falhas é feito diretamente no software quando o trem é recolhido da via para a oficina de manutenção. Esse processo pode variar de operadora para operadora, mas geralmente o primeiro registro é feito pelo próprio operador do trem de forma direta ou mesmo comunicando remotamente à oficina qual a anomalia presente no trem. Assim que o trem chega para manutenção, é feita uma inspeção detalhada do problema, confirmando ou não a informação do operador. Nesse momento ocorre uma pré-classificação da falha quanto ao seu tipo. Após o reparo, o trem é colocado à disposição para operação e são registradas quais as intervenções que foram feitas, como a troca de algum equipamento, por exemplo.

Periodicamente, por exemplo ao fim do mês, todos os registros de falha são compilados em uma única lista, contendo todas as informações relevantes para a classificação definitiva das falhas e levantamento dos índices de confiabilidade.

O conteúdo dessa lista é discutido em reuniões entre operadora e montadora, as quais determinam juntas a classificação das falhas, tomando como base a especificação técnica e o plano de confiabilidade elaborados no início do projeto. Vale destacar mais uma vez a importância da elaboração desse plano e a aprovação do mesmo pela operadora o quanto antes no desenvolvimento do projeto pois, como se pode imaginar, essas reuniões de classificação de falhas e cálculo dos índices tendem a ser um tanto quanto conturbadas e não raramente ocorrem disputas por interesses de ambos os lados, fugindo do contexto técnico e entrando 
em um contexto político. Quanto mais claro e detalhado forem o plano de confiabilidade e os procedimentos de seguimento operacional, menor será o impacto dessas reuniões.

Uma vez que as falhas tenham sido consolidadas e classificadas quanto ao seu tipo, faz-se a apuração dos índices de confiabilidade e geração de relatórios para divulgação de tais índices.

\subsubsection{Apresentação e interpretação dos resultados}

A Tabela 50 e a Figura 52 mostram a distância acumulada pela frota mês a mês em carro-quilômetro.

Tabela 50: Distância acumulada pela frota

\begin{tabular}{|l|c|c|c|c|c|c|c|c|}
\hline Mês & abr/06 & mai/06 & jun/06 & jul/06 & ago/06 & set/06 & out/06 & nov/06 \\
\hline Km & 1.250 .172 & 1.358 .847 & 1.275 .528 & 1.401 .810 & 1.629 .597 & 1.537 .347 & 1.653 .741 & 1.621 .014 \\
\hline
\end{tabular}

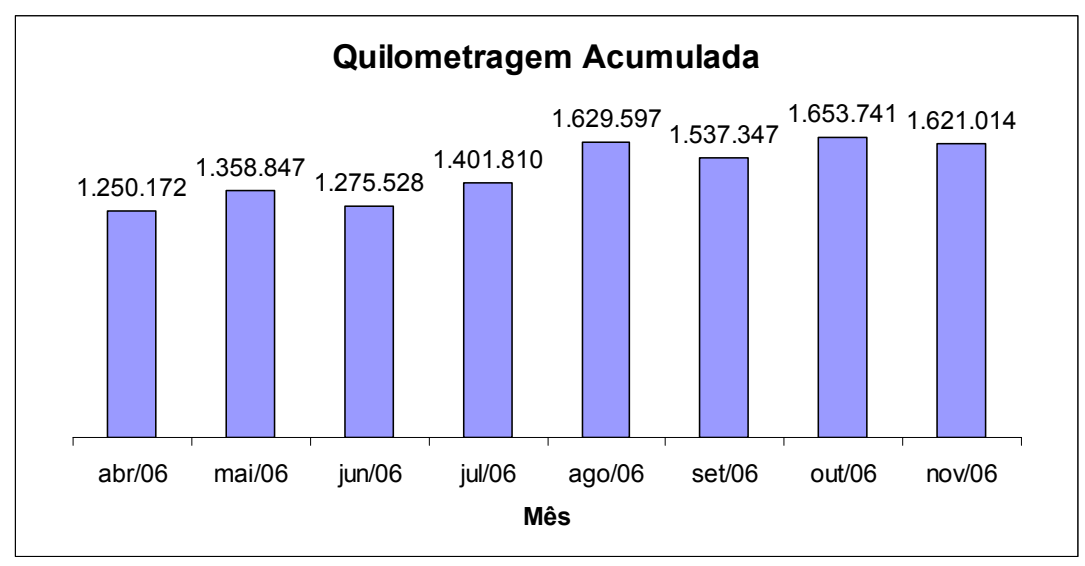

Figura 52: Distância acumulada pela frota

- A distância total percorrida pela frota de Abril/06 a Novembro/06 foi de: $11.728 .056 \mathrm{~km}$.

- A média mensal percorrida pela frota de Abril/06 a Novembro/06 é de: $1.466 .007 \mathrm{~km}$. 
A Tabela 51 apresenta a quantidade de falhas do Tipo A observadas mês a mês em cada sistema.

Tabela 51: Quantidade de Falhas Tipo A

\begin{tabular}{|c|c|c|c|c|c|c|c|c|c|}
\hline Mês & $a b r / 06$ & mai/06 & jun/06 & jul/06 & ago/06 & set/06 & out/06 & nov/06 & TOTAL \\
\hline Tração & 1 & & 1 & & & & & & 2 \\
\hline Portas & 4 & 1 & 2 & & 1 & & 2 & 1 & 11 \\
\hline Conforto & & & & & & & & & 0 \\
\hline Data-Bus & & & & & & & & & 0 \\
\hline Caixa & & 1 & & & & & & & 1 \\
\hline Freio & & & 1 & & 1 & & & & 2 \\
\hline Suprimento de Ar & 1 & & & & & & & & 1 \\
\hline
\end{tabular}

A Tabela 52 apresenta a quantidade de falhas do Tipo B observadas mês a mês em cada sistema.

Tabela 52: Quantidade de Falhas Tipo B

\begin{tabular}{|l|c|c|c|c|c|c|c|c|c|}
\hline Mês & abr/06 & mai/06 & jun/06 & jul/06 & ago/06 & set/06 & out/06 & nov/06 & TOTAL \\
\hline Interface com condutor & 23 & 24 & 27 & 32 & 28 & 27 & 30 & 16 & 207 \\
\hline Tração & 52 & 47 & 22 & 20 & 16 & 16 & 28 & 38 & 239 \\
\hline Portas & 33 & 33 & 25 & 33 & 28 & 23 & 19 & 27 & 221 \\
\hline Conforto & 6 & 8 & 8 & 11 & 6 & 5 & 7 & 4 & 55 \\
\hline Ventilação & 4 & 11 & 12 & 18 & 4 & 2 & 6 & 2 & 59 \\
\hline Data-Bus & 2 & 3 & 2 & 1 & 4 & 2 & 5 & 4 & 23 \\
\hline Caixa & 8 & 0 & 9 & 6 & 8 & 4 & 4 & 3 & 42 \\
\hline Freio & 2 & 8 & 5 & 3 & 5 & 1 & 4 & 0 & 28 \\
\hline Suprimento de Ar & 6 & 10 & 5 & 3 & 3 & 8 & 3 & 3 & 41 \\
\hline Truque & 9 & 9 & 4 & 3 & 9 & 2 & 2 & 1 & 39 \\
\hline Funções de manutenção & 0 & 0 & 0 & 0 & 0 & 1 & 1 & 0 & 2 \\
\hline Suprimento Elétrico & 3 & 1 & 0 & 2 & 1 & 0 & 1 & 0 & 8 \\
\hline
\end{tabular}

A Tabela 53 apresenta a quantidade de falhas dos Tipos A e B observadas mês a mês em cada sistema. 
Tabela 53: Quantidade de Falhas (A+B)

\begin{tabular}{|l|c|c|c|c|c|c|c|c|c|}
\hline Mês & abr/06 & mai/06 & jun/06 & jul/06 & ago/06 & set/06 & out/06 & nov/06 & TOTAL \\
\hline Interface com condutor & 23 & 25 & 28 & 32 & 28 & 27 & 30 & 16 & 209 \\
\hline Tração & 53 & 47 & 23 & 20 & 16 & 16 & 28 & 38 & 241 \\
\hline Portas & 37 & 34 & 27 & 33 & 29 & 23 & 21 & 28 & 232 \\
\hline Conforto & 6 & 8 & 8 & 11 & 6 & 5 & 7 & 4 & 55 \\
\hline Ventilação & 4 & 11 & 12 & 18 & 4 & 2 & 6 & 2 & 59 \\
\hline Data-Bus & 2 & 3 & 2 & 1 & 4 & 2 & 5 & 4 & 23 \\
\hline Caixa & 8 & 1 & 9 & 6 & 8 & 4 & 4 & 3 & 43 \\
\hline Freio & 2 & 8 & 6 & 3 & 6 & 1 & 4 & 0 & 30 \\
\hline Suprimento de Ar & 7 & 10 & 5 & 3 & 3 & 8 & 3 & 3 & 42 \\
\hline Truque & 9 & 9 & 4 & 3 & 9 & 2 & 2 & 1 & 39 \\
\hline Funções de manutenção & 0 & 0 & 0 & 0 & 0 & 1 & 1 & 0 & 2 \\
\hline Suprimento Elétrico & 3 & 1 & 0 & 2 & 1 & 0 & 1 & 0 & 8 \\
\hline
\end{tabular}

A Tabela 54 apresenta a evolução de MKBF para falhas do tipo A.

Tabela 54: Evolução de MKBF - Falhas Tipo A

\begin{tabular}{|l|c|c|c|c|c|c|c|c|}
\hline Mês & abr/06 & mai/06 & jun/06 & jul/06 & ago/06 & set/06 & out/06 & nov/06 \\
\hline Km & 1.250 .172 & 1.358 .847 & 1.275 .528 & 1.401 .810 & 1.629 .597 & 1.537 .347 & 1.653 .741 & 1.621 .014 \\
\hline Falhas Tipo A & 6 & 3 & 5 & 0 & 2 & 0 & 2 & 1 \\
\hline MKBF Tipo A & 208.362 & 452.949 & 255.106 & 1.530 .360 & 814.799 & 1.678 .326 & 826.871 & 1.621 .014 \\
\hline
\end{tabular}

A Tabela 55 apresenta a evolução de MKBF para falhas do tipo B.

Tabela 55: Evolução de MKBF - Falhas Tipo B

\begin{tabular}{|l|c|c|c|c|c|c|c|c|}
\hline Mês & abr/06 & mai/06 & jun/06 & jul/06 & ago/06 & set/06 & out/06 & nov/06 \\
\hline Km & 1.250 .172 & 1.358 .847 & 1.275 .528 & 1.401 .810 & 1.629 .597 & 1.537 .347 & 1.653 .741 & 1.621 .014 \\
\hline Falhas Tipo B & 148 & 154 & 120 & 132 & 112 & 91 & 110 & 98 \\
\hline MKBF Tipo B & 8.447 & 8.824 & 10.629 & 10.620 & 14.550 & 16.894 & 15.034 & 16.541 \\
\hline
\end{tabular}

Com base na Tabela 50 e na Tabela 53, pode-se calcular o MKBF de cada sistema mês a mês. Os resultados desses cálculos estão na Tabela 56 e na Figura 53. 
Tabela 56: Evolução de MKBF de cada sistema

\begin{tabular}{|l|r|r|r|r|r|r|r|r|}
\hline Mês & \multicolumn{1}{|c|}{ abr/06 } & \multicolumn{1}{c|}{ mai/06 } & \multicolumn{1}{c|}{ jun/06 } & \multicolumn{1}{c|}{ jul/06 } & \multicolumn{1}{c|}{ ago/06 } & \multicolumn{1}{c|}{ set/06 } & \multicolumn{1}{c|}{ out/06 } & \multicolumn{1}{c|}{ nov/06 } \\
\hline Interface com condutor & 54.355 & 54.354 & 45.555 & 43.807 & 58.200 & 56.939 & 55.125 & 101.313 \\
\hline Tração & 23.588 & 28.912 & 55.458 & 70.091 & 101.850 & 96.084 & 59.062 & 42.658 \\
\hline Portas & 33.788 & 39.966 & 47.242 & 42.479 & 56.193 & 66.841 & 78.750 & 57.893 \\
\hline Conforto & 208.362 & 169.856 & 159.441 & 127.437 & 271.600 & 307.469 & 236.249 & 405.254 \\
\hline Ventilação & 312.543 & 123.532 & 106.294 & 77.878 & 407.399 & 768.674 & 275.624 & 810.507 \\
\hline Data-Bus & 625.086 & 452.949 & 637.764 & 1.401 .810 & 407.399 & 768.674 & 330.748 & 405.254 \\
\hline Caixa & 156.272 & 1.358 .847 & 141.725 & 233.635 & 203.700 & 384.337 & 413.435 & 540.338 \\
\hline Freio & 625.086 & 169.856 & 212.588 & 467.270 & 271.600 & 1.537 .347 & 413.435 & 1.769 .666 \\
\hline Suprimento de Ar & 178.596 & 135.885 & 255.106 & 467.270 & 543.199 & 192.168 & 551.247 & 540.338 \\
\hline Truque & 138.908 & 150.983 & 318.882 & 467.270 & 181.066 & 768.674 & 826.871 & 1.621 .014 \\
\hline Funções de manutenção & 1.364 .817 & 1.483 .457 & 1.392 .498 & 1.530 .360 & 1.779 .036 & 1.537 .347 & 1.653 .741 & 1.769 .666 \\
\hline Suprimento Elétrico & 416.724 & 1.358 .847 & 1.392 .498 & 700.905 & 1.629 .597 & 1.678 .326 & 1.653 .741 & 1.769 .666 \\
\hline
\end{tabular}

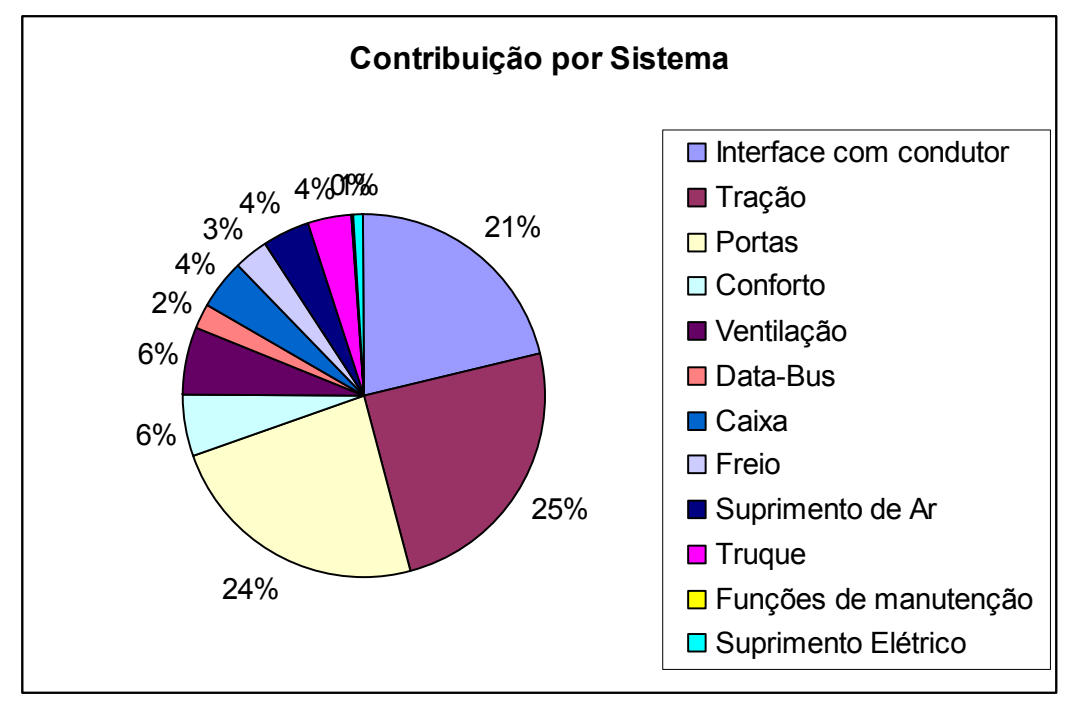

Figura 53: Contribuição por sistema

Pode-se levantar a evolução de FPMK (Falhas Por Milhão de Quilômetros) de cada sistema para análise detalhada. A Figura 54 mostra a evolução do sistema de portas nos primeiros meses de operação da frota. 


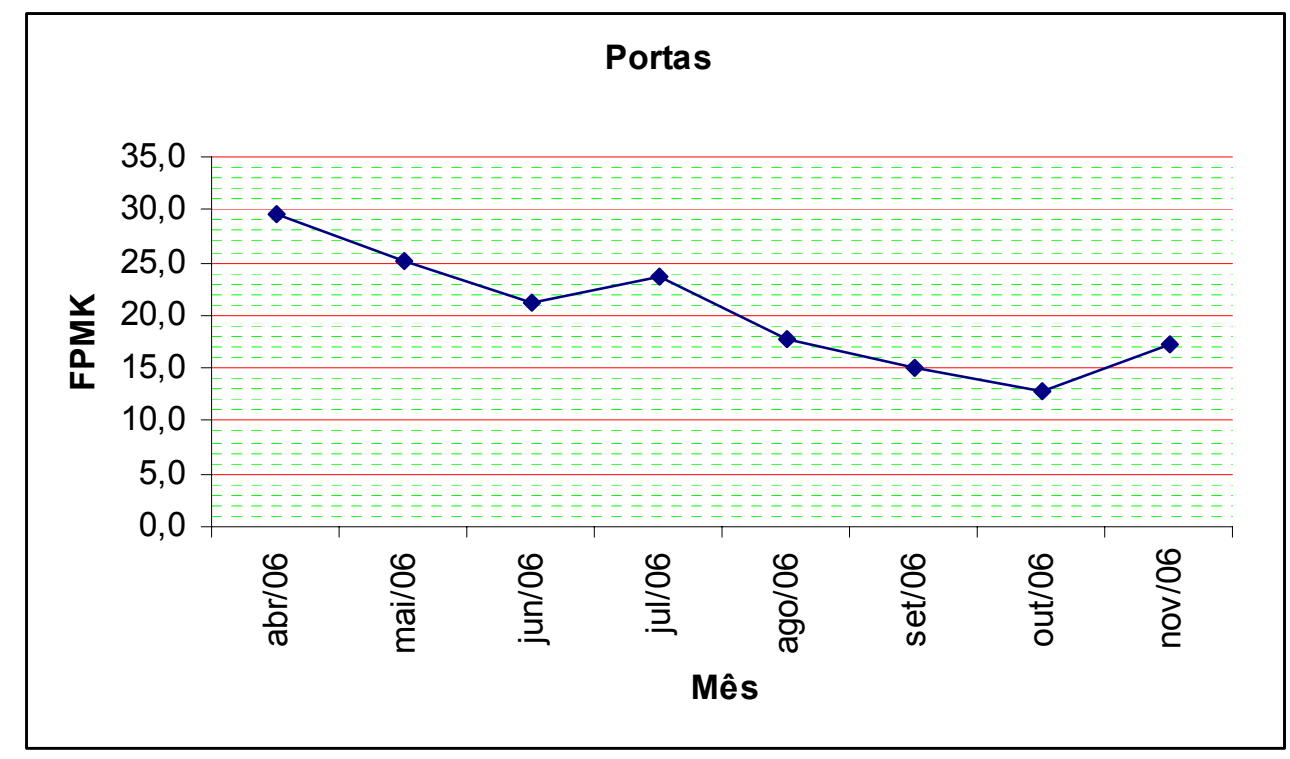

Figura 54: Evolução de FPMK - Portas

A Tabela 57 e a Figura 55 mostram os 10 itens que mais contribuíram para as falhas do sistema.

Tabela 57: TOP 10 - Falhas de Portas

\begin{tabular}{|l|c|c|c|c|c|c|c|c|c|}
\hline \multicolumn{1}{|c|}{ Portas } & abr/06 & mai/06 & jun/06 & jul/06 & ago/06 & set/06 & out/06 & nov/06 & Total \\
\hline Sensor Térmico & 6 & 5 & 5 & 11 & 6 & 5 & 7 & 5 & 50 \\
\hline Portas externas - passageiros & 8 & 5 & 3 & 2 & 2 & 3 & 1 & & 24 \\
\hline Fechadura porta lateral cabine & 5 & 3 & 4 & 1 & 3 & 1 & 2 & 2 & 21 \\
\hline Controlador geral de portas & 3 & 2 & 4 & 3 & 2 & 1 & 1 & 4 & 20 \\
\hline Micro-chave de porta fehada & 7 & 3 & 1 & 2 & & 2 & 2 & 2 & 19 \\
\hline Controlador de comunicação de portas & 1 & & & 4 & 3 & & 2 & 4 & 14 \\
\hline Controlador local de portas & & 5 & 4 & 2 & 2 & & & & 13 \\
\hline Micro-chave de porta travada & 1 & 2 & 1 & 1 & & 4 & 1 & 2 & 12 \\
\hline Botão de acionamento de emergência & & 2 & 2 & 2 & 4 & 1 & & 1 & 12 \\
\hline Mecanismo de porta & & 1 & & 2 & & 2 & 2 & 1 & 8 \\
\hline
\end{tabular}




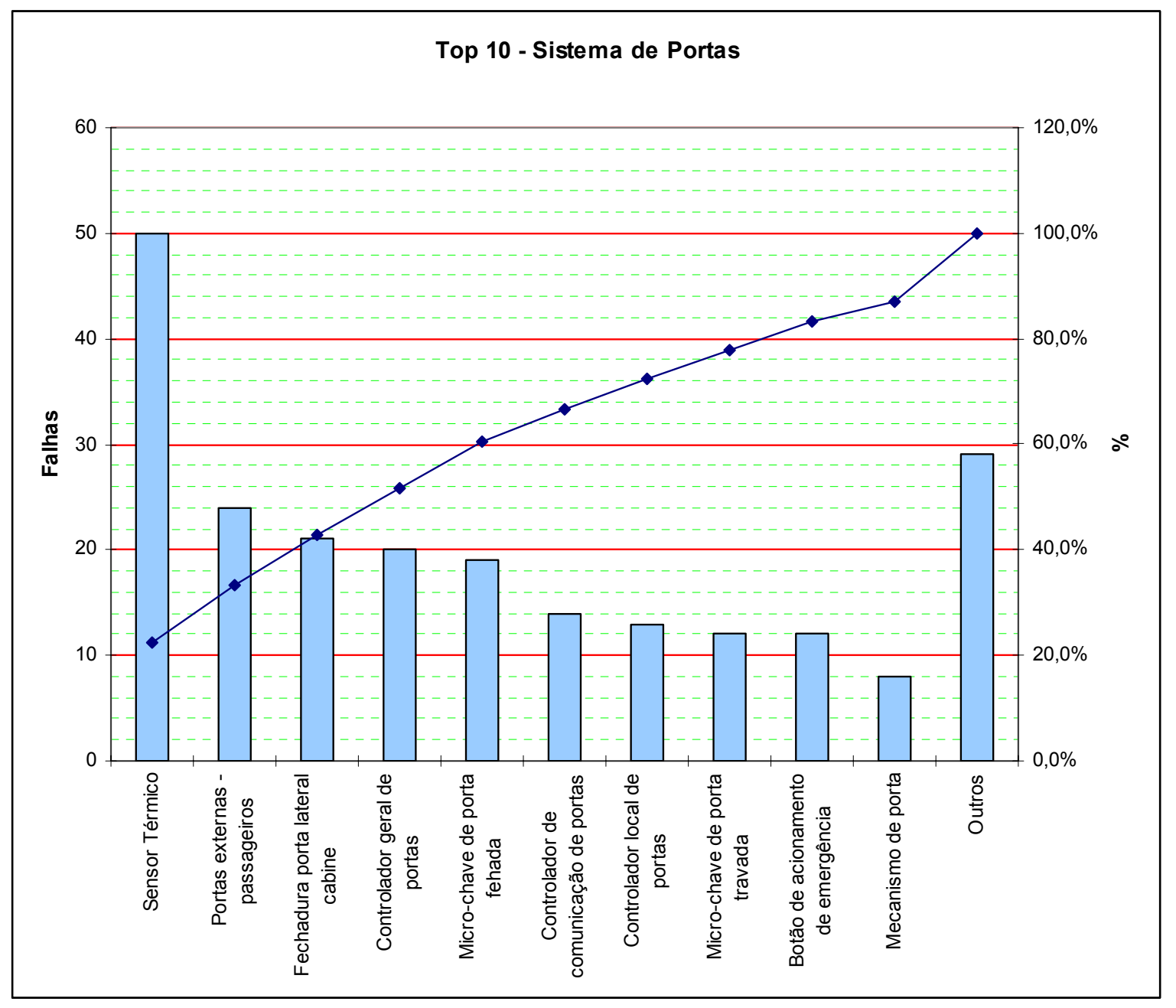

Figura 55: TOP 10 - Falhas de Portas

\subsubsection{Recomendações}

Neste exemplo dado, a confiabilidade global do trem atende ao MKBF especificado, que no caso é de $250.000 \mathrm{~km}$ para falhas do tipo A e $9.000 \mathrm{~km}$ para falhas do tipo $B$.

Ainda assim, é possível perceber quais os pontos de possível melhoria da confiabilidade visando o aprimoramento do produto em futuros projetos. Nota-se que, como na maioria dos projetos metroferroviários, os sistemas de portas, tração e interfaces com o condutor são os que mais contribuem para a falha do trem onde, somados, representam aproximadamente $70 \%$ das falhas. 
Dentre esses, no caso específico das portas, nota-se que o item "sensor térmico" é quem mais contribui para as falhas do sistema. Nota-se também a necessidade de melhoria na qualidade do apontamento das falhas, pois um item genérico "portas externas de passageiros" aparece como segundo mais importante sem que seja possível distinguir qual o real componente defeituoso do sistema.

Para o problema do sensor térmico, deve-se acionar o respectivo fornecedor para que sejam tomadas as devidas providências de forma a reduzir as falhas desse item. Caso houvesse metas específicas para os fornecedores quanto a componentes individuais, essa seria uma forma de constatação do cumprimento ou não das mesmas.

Já para o problema da qualidade no apontamento de falhas em campo, deve-se estabelecer um programa de treinamento e conscientização das pessoas envolvidas nesse processo. Com base nas experiências vividas, a maneira mais eficiente de se envolver as pessoas no processo é através da explanação de todo o sistema da confiabilidade e de que forma as pessoas estão inseridas nele. 


\section{CONCLUSÕES}

A confiabilidade do material rodante ferroviário é um fator de desempenho primordial na operação do transporte de passageiros. Tal desempenho só pode ser alcançado quando os esforços visando a confiabilidade são implementados ainda na fase de especificação e projeto.

O gerenciamento das ações é uma tarefa complexa e exige tanto uma visão sistêmica e abrangente, como também um conhecimento aprofundado do produto, das técnicas de análise, das regras e limitações envolvidas.

Este trabalho procurou demonstrar aspectos práticos da confiabilidade, levando-se em conta as necessidades da indústria e, ao mesmo tempo, procurou trazer para dentro da indústria os aspectos teóricos e científicos da engenharia da confiabilidade, mostrando que é possível evitar a divisão entre o "mundo acadêmico" e o "mundo industrial" em que algumas vezes nos deparamos, em especial no meio ferroviário.

As técnicas aqui apresentadas são, frequentemente, mostradas de forma genérica na literatura; dificilmente são encontradas informações específicas sobre a confiabilidade na ferrovia. Além disso, são poucas as referências que abordam o aspecto gerencial da confiabilidade. A maioria delas privilegiam os aspectos técnicos da confiabilidade, tais como ferramentas de análise, por exemplo. Raramente são apresentadas as dificuldades operacionais para se pôr em prática tais ferramentas e metodologias.

A indústria, por sua vez, necessita de soluções padronizadas, cientificamente aceitas e de eficiência comprovada que levem a resultados confiáveis e, ao mesmo tempo, que sejam suficientemente simples e práticas de tal forma que possam ser implementadas gerando o menor impacto possível em termos de custo, treinamento de mão de obra, e manutenção do processo ao longo do tempo.

Em função disso tudo, outro intuito deste trabalho foi o de reunir em um único documento algumas das principais referências e ferramentas para auxiliar a elaboração de especificações e projetos de material rodante, no que tange à confiabilidade dos mesmos. 
Atualmente, o entendimento geral de CDMS dentro da indústria ferroviária no Brasil ainda é muito heterogêneo. Freqüentemente observam-se interpretações equivocadas de resultados e até de conceitos relacionados com a confiabilidade. Essa foi uma outra motivação para a elaboração deste trabalho, que eventualmente poderá auxiliar na formação de mão de obra qualificada para aproveitamento em uma indústria que tende a crescer e a necessitar cada vez mais de profissionais habilitados, devido à demanda cada vez maior pela eficiência dos sistemas.

Como no Brasil ainda não existe agência reguladora e normas específicas para a confiabilidade e a segurança na ferrovia para o transporte de passageiros, este trabalho pode também auxiliar um início de uma discussão mais ampla sobre o tema.

\subsection{DESENVOLVIMENTOS FUTUROS}

Apesar de tudo isso, este trabalho não tem a pretensão de ser considerado um trabalho completo. O primeiro ponto que evidencia isso é que o foco do trabalho esteve o tempo todo sobre o aspecto confiabilidade. É importante destacar que, tão relevante quanto a confiabilidade, são os demais assuntos da sigla CDMS, ou seja, a Disponibilidade, a Mantenabilidade e a Segurança. A idéia inicial do trabalho era abordar todos esses pontos, porém, além de tornar o texto demasiado extenso, poderia fazer com que os principais aspectos perseguidos praticidade e aplicação direta - fossem afetados negativamente.

Outros pontos passíveis de melhorias são os casos exemplo que, apesar de suficientes para o propósito deste trabalho, não cobrem um projeto completo pelas razões explicadas no capítulo 5 , mas sim uma amostragem de algumas situações reais vividas em diversas obras. Certamente, uma exemplificação considerando um único projeto do seu início até o seu término permitiria uma correlação mais clara das etapas do processo.

Mesmo para as situações abordadas nos exemplos, a obtenção de informações e implementação das técnicas não foi um processo muito simples, dado o nível atual de maturidade das pessoas nesse assunto e a conseqüente 
disponibilidade reduzida de informações. De toda forma, apesar das dificuldades, os casos apresentados podem ser considerados bem sucedidos, principalmente se for levado em conta a implementação de um processo dessa magnitude e a mudança de cultura envolvida.

Com a evolução da discussão sobre o assunto no meio ferroviário e com o maior envolvimento das pessoas, surgirão oportunidades de complementação e melhorias deste trabalho. 


\section{REFERÊNCIAS}

(1) CONNOR, Piers R. Locomotivas diesel. In: editores BRANCO, J. E. C; FERREIRA, Ronaldo. Tratado de Estradas de Ferro - Material Rodante. Rio de Janeiro: Reflexus Estúdio de Produção Gráfica, 2000. p. 115-124.

(2) GRITLET, Irineu. Locomotivas adaptadas. In: editores BRANCO, J. E. C; FERREIRA, Ronaldo. Tratado de Estradas de Ferro - Material Rodante. Rio de Janeiro: Reflexus Estúdio de Produção Gráfica, 2000. p. 159-161.

(3) GÖLITZ, Peter Andreas. Veículos leves sobre trilhos. In: editores BRANCO, J. E. C; FERREIRA, Ronaldo. Tratado de Estradas de Ferro - Material Rodante. Rio de Janeiro: Reflexus Estúdio de Produção Gráfica, 2000. p. 125134.

(4) MCGRAW-HILL Engineering on line. Disponível em: http://www.digitalengineeringlibrary.com. Acesso em 12/jul/06.

(5) GRIECO, Ruy Marcos. Trens de subúrbio e metrô. In: editores BRANCO, J. E. C; FERREIRA, Ronaldo. Tratado de Estradas de Ferro - Material Rodante. Rio de Janeiro: Reflexus Estúdio de Produção Gráfica, 2000. p. 135-141.

(6) HERTZ FILHO, G. P.; GAL, Gilberto. Trens de alta velocidade. In: editores BRANCO, J. E. C; FERREIRA, Ronaldo. Tratado de Estradas de Ferro Material Rodante. Rio de Janeiro: Reflexus Estúdio de Produção Gráfica, 2000. p. 143-148.

(7) KEATING, Oliver. Disponível em: http://www.o-keating.com. Acesso em 23/jul/06.

(8) TRAINWEB. Disponível em: http://www.trainweb.org. Acesso em 23/jul/06.

(9) BAY RAIL ALLIANCE. Disponível em: http://bayrailalliance.org. Acesso em 23/jul/06.

(10) ENGINEER LIVE. Disponível em: http://www.engineerlive.com. Acesso em 23/jul/06. 
(11) RAILWAY TECHNICAL. Disponível em: http://www.railway-technical.com. Acesso em 14/08/06.

(12) LAFRAIA, João Ricardo Barusso. Manual de confiabilidade, mantenabilidade e disponibilidade. Rio de Janeiro. Quality Mark, 2001. 388p.

(13) O'CONNOR, Patrick D.T. Practical reliability engineering. Fourth Edition. West Sussex. John Willey \& Sons, LTD, 2001. 513 p.

(14) INTERNATIONAL ELECTROTECHNICAL COMMISSION. IEC-62278: Railway applications - Specification and demonstration of reliability, availability, maintainability and safety (RAMS). Geneva. IEC, 2002. 159 p.

(15) CENELEC. EN 50126: Railway applications - Specification and demonstration of reliability, availability, maintainability and safety (RAMS). 1999. 76 p.

(16) STEVENSON, William J. Estatística aplicada à administração. Tradução Alfredo Alves de Farias. São Paulo. HARBRA, 1981. 495 p.

(17) INTERNATIONAL ELECTROTECHNICAL COMMISSION. IEC-60863: Presentation of reliability, maintainability and availability predictions. Geneva. IEC, 1986. 28 p.

(18) ASSOCIAÇÃO BRASILEIRA DE CONTROLE DA QUALIDADE. Engenharia da confiabilidade: Apostila do curso. São Paulo. ABCQ, 2003. 317 p.

(19) QUALITY COUNCIL OF INDIANA. CRE primer. West Terre Haute. QCI, 1998. $698 \mathrm{p}$.

(20) DEPARTMENT OF DEFENSE. MIL-HDBK-217-F-notice 2: Reliability prediction of electronic equipment. DOD, 1995.

(21) UNION TECHNIQUE DE L'ELECTRICITE. UTE-C-80-810: Composant electroniques - Recueil de données de fiabilité. Paris. UTE, 1997.

(22) RELIABILITY ANALYSIS CENTER. NPRD-95: Nonelectronic parts reliability data. Rome. RAC, 1995. 1020 p.

(23) ASSOCIAÇÃO BRASILEIRA DE NORMAS TÉCNICAS. NBR 9325: Confiabilidade de equipamentos - planos de ensaio de conformidade para taxa 
de falhas e tempo médio entre falhas admitindo-se taxa de falhas constante Método de ensaio. São Paulo. ABNT, 1986. 31 p.

(24) ASSOCIAÇÃO BRASILEIRA DE NORMAS TÉCNICAS. NBR 9321: Cálculo de estimativas por ponto e limites de confiança resultante de ensaios de determinação da confiabilidade de equipamentos - Procedimento. São Paulo. ABNT, 1986. 34 p.

(25) SOUZA, Gilberto F. M. Análise de confiabilidade aplicada ao projeto de sistemas mecânicos. Apostila da disciplina PMR-5201 da Escola Politécnica da USP. São Paulo. 2003.

(26) GEORGE, Larry. MTBF prediction for redundant systems. Reliability Review, Milwaukee, v. 21, p. 5-9, publicação quadrimestral, dez. 2001.

(27) INTERNATIONAL ELECTROTECHNICAL COMMISSION. IEC-61078: Analysis techniques for dependability - Reliability block diagram method. Geneva. IEC, 1991. 62 p.

(28) STOREY, N. Safety critical computer systems. Addison-Wesley. 1996. 400p.

(29) JOHNSON, B.W. Design and analysis of fault-tolerant digital systems. Charlottesville. Addison-Wesley.

(30) DOVICH, ROBERT A. Reliability statistics. Milwaukee. ASQ Quality Press, 1990. 93 p.

(31) SIEWIOREK, D.P.; SWARS, R.S. The theory and practice of reliable system design. Digital press.

(32) RELIABILITY ANALYSIS CENTER. Reliability Toolkit: Commercial Practices Edition. Rome. RAC, 1995. 508 p.

(33) DEPARTMENT OF DEFENSE. MIL-STD-1629A: Procedures for performing a failure mode, effects and criticality analysis. DOD, 1984.

(34) INTERNATIONAL ELECTROTECHNICAL COMMISSION. IEC-60812: Analysis techniques for system reliability - Procedures for failure mode and effects analysis (FMEA). Geneva. IEC, 1985. 46 p. 
(35) SAE INTERNATIONAL. SAE 1739: Potential failure mode and effects analysis. Warrendale. SAE International, 2002. $57 \mathrm{p}$.

(36) BOWLES, J. B. Fundamentals of Failure modes and effects analysis. In: ANNUAL RELIABILITY AND MAINTAINABILITY SYMPOSIUM. Los Angeles, 2004. Tutorial Notes.

(37) DEPARTMENT OF DEFENSE. MIL-HDBK-338-B: Electronic reliability design. DOD, 1998.

(38) INTERNATIONAL ELECTROTECHNICAL COMMISSION. IEC-61025: Fault Tree Analysis. Geneva. IEC, 1990. 44 p.

(39) INTERNATIONAL ELECTROTECHNICAL COMMISSION. IEC-61014: Programmes for Reliability Growth. Geneva. IEC, 2003.

(40) Calculating Field MTBF Values. Relex Software Corporation. Disponível em: http://www.relex.com/resources/art/art fracas4.asp. Acesso em 06/2005.

(41) FRACAS: Providing Continual Improvement in Quality and Reliability. Relex Software Corporation. Disponível em: http://www.relex.com/resources/ art/art fracas.asp. Acesso em 06/2005.

(42) SIMEFRE. Controle de Tração - Conceituação. In: editores BRANCO, J. E. C; FERREIRA, Ronaldo. Tratado de Estradas de Ferro - Material Rodante. Rio de Janeiro: Reflexus Estúdio de Produção Gráfica, 2000. p. 293-302.

(43) HASEGAWA, I; UCHIDA, S. Braking Systems. Japan Railway \& Transport Review, v.20, p.52-59, jun 1999.

(44) CARESSATO, Pedro L.T. Sistemas de Freio - Trens de carga e de passageiro. In: editores BRANCO, J. E. C; FERREIRA, Ronaldo. Tratado de Estradas de Ferro - Material Rodante. Rio de Janeiro: Reflexus Estúdio de Produção Gráfica, 2000. p. 205-214.

(45) ROSA, P. M. C. F. Truques - Estruturas. In: editores BRANCO, J. E. C; FERREIRA, Ronaldo. Tratado de Estradas de Ferro - Material Rodante. Rio de Janeiro: Reflexus Estúdio de Produção Gráfica, 2000. p. 170-175.

(46) $\mathrm{KOCH}$, H.T. Truques - Transmissões e Engrenagens. In: editores BRANCO, J. E. C; FERREIRA, Ronaldo. Tratado de Estradas de Ferro - Material 
Rodante. Rio de Janeiro: Reflexus Estúdio de Produção Gráfica, 2000. p. 177182.

(47) ROSA, P. M. C. F. Engates Universais. In: editores BRANCO, J. E. C; FERREIRA, Ronaldo. Tratado de Estradas de Ferro - Material Rodante. Rio de Janeiro: Reflexus Estúdio de Produção Gráfica, 2000. p. 223-228.

(48) BARCA, J.A.V. Engates Automáticos. In: editores BRANCO, J. E. C; FERREIRA, Ronaldo. Tratado de Estradas de Ferro - Material Rodante. Rio de Janeiro: Reflexus Estúdio de Produção Gráfica, 2000. p. 229-233.

(49) VIEIRA, A; TAMASHIRO, S. Salões de Passageiros de trens urbanos e metrôs - Arranjo interno. In: editores BRANCO, J. E. C; FERREIRA, Ronaldo. Tratado de Estradas de Ferro - Material Rodante. Rio de Janeiro: Reflexus Estúdio de Produção Gráfica, 2000. p. 254-260. 


\section{APÊNDICE A - CARACTERÍSTICAS BÁSICAS DOS PRINCIPAIS SISTEMAS:}

\section{- Alimentação}

Os trens elétricos necessitam de uma fonte de alimentação a qual possam acessar durante toda a extensão da via e que deve ser segura, econômica e simples. Pode ser tanto em Corrente Contínua (CC) como em Corrente Alternada (CA), tendo sido a primeira preferida por muito tempo em função do sistema de tração dos trens, e a segunda sendo a melhor opção para longas distâncias e com custos menores de instalação, porém, até bem pouco tempo, mais complicada para o controle pelo lado do trem, (11).

A alimentação é sempre ao longo da via por meios de cabo aéreo, chamado catenária, ou pelo chão usando-se um terceiro trilho próximo aos trilhos de rodagem. Os sistemas de alimentação CA sempre usam catenárias. Já os sistemas CC podem operar tanto com catenárias como com terceiro trilho.

O retorno da corrente é através dos trilhos de rodagem que são aterrados e conectados entre si e com a subestação.

\section{Alimentação aérea}

Os sistemas aéreos requerem ao menos um coletor de corrente instalado no trem de forma que possa manter contato elétrico com a catenária durante a movimentação do trem. Esses coletores recebem o nome de pantógrafo.

O cabo deve ser capaz de conduzir altas correntes, da ordem de milhares de ampéres, permitir bom contato com o pantógrafo dos trens e permanecer paralelo com a via. Tais condições devem ser mantidas resistindo a vento, extremo frio e calor e outras intempéries como maresia e umidade.

O cabo de contato da catenária deve ser mantido sob tensão mecânica na direção horizontal e também lateralmente para acompanhar as curvas da via. Deve ser instalado em forma de "zigue-zague" em relação à linha de centro da via para 
reduzir o desgaste da canoa dos pantógrafos. Cada seguimento é sobreposto pelo próximo para assegurar uma passagem suave do pantógrafo.

Uma tensão mecânica indevida no cabo combinada com uma velocidade anormal de um trem para o trecho, pode provocar mau contato entre pantógrafo e catenária, gerando arcos e aumentando o desgaste da canoa do pantógrafo, reduzindo assim significativamente sua vida útil. Mais de um pantógrafo no trem conectado à catenária pode causar um problema similar quando a passagem do primeiro pantógrafo gera uma onda mecânica no cabo prejudicando o contato na passagem do segundo. Quanto mais alta a velocidade, pior o problema.

Os pantógrafos, por sua vez, possuem mecanismo que possibilita a fácil isolação do trem da catenária de alta tensão simplesmente baixando a canoa de contato. Para reduzir o problema do mau contato, o pantógrafo mantém uma pressão da canoa contra a catenária através de molas ou ar comprimido.

\section{Alimentação por terceiro trilho}

Os sistemas de alimentação por terceiro trilho utilizam uma sapata coletora de corrente no truque para captação da energia elétrica.

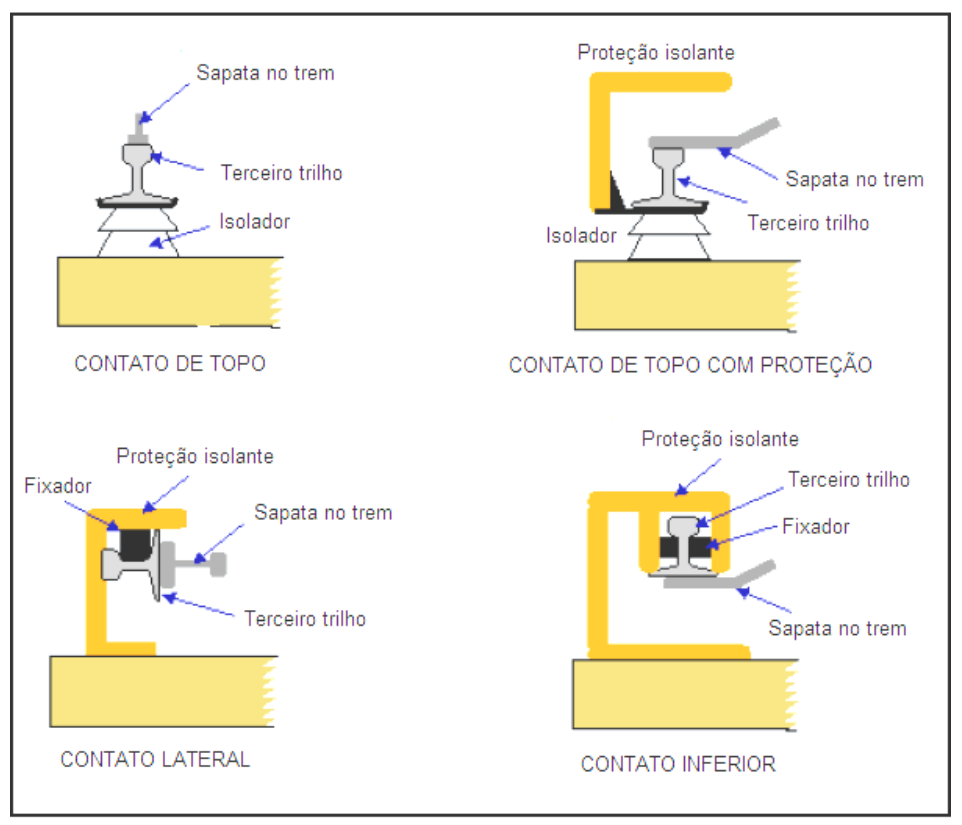

Figura 56: Coletor de corrente de terceiro trilho 
A Figura 56 mostra as formas de contato entre sapata e terceiro trilho.

As sapatas, assim como os pantógrafos em relação à catenária, possuem mecanismo de desconexão com o terceiro trilho, geralmente por questões de segurança. O caso mais comum é quando ocorre quebra de uma sapata onde, para seu reparo, deve-se desconectar as demais. As sapatas atuais também possuem sistemas mecânicos ou pneumáticos que tornam possível a atuação sobre as mesmas remotamente, pela cabina de condução, por exemplo.

Em termos operacionais, o sistema de terceiro trilho oferece riscos adicionais à segurança devido a sua proximidade com o solo. Isso significa que, se um trem deve ser parado e evacuado, a energia no terceiro trilho deve ser desligada antes dos passageiros terem acesso à via. Por isso, as vias alimentadas por terceiro trilho necessitam de proteção especial para evitar o acesso por pessoas e animais, (11).

\section{Fendas (gaps)}

Os sistemas aéreos normalmente possuem um único pantógrafo conectado à catenária, porém nos sistemas de alimentação por terceiro trilho, sempre existem várias sapatas conectadas. Isso ocorre pois o contato com a catenária não é normalmente interrompido, enquanto que o terceiro trilho deve ser interrompido para permitir a continuidade das vias. Essas interrupções, ou gaps em inglês como são conhecidas, podem levar a cortes na alimentação do trem. Essas perdas de alimentação podem ser reduzidas com a colocação de várias sapatas coletoras de corrente ao longo do trem, conectadas entre si por cabos, (11).

\section{$\underline{\text { Retorno de corrente }}$}

Para se fechar o circuito elétrico desde a fonte de energia, passando pelo trem e retornando a essa fonte, um condutor de retorno é necessário. A solução adotada é o uso dos próprios trilhos de rodagem. Precauções são tomadas para que a tensão elétrica nos trilhos não seja elevada, aterrando os mesmos e garantindo assim o mesmo potencial do solo. Logicamente, como muitos sistemas ferroviários utilizam os trilhos também para circuitos de sinalização, precauções adicionais são 
tomadas para prevenir interferências. O circuito de potência do trem é então completado pela conexão de escovas aos eixos dos truques. As rodas, sendo de aço como os trilhos, fazem o contato elétrico final entre trem e trilho, (11).

\section{- Tração}

\section{Motores CC e CA}

Tanto os motores de Corrente Alternada (CA) como os de Corrente Contínua (CC) possuem a mesma estrutura básica, porém existem diferenças e, por várias razões, os motores $\mathrm{CC}$ foram originalmente os preferidos para utilização na tração elétrica, os quais foram muito utilizados ao longo do tempo. Hoje em dia, a eletrônica de potência moderna tem permitido o uso de motores CA e, para a grande maioria dos trens construídos hoje, esse tem sido o motor empregado.

As diferenças técnicas entre os motores CC e CA e os limites tecnológicos favoreceram os motores CC a longo do tempo, pois dispunham de características de torque adequado para aplicação na ferrovia e eram razoavelmente simples de serem controlados.

A partir do início da década de 1980, com a evolução da eletrônica, os motores CA trifásicos se tornaram uma alternativa mais eficiente em relação aos motores CC pois, (11):

- São mais simples de serem construídos, não requerem escovas para funcionar e são mais leves para uma potência equivalente;

- A eletrônica moderna permite que os motores CA sejam efetivamente controlados para melhorar tanto a aderência como a tração;

- Os motores CA podem ser controlados através de circuitos microprocessados com elevado grau de ajuste e podem regenerar corrente até quase a parada do trem, enquanto nos motores $\mathrm{CC}$, a regeneração decai rapidamente em baixas velocidades.

- São mais robustos e com melhor mantenabilidade que os motores CC. 


\section{$\underline{\text { Controles }}$}

No início, o controle da velocidade era feito manualmente por chaves de cames ligados à resistência, ao motor de tração e à rede de alta tensão. Com o passar do tempo, por razões de segurança a chave de cames foi colocada longe da cabina do condutor passando a ser acionada com a ajuda de pequenos motores elétricos ou por acionamento eletro-pneumático. A introdução de componentes eletrônicos, tanto no circuito de potência como no de controle tornou possível a execução de frenagem regenerativa, que reduz consideravelmente o consumo de energia.

Os principais sistemas de controle de tração elétrica são aqueles através de contatores e chopper para os motores de corrente contínua e o acionamento trifásico e por controle microprocessado para motores de corrente alternada.

\section{- Controle por contatores}

A partida dos motores se dá através do escalonamento de resistência para o controle da tensão aplicada. Os contatores desempenham a função de colocar em curto-circuito parte das resistências em série, estabelecendo estágios de tração e frenagem.

- Controle tipo chopper

O sistema chopper se caracteriza por efetuar o controle contínuo do esforço dos motores de tração, através de dispositivos semicondutores de chaveamento, comandados por equipamentos eletrônicos de controle, dispensando os resistores de partida.

\section{- Controle por acionamento trifásico}

Esse acionamento utiliza a combinação de um chopper com um inversor trifásico. O chopper é empregado para regular a intensidade de corrente dependendo da solicitação, variando desde um valor mínimo de magnetização até plena carga, e fornecendo ao inversor uma corrente contínua de intensidade regulada. 
O inversor transforma a corrente contínua vinda do chopper em corrente alternada trifásica de freqüência variável que é fornecida ao motor. O processo de comutação é provocado pelo disparo de tiristores.

- Controle microprocessado

O emprego de circuitos transistorizados e, posteriormente, dos circuitos digitais acrescentou algumas inovações na concepção e construção dos controles. Reduziram-se as dimensões físicas, entretanto as funções tornaram-se mais complexas. Com o advento dos microprocessadores a concepção do controle eletrônico teve avanço considerável, apresentando vantagens e possibilitando modificações e ajustes de projeto apenas pela modificação de software, (42).

Dessa maneira, com a utilização de controles eletrônicos microprocessados, tem-se hoje a possibilidade de se obter o total automatismo do veículo.

\section{Freio Elétrico}

Um dos sistemas de frenagem empregados nos trens de tração elétrica é o chamado Freio Elétrico ou Freio Dinâmico, que converte o motor de tração em um gerador, transformando a energia cinética do trem em energia elétrica.

Os freios elétricos Reostáticos dissipam essa energia em forma de calor. Já os freios elétricos Regenerativos aproveitam a eletricidade gerada ao invés de dissipá-la, tornando-os os preferidos das operadoras devido a sua capacidade de economizar energia.

A Figura 57, mostra o princípio da tração elétrica, do freio elétrico reostático e do freio elétrico regenerativo. Embora os motores de tração acelerem o trem, durante a frenagem eles atuam como geradores, fazendo parte de um circuito que contém um resistor principal (reostato). A eletricidade flui através do circuito e é dissipada no resistor, convertendo a energia cinética em calor e ao mesmo tempo atuando como freio do trem. O freio regenerativo usa o mesmo tipo de circuito, porém a eletricidade gerada não é consumida pelo resistor, mas sim transmitida de volta para a rede de alimentação (catenária ou terceiro trilho). O fluxo dessa eletricidade é controlado por um circuito que abre e fecha convenientemente. 

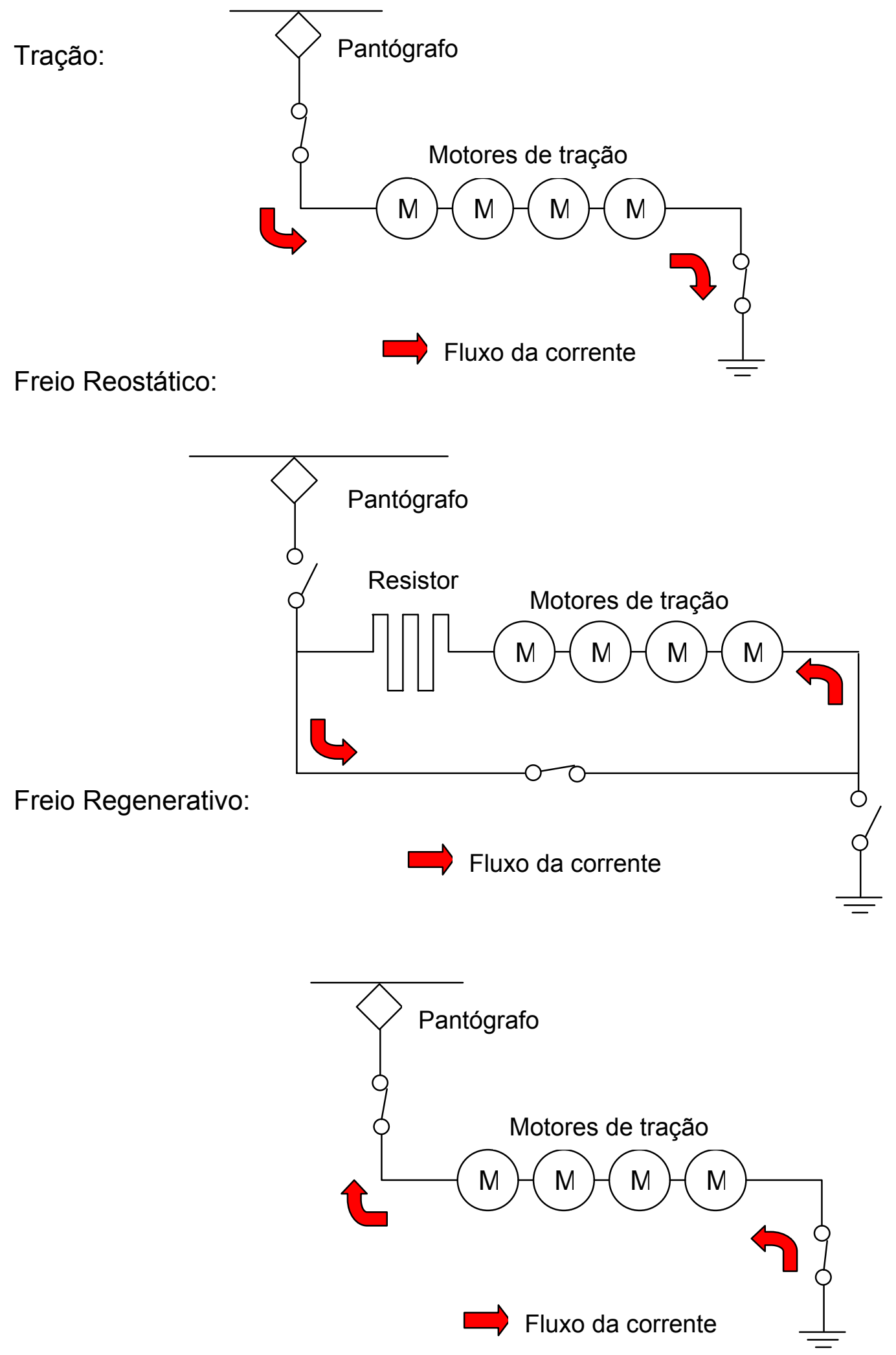

Figura 57: Princípio do freio elétrico 
Os sistemas de freio elétrico são econômicos pois não usam elementos de atrito, ao contrário dos freios mecânicos. O sistema de freio elétrico regenerativo é ainda mais econômico pois a energia gerada na frenagem de um trem pode ser aproveitada por outro, desde que a rede esteja receptiva. Normalmente, os freios

elétricos regenerativos também possuem resistor, para garantir sua atuação mesmo quando a rede não esteja receptiva.

O problema dos freios elétricos é que eles possuem circuitos de controle eletrônicos e que, eventualmente, podem falhar sem que exista um modo de falha seguro ("fail-safe"). Além disso, em baixas velocidades os freios elétricos perdem sua eficiência devido às características do motor. Por essas razões, eles não podem ser empregados como freio de emergência, (11) e (43).

\section{- Freio mecânico}

O freio é o sistema mais importante do trem, para efeito de segurança, portando deve ser concebido atendendo à premissa de falha-segura, ou seja, nenhum modo de falha pode levar o trem a uma condição de falta de segurança.

Um trem em movimento contém energia cinética, a qual deve ser removida para que o trem seja parado. A forma mais simples de fazê-lo é através da conversão dessa energia em calor. Tal conversão é feita normalmente pela aplicação de um material em contato com as rodas ou mesmo com discos ligados aos eixos. O material provoca atrito e converte a energia em calor. As rodas têm sua rotação diminuída até a parada do trem. O material de atrito usado nos freios é normalmente chamado de sapata.

A grande maioria dos trens é equipada com sistemas de freio que usam ar comprimido como principal meio de aplicação de força nas sapatas contra as rodas ou contra os discos. Esses sistemas são conhecidos como freio a ar ou freio pneumático. $\mathrm{O}$ ar comprimido é conduzido ao longo do trem pela tubulação de freio. Mudanças na pressão dessa tubulação causam mudanças no estado do freio em cada veículo. Podem levar à aplicação, ao alívio do freio, ou ainda a uma aplicação parcial.

Os principais tipos de sistemas freio podem ser classificados como: 
- Freio a ar

- Freio a vácuo

- Freio eletro-pneumático

- Freio pneumático controlado eletronicamente

\section{Freio a ar}

Esse é o tipo mais comum de freio. Utiliza ar comprimido para acionar a sapata contra a roda e para controlar a operação do freio ao longo do trem. $\mathrm{O}$ ar comprimido é fornecido por um motor-compressor.

O controle do freio é acionado pela válvula de freio do operador. Essa válvula é usada para alimentar a tubulação de freio com ar ou para permitir a fuga do ar dessa tubulação. Uma queda de pressão nessa tubulação causa a aplicação de freio em cada um dos veículos, enquanto o restabelecimento da pressão causa o alívio do freio.

Um distribuidor, também chamado válvula tripla, em cada veículo monitora a pressão na tubulação de freio. Quando a pressão cai, o distribuidor permite a passagem de ar de um reservatório auxiliar para os cilindros de freio provocando a frenagem do trem. Quando a pressão na tubulação sobe, o distribuidor libera o ar dos cilindros e recarrega o reservatório auxiliar para a próxima aplicação. A liberação de ar do cilindro de freio permite que as sapatas sejam afastadas das rodas através de molas.

- Freio de estacionamento

O freio de estacionamento é usado para manter o trem parado enquanto fora de serviço e, conseqüentemente, com o sistema de freio desligado. Pode ser aplicado de forma manual ou automática. Nem todos os trens possuem freio de estacionamento.

\section{Freio a vácuo}

O freio a vácuo foi, por muitos anos, usado como sistema de freio padrão. Como no freio a ar, o freio a vácuo é controlado por uma tubulação de freio 
conectada a uma válvula de freio na cabine e aos equipamentos de freio em cada carro. A operação do freio em cada carro depende da condição de um vácuo criado na tubulação por um ejetor ou exaustor. Tanto o ejetor, que era usado em locomotivas a vapor, como o exaustor, usado mais recentemente, removem a pressão atmosférica da tubulação de freio para criação do vácuo. Com vácuo total os freios são aliviados. Na ausência de vácuo como por exemplo, à pressão atmosférica normal, os freios são completamente aplicados.

O vácuo na tubulação de freio é produzido e mantido por um motoexaustor. O exaustor possui duas velocidades, sendo a mais alta para criar o vácuo e em seguida aliviar os freios, e a mais baixa para manter o freio aliviado. Isso mantém o vácuo mesmo na presença de pequenos vazamentos na tubulação.

Há uma válvula de alívio que evita que a pressão no interior da tubulação exceda determinados níveis, permitindo a passagem de ar após um determinado valor de pressão.

\section{Freio eletro-pneumático}

Originalmente projetado para metrôs, sua principal vantagem sobre o freio a ar é sua velocidade de controle e rápido tempo de reação, permitindo controle instantâneo de todo o trem pelo operador. Sua velocidade de operação o torna ideal para aplicações com Operação Automática de Trens (ATO).

Mesmo o mais moderno dos sistemas de freio puramente a ar está baseado na transmissão do ar ao longo da tubulação de freio. Esse percurso iniciase na cabine até a parte traseira do trem. Sempre haverá um tempo de propagação entre o comando pelo operador e o acionamento do primeiro até o último freio do trem. Esse atraso é considerado uma limitação para a operação. Isso causa também o acionamento do freio dos carros em instantes diferentes de forma que enquanto alguns carros estão freando, outros estão tentando empurrar o trem. Pelo mesmo motivo, quando liberado o freio, os carros dianteiros tendem a puxar os demais. Todo esse processo leva à deterioração excessiva dos engates. Outro ponto é a dificuldade de uma aplicação gradual dos freios. 
- Princípio do freio eletro-pneumático

Existem vários tipos de freio eletro-pneumático em uso atualmente e a maioria deles foi desenvolvida como um incremento no sistema de freio a ar original e, como conseqüência, incorporaram alguns princípios de projeto como:

- O freio eletro-pneumático opera como freio de serviço, enquanto o freio puramente a ar opera como freio de emergência apenas;

- $\quad$ O freio eletro-pneumático não compromete a característica de falha segura do freio a ar;

- O freio a ar normalmente permanece aliviado, mesmo enquanto o freio eletro-pneumático está sendo aplicado e os mesmos cilindros de freio são compartilhados;

- Freios eletro-pneumáticos são invariavelmente usados em trensunidade múltiplos para transporte de passageiros;

- Os freios eletro-pneumáticos utilizam um certo número de cabos de controle que comandam eletricamente as válvulas de freio em cada carro;

\section{Freio pneumático controlado eletronicamente}

Como já mencionado, o freio puramente a ar leva um tempo relativamente alto para aplicação e não possui aplicação gradual. Além disso, após um ciclo de aplicação e alívio completo do freio, deve-se aguardar o re-carregamento dos reservatórios para uma nova aplicação. $O$ controle eletrônico pode facilmente superar essas dificuldades.

Um carro com esse tipo de freio pode realizar rotinas de auto-diagnóstico de falhas, além de monitorar parâmetros de peso e de desempenho solicitando apenas o esforço de frenagem necessário.

Alguns dos benefícios do controle eletrônico já foram de certa forma mencionados, como tempo instantâneo de resposta em todos os carros, aplicação e alívio gradual dos freios e reabastecimento contínuo dos reservatórios. Porém existem outros e mais significantes benefícios para a indústria ferroviária como um todo. Com as funcionalidades dos freios controlados eletronicamente, as distâncias 
de frenagem podem ser significativamente reduzidas. Isso permite tempos menores de parada e, conseqüentemente, uma maior velocidade média de percurso. Permite ainda um controle de anti-deslizamento, aumentando a eficiência e reduzindo a possibilidade de quebras e descarrilamentos além da incidência de manutenção corretiva.

\section{- Suprimento elétrico}

Um trem unidade elétrico (TUE) possui de fato 2 sistemas elétricos: Alta Tensão (AT) e Baixa Tensão (BT). O trem é alimentado em AT de onde vem a energia necessária para o sistema de tração e para o sistema de BT. O sistema de BT, por sua vez, alimenta os sistemas auxiliares do trem, tais como iluminação, climatização e circuitos de controle. Os dois sistemas são assim separados pois a alta tensão necessária para tração não é necessária para a maioria dos outros sistemas do trem, o que tornaria inviável técnica e economicamente a alimentação desses sistemas com AT.

A BT é obtida através da redução da alta tensão de alimentação do trem. Essa redução é feita para níveis normalmente abaixo dos $450 \mathrm{~V}$. Para tal utiliza-se de geradores, alternadores ou de conversores estáticos de forma a obter a baixa tensão desejada. Geralmente, produzem-se diferentes tensões, tanto alternadas como contínuas, para diferentes aplicações.

\section{Gerador}

Tradicionalmente usado como fonte de BT nos trens, o gerador é uma máquina CC movida por motores diesel ou, nos trens elétricos, por motores alimentados diretamente em AT. Em alguns casos, eram empregados diretamente nos eixos do truque, atuando como dínamo. Nesses casos, baterias forneciam alimentação quando o trem se encontrava parado. 
Alternador

É o substituto do gerador CC para obtenção de CA. A utilização de CA ao invés de CC é melhor do ponto de vista da transmissão ao longo do trem, reduzindo quedas de tensão e, conseqüentemente, permitindo o uso de cabos de bitola menor, que são mais leves e mais baratos. São necessários retificadores para converter a tensão CA em CC para carregamento de baterias e alimentação de circuitos CC.

\section{Conversor Estático}

Os conversores estáticos utilizam eletrônica de estado sólido para conversão dos níveis de tensão. Podem possuir inversores para transformar tensão contínua em alternada, retificadores para transformar tensão alternada em contínua, ou ambos no mesmo equipamento. Os conversores substituem os geradores e alternadores que são máquinas rotativas e possuem ainda a vantagem de oferecer um custo menor de manutenção.

\section{Baterias}

A eletrônica moderna proporcionou a utilização dos conversores estáticos como fonte de alimentação BT nos trens. Porém, por não serem máquinas rotativas, eles não possuem inércia e cortam o fornecimento de energia assim que uma interrupção momentânea ocorre devido a um gap na rede. Para prevenir problemas com esses cortes momentâneos de energia, que são relativamente freqüentes, os conversores são ligados a baterias que mantêm constante a alimentação dos sistemas BT. As baterias também são utilizadas em emergências, no caso de falha do conversor estático, mantendo alguns sistemas vitais de controle, comunicação, iluminação de emergência e ventilação, por exemplo, (11). 


\section{- Suprimento de ar}

Para acionamento dos sistemas que necessitam de ar comprimido, é necessário que os mesmos sejam supridos com ar comprimido de vazão, pressão e qualidade adequadas para garantir o seu bom funcionamento.

$\mathrm{O}$ ar comprimido é quase sempre usado nos sistemas de freio e algumas vezes em portas com acionamento pneumático. Também é usado no acionamento de pantógrafo. Sempre necessita de secagem após compressão para evitar que a umidade da condensação entre nas válvulas. O compressor é normalmente acionado por motores elétricos diretamente alimentados pelo sistema de suprimento elétrico.

Os sistemas de ar comprimido hoje utilizados são compostos basicamente de unidade compressora e unidade de tratamento de ar, além dos reservatórios e controles.

\section{Compressor}

O compressor consiste de uma bomba acionada por motor elétrico, que por sua vez é alimentado pelo sistema de suprimento elétrico.

\section{Bomba}

Inicialmente, a bomba tradicional do compressor era composta por um pistão dentro de um cilindro. Mais tarde, passaram a ter dois ou três pistões para proporcionar maior velocidade de compressão $e$, conseqüentemente, maior capacidade. Alguns fabricantes possuem bombas rotativas, que são geralmente muito mais rápidas e consideravelmente mais silenciosas. Todavia, são mais susceptíveis a defeitos mecânicos e têm menor capacidade.

\section{$\underline{\text { Refrigeração }}$}

A compressão do ar faz com que ele seja aquecido e, em função disso, é necessário ao menos um conjunto de tubos para sua refrigeração. $O$ bombeamento 
é dividido em dois estágios e um conjunto de tubos de refrigeração entre cada estágio. Logicamente, a refrigeração produz condensação de água que, combinada com óleo lubrificante do compressor, forma uma borra que pode rapidamente causar o entupimento das válvulas. Para sanar esse problema, os sistemas de suprimento de ar dispõem de secadores de ar.

\section{Secagem}

O secador de ar consiste de um par de cilindros que extraem a água e permitem que o ar seco passe até o reservatório principal. A água coletada é automaticamente expurgada em cada ciclo de bombeamento, produzindo um ruído característico.

\section{$\underline{\text { Controle }}$}

O compressor é controlado automaticamente por um circuito capaz de detectar o ponto no qual o nível de ar comprimido no sistema cai abaixo do nível mínimo permitido. Quando isso acontece, o contator do motor do compressor é energizado para carregar o sistema. Quando a pressão atinge o limite superior, o motor é desligado. Em caso de falha desse controle, normalmente, é possível prever uma chave de redundância que permite o acionamento manual dos compressores.

\section{$\underline{\text { Sincronismo }}$}

Em trens unidade com vários carros a operação dos compressores é normalmente sincronizada. Isso quer dizer que se um controle de compressor detecta baixa pressão no sistema, todos os compressores são ligados para tentar suprir a demanda. Quando o último detecta o restabelecimento da pressão, todos são desligados. Além disso, em condições normais, apenas para manter o nível de ar no sistema, é possível estabelecer um rodízio entre os compressores para reduzir o desgaste mais acentuado de um ou outro. 
Cada compressor possui seu próprio reservatório, normalmente chamado de reservatório principal. Trata-se de um vaso de pressão capaz de armazenar ar suficiente para várias operações de freio e dos demais equipamentos pneumáticos. Alguns sistemas pneumáticos como freio, por exemplo, requerem também reservatórios auxiliares próximos dos pontos de aplicação. Tal redundância propicia maior segurança ao sistema.

\section{Compressor do pantógrafo}

Um compressor adicional é geralmente previsto em trens operados por pantógrafos com acionamento pneumático. Isso é necessário pois, caso um trem seja mantido desenergizado por um longo período a ponto do sistema de suprimento de ar ser totalmente esgotado devido a vazamentos, a única forma de subir os pantógrafos é através de um pequeno compressor auxiliar, alimentado pela bateria de forma a prover a devida pressão capaz de levantar o mecanismo do pantógrafo e alimentar o trem com alta tensão. Assim que o pantógrafo conecta com a catenária, é possível ligar os compressores principais, (11) e (44).

\section{- Portas}

Existem alguns tipos de porta usados em trens de passageiros como portas plugue, portas dobráveis e portas deslizantes, sendo esse último, o tipo mais comum.

Portas plugue são normalmente encontradas em VLTs, mas também podem ser encontradas em trens de subúrbio e metrôs. São portas bipartidas, ou seja, duas folhas que se abrem pelo meio, de forma que quando são abertas, essas folhas descolam-se uma da outra e movem-se para fora do trem em um movimento articulado, terminando a abertura pelo lado externo do veículo. O processo contrário ocorre no fechamento das mesmas, com as folhas entrando novamente no vão de porta e culminado com o ajuste perfeito com a lateral do veículo. Existe uma guarnição de borracha ao redor dessas folhas que promovem a vedação das portas 
quando na posição fechada. Esse tipo de porta gera problemas para manutenção devido à quantidade de partes móveis e, eventualmente, devido à baixa confiabilidade das juntas de vedação de borracha. Por outro lado, proporciona um acabamento externo bonito além de ser de fácil limpeza.

Portas dobráveis são mais comuns em VLTs e consistem de dois pares de folha de porta, dobráveis entre si, sendo um par para cada lado da abertura. Em alguns casos apenas um par de folhas dobrável é usado por vão de porta. Quando o comando de abertura é recebido, as folhas de porta movem-se para dentro e terminam paralelas com a lateral dos degraus. O problema com esse tipo de porta é que o trem fica repleto de painéis móveis que podem atingir uma pessoa que esteja na região de portas. Também são difíceis de garantir uma boa vedação pois requerem um vão na parte inferior para movimentação, o que permite o ingresso de água.

As portas deslizantes são encontradas em todos os tipos de material rodante ferroviário e, como o próprio nome sugere, tratam-se de portas que deslizam entre a lateral externa e o revestimento interno do veículo. Essa região é chamada de bolsa de porta, e o revestimento interno nessa região avança para o interior do veículo para poder acomodar as folhas de porta. As folhas de porta podem ser bipartidas ou inteiras. O mecanismo de portas pode estar localizado sobre o vão de portas ou mesmo no piso, atrás de algum assento estrategicamente posicionado, sendo a primeira opção a mais comum. Uma preocupação da manutenção com esse tipo de portas são os trilhos guia existentes na parte inferior que podem acumular sujeira, bloqueando assim a abertura e fechamento das portas.

Existem também as portas deslizantes externas, que são encontradas em vários tipos de veículo ferroviário. São utilizadas por serem mais simples de projetar, porém possuem uma aparência externa ruim devido aos trilhos de porta visíveis pelo lado externo do veículo. Alguns sistemas desse tipo simplesmente deslizam de um lado para outro nos trilhos. Outros mais sofisticados trabalham de maneira similar às portas plugue fazendo com as folhas entrem e saiam do vão de portas. A diferença é que nas portas plugue não existem os trilhos externos.

A forma de acionamento das portas pode ser elétrica ou pneumática. São controladas eletronicamente e o comando de abertura é dado pelo operador ou, eventualmente em alguns trens, o próprio passageiro tem permissão de abrir as 
portas. O sistema deve dispor de intertravamentos de segurança para que as portas não se abram acima de determinada velocidade ou fora da plataforma, por exemplo, (11).

\section{- Truque / Suspensão}

O truque tem por função prover suporte, amortecimento, e guia aos veículos ferroviários. Nos truques de TUEs são instalados também os motores elétricos, as engrenagens de transmissão e os equipamentos de freio, além de coletores de corrente, sensores de velocidade e antenas de comunicação com o sistema de operação automática e sinalização de via.

Os truques são submetidos a vibrações, choques e estresses severos. Além da suspensão primária, os truques de veículos de passageiros possuem suspensão a ar. As bolsas de ar proporcionam um maior conforto aos passageiros e a pressão nas mesmas pode ser ajustada automaticamente para compensar as variações de carga no interior dos carros. As variações na pressão das bolsas são usadas para informar a variação de peso aos sistemas de tração e freio, que por sua vez ajustam os esforços necessários para manter as taxas de aceleração e frenagem dentro do especificado, (11), (45) e (46).

A Figura 58 ilustra um truque utilizado em veículos ferroviários e algumas de suas partes principais. 


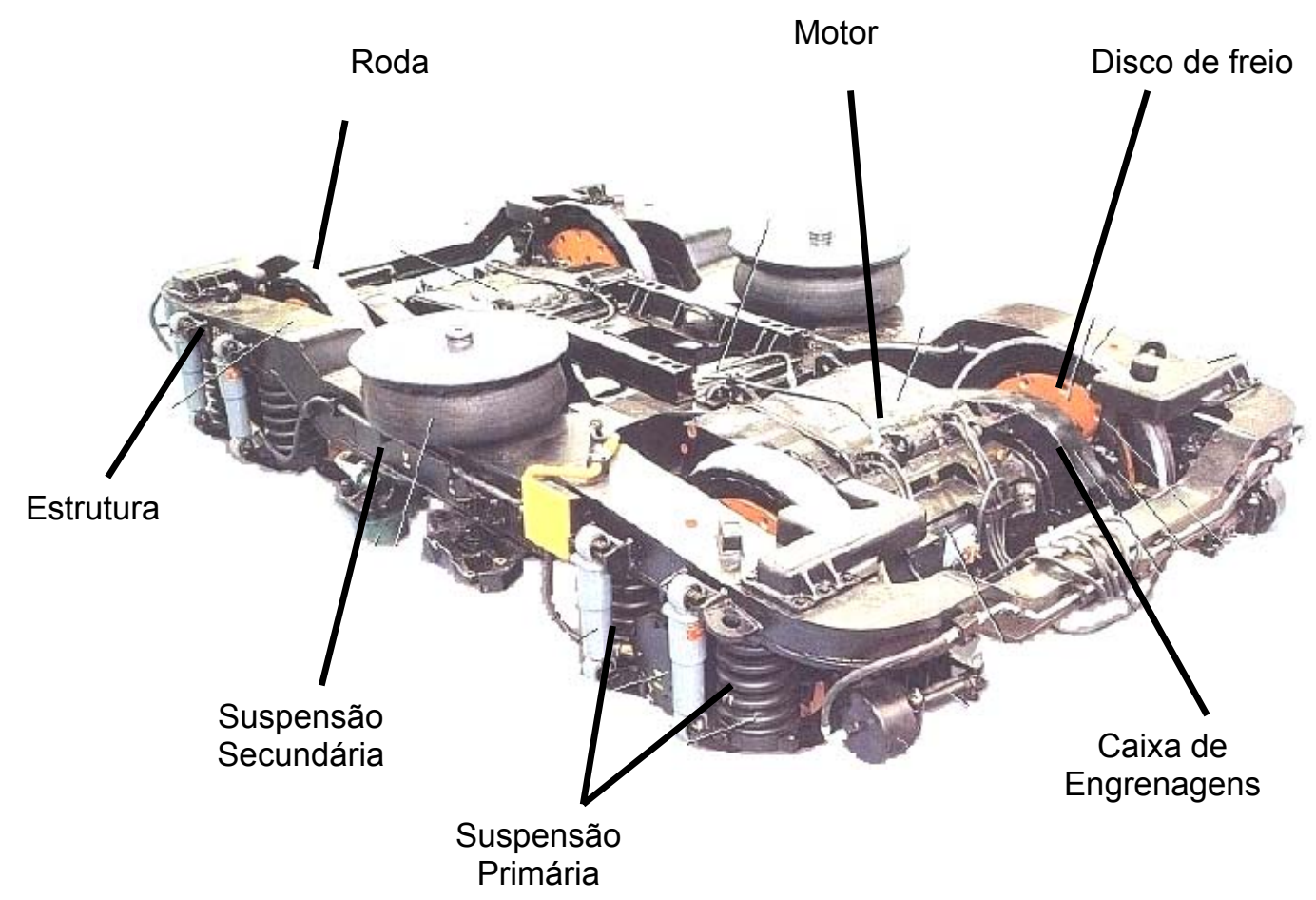

Figura 58: Partes de um truque

\section{- Acoplamento}

Para que dois veículos ferroviários sejam acoplados um ao outro, eles devem ser equipados com engates. Existe uma variedade de tipos de engate, todavia, há um alto grau de padronização tornando alguns tipos de engate comuns em vários países.

\section{Ligação e Pino}

O tipo mais simples de engate é uma ligação por meio de manilhas horizontais presas por pinos. Cada veículo tem uma barra ligada ao centro da cabeça de estrado, a qual possui um orifício circular. Cada engate possui um funil na extremidade para auxiliar a passagem da barra. Os furos são alinhados e um pino é colocado por eles. Não é um sistema muito sofisticado, mas foi utilizado em muitos trens durante o século XIX e existem ainda algumas poucas linhas com esse tipo de engate hoje em dia. 
Os engates do tipo Ligação e Pino, requerem a presença de pessoas entre os carros no momento do acoplamento e do desacoplamento para colocação ou remoção do pino, o que leva à ocorrência de ferimentos e até fatalidades.

\section{Engate semipermanente}

Esse tipo de engate não pode ser desconectando a menos que o trem esteja na oficina e que exista uma vala para acesso à parte inferior do trem. É usado normalmente em TUEs, os quais são mantidos em formações fixas de dois ou mais carros. A barra de acoplamento é localizada entre os carros, enquanto em cada extremidade do trem é utilizado outro tipo de engate de desconexão rápida. Os engates semipermanentes são simples, consistindo apenas de uma barra com furos nas extremidades através dos quais os carros são acoplados.

\section{Engate Universal}

O tipo de engate mais comumente encontrado no mundo é conhecido como engate universal, conforme diagrama da Figura 59.

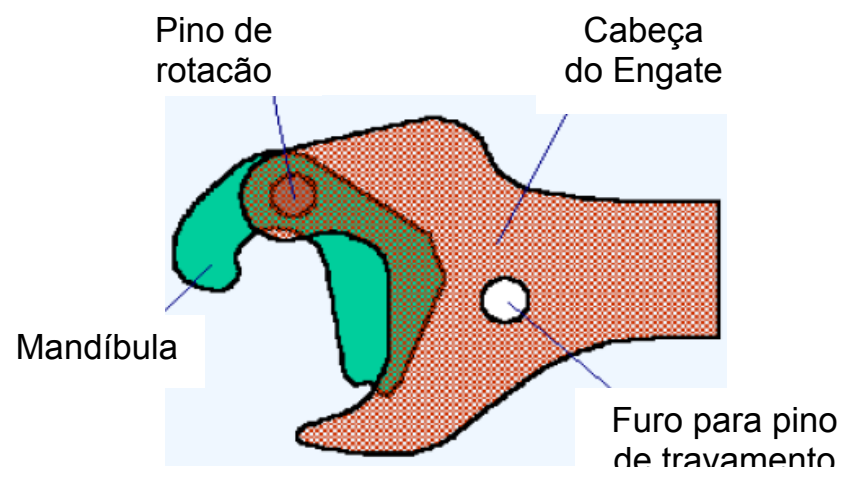

Figura 59: Diagrama simplificado de um engate universal

O engate mostrado na Figura 59, é feito de aço fundido e consiste de quatro partes principais. A cabeça do engate, uma mandíbula, o pino de rotação, no qual a mandíbula rotaciona durante o processo de acoplamento ou desacoplamento, e um pino de travamento. O pino de travamento é levantado para liberar a mandíbula. Isso é feito pelo levantamento de um bloco de aço localizado dentro da 
cabeça do engate, o qual libera a mandíbula e permite sua rotação. A Figura 60 mostra as etapas de acoplamento.

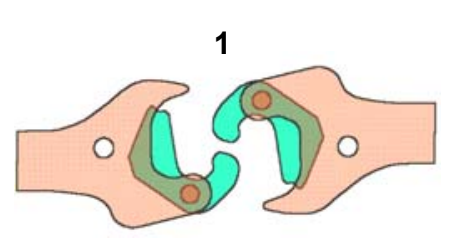

3

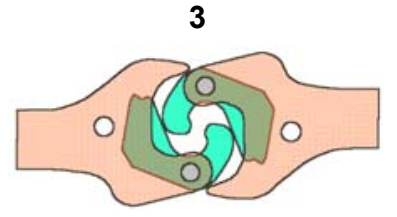

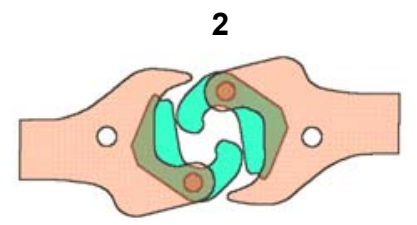

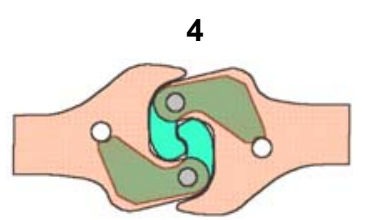

Figura 60: Etapas de acoplamento de um engate universal

Para acoplar dois carros, as mandíbulas devem estar abertas. Quando os dois carros são empurrados um contra o outro, as mandíbulas dos dois engates são fechadas e travadas por trás por um pino vertical baixando um bloco de aço.

Para desacoplar, um dos pinos deve ser puxado para cima para liberar o bloco de travamento da mandíbula. Isso é feito acionando uma alavanca ou corrente na lateral do veículo.

\section{Engates totalmente automáticos}

Cada vez mais os trens estão sendo equipados com engates totalmente automáticos. Um engate totalmente automático conecta os veículos mecanicamente, eletricamente e pneumaticamente, normalmente empurrando um veículo contra o outro e operando um botão ou pedal na cabine para completar a operação.

O desacoplamento é feito por outro botão ou pedal para desconectar os contatos elétricos e conexões pneumáticas e a separação dos carros é feita mecanicamente afastando-os. Os engates totalmente automáticos são complexos e necessitam de cuidados especiais de manutenção. Necessitam ser usados freqüentemente para que sejam mantidos em boas condições operacionais. Existem alguns diferentes engates desse tipo em uso, (11), (47) e (48). A Figura 61 ilustra um exemplo de engate totalmente automático. 


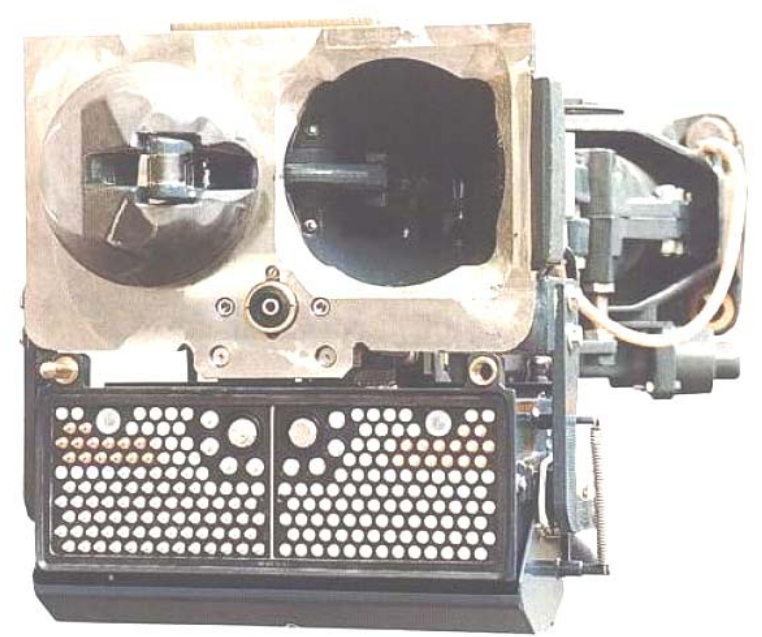

Figura 61: Engate totalmente automático

Esse modelo de engate é amplamente utilizado em TUEs de todos os tipos, desde trens de alta velocidade até VLTs. O engate possui uma parte mecânica com conexões elétricas e pneumáticas. Os contatos montados sob o engate mecânico são protegidos por uma tampa quando estão desacoplados.

A Figura 62 mostra outra versão de engate totalmente automático com os contatos elétricos acima do engate. Nesta figura estão descritas as partes principais do engate.

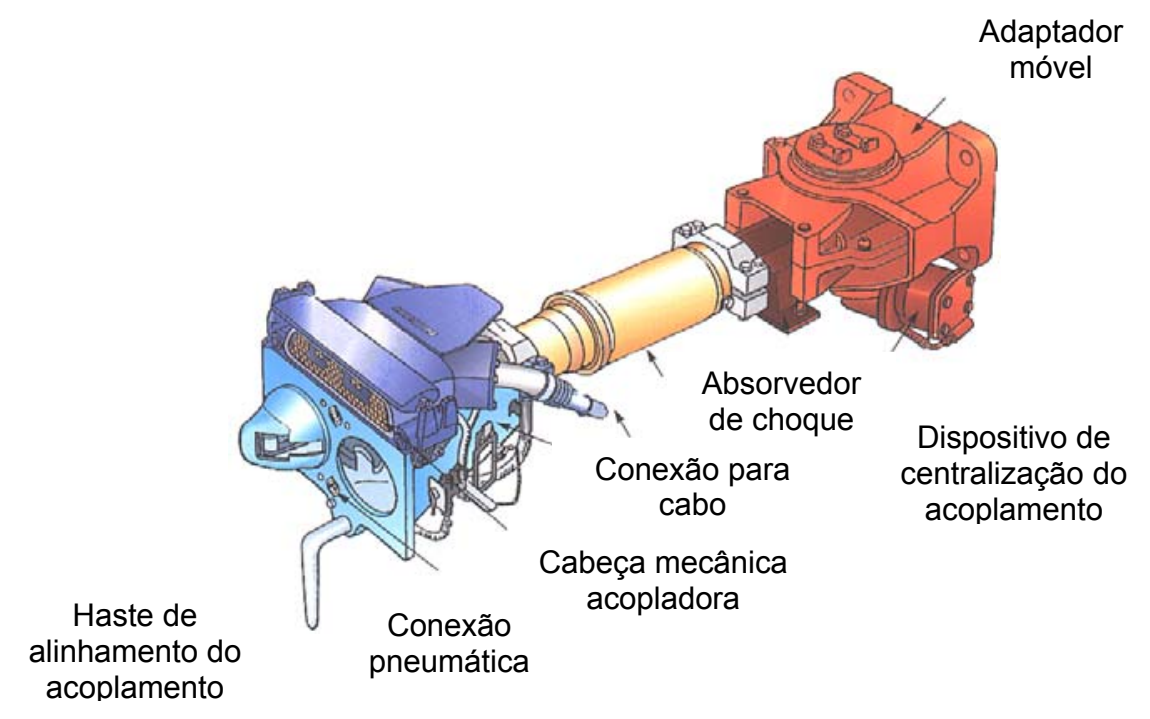

Figura 62: Partes de um engate totalmente automático 


\section{- Outros}

\section{lluminação}

O sistema de iluminação de carros de passageiros possui normalmente dois tipos de luminárias: As convencionais, alimentadas diretamente por tensão alternada, e as de emergência, alimentadas por tensão contínua. Tanto a alimentação AC como DC são provenientes do sistema de suprimento elétrico do trem.

Também fazem parte do sistema de iluminação as luminárias de cabine, faróis e luzes de cauda, todos eles alimentados por tensão contínua.

\section{$\underline{\text { Climatização }}$}

O sistema de ventilação é projetado de forma a garantir um determinado número de trocas do volume de ar no interior do salão em um determinado intervalo de tempo. Normalmente é composto por ventiladores insufladores, ventiladores exaustores e, eventualmente por recirculadores de ar.

A maioria dos trens de passageiros modernos é equipada com ar condicionado e, nos países onde o clima é muito frio, também são equipados com aquecedores.

\section{Monitoramento do trem e registro de eventos}

Esse sistema executa basicamente as funções de assistência ao operador, assistência à manutenção e o registro de eventos para investigações futuras. As informações são adquiridas dos outros sistemas do trem através de redes de comunicação serial e através de entradas lógicas digitais que monitoram o status de equipamentos e componentes do trem.

Dentre as funções de assistência ao operador, pode-se destacar as funções de checagem do status dos sistemas, alertas de falha, verificação das informações operacionais como velocidade, tempo de operação, tensão na linha, etc. 
Já entre as funções de assistência à manutenção, sem dúvida alguma, destacam-se as funções de registro de eventos, proporcionando um armazenamento centralizado de informações de falha durante a operação e o respectivo contexto da ocorrência. Isso também facilita a investigação de ocorrências mais graves.

\section{Comunicação visual e sonora}

Hoje em dia, com o advento da mídia eletrônica, são utilizados painéis eletrônicos com LEDs ou cristal líquido, comandados local ou remotamente, para transmissão de orientações aos passageiros, informações institucionais e propagandas.

O sistema de sonorização serve para comunicação com os passageiros, quer seja para anunciar a próxima estação ou para fornecer orientações específicas aos passageiros através de intercomunicadores, em caso de emergência. Esse sistema pode possuir um conjunto de mensagens pré-gravadas e pode ainda ser usado com funções de entretenimento, como sonorização ambiente, por exemplo, (49).

\section{$\underline{\text { Homem morto }}$}

"Homem morto" é o nome dado ao dispositivo de vigilância que assegura que o operador esteja alerta e sempre presente na cabine enquanto o trem estiver em movimento. Esse dispositivo foi criado visando cobrir uma situação onde o operador, em função de um mal súbito ou algo semelhante, não pudesse mais operar o veículo já em movimento.

Consiste normalmente de uma alavanca com mola no controlador mestre ou de uma eletrônica acionada por botão ou pedal, que obriga uma atuação periódica por parte do operador e que, na falta desta, o dispositivo aplica freio no trem, levando a uma condição segura. 


\section{APÊNDICE B - ARTIGO}

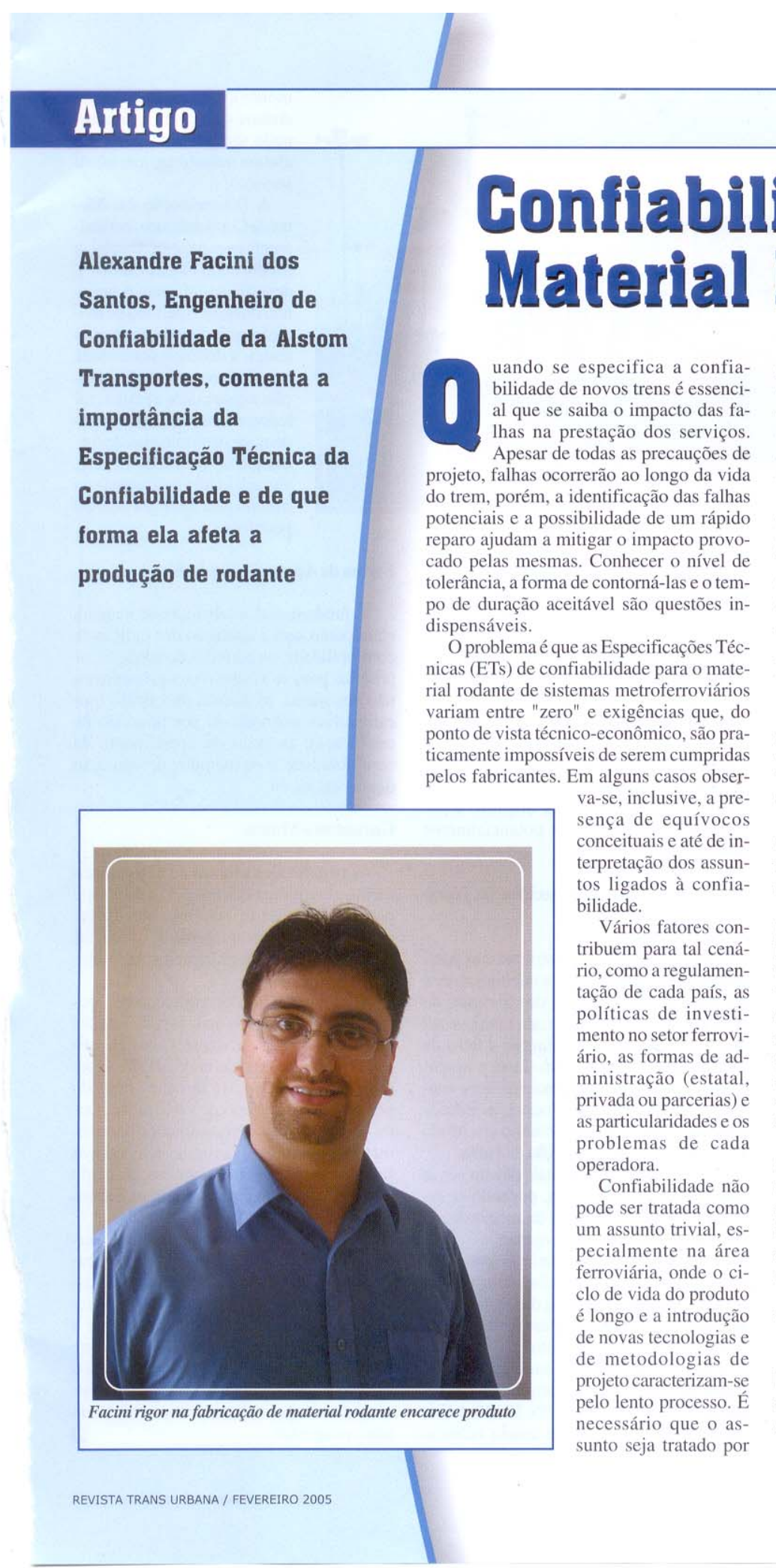

pessoas capacitadas e que conheçam confiabilidade. Sem as devidas providências durante o projeto as consequiências são os elevados custos com retrabalho, acarretando transtornos financeiros e de segurança.

A melhor maneira da operadora se precaver é por meio de uma Especificação Técnica bem feita, o que não significa absoluto rigor, para não encarecer o produto. $\mathrm{E}$ necessário distinguir o que realmente deve ser feito pelo fabricante para atingir níveis adequados de confiabilidade.

\section{Importância da especificação técnica}

O mercado ferroviário mundial caminha rapidamente para a adoção de trens modulares como padrão. Cada vez mais é feito, para novas encomendas, o chamado carry over das soluções anteriormente empregadas.

Todavia, os requerimentos de performance e de confiabilidade são divergentes de operadora para operadora. Então quanto deve ser pago por algo melhor ou diferente?

Hoje em dia, como são grandes as responsabilidades dos fabricantes nos equipamentos fornecidos, inclusive manutenção, aquilo que é especificado tende a provocar um impacto maior no custo de aquisição. É muito importante especificar o que realmente se deseja. $\mathrm{O}$ excesso de rigor resulta em um custo maior do produto e a falta de especificações adequadas leva a operadora a assumir boa parte dos custos e riscos operacionais.

Normalmente, na Especificação Técnica de novos trens, não é dada a devida atenção quanto à confiabilidade necessária ou é tratada de forma inadequada. Por isso é importante entender o que são seus requerimentos de confiabilidade e as consequiências de não atingi-los.

\section{Como as falhas afetam a ferrovia}

As falhas podem ser divididas naquelas que causam atraso ou falha da missão e as que requerem apenas uma parada programada para intervenções de manutenção.

As falhas de longa duração são muito in- 
desejáveis. Mesmo com um sistema altamente confiável, a ocorrência de uma única falha pode aborrecer profundamente os usuários.

As falhas de curta duração (aproximadamente 5 minutos) são, na maioria das vezes, toleradas pelos usuários. O problema é quando se tornam freqüentes.

As falhas que não causam impacto nos serviços podem ser reparadas quando o trem estiver detido para intervenções de manutenção preventiva, ou em horários de vale. Eventualmente são percebidas pelos usuários. Por exemplo, na operação degradada de algum sistema de conforto.

Qualquer um dos tipos mencionados requer atenção especial de manutenção e o tempo de reparo não pode ser demasiadamente longo, a ponto de não permitir que o trem esteja disponível quando necessário, pois implica em trens mais lotados e maiores tempos de espera.

\section{Fatores que restringem a confiabilidade}

Certamente a situação ideal seria evitar a ocorrência de qualquer tipo de falha e, caso acontecesse, promover um restabelecimento imediato. Mas, infelizmenrestabelecimento imediato. Mas,
te, isso nem sempre é possível.

O Custo acaba sendo o maior vilão de todos. Se o que se deseja é um trem mais barato possível, uma das primeiras coisas a serem afetadas é a confiabilidade, independente dos esforços de operação e manutenção. Da mesma forma, quanto maior os requisitos de confiabilidade maior o custo do produto.

Especial atenção deve ser dada à Formação do Trem e à Compatibilidade com os trens já existentes na frota. Mesmo que se adquira trens de "alta confiabilidade" para rodar com os de menor confiabilidade, o ganho proporcionado muitas vezes é insignificante.

Os passageiros e o público de uma forma geral esperam que o transporte ferroviário seja, acima de tudo, seguro. Todavia Segurança e confiabilidade são freqüentemente conflitantes devido à necessidade de redundâncias e dispositivos que garantam tal segurança.

Aumentam também as Expectativas dos Passageiros por ar-condicionado, sistemas comunicação, banheiros, etc. Assim, quanto mais equipamentos são agregados ao trem, maior o impacto na confiabilidade e na manutenção.

Diante da dificuldade de se obter os requerimentos adequados de confiabilidade, deve-se priorizar determinadas características em detrimento de outras. E para isso não existe uma solução padrão. Cada operadora deve fazer a especificação de acordo com suas necessidades. Devese entender o que se está disposto a pagar versus o que se pode potencialmente perder.

Conteúdo mínimo da Especificação Técnica da Confiabilidade

Mesmo com todas as restrições e as particularidades, alguns cuidados mínimos devem ser tomados. A Definição dos Sistemas do trem e o que compreende cada um deve ser claro o suficiente para distinguir a falha de um ou outro sistema. Além disso, a descrição das características principais deve contemplar o Desempenho Normal, as Redundâncias, o Desempenho Mínimo em Modo Degradado e a Caracterização de Falha.

As Condições Ambientais devem ser as mais detalhadas possíveis, podendo-se recorrer a dados estatísticos da meteorologia da região onde o trem vai operar.

A Missão Típica de Operação (como por exemplo, tempo de operação diária, utilização da frota, características da via, etc) também deve ser informada para realização de predições durante o projeto.

Outro cuidado importante é a Definição dos Tipos de Falha para determinar as metas de confiabilidade. A EN 50126 define como Significante (que causa reboca- mento), Maior (que causa atrasos superiores a determinado tempo) e Menor (que afetam o conforto, mas não o serviço).

A Determinação das Metas de Confiabilidade, normalmente expressas em Distância Média entre Falhas (MDBF), deve levar em conta o tamanho da frota, o período de medição, os índices de frotas existentes, a distância acumulada pela frota no período de medição, a quantidade de falhas toleráveis, etc. Essas metas podem ser determinadas de forma global para todo o trem, alocadas entre os sistemas ou mesmo para equipamentos específicos.

\section{Forma de Apuração dos Índices}

É fundamental estabelecer de maneira clara como será a apuração dos índices de confiabilidade, os períodos de medição, os critérios para se avaliar o cumprimento ou não das metas, as formas de cálculo (por estimativas pontuais ou por intervalo de confiança), as taxas de crescimento da confiabilidade e os métodos de apuração dessas taxas, etc.

\section{Garantias e Multas}

As penalidades no caso de não cumprimento das metas devem ser previstas e estar claramente definidas. Essas penalidadesafetam diretamente os riscos do fabricante e, conseqüentemente, o preço final do trem.

Algumas definições equivocadas podem ser encontradas nas especificações técnicas de material rodante. Uma delas é o estabelecimento de metas de MDBF superiores ao que é previsto de ser acumulado pelos trens no período de verificação. Outra é a adoção de demonstrações por estimativas pontuais quando se tem poucas falhas ocorridas. O mais correto, do ponto de vista estatístico, são as demonstrações por intervalo de confiança.

Mas o maior equívoco de todos é, certamente, a inexistência total de especificações de confiabilidade. É o mesmo que assinar um cheque em branco. A falta de requisitos de confiabilidade poderá levar a concorrências desleais, uma vez que este item é um fator muito significativo para a formação do preço final e que deve ser considerado por todos os concorrentes em suas propostas. 
ANEXO A - TABELA QUI-QUADRADO

\begin{tabular}{|c|c|c|c|}
\hline & \multicolumn{3}{|c|}{$\theta_{\text {inf }}$} \\
\hline & \multicolumn{3}{|c|}{$\lambda_{\text {sup }}$} \\
\hline & Falhas & $\begin{array}{c}\text { Graus de } \\
\text { Liberdade }\end{array}$ & $\chi_{1-\alpha / 2}^{2}(2 r+2)$ \\
\hline & [r] & [GL] & $\chi_{0,8}^{2}(2 r+2)$ \\
\hline Excel: & & $=2 * r+2$ & =INV.QUI(0,2;GL) \\
\hline & 1 & 4 & 5,98862 \\
\hline & 2 & 6 & 8,55806 \\
\hline & 3 & 8 & 11,03009 \\
\hline & 4 & 10 & 13,44196 \\
\hline & 5 & 12 & 15,81199 \\
\hline & 6 & 14 & 18,15077 \\
\hline & 7 & 16 & 20,46507 \\
\hline & 8 & 18 & 22,75955 \\
\hline & 9 & 20 & 25,03750 \\
\hline & 10 & 22 & 27,30145 \\
\hline & 11 & 24 & 29,55332 \\
\hline & 12 & 26 & 31,79461 \\
\hline & 13 & 28 & 34,02657 \\
\hline & 14 & 30 & 36,25018 \\
\hline & 15 & 32 & 38,46630 \\
\hline & 16 & 34 & 40,67564 \\
\hline & 17 & 36 & 42,87879 \\
\hline & 18 & 38 & 45,07628 \\
\hline & 19 & 40 & 47,26853 \\
\hline & 20 & 42 & 49,45596 \\
\hline & 21 & 44 & 51,63891 \\
\hline & 22 & 46 & 53,81770 \\
\hline & 23 & 48 & 55,99257 \\
\hline & 24 & 50 & 58,16379 \\
\hline & 25 & 52 & 60,33157 \\
\hline & 26 & 54 & 62,49613 \\
\hline & 27 & 56 & 64,65763 \\
\hline & 28 & 58 & 66,81620 \\
\hline & 29 & 60 & 68,97206 \\
\hline & 30 & 62 & 71,12531 \\
\hline & 31 & 64 & 73,27608 \\
\hline & 32 & 66 & 75,42449 \\
\hline & 33 & 68 & 77,57065 \\
\hline & 34 & 70 & 79,71466 \\
\hline & 35 & 72 & 81,85658 \\
\hline & 36 & 74 & 83,99654 \\
\hline & 37 & 76 & 86,13460 \\
\hline & 38 & 78 & 88,27085 \\
\hline & 39 & 80 & 90,40535 \\
\hline & 40 & 82 & 92,53815 \\
\hline & 41 & 84 & 94,66933 \\
\hline & 42 & 86 & 96,79897 \\
\hline & 43 & 88 & 98,92706 \\
\hline & 44 & 90 & 101,05371 \\
\hline & 45 & 92 & 103,17895 \\
\hline & 46 & 94 & 105,30283 \\
\hline & 47 & 96 & 107,42539 \\
\hline & 48 & 98 & 109,54667 \\
\hline & 49 & 100 & 111,66672 \\
\hline & 50 & 102 & 113,78553 \\
\hline
\end{tabular}

\begin{tabular}{|c|c|c|c|}
\hline & \multicolumn{3}{|c|}{$\theta_{\text {sup }}$} \\
\hline & \multicolumn{3}{|c|}{$\lambda_{\text {inf }}$} \\
\hline & Falhas & \begin{tabular}{|c|} 
Graus de \\
Liberdade
\end{tabular} & $\chi_{\alpha / 2}^{2}(2 r)$ \\
\hline & [r] & [GL] & $\chi_{0,2}^{2}(2 r)$ \\
\hline Excel: & & $=2 * r$ & $=$ =INV.QUI(0,8;GL) \\
\hline & 1 & 2 & 0,44629 \\
\hline & 2 & 4 & 1,64878 \\
\hline & 3 & 6 & 3,07009 \\
\hline & 4 & 8 & 4,59357 \\
\hline & 5 & 10 & 6,17908 \\
\hline & 6 & 12 & 7,80733 \\
\hline & 7 & 14 & 9,46733 \\
\hline & 8 & 16 & 11,15212 \\
\hline & 9 & 18 & 12,85695 \\
\hline & 10 & 20 & 14,57844 \\
\hline & 11 & 22 & 16,31404 \\
\hline & 12 & 24 & 18,06180 \\
\hline & 13 & 26 & 19,82019 \\
\hline & 14 & 28 & 21,58797 \\
\hline & 15 & 30 & 23,36411 \\
\hline & 16 & 32 & 25,14778 \\
\hline & 17 & 34 & 26,93827 \\
\hline & 18 & 36 & 28,73496 \\
\hline & 19 & 38 & 30,53734 \\
\hline & 20 & 40 & 32,34495 \\
\hline & 21 & 42 & 34,15740 \\
\hline & 22 & 44 & 35,97435 \\
\hline & 23 & 46 & 37,79548 \\
\hline & 24 & 48 & 39,62051 \\
\hline & 25 & 50 & 41,44921 \\
\hline & 26 & 52 & 43,28134 \\
\hline & 27 & 54 & 45,11673 \\
\hline & 28 & 56 & 46,95519 \\
\hline & 29 & 58 & 48,79653 \\
\hline & 30 & 60 & 50,64062 \\
\hline & 31 & 62 & 52,48731 \\
\hline & 32 & 64 & 54,33650 \\
\hline & 33 & 66 & 56,18804 \\
\hline & 34 & 68 & 58,04184 \\
\hline & 35 & 70 & 59,89781 \\
\hline & 36 & 72 & 61,75583 \\
\hline & 37 & 74 & 63,61583 \\
\hline & 38 & 76 & 65,47774 \\
\hline & 39 & 78 & 67,34145 \\
\hline & 40 & 80 & 69,20695 \\
\hline & 41 & 82 & 71,07410 \\
\hline & 42 & 84 & 72,94290 \\
\hline & 43 & 86 & 74,81325 \\
\hline & 44 & 88 & 76,68511 \\
\hline & 45 & 90 & 78,55843 \\
\hline & 46 & 92 & 80,43316 \\
\hline & 47 & 94 & 82,30926 \\
\hline & 48 & 96 & 84,18669 \\
\hline & 49 & 98 & 86,06540 \\
\hline & 50 & 100 & 87,94533 \\
\hline
\end{tabular}




\begin{tabular}{|c|c|c|c|}
\hline & \multicolumn{3}{|c|}{$\theta_{\text {inf }}$} \\
\hline & \multicolumn{3}{|c|}{$\lambda_{\text {sup }}$} \\
\hline & Falhas & $\begin{array}{l}\text { Graus de } \\
\text { Liberdade }\end{array}$ & $\chi_{1-\alpha / 2}^{2}(2 r+2)$ \\
\hline & [r] & [GL] & $\chi_{0,8}^{2}(2 r+2)$ \\
\hline Excel: & & $=2 * r+2$ & $=\mid \mathrm{INV} . \mathrm{QUI}(0,2 ; \mathrm{GL})$ \\
\hline & 51 & 104 & 115,90321 \\
\hline & 52 & 106 & 118,01977 \\
\hline & 53 & 108 & 120,13519 \\
\hline & 54 & 110 & 122,24955 \\
\hline & 55 & 112 & 124,36287 \\
\hline & 56 & 114 & 126,47516 \\
\hline & 57 & 116 & 128,58650 \\
\hline & 58 & 118 & 130,69687 \\
\hline & 59 & 120 & 132,80627 \\
\hline & 60 & 122 & 134,91480 \\
\hline & 61 & 124 & 137,02240 \\
\hline & 62 & 126 & 139,12915 \\
\hline & 63 & 128 & 141,23505 \\
\hline & 64 & 130 & 143,34015 \\
\hline & 65 & 132 & 145,44441 \\
\hline & 66 & 134 & 147,54787 \\
\hline & 67 & 136 & 149,65058 \\
\hline & 68 & 138 & 151,75251 \\
\hline & 69 & 140 & 153,85373 \\
\hline & 70 & 142 & 155,95420 \\
\hline & 71 & 144 & 158,05398 \\
\hline & 72 & 146 & 160,15305 \\
\hline & 73 & 148 & 162,25147 \\
\hline & 74 & 150 & 164,34917 \\
\hline & 75 & 152 & 166,44625 \\
\hline & 76 & 154 & 168,54270 \\
\hline & 77 & 156 & 170,63850 \\
\hline & 78 & 158 & 172,73372 \\
\hline & 79 & 160 & 174,82830 \\
\hline & 80 & 162 & 176,92233 \\
\hline & 81 & 164 & 179,01573 \\
\hline & 82 & 166 & 181,10858 \\
\hline & 83 & 168 & 183,20089 \\
\hline & 84 & 170 & 185,29264 \\
\hline & 85 & 172 & 187,38383 \\
\hline & 86 & 174 & 189,47449 \\
\hline & 87 & 176 & 191,56468 \\
\hline & 88 & 178 & 193,65431 \\
\hline & 89 & 180 & 195,74342 \\
\hline & 90 & 182 & 197,83206 \\
\hline & 91 & 184 & 199,92021 \\
\hline & 92 & 186 & 202,00789 \\
\hline & 93 & 188 & 204,09507 \\
\hline & 94 & 190 & 206,18181 \\
\hline & 95 & 192 & 208,26812 \\
\hline & 96 & 194 & 210,35394 \\
\hline & 97 & 196 & 212,43930 \\
\hline & 98 & 198 & 214,52425 \\
\hline & 99 & 200 & 216,60876 \\
\hline & 100 & 202 & 218,69286 \\
\hline
\end{tabular}

\begin{tabular}{|c|c|c|c|}
\hline & \multicolumn{3}{|c|}{$\theta_{\text {sup }}$} \\
\hline & \multicolumn{3}{|c|}{$\lambda_{\text {inf }}$} \\
\hline & Falhas & $\begin{array}{c}\text { Graus de } \\
\text { Liberdade }\end{array}$ & $\chi_{\alpha / 2}^{2}(2 r)$ \\
\hline & [r] & [GL] & $\chi_{0,2}^{2}(2 r)$ \\
\hline Excel: & & $=2 * r$ & $=$ INV.QUI(0,8;GL) \\
\hline & 51 & 102 & 89,82648 \\
\hline & 52 & 104 & 91,70879 \\
\hline & 53 & 106 & 93,59224 \\
\hline & 54 & 108 & 95,47678 \\
\hline & 55 & 110 & 97,36241 \\
\hline & 56 & 112 & 99,24909 \\
\hline & 57 & 114 & 101,13677 \\
\hline & 58 & 116 & 103,02541 \\
\hline & 59 & 118 & 104,91504 \\
\hline & 60 & 120 & 106,80561 \\
\hline & 61 & 122 & 108,69708 \\
\hline & 62 & 124 & 110,58944 \\
\hline & 63 & 126 & 112,48268 \\
\hline & 64 & 128 & 114,37676 \\
\hline & 65 & 130 & 116,27169 \\
\hline & 66 & 132 & 118,16742 \\
\hline & 67 & 134 & 120,06392 \\
\hline & 68 & 136 & 121,96122 \\
\hline & 69 & 138 & 123,85927 \\
\hline & 70 & 140 & 125,75804 \\
\hline & 71 & 142 & 127,65755 \\
\hline & 72 & 144 & 129,55777 \\
\hline & 73 & 146 & 131,45870 \\
\hline & 74 & 148 & 133,36028 \\
\hline & 75 & 150 & 135,26254 \\
\hline & 76 & 152 & 137,16545 \\
\hline & 77 & 154 & 139,06900 \\
\hline & 78 & 156 & 140,97318 \\
\hline & 79 & 158 & 142,87796 \\
\hline & 80 & 160 & 144,78338 \\
\hline & 81 & 162 & 146,68935 \\
\hline & 82 & 164 & 148,59593 \\
\hline & 83 & 166 & 150,50309 \\
\hline & 84 & 168 & 152,41079 \\
\hline & 85 & 170 & 154,31902 \\
\hline & 86 & 172 & 156,22781 \\
\hline & 87 & 174 & 158,13714 \\
\hline & 88 & 176 & 160,04697 \\
\hline & 89 & 178 & 161,95733 \\
\hline & 90 & 180 & 163,86821 \\
\hline & 91 & 182 & 165,77957 \\
\hline & 92 & 184 & 167,69142 \\
\hline & 93 & 186 & 169,60371 \\
\hline & 94 & 188 & 171,51652 \\
\hline & 95 & 190 & 173,42977 \\
\hline & 96 & 192 & 175,34348 \\
\hline & 97 & 194 & 177,25768 \\
\hline & 98 & 196 & 179,17229 \\
\hline & 99 & 198 & 181,08732 \\
\hline & 100 & 200 & 183,00281 \\
\hline
\end{tabular}




\begin{tabular}{|c|c|c|c|}
\hline & \multicolumn{3}{|c|}{$\theta_{\text {inf }}$} \\
\hline & \multicolumn{3}{|c|}{$\lambda_{\text {sup }}$} \\
\hline & Falhas & Graus de & $\chi_{1-\alpha / 2}^{2}(2 r+2)$ \\
\hline & {$[\mathrm{r}]$} & [GL] & $\chi_{0,8}^{2}(2 r+2)$ \\
\hline Excel: & & $=2 * r+2$ & $=$ INV.QUI(0,2;GL) \\
\hline & 101 & 204 & 220,77655 \\
\hline & 102 & 206 & 222,85982 \\
\hline & 103 & 208 & 224,94272 \\
\hline & 104 & 210 & 227,02516 \\
\hline & 105 & 212 & 229,10721 \\
\hline & 106 & 214 & 231,18891 \\
\hline & 107 & 216 & 233,27024 \\
\hline & 108 & 218 & 235,35112 \\
\hline & 109 & 220 & 237,43172 \\
\hline & 110 & 222 & 239,51188 \\
\hline & 111 & 224 & 241,59171 \\
\hline & 112 & 226 & 243,67120 \\
\hline & 113 & 228 & 245,75029 \\
\hline & 114 & 230 & 247,82907 \\
\hline & 115 & 232 & 249,90750 \\
\hline & 116 & 234 & 251,98562 \\
\hline & 117 & 236 & 254,06335 \\
\hline & 118 & 238 & 256,14079 \\
\hline & 119 & 240 & 258,21788 \\
\hline & 120 & 242 & 260,29464 \\
\hline & 121 & 244 & 262,37112 \\
\hline & 122 & 246 & 264,44728 \\
\hline & 123 & 248 & 266,52310 \\
\hline & 124 & 250 & 268,59865 \\
\hline & 125 & 252 & 270,67387 \\
\hline & 126 & 254 & 272,74883 \\
\hline & 127 & 256 & 274,82343 \\
\hline & 128 & 258 & 276,89779 \\
\hline & 129 & 260 & 278,97185 \\
\hline & 130 & 262 & 281,04560 \\
\hline & 131 & 264 & 283,11912 \\
\hline & 132 & 266 & 285,19230 \\
\hline & 133 & 268 & 287,26525 \\
\hline & 134 & 270 & 289,33790 \\
\hline & 135 & 272 & 291,41032 \\
\hline & 136 & 274 & 293,48242 \\
\hline & 137 & 276 & 295,55430 \\
\hline & 138 & 278 & 297,62592 \\
\hline & 139 & 280 & 299,69722 \\
\hline & 140 & 282 & 301,76832 \\
\hline & 141 & 284 & 303,83918 \\
\hline & 142 & 286 & 305,90974 \\
\hline & 143 & 288 & 307,98008 \\
\hline & 144 & 290 & 310,05021 \\
\hline & 145 & 292 & 312,12003 \\
\hline & 146 & 294 & 314,18968 \\
\hline & 147 & 296 & 316,25904 \\
\hline & 148 & 298 & 318,32822 \\
\hline & 149 & 300 & 320,39709 \\
\hline & 150 & 302 & 322,46579 \\
\hline
\end{tabular}

\begin{tabular}{|c|c|c|c|}
\hline & \multicolumn{3}{|c|}{$\theta_{\text {sup }}$} \\
\hline & \multicolumn{3}{|c|}{$\lambda_{\text {inf }}$} \\
\hline & Falhas & $\begin{array}{l}\text { Graus de } \\
\text { Liberdade }\end{array}$ & $\chi_{\alpha / 2}^{2}(2 r)$ \\
\hline & {$[\mathbf{r}]$} & [GL] & $\chi_{0,2}^{2}(2 r)$ \\
\hline Excel: & & $=2 * r$ & $=$ INV.QUI $(0,8 ; G L)$ \\
\hline & 101 & 202 & 184,91870 \\
\hline & 102 & 204 & 186,83500 \\
\hline & 103 & 206 & 188,75173 \\
\hline & 104 & 208 & 190,66886 \\
\hline & 105 & 210 & 192,58638 \\
\hline & 106 & 212 & 194,50432 \\
\hline & 107 & 214 & 196,42264 \\
\hline & 108 & 216 & 198,34133 \\
\hline & 109 & 218 & 200,26039 \\
\hline & 110 & 220 & 202,17982 \\
\hline & 111 & 222 & 204,09962 \\
\hline & 112 & 224 & 206,01979 \\
\hline & 113 & 226 & 207,94032 \\
\hline & 114 & 228 & 209,86121 \\
\hline & 115 & 230 & 211,78243 \\
\hline & 116 & 232 & 213,70400 \\
\hline & 117 & 234 & 215,62590 \\
\hline & 118 & 236 & 217,54814 \\
\hline & 119 & 238 & 219,47071 \\
\hline & 120 & 240 & 221,39361 \\
\hline & 121 & 242 & 223,31685 \\
\hline & 122 & 244 & 225,24036 \\
\hline & 123 & 246 & 227,16420 \\
\hline & 124 & 248 & 229,08837 \\
\hline & 125 & 250 & 231,01283 \\
\hline & 126 & 252 & 232,93763 \\
\hline & 127 & 254 & 234,86267 \\
\hline & 128 & 256 & 236,78802 \\
\hline & 129 & 258 & 238,71370 \\
\hline & 130 & 260 & 240,63962 \\
\hline & 131 & 262 & 242,56584 \\
\hline & 132 & 264 & 244,49235 \\
\hline & 133 & 266 & 246,41913 \\
\hline & 134 & 268 & 248,34623 \\
\hline & 135 & 270 & 250,27353 \\
\hline & 136 & 272 & 252,20114 \\
\hline & 137 & 274 & 254,12902 \\
\hline & 138 & 276 & 256,05717 \\
\hline & 139 & 278 & 257,98557 \\
\hline & 140 & 280 & 259,91421 \\
\hline & 141 & 282 & 261,84309 \\
\hline & 142 & 284 & 263,77226 \\
\hline & 143 & 286 & 265,70170 \\
\hline & 144 & 288 & 267,63132 \\
\hline & 145 & 290 & 269,56121 \\
\hline & 146 & 292 & 271,49138 \\
\hline & 147 & 294 & 273,42173 \\
\hline & 148 & 296 & 275,35237 \\
\hline & 149 & 298 & 277,28322 \\
\hline & 150 & 300 & 279,21431 \\
\hline
\end{tabular}




\begin{tabular}{|c|c|c|c|}
\hline & \multicolumn{3}{|c|}{$\theta_{\text {inf }}$} \\
\hline & \multicolumn{3}{|c|}{$\lambda_{\text {sup }}$} \\
\hline & Falhas & $\begin{array}{l}\text { Graus de } \\
\text { Liberdade }\end{array}$ & $\chi_{1-\alpha / 2}^{2}(2 r+2)$ \\
\hline & {$[r]$} & [GL] & $\chi_{0,8}^{2}(2 r+2)$ \\
\hline Excel: & & $=2 * r+2$ & $=$ =INV.QUI(0,2;GL) \\
\hline & 151 & 304 & 324,53425 \\
\hline & 152 & 306 & 326,60245 \\
\hline & 153 & 308 & 328,67049 \\
\hline & 154 & 310 & 330,73827 \\
\hline & 155 & 312 & 332,80581 \\
\hline & 156 & 314 & 334,87318 \\
\hline & 157 & 316 & 336,94031 \\
\hline & 158 & 318 & 339,00723 \\
\hline & 159 & 320 & 341,07394 \\
\hline & 160 & 322 & 343,14045 \\
\hline & 161 & 324 & 345,20678 \\
\hline & 162 & 326 & 347,27284 \\
\hline & 163 & 328 & 349,33872 \\
\hline & 164 & 330 & 351,40443 \\
\hline & 165 & 332 & 353,46992 \\
\hline & 166 & 334 & 355,53521 \\
\hline & 167 & 336 & 357,60033 \\
\hline & 168 & 338 & 359,66521 \\
\hline & 169 & 340 & 361,72991 \\
\hline & 170 & 342 & 363,79442 \\
\hline & 171 & 344 & 365,85880 \\
\hline & 172 & 346 & 367,92290 \\
\hline & 173 & 348 & 369,98686 \\
\hline & 174 & 350 & 372,05062 \\
\hline & 175 & 352 & 374,11425 \\
\hline & 176 & 354 & 376,17764 \\
\hline & 177 & 356 & 378,24089 \\
\hline & 178 & 358 & 380,30393 \\
\hline & 179 & 360 & 382,36681 \\
\hline & 180 & 362 & 384,42949 \\
\hline & 181 & 364 & 386,49204 \\
\hline & 182 & 366 & 388,55440 \\
\hline & 183 & 368 & 390,61660 \\
\hline & 184 & 370 & 392,67861 \\
\hline & 185 & 372 & 394,74048 \\
\hline & 186 & 374 & 396,80218 \\
\hline & 187 & 376 & 398,86365 \\
\hline & 188 & 378 & 400,92502 \\
\hline & 189 & 380 & 402,98622 \\
\hline & 190 & 382 & 405,04724 \\
\hline & 191 & 384 & 407,10812 \\
\hline & 192 & 386 & 409,16886 \\
\hline & 193 & 388 & 411,22938 \\
\hline & 194 & 390 & 413,28981 \\
\hline & 195 & 392 & 415,35003 \\
\hline & 196 & 394 & 417,41012 \\
\hline & 197 & 396 & 419,47006 \\
\hline & 198 & 398 & 421,52985 \\
\hline & 199 & 400 & 423,58951 \\
\hline & 200 & 402 & 425,64898 \\
\hline
\end{tabular}

\begin{tabular}{|c|c|c|c|}
\hline & \multicolumn{3}{|c|}{$\theta_{\text {sup }}$} \\
\hline & \multicolumn{3}{|c|}{$\lambda_{\text {inf }}$} \\
\hline & Falhas & $\begin{array}{l}\text { Graus de } \\
\text { Liberdade }\end{array}$ & $\chi_{\alpha / 2}^{2}(2 r)$ \\
\hline & {$[\mathbf{r}]$} & [GL] & $\chi_{0,2}^{2}(2 r)$ \\
\hline Excel: & & $=2 * r$ & $=$ INV.QUI $(0,8 ; G L)$ \\
\hline & 151 & 302 & 281,14566 \\
\hline & 152 & 304 & 283,07717 \\
\hline & 153 & 306 & 285,00893 \\
\hline & 154 & 308 & 286,94093 \\
\hline & 155 & 310 & 288,87315 \\
\hline & 156 & 312 & 290,80559 \\
\hline & 157 & 314 & 292,73821 \\
\hline & 158 & 316 & 294,67107 \\
\hline & 159 & 318 & 296,60416 \\
\hline & 160 & 320 & 298,53743 \\
\hline & 161 & 322 & 300,47094 \\
\hline & 162 & 324 & 302,40463 \\
\hline & 163 & 326 & 304,33858 \\
\hline & 164 & 328 & 306,27265 \\
\hline & 165 & 330 & 308,20699 \\
\hline & 166 & 332 & 310,14146 \\
\hline & 167 & 334 & 312,07621 \\
\hline & 168 & 336 & 314,01107 \\
\hline & 169 & 338 & 315,94617 \\
\hline & 170 & 340 & 317,88148 \\
\hline & 171 & 342 & 319,81693 \\
\hline & 172 & 344 & 321,75260 \\
\hline & 173 & 346 & 323,68848 \\
\hline & 174 & 348 & 325,62451 \\
\hline & 175 & 350 & 327,56071 \\
\hline & 176 & 352 & 329,49713 \\
\hline & 177 & 354 & 331,43372 \\
\hline & 178 & 356 & 333,37048 \\
\hline & 179 & 358 & 335,30745 \\
\hline & 180 & 360 & 337,24454 \\
\hline & 181 & 362 & 339,18183 \\
\hline & 182 & 364 & 341,11932 \\
\hline & 183 & 366 & 343,05697 \\
\hline & 184 & 368 & 344,99477 \\
\hline & 185 & 370 & 346,93273 \\
\hline & 186 & 372 & 348,87089 \\
\hline & 187 & 374 & 350,80918 \\
\hline & 188 & 376 & 352,74768 \\
\hline & 189 & 378 & 354,68635 \\
\hline & 190 & 380 & 356,62511 \\
\hline & 191 & 382 & 358,56410 \\
\hline & 192 & 384 & 360,50321 \\
\hline & 193 & 386 & 362,44251 \\
\hline & 194 & 388 & 364,38193 \\
\hline & 195 & 390 & 366,32157 \\
\hline & 196 & 392 & 368,26129 \\
\hline & 197 & 394 & 370,20122 \\
\hline & 198 & 396 & 372,14127 \\
\hline & 199 & 398 & 374,08151 \\
\hline & 200 & 400 & 376,02184 \\
\hline
\end{tabular}

